\title{
Motion patterns in the cervical spine
}

Citation for published version (APA):

van Mameren, H. (1988). Motion patterns in the cervical spine. [Doctoral Thesis, Maastricht University]. Rijksuniversiteit Limburg. https://doi.org/10.26481/dis.19880616hm

Document status and date:

Published: 01/01/1988

DOI:

10.26481/dis.19880616hm

Document Version:

Publisher's PDF, also known as Version of record

\section{Please check the document version of this publication:}

- A submitted manuscript is the version of the article upon submission and before peer-review. There can be important differences between the submitted version and the official published version of record.

People interested in the research are advised to contact the author for the final version of the publication, or visit the DOI to the publisher's website.

- The final author version and the galley proof are versions of the publication after peer review.

- The final published version features the final layout of the paper including the volume, issue and page numbers.

Link to publication

\footnotetext{
General rights rights.

- You may freely distribute the URL identifying the publication in the public portal. please follow below link for the End User Agreement:

www.umlib.nl/taverne-license

Take down policy

If you believe that this document breaches copyright please contact us at:

repository@maastrichtuniversity.nl

providing details and we will investigate your claim.
}

Copyright and moral rights for the publications made accessible in the public portal are retained by the authors and/or other copyright owners and it is a condition of accessing publications that users recognise and abide by the legal requirements associated with these

- Users may download and print one copy of any publication from the public portal for the purpose of private study or research.

- You may not further distribute the material or use it for any profit-making activity or commercial gain

If the publication is distributed under the terms of Article $25 \mathrm{fa}$ of the Dutch Copyright Act, indicated by the "Taverne" license above, 
MOTION PATTERNS IN THE CERVICAL SPINE 



\section{MOTION PATTERNS IN THE CERVICAL SPINE}

\section{PROEFSCHRIFT}

ter verkrijging van de graad van doctor aan de Rijksuniversiteit Limburg te Maastricht, op gezag van de de Rector Magnificus, Prof. Dr. F.I.M. Bonke, volgens het besluit van het College van Dekanen, in het openbaar te verdedigen op donderdag 16 juni 1988 om 16.00 uur

door

\section{HENDRIK VAN MAMEREN}

geboren op 14 december 1947 te Alphen a/d Rijn 
Promotor: Prof. Dr. J. Drukker

Beoordelingscommissie:

Prof. Dr. Ir. J.D. Janssen, Fijksuniversiteit Limburg (voorzitter)

Prof. Dr. J.M.A. van Engelshoven, Rijksuniversiteit Limburg

Prof. Dr. A. Huson, Rijksuniversiteit Leiden

Prof. Dr. P.G. Knipschild, Rijksuniversiteit Limburg

Prof. Dr. L. Penning, Rijksuniversiteit Groningen

Colofon:

tekeningen $H$. Rensema

vormgeving J. Beursgens

H. Rensema

vertaling Euroterm Maastricht, F. van Lieshout

druk Krips Repro B.V. Meppel 
voor: Eveline Monique Kees Jan 
De uitgave van dit proefschrift werd mede mogelijk gemaakt door financiële steun van de Jan Dekkerstichting \& dr. Ludgardine Bouwmanstichting

(6) 1988 No part of this book may be reproduced in any form, by print, photoprint, microfilm or any other means, without written permission from the author. 


\section{Table of Contents}

\section{Chapter 1}

\section{Introduction}

1.1 Physical examination 11

1.2 Need of quantitative data $\quad 11$

1.3 X-ray, morphology 12

1.4 X-ray, function $\quad 12$

1.5 Design 13

$\begin{array}{lll}1.6 & \text { Objectives } & 14\end{array}$

Chapter 2

Determining positions of contours of bony structures during motion, with the aid of X-ray cinematography

2.1 Introduction 17

2.2 X-ray equipment and exposure procedure used 18

$\begin{array}{ll}2.3 \quad \mathrm{X} \text {-ray radiation dose } & 19\end{array}$

2.4 Equipment 20

2.5 Marking skull and vertebrae 21

2.6 The $x$-y coordinates of the coordinate system and marker points 23

2.7 Calculating the position of the vertebral contours per image 23

2.8 Segmental motion during motion of the cervical spine 29

2.9 Normalizing the values 31

2.10 Method of data reproduction 31

2.11 Reproducibility of the method 31

2.12. Discussion 33

\section{Chapter 3}

Test persons

3.1 Data on the persons tested , $\quad 35$

3.2 Selection criteria 35 


\section{Chapter 4}

Range of motion in the sagittal plane of the segments in the cervical spine
4.1. Introduction
4.2 Method
4.3 Reproducibility
4.4 Results
4.4.1 Range of motion of the head in relation to C7
4.4.2 Segmental range of motion
4.5 Discussion

\section{Chapter 5}

Position of the average instantaneous centre of rotation in segments $(\mathrm{CO}-\mathrm{Cl})$ to (C6-C7)

5.1 Introduction

5.2 Method 50

5.3 Reproducibility

5.4 Results $\quad 56$

$\begin{array}{ll}5.5 & \text { Discussion }\end{array}$

\section{Chapter 6}

Intrasegmental distortion of segments (C2-C3) to (C6-C7)

6.1 Introduction

6.2 Method 65

$\begin{array}{lll}6.3 & \text { Reproducibility } & 67\end{array}$

6.4 Results 67

$\begin{array}{ll}6.5 & \text { Discussion }\end{array}$

\section{Chapter 7}

Sequences of motion in the sagittal plane in block $(\mathrm{CO}-\mathrm{C} 2)$

$\begin{array}{lll}7.1 & \text { Introduction } & 81\end{array}$

7.2 Method 82

7.2.1 Sequence and inversion on film $\quad 82$

7.2.2 Comparison of inversion on film to inversion on function pictures 84

7.3 Reproducibility 86

7.3.1 Sequence and inversion on film 86

7.3.2 Comparison of inversion on film to inversion on function pictures 87

$\begin{array}{lll}7.4 & \text { Results } & 89\end{array}$

7.4.1 Sequence and inversion on film 89

7.4.2 Comparison of inversion on film to inversion on function pictures 90

7.5 Discussion 92 


\section{Chapter 8}

A model of block ( $\mathrm{C} 0-\mathrm{C} 2)$

8.1 Introduction 95

8.2 Method 96

8.2.1 Construction of a model of block (CO-C2) 96

8.2.2 Model in relation to the contours of the bony structures $\quad 102$

$\begin{array}{ll}8.2 .3 \text { Model verification } & 102\end{array}$

8.3 Results $\quad 102$

8.3.1 Segmental order of motion in terms of the model 102

8.3.2 Model verification $\quad 113$

8.4 Discussion $\quad 114$

\section{Chapter 9}

Sequences of motion in the other segments and blocks

$\begin{array}{lll}9.1 & \text { Introduction } & 117\end{array}$

9.2 Method 119

9.3 Reproducibility 119

9.4 Results 119

9.4.1 Segments (C4-C5), (C5-C6) and (C6-C7) in block (C4-C7) 119

9.4.2 Segments (C2-C3), (C3-C4) and (C4-C5) in block (C2-C5) 123

9.4.3 Blocks ( $\mathrm{C} 0-\mathrm{C} 2)$ and $(\mathrm{C} 4-\mathrm{C} 7)$ in the cervical spine ( $\mathrm{C} 0-\mathrm{C} 7) \quad 126$

9.4.4 Blocks (C2-C4) and (C5-C7) in block (C2-C7) 130

9.4.5 Blocks (C0-C2) and (C2-C4) in block (C0-C4) 131

9.5 Discussion 133

\section{Chapter 10}

\section{Summary and conclusions}

Range of motion 139

Position of the segmental instantaneous centre of rotation $\quad 140$

Intrasegmental distortion $\quad 140$

Sequences of contribution 141

Inversion 141

Continuation of this research 141 
Samenvatting en conclusies

De bewegingsornvang

144

De positie van de segmentale rotatieas

144

Intrasegmentale verworming

144

De volgorde van bijdragen

145

Inversie

145

Voortzetting van het onderzoek

146

Nawoord 


\section{Introduction}

Many people suffer from so much pain in the neck that they express it as a complaint. A report on Sweden states that $70 \%$ of the population claims to have had pain in the neck at least once (Hult, 1954). Such patients show patterns of complaints consisting of muscular weakness, impaired sensibility and pain in the neck radiating towards the shoulder(s) or the face. In addition, there may be symptoms that belong to the "painful arc", tennis elbow, carpal tunnel syndrome, several types of dizziness which may or may not be accompanied by nausea or blurred sight. A combination with Horner's syndrome is also possible (Brunton et al., 1982).

Patients with these complaints often refer to their general practitioner, although less often than those with back troubles (Lamberts, 1984). A number of authors (Nachemson, 1975 , Kelsey, 1982) indicate that in 50-80\% of these patients no underlying pathology can be found. We therefore speak of nonspecific complaints. These complaints presumably relate to a (not further defined) dysfunction of the vertebral column.

\subsection{Physical examination}

In patients with such complaints, further information is usually gathered about, for instance, pathological alterations in shape and function of the neck and back. In such a patient we first try to get information by means of a physical examination. In many patients, this shows no clear morphological alterations corresponding to the complaints. A function examination (active and passive examination of motion) often shows no more than that the complaints are accompanied by disorders of motion and/or range of motion of the cervical spine and the head. This active and passive examination of motion only allows a qualitative examination of the movements of the cervical spine as a whole. Moreover, the data resulting from this examination are partly dependent on the interpretation of the examiner/therapist. The movements between two individual vertebrae cannot be determined quantitatively at all.

\subsection{Need of quantitative data}

With quantitative information about the function, any data obtained with the help of more specific diagnostic methods could be judged more objectively. In addition, the possibility exists to see whether a patient showing a change in the pattern of complaints (e.g. after treatment) also shows a functional change of the cervical spine (therapy evaluation). It can then be determined whether such a change leads to a functioning of the cervical spine that corresponds with the function existing in persons who are free of complaints. When combined, the pattern of complaints and the difference observed in function can give an indication as to the mechanism which has led to the origin of the complaints. There is, therefore, a need for quantitative data about the segmental shape and functions.

To be able to make a statement on the basis of quantitative data on shape and function of a patient as to a diagnosis and/or therapy, it is necessary to compare those to values of parameters which serve to describe shape and function obtained from persons free of complaints. The "normal value" is the value of a given shape and function parameter, occurring in a group of people free of complaints (interindividual variability). Furthermore it is necessary to know the value of this parameter at different times of examin ation (measuring moments) to have an indication as to the variability within a certain individual (intraindividual variability). To evaluate the degree of intra- and interindividual variability it is necessary to know the accuracy of the method used to determine the values of the parameters chosen. In this thesis this is called reproducibility. 


\subsection{X-ray, morphology}

$X$-ray examination often provides us with more comprehensive information about the shape parameters of the bony parts of the cervical spine. The cervical spine is studied in several planes of projection (Diethelm, 1974):

- Sagittal plane: changes in the region of the intervertebral disc, the projection of the vertebrall body and calcification around the endplates.

- Frontal plane: changes in the region of the joints of Luschka.

- A plane (inclined projection) between the preceding two: changes in the facet joints and the intervertebral foramen.

- Frontal plane, from the cranial area of the cervical spine through the open mouth: the atlantooccipital axial region.

- The plane of the foramen magnum (Kienbock): changes of the dens axis, the posterior arch of the atlas and spinous process of the 2nd and 3 rd vertebra.

There have been many attempts to determine a coherence between "deviations" observed by X-ray and such patterns of complaints on the basis of X-rays of patients with the pattern of complaints described above. In an examination of the possibility to interpret $X$-rays in a group of persons older than 40 , McRay (1960) showed that it was not possible on the basis of deviations from the normal shape that were noticeable in X-ray, to predict which persons within the group examined suffered from complaints in the neck. Rössler and Schmeisser (1975) and Rothman and Simeone (1982) determined that "deviations" observed in X-ray and attributed to degenerative processes within the cervical spine, correspond more to the person's age than to the existence of complaints. Zeitler and Markuske (1962) indicate that the deviations described also occur in children and adolescents free of complaints. Considering the large number of directions which can be chosen to examine the cervical spine by means of X-ray, it is unlikely that changes within the structure which can be observed with this research method have been overlooked. Thus in many cases it is not possible, even with this number of $\mathrm{X}$-ray projections, to determine whether the shape of the bony structures is a deviating or a normal one. The existence of a large diversity of what is considered a normal shape of the vertebrae (Med, 1973; Putz, 1981; Cihak, 1981; van Mameren, 1983), as well as the size of the intervertebrall foramen and the spaces between the vertebral bodies which are visible through X-ray (Veleanu and Klepp, 1975), may add to this problem.

\subsection{X-ray, function}

$\mathrm{X}$-ray examination can also give information on the movements. The parameters of the entire cervical spine and the head are determined and usually given as (a) motion of the head and (b) segmental motion.

The following concepts and definitions are common to the determination of the motion parameters within the sagittal plane:

- The head is called $\mathrm{C} 0$, the vertebrae $\mathrm{Cl}$ to C7.

- The (movable) connections are called segments (e.g. CO-C1).

A segment is defined as a unit consisting of two bony parts, the vertebrae, and their flexible connections. This is known as Bewegungssegment (Schmorl and Junghanns, 1968), vertebral unit (Veleanu and Diaconescu, 1975, Töndury, 1972) or basic vertebral unit (Roaf, 1960).

- The cervical spine is a chain (of motion) of 7 segments. Presumably it is possible that each segment between skull and 7 th cervical vertebra contributes to the motion of the head in relation to the 7 th cervical vertebra. - Motions between $\mathrm{C7}$ and the 1st thoracic vertebra, as well as motions between the thoracic vertebrae have not been included in the examination.

Quantitative data on parameters of a motion can be obtained through biplanar X-ray examination (three-dimensional examination) of the vertebral column (Hindmarsch et al., 1980; Suh, 1974; Brown et al., 1976). These methods cannot be used to obtain de- 
tailed information on the movements, e.g. on a segmental level. Another three-dimensional $\mathrm{X}$-ray examination method requires metal marking points in the bony structures (Selvik, 1974), which constitutes an unjustifiable burden on the test person/patient.

Two-dimensional X-ray examination serves to determine the parameters of motion in the projected plane on the basis of the contours of the bony structures within that plane. A prerequisite for reliable measurement of these contours is that they are identical at several steps within a path of motion. This will] only occur if the skull or the vertebrae do not move in other directions than parallel to the X-ray projection plane during motion of the cervical spine (Brown et al., 1976). This is only the case in anteflexion-retroflexion (White and Panjabi, 1978).

Therefore the only reproducible, quantitative values of motion parameters that can be determined are those of the motion of (segments within) the cervical spine within the anteflexion-retroflexion. Motion of the bony structures within the sagittal plane can be established as rotation and translation within this plane.

Two methods of two-dimensional X-ray examination are used to determine the motion parameters:

\section{1. "Function pictures".}

This examination implies that an X-ray is made of a number of positions of the cervical spine, of both a maximum anteflexion and a maximum retroflexion position of the cervical spinal column, sometimes supplemented by a number of intermediate positions (e.g. Penning, 1960, 1978, 1988; Gutmann, 1968; Dimnet et al., 1982).

The contours of the bony structures on these pictures are marked, and subsequently the differences in position of the bony structures on the pictures are described in terms of:

- range of motion,

- instantaneous centre of rotation.

2. X-ray registration of actual motion.

This registration may be done by means of $\mathrm{X}$ - ray film (16 and $35 \mathrm{~mm}$ ) (e.g. Fielding, 1957 ). In examinations with these techniques, the maximum rotation within the sagittal plane of the bony structures is also determined. In a single case, an indication of the order of motion was given (Buonocore et al., 1966). Furthermore, a number of phenomena that occur during motion within the sagittal plane were described (Brunton et al., 1982).

The following is concluded:

1. The "function pictures" method only serves to give information on the differences in segmental positions between a number of positions of the cervical spine within the path of motion in the sagittal plane.

2. Information on the actual motion carried out cannot be obtained.

3. With this technique it is not possible to gain insight in the sequence in which smaller parts of the cervical spine and the head contribute to motion.

4. This is only possible by means of an X-ray cinematographic registration method of the actual motion carried out.

5. So far, the resolution of these methods has proved to be too small to allow a reproducible quantitative determination of a position. 6 . Furthermore, there is no simple and reliable method to registrate positions, and consequently no corresponding reproduction method which enables determination of all parameters mentioned.

\subsection{Design}

This thesis describes an $\mathrm{X}$-ray registration method, implying that:

1. X-ray registration of the actual motion is carried out with a $105 \mathrm{~mm}$ spot film camera. In this research this is also called $\mathrm{X}$-ray cinematography.

2. The positions of the contours of the bony structures can be determined on each picture. The method to be used also includes the possibility to automatically change incorrectly defined positions (chapter 2).

3. Rendering of the order to be determined is possible.

4. The method can be used in larger groups 
of patients; hence the information will be available relatively quickly.

The position information serves to determine the normal values of the above-mentioned motion parameters. These are:

1. Range of motion. This means the maximum rotation occurring between any two bony structures linked or unlinked (chapter 4).

2. Instantaneous centre of rotation. This is a point within the projection plane in respect of which each point of the contours of an bony structure can be rotated from one given position to another position (chapter 5).

3. Distortion of the intervertebral disc, expressed as the difference in position of the projection of the caudal face of the vertebral body, compared to the cranial face of the underlying vertebral body between two different positions of these vertebral bodies (chapter 6).

4. The sequence in which parts of the cervical spine contribute during motion of the entire cervical spine (chapters 7 and 9).

Motion between skull and axis occupies a special place in the motion of the cervical spine. This part has two synovial joints, the atlantooccipital and the atlantoaxial joint, whose shape differs considerably from that of the other connections between vertebrae. This applies both to the shape of the surface of the joints and to the shape of the surrounding connective tissue and the muscular tissue (Williams and Warwick, 1980). Motion between these three bony structures is linked (Werne, 1957; Depreux and Mestdagh, 1974; Penning, 1978). The segmental sequence of contributions within this part of the cervical spine is therefore discussed separately (chapter 7) and linked to previously described specific data on the shape of the articular surfaces and the ligamentous structures (chapter 8 ). The sequence of the contribution of this entire part of the cervical spine compared to other parts of the cervical spine within the entire motion, is discussed together with the sequence of segmental contributions in the remaining part of the cervi- cal spine (chapter 9).

The parameters have been determined within a group of people free of complaints at a given time of examination, two weeks later and ten weeks later (three measuring moments). These persons were identified on the basis of a specific physical examination carried out by a manual therapist (see chapter 3). "Normal values" are compared to the "normal values" described up to now (where they are available).

\subsection{Objectives}

The aim of this study is to develop methods which produce other and more distinct parameters, and their normal values, of function of the cervical column than hitherto available.

It is hoped that they will enable us to correlate (dys-)function with complaints better than up to now. This is a condition for improvement of prognostics and diagnostics and assessment of therapy of cervical complaints.

\section{Bibliography}

Brown, R.H., Burstein, A.H., Nash, C.L., Shock, C.C.p Spinal analysis using a three-dimensional radiographic technique, $J_{n}$ Biomechanics, 9, 355-365, 1976.

Bninton, F.J., Wilkinson, J.A., Wise, K.S.H., Simmons, R.B., Cineradiography in cervical spondylosis as a means of deternining the level for anterio-fusion, $J$. Bone and Jt. Surg, 64B, 399-404, 1982.

Buonocore, E., Hanman, J.T., Nelson, C.L., Cineradiograms of cervical spine in diagnosis of soft-tissue injuries, JAMA, 198, 25 29, 1966.

Cihák, $R$. Die Morphologie und Entwick/ung der Winbelbogengelenke, Die Wibelsdule in Forschung und Praxis, $87,13-28,1981$.

Deprewx, $R$, Mestdagh, $H$., Anaromie fonctionelle de l'articulation sous-occipitale, Lille Méd., 19, 122-125, 1974.

Diethelm, L. Röntgendiagnostik der Wibelsäule, In: Handbuch der Medizinischen Radiologie, Teil 1 , Springer Kerlag Berlin-Heidelberg-New York, 79, 1974 .

Dimnet, J., Pasquet, A., Krag, M.H., Parjabi, M.M., Cervical spine motion in the sagittal plane: Kinematic and 
geometric parameters, J. Biomechanücs. 15, no. 12,959969,1982

Fielding, J.W Cineroentgenography of the nom of cenical spine, f. Bome and It. Surg, 39, 1280-1288, 1957.

Gutmann, $G$, Schulkopfschmerz wnd Kopphaltumg, Ein Betrag zur Pathogenese des Ameflexions-Kopfschmerzes writ zur Diagnostik der Kopfgelenke, Z. Orthop, 105, $497-515,1968$.

Hindmasch, $f$, Lasson, F., Mattsom, $O$, Anabisis of changes in the scoliotic spine using a three-dintensional radiographic lechmique, $J$. Biomechonics, 13, 279-290, 1980.

Hult, L., Cenvical, dorsal and Mumbar syndrames, Thesis, Acta Orhop. Scand., suppl. 17, 1954.

Kelsey, J.L, Epidemiology of musculoskelefal disorders, New York, 1982.

Lambens, H., Mondidity in general practise, Utrecht, 1984.

Mameren van, $H$., Niewwe inzichten in de anatomie van de wervelkolom, In: De cenvicale wervelkolom, serie Fy" siocherapie in antwikkeling, Siafleu, Alphen aid Rijt/Brussel, $9-27,1983$.

McRay, D.L., The significance of abnomalities in the cervical spine, Am I. Roentgenol, 84, 3-25, 1960.

Med, $M$., Anticulations of the cerwical vertebrae and their variability, Folia Mophol.(Praha), 21, 324-327, 1973.

Nachemson, A, Towards a better understanding of low back paim, Rheum. Reh., 14, 129-143, 1975.

Penwing L., Funktioneel röntgenonderzoek bil degeneratieve en traumatische afwijkingen der laag-cenvicale bewegingssegmenten, Thesis, Univ. of Growingen, The Nethertands 1960

Penning, L., Nomal mowements in the cenical spine, Am. J. Roentgenol., 130, 317-326,1978.

Pemning L, Differences in anatomy, motion dewelopment and aging of the upper and lower cervical disk segments, Clin. Biomechanics, 3, 37-47, 1988.
Put, R. Funktiontelle Anaromite der Wholgelenke Nom

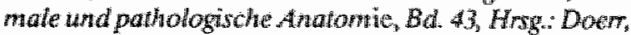
W. Leonhard, H., Thume Stumgar-New York, 1981.

Roaf, $R$. A study of the wechanics of spinal injuries, $d$. Bone and It. Swn $428,810-82$, 1960 .

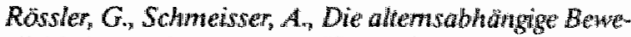
glichkeitsvemindenug der Halswirbelsäule, Z A Altenth forsch, II, 75-80, 1957 .

Rothman, R.H., Simeone, F, A., The Spine, W.B. Saunders Company, 1982 .

Schmorl, G., Junghanms, H., Die gesinde und die kramke Wirbelsäule in Römtgenbild und Klinik, Geong Thieme Verlag Stuitgan, 190\%.

Selvik, G., A roentgenstereophorogrammetric method for the suaty of kinennatics of the skevetal system, Theris, Univ. of Lund, Sweden, 1974

Suh, C.H., The fundamentals of computer aded $X$-ray analysis of the spine, J. Biomechanics, 7, 161-169, 1974.

Töndury, $G$, Anatomie fonctionelle des petites arriculationes du rachis, Anch. Med. Phys, 15, 173-191, 1972.

Veleanu, $C$, Diaconescu, $N$, Contributions to the clinical anatomy of the vertebral columm, Considerations on the stability and instability at the height of the "vertebral units", Anot. Anz, 137, 287-295, 1975.

Veleanu, C., Klepp H.J., Relationships between the wertebral parameters C2-C6 during movement of the "cenical units" in the sagittal plane, Newroradiol, $10,173-176$. 1975.

Werne, S., Studies in sportaneous atlas dislocation. Acta Orthop. Scand. 23, suppl, 7957.

Williams, P.L, Warwick, R. Gray's Anatomy, Churchill Livingstone, Edinbonongh-London-New York, 1980.

White, A.A., Panjobi, M.M., Clinical biomechanicr of the spine, J.B. Lippincont Company, Philadelphia-Toronto, 1978 .

Zeitler, E., Markuske, $H_{4,}$ Röngentologische Bewegungsanalyse der Halswirbelsaule bei gesunden Kindern, Fontschr. Roentgenstr., 96, 87-93, 1962. 


\section{Chapter 2}

\section{Determining positions of contours of bony structures during motion, with the aid of X-ray cinematography}

\subsection{Introduction}

This thesis comprises motion of adjacent vertebrae, larger parts of the spine and the entire cervical spine. Motion within the sagittall plane is defined as follows:

- Motion between two adjacent vertebrae is called segmental motion;

- Motion between two nonadjacent vertebrae is called motion within a block;

- Motion between skull and seventh cervical vertebra is called motion of the entire cervical spine (figure 2.1.).

In order such motion to be registered with
$\mathrm{X}$-ray cinematographic methods, projections of the bony structures in the images must be marked. This may be done by applying tangents to the cervical contours (Bakke, 1931; De Sèze et al., 1951; Albers, 1954; BuettiBäuml, 1954; Aho et al., 1955, Werne, 1957; Lewit and Krausovà, 1963; Bhalla and Simmons, 1969; Markuske, 1971; Depreux and Mestdagh, 1974, Arlen, 1977, 1978, 1979; Dimnet et al., 1982) or by superimposing images of vertebral contours before and after

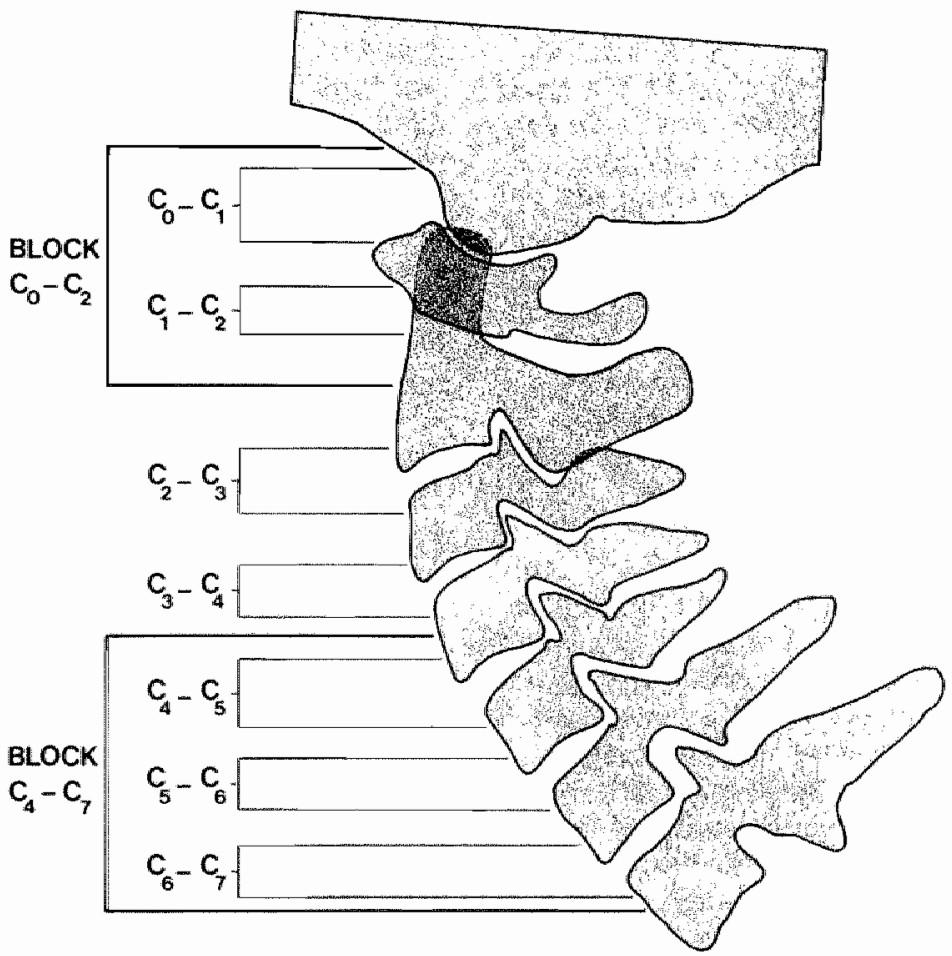

fig. 2.1 Cervical spine and part of the skull

- Segments, (CO-C1) to (C6-C7).

- Blocks, indicated are (CO-C2) and (C4-C7). 
motion over each other (Virchow, 1928, Penning, 1960, 1961, 1968, 1978; Gutmann, 1968; Gros et al., 1968).

These methods have a number of disadvantages when used to determine rotation within the sagittal plane on the basis of X-ray film of the actual motion carried out:

1. The methods use superimposing of contours or indicating tangents on the contour. The contour, however, is not sharp. Tangents must be placed with the utmost precision. The examinations referred to do not give details on reproducibility of the indication of tangents to the contours (except for one, which presumes reproducibility of three degrees, Lewit and Krausova, 1963).

2 . The chance of obtaining lines that are incorrectly indicated within a series of images is very high.

* For this reason in this research marking of the contours is not carried out by means of tangents.

3. The method of superimposing two X-rays on top of each other makes it difficult, especially for the 3 th vertebra, axis, atlas and skull, to have the contours overlap, because of their non-transparency and vague contours.

* The method of superimposing is impossible when using a larger number of images as in $105 \mathrm{~mm}$. roll film.

4. When the skull or vertebrae do not move entirely within the plane perpendicular to the central X-ray, the outlines of the contour will be created by other compact bony tissue on the picture; the shape of the outline is different then: the line does not pass the same points and the angle between a line on the first picture and on the second one therefore represents not only the extent of motion of the relevant segment but also the change in projection (Brown et al., 1976).

* It is necessary to average these differences in shape of contours per image among all images.

5. Application of these methods to 40 consecutive images of an $\mathrm{X}$-ray is very time-consuming.

We therefore developed a different marking method with the following characteristics (van Mameren, 1986).

1. Marking can be reproduced better than in the methods described.

2. Marking of a contour is carried out by means of a great number of points instead of superimposing images or indicating tangents. 3. Marking faults on a certain image are corrected automatically by the results of marking the contour on the other image.

4. Differences in contour marking, caused by changes in the shape of the contour within the sagittal plane (the image plane) during the motion carried out, will be averaged among all images.

5. Marking of the contours of vertebrae and skull may be carried out faster than with the methods mentioned above.

Ten persons are examined (see chapter 3 ). They are named $L$ to $U$. Per measuring moment of each person anteflexion is registered as well as retroflexion. The former is indicated by odd numbers, the latter by even numbers.

Eight persons are examined at a given moment, two weeks and ten weeks later $(0,+2$ wks and +10 wks). Two persons ( $P$ and $R$ ) are examined only at 0 and +2 wks.

Thus of eight persons $6 \mathrm{X}$-ray films are available. For example of person $\mathrm{L}$, the films $\mathrm{L} 1$, $\mathrm{L} 3$ and $\mathrm{L} 5$ represent the anteflexion and the films $L 2, L 4$ and $L 6$ the retroflexion registrations. Of person $\mathrm{P}$ and $\mathrm{R}$ only the films 1 and 3 , respectively 2 and 4 are available.

\subsection{X-ray equipment and exposure procedure used}

$X$-ray examination was carried out with a Philips Diagnost $120 \mathrm{X}$-ray apparatus. This equipment has a telecommander equipped with a 14 inch image intensifier (II) and a 105 $\mathrm{mm}$ foto spot film camera. The TV circuit is a Philips Plumbicon XTV4. The generator consists of a MTM100 Philips 12 pulse circuit, $100 \mathrm{~kW}-150 \mathrm{kV}$. Exposure of the 105 $\mathrm{mm}$ camera takes place through an entry screen II $=25 \mathrm{~cm}=10 \mathrm{inch}$, the F-f distance is $1.25 \mathrm{~m}$ with a $0.6 \mathrm{~mm}$ focus. Exposure setting is $55 \mathrm{kV}-7 \mathrm{mAs}-16 \mathrm{msec}$. Image speed is 4 images $/ \mathrm{sec}$. The roll film used was a Kodak 
PF874/105mm, category 17108888 . One image measures $100 \times 100 \mathrm{~mm}$.

Shooting procedure consists of the following steps:

- The person to be examined is positioned sideways in front of the X-ray machine, which is in a vertical position. $\mathrm{He} / \mathrm{she}$ sits straight, with the knees bent in a 90 degrees angle and the upper legs in 90 degrees anteflexion compared to the trunk. During shooting the person wears gonad protection.

- He/she is instructed as to the motion to be examined. These are:

1. Anteflexion from maximum retroflexion to maximum anteflexion, the chin resting as caudal as possible on the sternum (called "bending" anteflexion position).

2. The opposite motion, retroflexion between both these extreme positions.

The shots were made in the same order for all persons. First, registration of the anteflexion motion of the cervical spine takes place, followed after approximately five minutes (the film cassette has to be exchanged), by shots of the opposite motion. These motions are practised several times before the shots are being taken. The person to be examined and the tube shall not be moved during registration. These have been positioned before the start, in such a way that the entire motion lies within the image during registration.

- Subsequently, the $X$-ray is set; first the dominante for $\mathrm{X}$-ray data on the cervical spine is chosen, and then the in-look position. is used.

-A run is now taken on $105 \mathrm{~mm}$. roll film. The diaphragm of the X-ray tube is completely open during shooting.

Anteflexion and retroflextion are performed in approximately $10 \mathrm{sec}$. The recording speed is 4 images/sec. Each motion is therefore registered on approximately $40 \mathrm{im}$ ages.

During automatic exposure the dominante of the shots will not always be within the object. So, manual exposure is used during these roll film shots, in order to have constant exposure of each image during the entire motion. This is necessary because images of equal density are needed to indicate the marker points.

\section{$2.3 \mathrm{X}$-ray radiation dose}

During a phantom study the radiation dose relating to this $\mathrm{X}$-ray technique was determined. The goal of this measurement was to determine "the effective dose equivalent" and the risk resulting from shots of the cervical spine. The measurement was carried out with an "Alderson Rando human phantom" and Lif thermoluminescention dosimeters (TLD-chip) of the HARSHAW make and TLD-100 type. The phantom was filled with 84 TLD-chips. Radiation dose was approximately the same as during actual registration (50 kV and $8 \mathrm{mAs}$, film-focus distance: 1.25 m).

Input and output dose were compared to those in a "real" test person. There was a minor difference, which, however, was not of such a nature that the phantom values diverge too much from the clinical values. Table 2.1 gives the organ doses and effective dose equivalent during registration $(40 \mathrm{im}-$ table 2.1

\begin{tabular}{|ll|}
\hline Organ area & $\mathrm{mSv}$ \\
\hline thyroid gland & 0.044 \\
cranium & 0.003 \\
mandible & 0.000 \\
apex of the lung & 0.004 \\
lung (remainder) & 0.018 \\
chest & 0.008 \\
gonads & 0.013 \\
\hline Heff. & 0.009 \\
\hline
\end{tabular}

ages). The following was concluded (Radiodiagnostics department of "Ziekenhuis Maastricht" and "Academisch Centrum Tandheelkunde Amsterdam): the effective dose equivalent and the death risk resulting from it (a 6th order risk) are comparable to other risks in daily life. If salivary glands and other organs are included as well, the Heff. does not change significantly. 


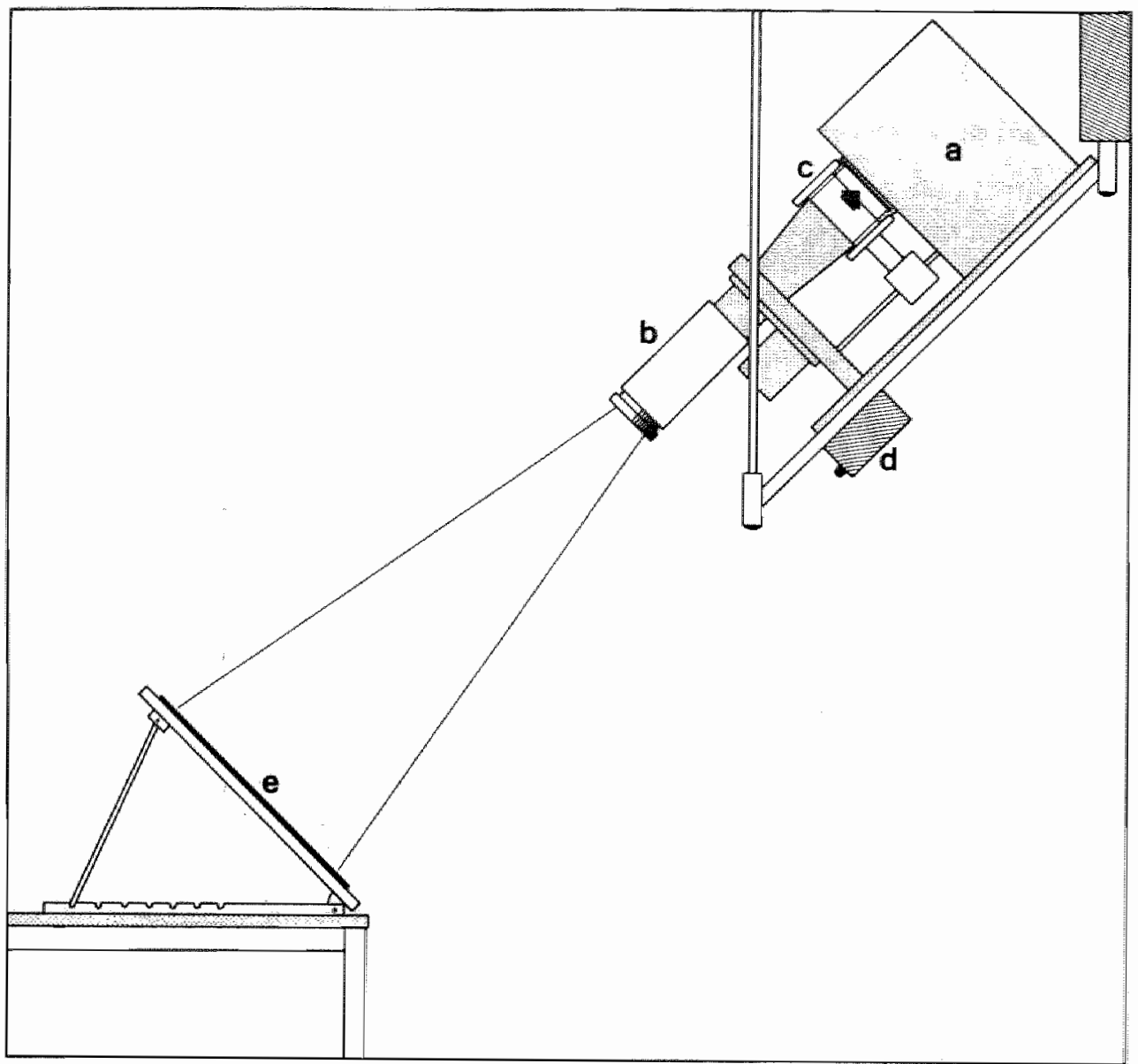

fig. 2.2 Projection of X-ray pictures (Leitz projector): a Source of light, $1000 \mathrm{Watt}$.

b extension tube.

c advance of film.

dremote control.

e drawing pad.

\subsection{Equipment}

Pictures are projected with a slide projector on a drawing pad, size A3. This slide projector - make Leitz-Wetzlar EPIS/lens 1:1.4/400 $\mathrm{mm}$, projection lamp 1000 Watt, is equipped with remote control image transportation suitable for $105 \mathrm{~mm}$. roll film. Such projectors are usually only used for projection on distances of approximately $15 \mathrm{~m}$. By means of an extra extension tube between lens and film the projector was adapted to projection on a $2.5 \mathrm{~m}$ distance.

The slide projector was suspended under a 45 degrees angle whereas the drawing pad was mounted on a table, also under a 45 degrees angle (figure 2.2).

A calibration template makes sure projection is effected perpendicular to the drawing pad. This calibration template is an image built up from a squared pattern. This also serves to insure that the image distortion is less 
than $0,5 \mathrm{~mm}$ per $400 \mathrm{~mm}$. The marker points of one image (see 2.5) are applied to the sheet of drawing paper. When the marker points have been applied to a sheet of drawing paper this is torn off. The distance between the latter and the lens changes therefore as the pad gets thinner, the 4-5 mm difference in distance are of no importance to the sharpness. The image is focused once on a sheet in the middle of the pad. The change in size of this projection of the cervical spine is neglected. The light intensity of the projection lamp makes it possible to apply the marker points from the images at a distance of 2.5 $\mathrm{m}$ in daylight. It is therefore not necessary to perform this work in a darkened room. Remote control allows the images of the roll film to be analyzed successively without the examiner having to stand behind the drawing pad to turn over the next image.

On these images the cervical spine is approximately 0.5 times its actual size. This projection method enlarges the $100 \times 100 \mathrm{~mm}$ image 2.5 times, which leads to enlargement of approximately $1.25 \mathrm{x}$, with the same sharpness as of a standard $\mathrm{X}$-ray. This allows accurate marking of the contours.

\subsection{Marking skull and vertebrae}

The contours of the skull and seven cervical vertebrae are registered on each image by marker points (fig. 2.3a). The contour of the skull is marked by three points, the atlas by four and the remaining vertebral contours by five points. The three points for the cranial contour are marked on a template of the contour of the cranium. On this template, the contours of parts of the sella turcica, the maxilla, the external occipital protuberance, and the inner and outer contours of the occipital bone, including the occipital condyle are indicated. These contours are copied from their projection within the image in the middle of the picture. The template is put on a sheet of drawing paper, in such a way that it overlaps the cranial contour of the image projected on the sheet of drawing paper. The points of the template are transferred to the sheet of drawing paper. The use of a template to register the contour of the skull is necessary because there are usually no clear identification points along this contour. This method of contour registration is also used to register the position of the contour of the seventh cervical vertebra. With this vertebra the problem often occurs that in a number of images the shoulder girdle is projected partly on top of the vertebral contour. It would be possible to register this vertebra without a template by marking for instance only three visible - identification points. In this case registration of the seventh cervical vertebra is less precise than that of the other vertebral contours, registered by five marker points. For the seventh cervical vertebra we have opted for five points on the template, because the other vertebrae are also registered by five points. It would have sufficed to register the positions of these templates by registering only two points on the sheet of drawing paper. As to the contour of the skull we have opted for three points in order to get a recognizable shape (a triangle as opposed to a pentagon).

The other vertebrae are marked without the help of a template. For these vertebrae it would be desirable to have a great number of marker points because reiteration with "replacement of incorrectly applied points" takes place in the calculation procedure (see 2.7 point 9 to 12 ). The number of points per vertebral contour given below is limited, but comprises all clearly recognizable points for the vertebral contour.

The contour of the atlas is indicated by four marker points on the sheet of drawing paper, two points on the position of the anterior arch of the atlas, and two on the posterior arch. We have confined ourselves to these four marker points because no fifth identification point can be given. The remaining vertebral contours are registered by four marker points at the vertexes of the projection of the vertebral body and one at the cranial point of the projection of the spinous process implantation contour within the vertebral arch. The two cranial points for projection of the vertebral body at the axis, are given at the transi- 

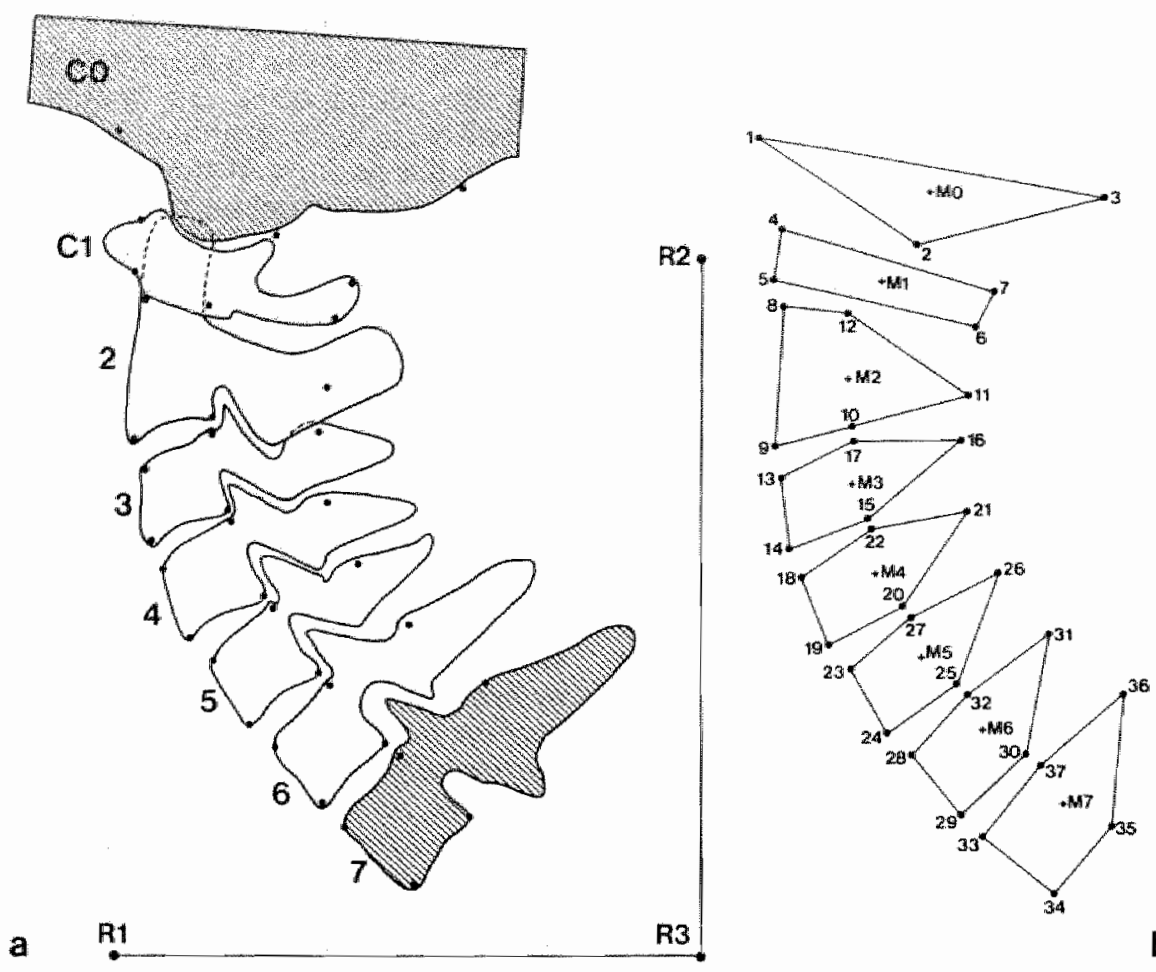

b

fig. 2.3 Projection in the sagittal plane of the contours: The marker points of skull (C0) and cervical wertebrae ( $\mathrm{C} 1$ to $\mathrm{C7}$ ), and the reference coordinate system.

a Outlines of the contours.

- marker points of the coordinate system (R1 to R3).

- marker points of $\mathrm{CO}$ to $\mathrm{C7}$.

The hatched contours are marked with a template.

b Marking of the skull and cervical vertebrae.

- Skull by means of a triangle ( 1 to 3 ).

- Atlas by means of a guadrangle (4 to 7$)$.

- Remaining vertebrae by means of a pentagon (8 1037 ).

The points are numbered in the sequence in which they are fed into the computer. The arithmetic centre of each contour is given (M0 to M7).

tion of dens to vertebral body.

The coordinate system of each film is applied as follows to each sheet of drawing paper. Each image produces, always in the same position, a projection of the round diaphragm of the $\mathrm{X}$-ray tube and the patient registration plate. A template was made of the projection of the aperture and this registration plate. This template has three holes. The template is placed on the sheet of drawing paper, overlapping the projections of the aperture and registration plate as much as possible. This position is transferred via the three holes to the sheet of drawing paper. These three marker points (R1, R2 and R3 in figure 3a) are being used to construct the coordinate system on the image (see 2.7 point 1 ).

For each image, therefore, 40 marker points are given:

- 3 for the coordinate system;

- 3 for the contour of the skull; 
-4 for the contour of the atlas;

$-6 \times 5$ for the contours of the remaining vertebrae.

Each sheet of drawing paper is provided with the serial number of the film and the person examined.

\subsection{The $x-y$ coordinates of the coordinate system and marker points}

In order to determine the coordinates of the marker points compared to the coordinate system, we used an $x-y$ digitizer (Summagraphics ID), the resolution of which is 0.2 $\mathrm{mm}$. It was linked to the PDP 11/73 (Digital Equipment Corporation) computer with the aid of an interactive program. With this program the following procedure is carried out. The sheet of drawing paper belonging to a certain image is fixed to the $x$-y digitizer, such that it cannot move. Point (R1) is considered zero $(0 ., 0$.) of the $x$-y digitizer. In order to create a coordinate system of the $x-y$ digitizer, all the following positions are compared to both this point (R1) and a vertical $y$-axis and horizontal $x$-axis through this point.

The sequence in which the coordinates of the 40 points are determined is identical for each sheet of drawing paper.

These are:

- Point (R2), this point is situated on the $y$ axis of the image (figure 2.3a);

- Point (R3), as (R2) this point is situated on the $y$-axis of the image (figure $2.3 \mathrm{a}$ );

- The points of the skull ( 1 to 3 ), the atlas ( 4 to 7 ), etc. (figure $2.3 \mathrm{~b}$ ).

The data is stored on a disc.

\subsection{Calculating the position of the vertebral contours per image}

Although the skull is marked by a triangle and the atlas by a quadrangle, calculation of the positions of this triangle and quadrangle is equal to that of the pentagon of the remaining vertebrae. The following steps are used for the calculation of the position of the contour of each vertebra on the picture.
1. The $y$-axis is constructed by points ( $R 2$ ) and (R3) (see figure 2.3a). From point (R1) on the $\mathrm{x}$-axis of the reference frame a perpendicular is set up on the y-axis. This line constitutes the $x$-axis of the picture (figure 2.4 ). Where these two lines cross, lies the origin of the coordinate system of the picture. The $\mathrm{x}$ and $y$-coordinates of each position taken are transferred from the coordinate system of the $x-y$ digitizer to the coordinate system of the picture. Hence the difference in coordinates between the pictures, which results from each picture having a different position on the $x$-y digitizer, is corrected.

2. From each pentagon the arithmetic centre (the sum of $x$-coordinates and $y$-coordinates divided by the number of points) ( $M$ in figure $2.3 \mathrm{~b}$ ) and the length of the sides and distances of the vertexes to the centre (radius) is calculated on each picture (figure 2.4).

Subsequently, the angles between the radii are computed with the aid of the cosine (alpha1, alpha2, alpha3 and alpha 4).

3. Each picture consists of approximately 40 images and consequently a similar number of pentagons are computed from each vertebral contour. These pentagons of a vertebral contour on a picture will not be identical. This is caused by inaccuracies during marking and positioning, or because projection in the plane of the picture changes shape as a result of rotation during motion of the cervical spine in an other plane than the plane of the picture. To reduce the influence of these faults to a minimum, an average was computed of each contour pentagon in the film. A fault in one picture was averaged over all pictures of that film. This pentagon is determined per film by the average radii and average angles between the radii. It is called the "average" pentagon of the vertebral contour concerned.

4. In each picture the average pentagon is superimposed upon the original pentagon of the relevant wertebral contour, in such a way that the $x-y$ coordinates of the centre of the average pentagon is equal to the $x$ - and $y$-coordinates of the centre of the original pentagon. Rotation position of the average pentagon is arbitrary (figure 2.5 ). 


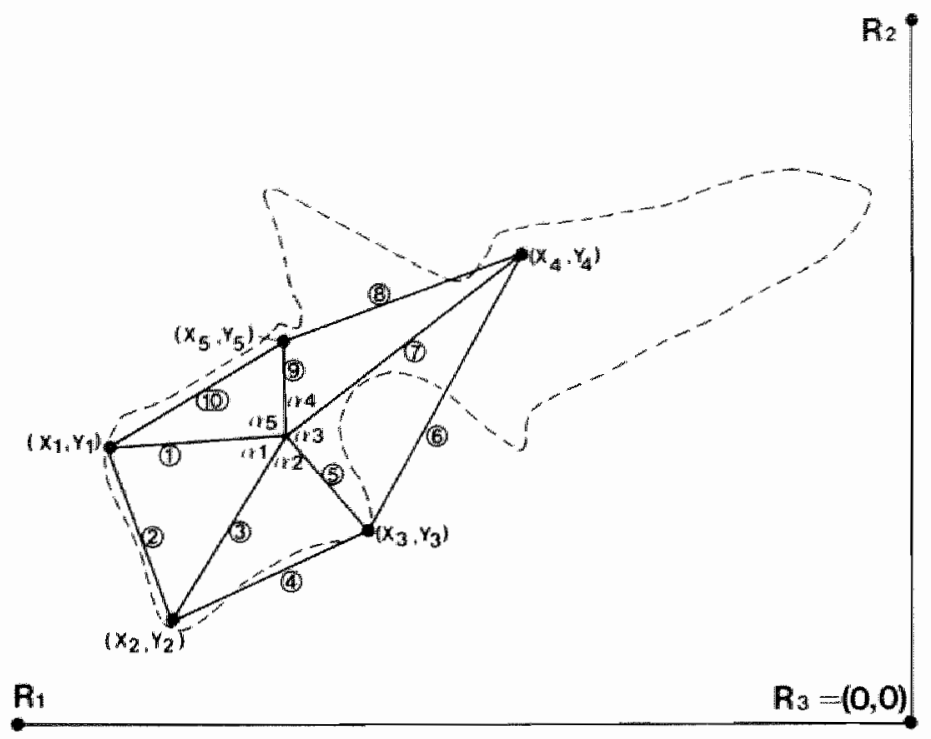

fig. 2.4 Contour (interrupted line) and pentagon of a vertebra on a frame in relation to the reference coordinate system (R1 to R3).

5. The sum of the distances between the corresponding vertexes of the pentagon taken up and the average pentagon are computed (figure 2.5).

6. The average pentagon is turned 1.0 degree in positive direction around the centres, which are on top of each other.

7. Once again the sum of the distances between corresponding vertexes of the pentagon is determined.

8. These iterations are repeated untill the following criterion has been met:

After an unknown number of reiterations the sum of the next one will get smaller than the preceding sum. Reiteration continues until the sum increases again in a next step. The step preceding the one in which the sum increases will be the position at which the average pentagon of a vertebral contour fits best on the pentagon taken of the vertebral contour on that picture (figure 2.6).

9. In the position determined under 8 of the average vertebral contour, each distance between the corresponding vertexes of the average vertebral contour and the pentagon taken up by this wertebral contour is computed separately.

10. If one of these distances in a picture is longer than $1 \mathrm{~mm}$, the $x$-y coordinates of the relevant vertex of the pentagon taken up is replaced by that of the corresponding vertex of the average pentagon in the position found under 8 . If more distances are longer than 1 $\mathrm{mm}$, a maximum of 2 vertexes is replaced per reiteration (figure $2.7 \mathrm{a}$ and $2.7 \mathrm{~b}$ ).

11. The $x-y$ coordinates of the arithmetic centre on that picture of the original pentagon of the relevant vertebral contour concerned are determined once more, allowing for the $x$ - and $y$-coordinates of the vertex replaced, after which the arithmetic procedure mentioned above ( 4 to 10 ) is repeated.

12. This reiteration is repeated as many times until the distances of the corresponding vertexes of the pentagon taken up and the average pentagon are all less than $1 \mathrm{~mm}$.

Reiteration of the average pentagon may in principle be carried out in relation to any point. Should this point be outside the original pentagon, the sum of the distances of the 


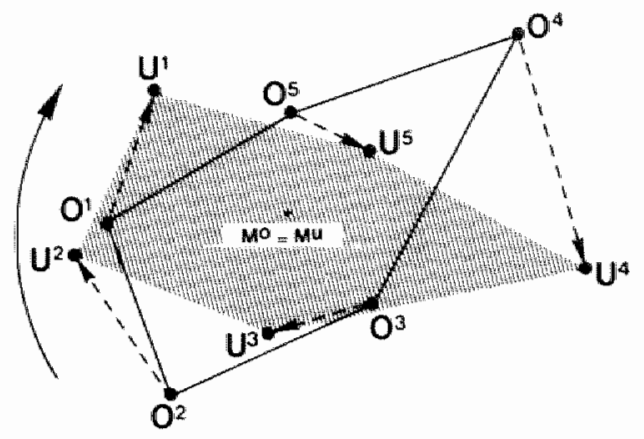

ng. 2.5 Positioning of the average pentagon (U1-US) in relation to the original pentagon, (01.05), of fig. 2,4 , before iteration (direction of arrow). The sum of distances (O1-U1) to (O5-U5) is the sum of the distances between corresponding vertexes.

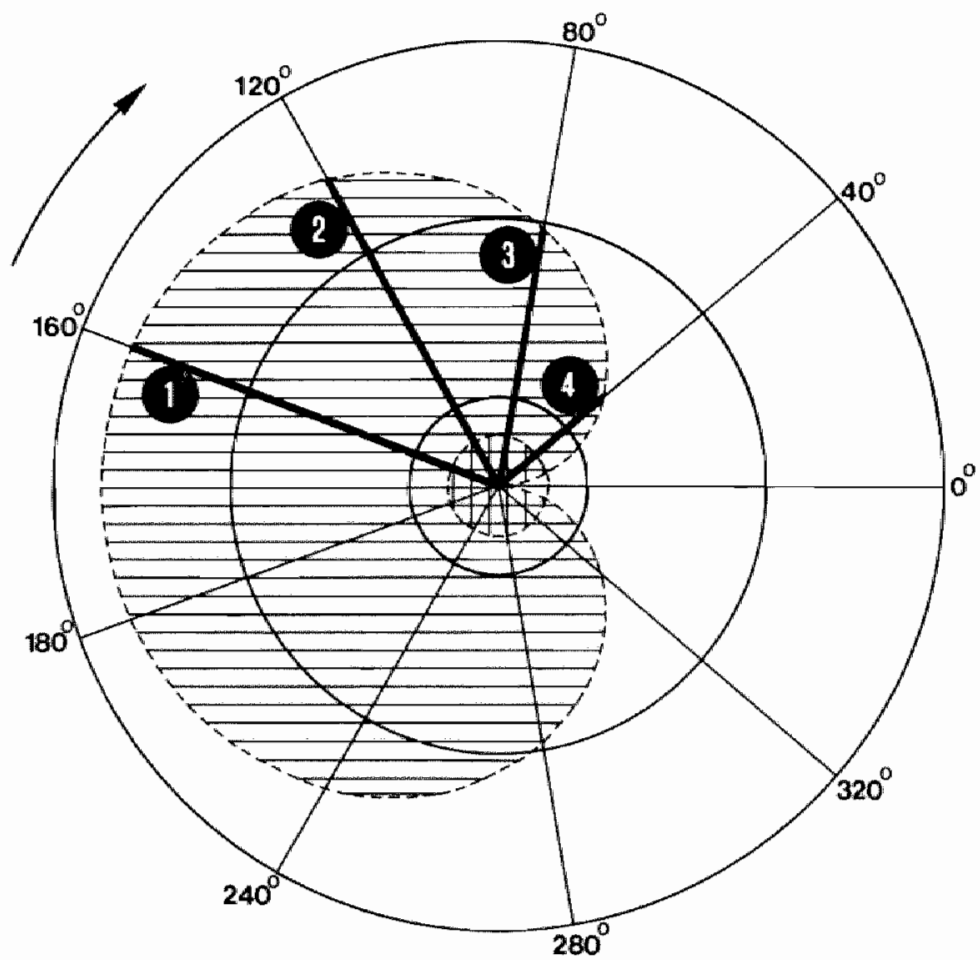

nig. 2.6 The sum of distances in case of iteration of 360 degrees. As examples of the value of this sum of distances the straight lines of 1 to 4 are drawn. In this example the minimall value of this sum is 0 . The minimall value has to be found within the cross hatched area. 

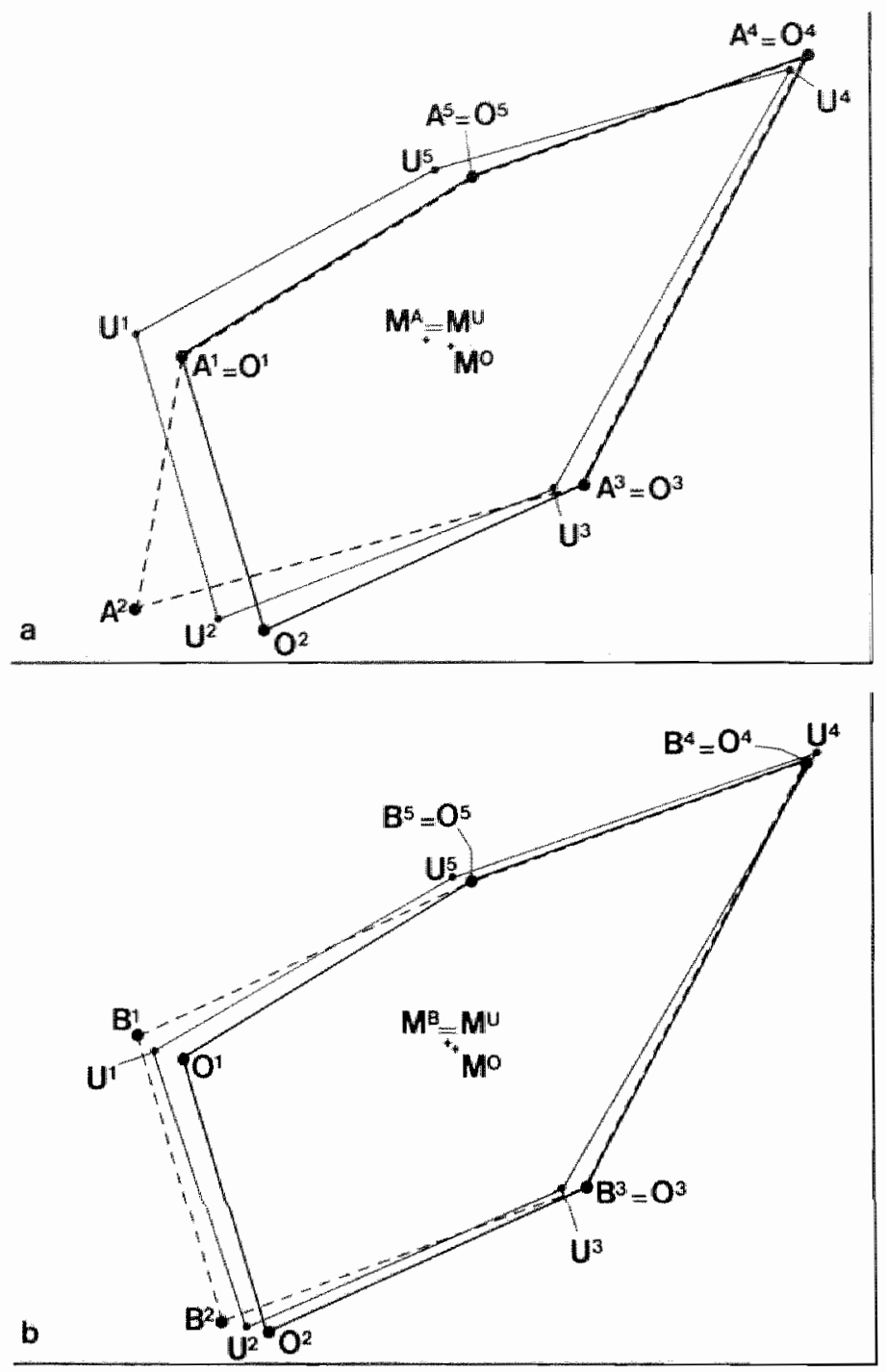

Iig 2.7Automatic correction of incorrectly marked points.

a - Correct position of the original pentagon (O) with arithmetic centre $\left(M^{\circ}\right)$.

- Position of the original pentagon (A) with arithmetic centre $\left(M^{a}\right)$. Angular point (A2) is positioned incorrectly.

- Position of the average pentagon (U) superimposed on the original pentagon (A) after iteration. In this position the values of the distances (A1-U1) and (A2-U2) are more than $1 \mathrm{~mm}$.. The coordinates of the angular points $A 1$ and $A 2$ are replaced by the coordinates of $U 1$ and $U_{2}$.

b - Correct position of the original pentagon $(O)$ with arithmetic centre $\left(M^{0}\right)$.

- Position of pentagon $(B)$ with arithmetic centre $\left(M^{b}\right)$ (identical to pentagon $(A)$ in fig. a, consisting of the angular points $\mathrm{U1}, \mathrm{U2}, 03, \mathrm{O}$ and $\mathrm{O5}$ ). This is the pentagon in fig. a after iteration.

- Position of the average pentagon (U) superimposed on the pentagon (B) after iteration.

The angular points (B1) and (B2) are replaced after iteration in fig. $b$ and a new iteration starts. This reiterationprocedure is repeated untill the values of all distances between corresponding angular points are lesser than $1 \mathrm{~mm}$. 


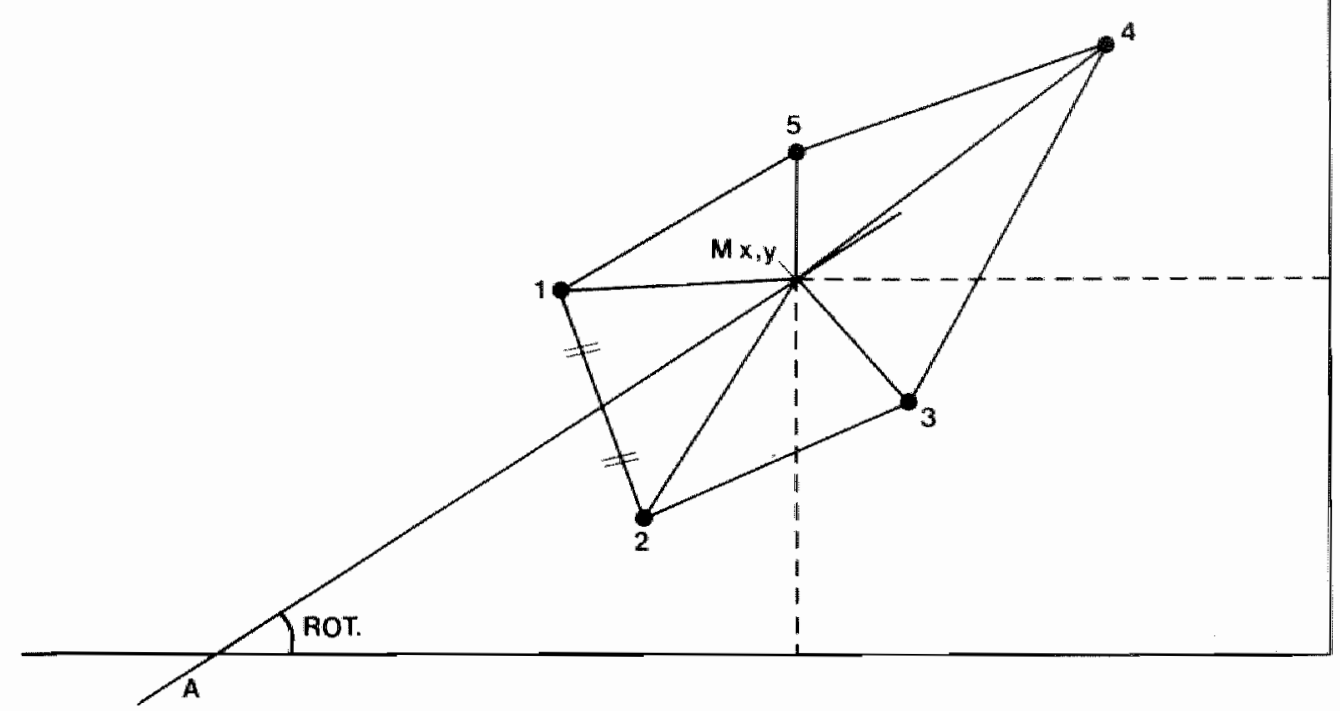

fig. 2.8 Angle ROT between abscissa and straight line A, this is a line through the arithmetic centre (M) and the middle of the line between angular points 1 and 2 of the average pentagon on a given frame after final iteration.

corresponding vertexes (see 8 .) either have a number of minimum values, or the minimum is high compared to the other values. If a vertex of the original pentagon is chosen as a reference for the point compared to which reiteration is performed, a situation may also occur in which the minimum stays high, if this is a vertex which is inaccurately indicated. It is impossible then to replace this point (see 10.) From the points within the pentagon the arithmetical centre of the original pentagon is the most favourable point for performing reiteration. In all cases, a clearly distinguishable minimum will arise and an incorrectly indicated vertex is clearly deviating and thus recognizable.

13. The $x-y$ coordinates of the vertexes of the average pentagon in this position are registered.

14. A straight line $\mathrm{A}$ is determined through the arithmetical centre and the middle of the line between points 1 and 2 of the average pentagon in the position determined under 13 (see figure 2.8 ).

15. The angle, called ROT, between the straight line A determined under 14 and the positive $x$-axis is computed. ROT is the rotating position of the relevant vertebra within that image.

16. Motion of the cervical spine is assumed to be fluent. This means that the change of position of the cervical contours will take place along a continuous path within the sagittal plane. Marked out against the images, the values of the ROT angle, the $x$-coordinate and the $y$-coordinate of the centre will follow a continuous path.

Marking, positioning and calculating will create faults indicated as "noise".

The coordinate system is assumed to be cor- 


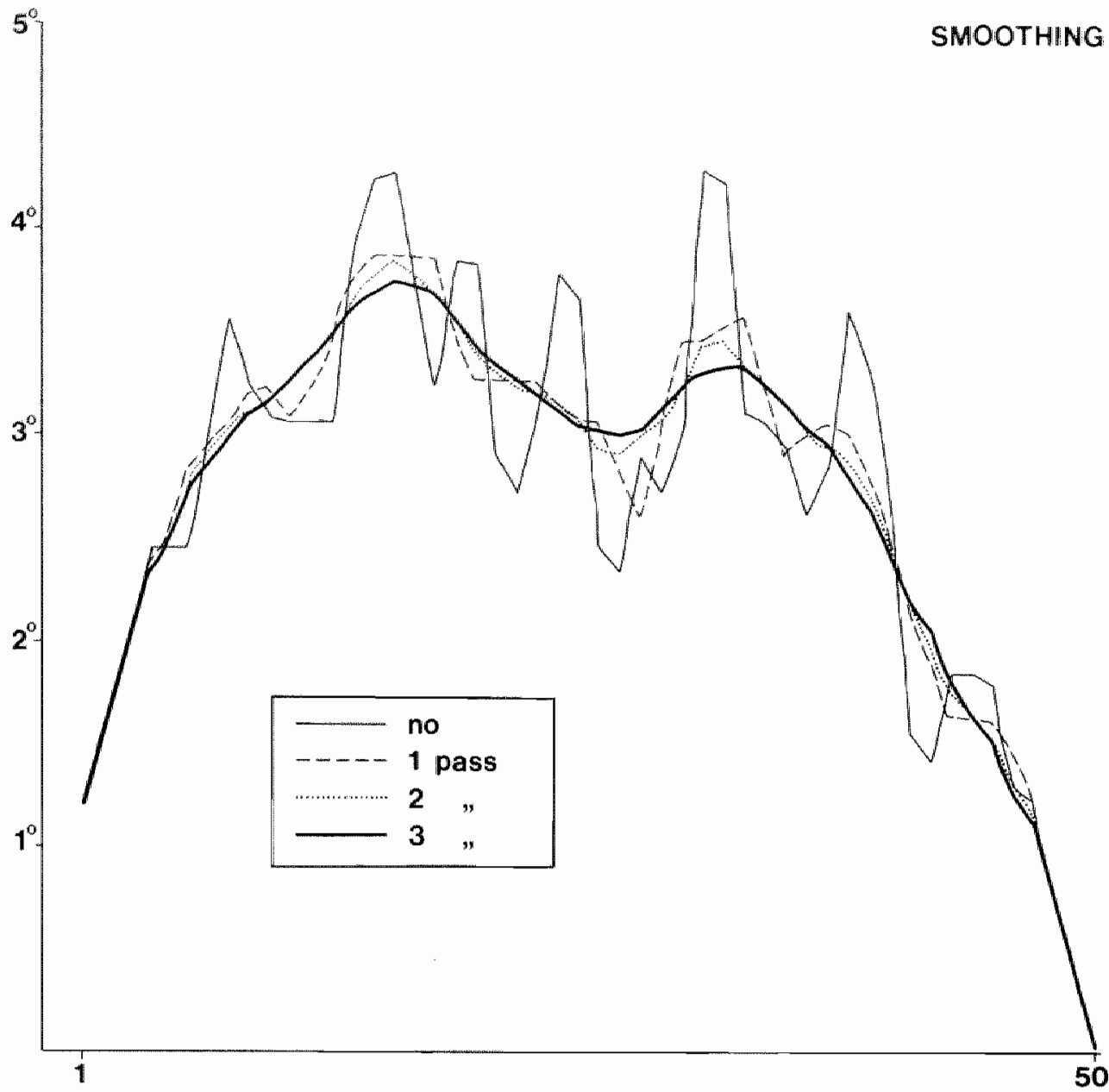

fig. 2.9 "Smoothing" ("running mean") of the values of the position parameters of the average pentagon on all frames. As an example in this graphics the value of ROT on a given picture minus ROT on the preceeding picture is plotted against all frames of a film. The graphs represent $0,1,2$ and 3 "passes of smoothing".

rectly indicated on each picture, therefore it is possible to correct the noise by means of an "averaging" method for the values of ROT, $x$-coordinate or $y$-coordinate (running mean). The final value of each of the three parameters of each vertebral contour per image, is the mean of the sum of the value of this parameter on the preceding, the present and the next picture. This method is applied three times to the parameters mentioned (figure 2.9).
17. Of all vertebral contours of a film and of each picture, the parameters of the position of the vertebral contour found with the calculation procedure described above, are stored in one file, i.e.:

- The rotating position.

- The $\mathrm{x}$ - and $\mathrm{y}$-coordinates of the arithmetic centre.

In addition, the following values are filed of the average pentagon (or quadrangle or triangle) and of each vertebral contour on the 


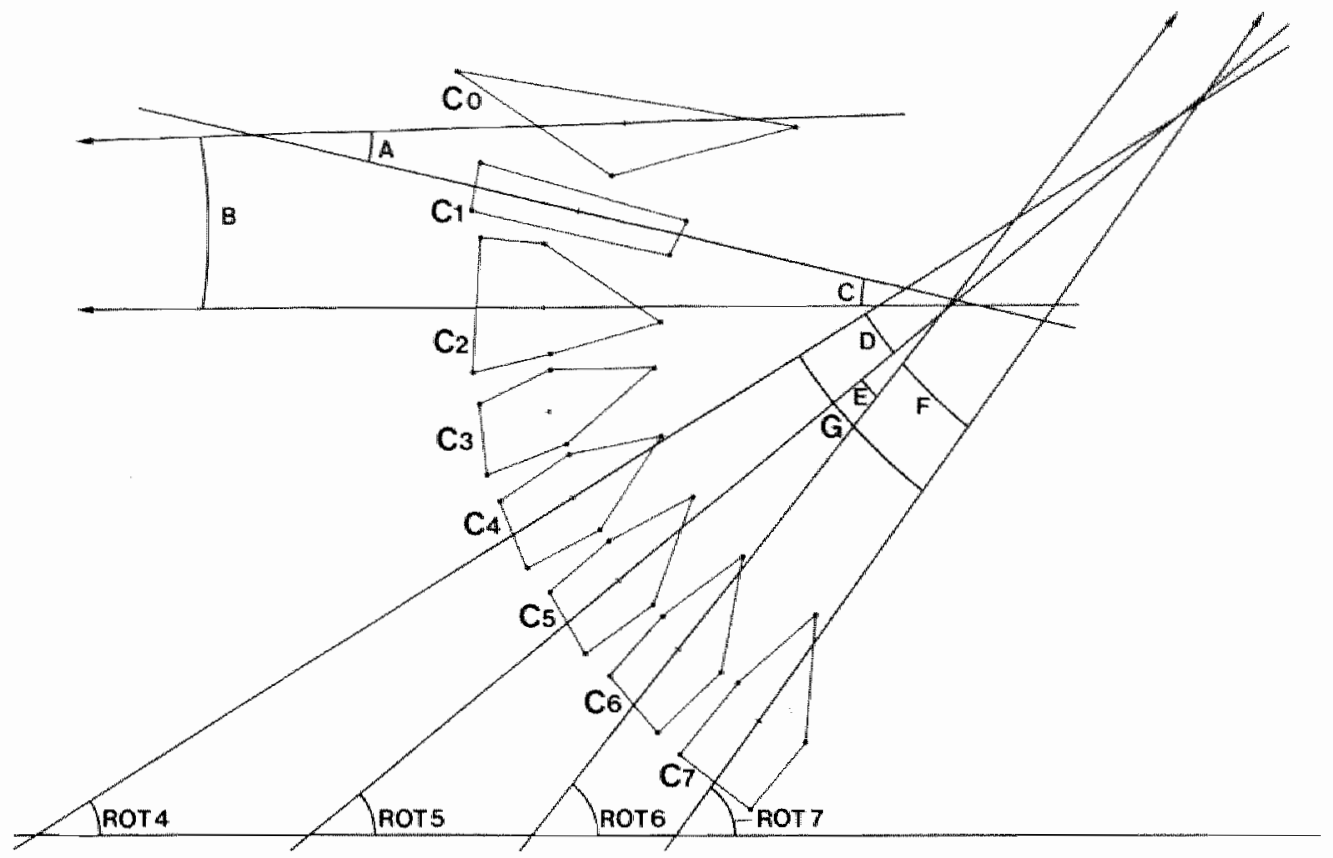

fig. 2.10 Angles between the vertebrae of a segment, respectively between extreme vertebrae of a block on a given frame.

On this frame of the block $(\mathrm{C} 4 \mathrm{C7})$ are indicated:

Angle G: ROT7 - ROT4.

Angle D: ROT5 - ROT4.

Angle E: ROT6 - ROT5.

Angle F: ROT7 - ROT6.

In the block (CO-C2) (angle B) the angles of the segments (CO-C1) (angle $A$ ) and (C1-C2) (angle $\mathrm{C}$ ) are indi-cated.

film:

- Length of the radii.

- Angles between the radii.

The position of each vertebral contour on each picture is stored with the parameters filed under 17. A great number of calculations must be made with these values. The results of these calculations of the anteflexion and retroflexion contributions to motion of the entire cervical spine or to parts (blocks) of it, are reproduced in diagrams made with a Tektronix 4662 (option 31) plotter.

In order to be able to do this quickly a command language was developed. This command language serves to perform the calculations desired for each file given (i.e. motion of a certain person). Each type of diagram can be plotted with this command language.

\subsection{Segmental motion during motion of the cervical spine}

The angle between two vertebrae within a given picture is calculated as follows:

On each picture the ROT angle of each vertebral contour is already known (figure 2.10). The difference between the ROT angles of two vertebrae on a given picture is calculated.

E.g. the angle between $\mathrm{C} 4$ and $\mathrm{C} 5$ is:

(ROT,4 - ROT,5) $=\mathrm{D}$ (fig. 2.10).

For the segments ( $\mathrm{CO}-\mathrm{C} 1)$ to $(\mathrm{C} 6-\mathrm{C} 7)$ these are $A$ to $F$ respectively in figure 2.10 , and e.g. for the block (C4-C7) this is $G_{\text {. }}$. The difference between these angles within conse- 


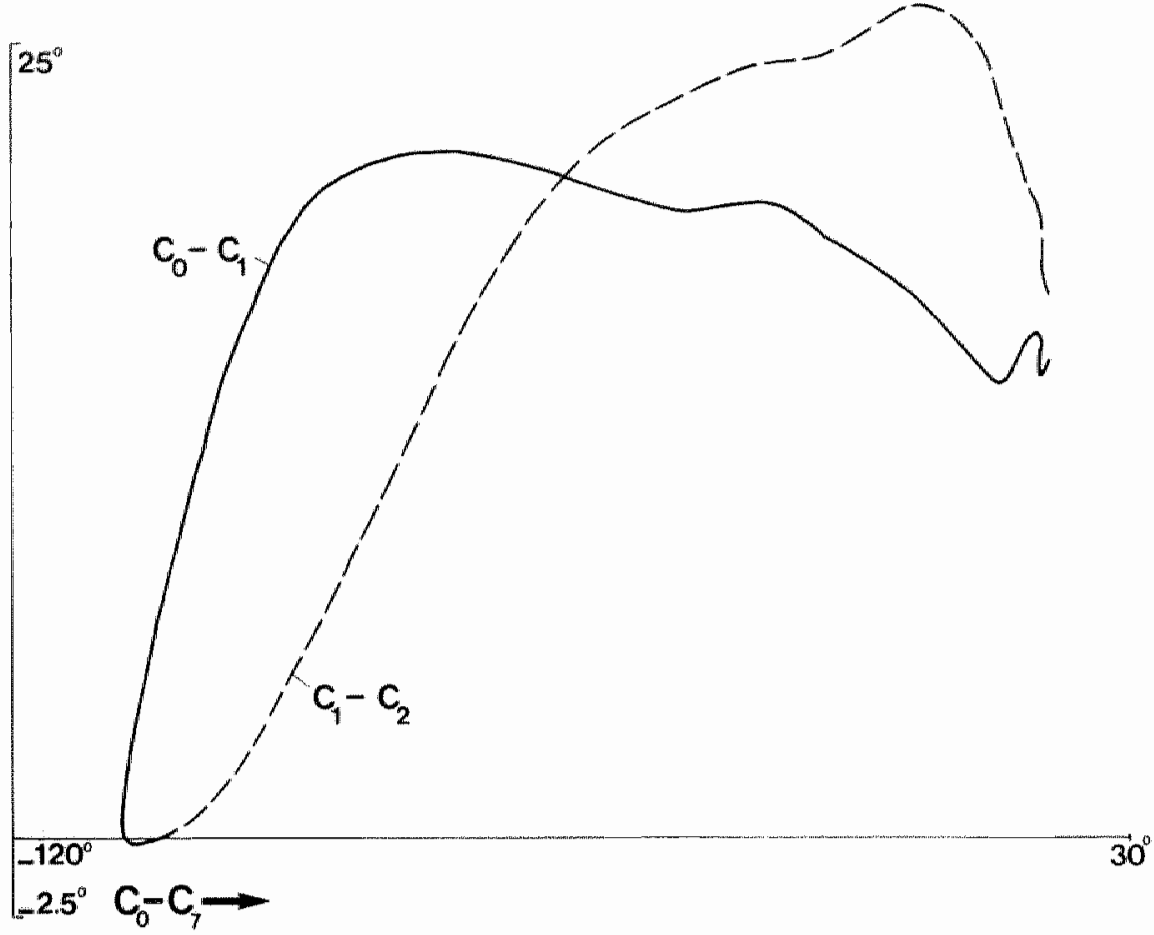

fig. 2.11 Absolute rotation of the segments (CO-C1) and (C1-C2) plotted against the absolute rotation of the whole cervical spine and the head (CO-C7).

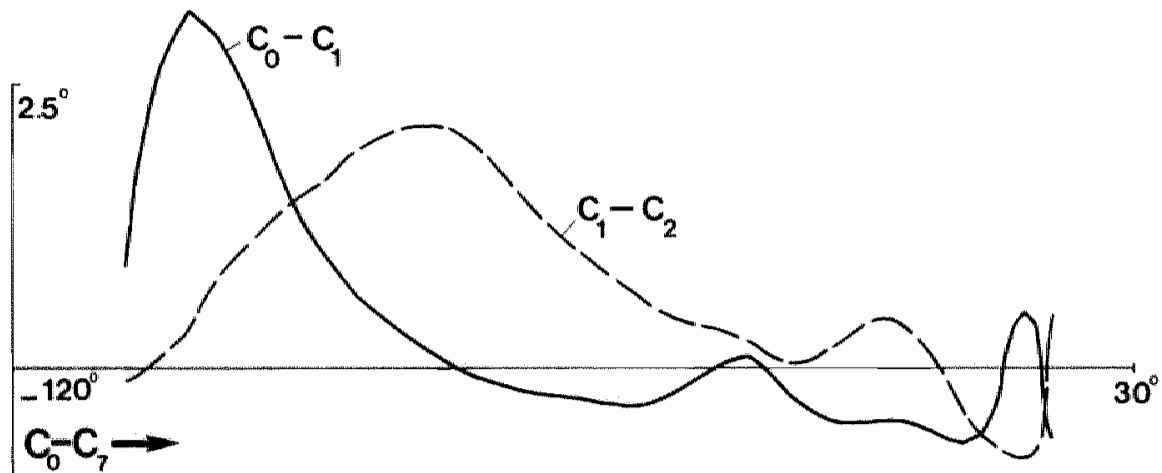

$-2.5$

7g. 2.12 Relative rotation of the segments $(\mathrm{CO}-\mathrm{C1})$ and $(\mathrm{Cl}-\mathrm{C} 2)$ plotted against the absolute rotation of the whole cervical spine and the head (CO-C7). 
cutive pictures of a film is the rotation within the sagittal plane between two vertebrae during motion.

Rotation within the sagittall plane between two adjacent vertebrae - motion within a segment- or between two nonadjacent vertebrae - motion within a block or within the entire cervical spine - can be indicated in two ways. 1. As the difference between the ROT values on a certain picture and the ROT value on the first picture. This is called absolute rotation (figure 2.11).

2. As the difference between the ROT values on a certain picture and its value on the preceding picture. This is called relative rotation (figure 2.12).

The rotation within the range of motion of the relevant segment or block can be studied in the diagrams in which absolute rotation is plotted. On the basis of this, the range of motion of the segments was determined (see chapter 4). The diagrams in which relative rotations were plotted show the part in which a certain segment contributes considerably to the motion of a block and - if more segments were plotted - the sequence of their contribution can be read out.

The peaks in the diagram of figure 2.12 correspond to the steep parts in the diagram of figure 2.11. The sequence in which the segments contribute to motion can be read out from the sequence of the peaks in figure 2.12.

\subsection{Normalizing the values}

$\mathrm{X}$-ray registration always took place with a rate of 4 images per second. Motions were performed "slowly". The motion time is 7-12 seconds. This means that the films will have a different number of pictures. We assumed that the accelerating and decelerating pattern in the segments for a certain person is the same at the different measuring moments. It is also supposed that it will not make any difference whether the motion was performed within 7 or 12 seconds (faster rates would probably make a difference). If there is a smaller number of images per motion, the gap between two images will be larger and so will be the value of rotation within a segment or within a block between these two images. This phenomenon is undesirable, because the reproduction technique will cause a distorted view in diagrams that show relative rotation. This is why the values of each film are normalized to 50 virtual images, such that accelerations and decelerations will remain. In case of only normalizing the number of images over the path of motion, differences in height of peaks in diagrams of relative rotation occurs (figures $2.13 \mathrm{~b}$ and $2.13 \mathrm{~d}$ ). This is not the case in diagrams of absolute rotation (figures 2.13a and 2.13c). Proportional division of the values (ROT and $x$ - and $y$-coordinates) prevents difference between the height of peaks in these diagrams (compare fig. $2.13 \mathrm{~b}$ with fig. $2.13 \mathrm{~d}$ ). This procedure is followed up for all ROT-values and $x$ - and $y$ coordinates of the centre of all vertebrae for all films prior to drawing the diagrams. These values serve to carry out all calculations and draw all diagrams.

\subsection{Method of data reproduction}

The data found can be reproduced in a great number of ways. Subject to the questions, different reproduction methods will be used. These methods and the reason why they were chosen will be discussed in the relevant chapters.

\subsection{Reproducibility of the method}

Marking vertebral contours on the images was always done by the same person. We therefore refrained from determining the "interobserver" variation of this method, by letting a number of different examiners indicate marker points. The person mentioned

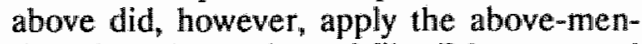
tioned marker points of film R3 on several days spread out over approximately one month. Ten files of data are made. The following chapters will illustrate reproducibility of the results deriving from the diagrams used to answer the questions, on the basis of five files of data of film R3 (R3P1 to R3P5) 

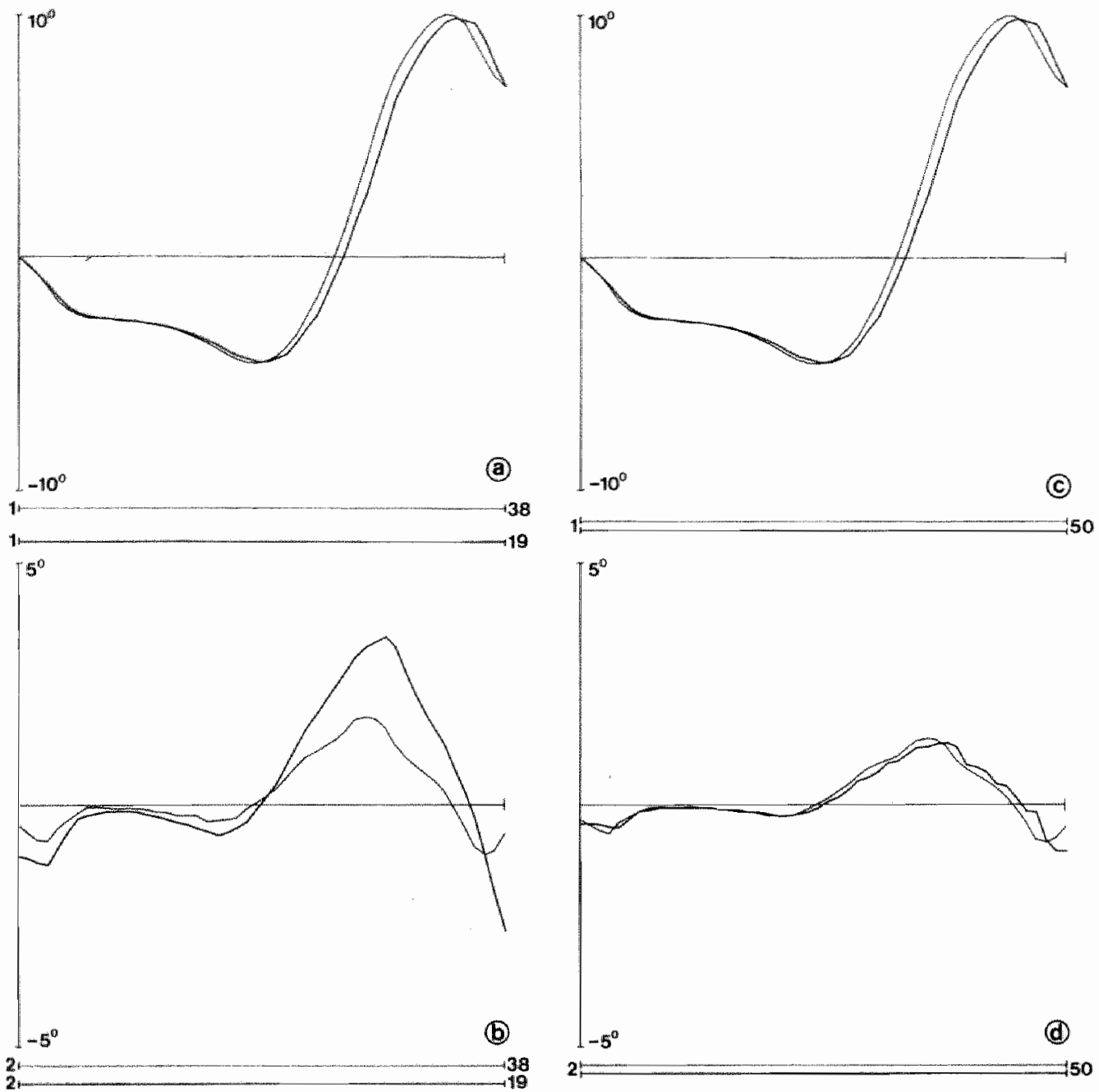

fig. 2.13 Normalizing to 50 wirtual pictures.

a Absolute rotation plotted against real number of frames (19 respectively 38 ).

b Relative rotation plotted against real number of frames (19 respectively 38).

c Absolute rotation plotted against virtual number of frames (for both 50 ).

d Relative rotation plotted against virtual number of frames (for both 50 ).

In a and b only the number of images is normalized along the $\mathrm{x}$-axis. In $\mathrm{c}$ and $\mathrm{d}$ also proportional division (nor. malizing) of the values in y-direction is carried out.

marked at five different days. In chapter 5 next to these five files a sixth file is used (R3PAT) The "intraobserver" variability was also determined numerically. For this purpose diagrams were drawn of the film which was taken up five times (R3P1 to R3P5) in which of all segments the relative segmental rotation was plotted as $y$-value against the 50 normalized images along the $x$-axis. Standard deviation of the $y$-values of the data of these five files was determined per segment and per image. This varied between 0.3 and 0.7 degrees. This standard deviation is not given in the diagrams in the following chapters, be- 
cause the values plotted on the $x$-axis can differ from the ones in the diagram which served to calculate this standard deviation.

\subsection{Discussion}

For each X-ray film of approximately $40 \mathrm{im}$ ages, circa 1600 marker points must be positioned. This requires a fast marking method. The marking method per image of the contours of the skull and the vertebrae is indeed faster than those described until now. 40 points are positioned per image. The methods described until now require at least the positioning of tangents (Bakke, 1931; De Sèze et al., 1951; Lewit and Buetti-Bäuml, 1954; Aho et al., 1955, Werne, 1957; Lewit and Krausovà, 1963; Bhalla and Simmons, 1969; Markuske, 1971; Depreux and Mestdagh, 1974, Arlen, 1977, 1978, 1979; Dimnet et al., 1982), or the placing of the corresponding vertebral contours of two X-rays on top of each other as accurately as possible (Virchow, 1928; Penning, 1960, 1961, 1968, 1978; Gutmann, 1968; Gros et al., 1968). Both procedures are more time-consuming than the marking of five points. Since five points are positioned per contour for each vertebra, the position of that vertebral contour is not marked as strongly deviating if one of the points is indicated less accurately. This is not the case when positioning a tangent on a vague contour. It is likely that out of the 1600 marker points an unknown number per film is indicated wrongly. Using the "average pentagon" (or quadrangle for atlas, and triangle for skull respectively) method for all pictures on a film, marker points which were positioned wrongly will be replaced automatically during calculation of the position of the vertebral contour. By averaging the differences in shape of the contours over approximately 40 images (the "average" pentagon belonging to a vertebral contour), the error which arose from the differences in shape between two shots in the extreme positions, as is the case during determination of the segmental range of motion using only two Xrays, is avoided. The method using the command language to make diagrams allows one to quickly make new diagrams in which other values have been plotted.

\section{Bibliography}

Aho, A., Vartianen, O, Salo, O., Segntertary anteroposlerior mobility of the cervical spine, Ann. Med intern. Fenn, 44, 287-299, 1955.

Abers, D, Eine Studie aber die Funktion der Halswir belsäule bei dorsaler und wentraler Flevion, Forsch. Röntg. 81, 606-615, 1954.

Arlen, A., Die "paradove Kippbewegung des Allas" in der Funktionsdiagnostik der Halswirbelsabule, Man. Med, $15,16-22,1977$

Arlen, A., Messwerfahren zur Erfassung won Statik und Dynamik der Halswirbelsäule in der sagittalen Ebene, Man. Med, 16, 25-35, 1978.

Arlen, A., Biometrische Röngen-Funktions-Diagnostik der Halswirbelsäule, In. Schriftenreihe Mannelle Medizin $_{.}$Band 5, Verlag fiur Medizin Dr. Ewald Fischer $\mathrm{GmbH}$, Heidelberg, 1970 .

Bakke, S.N., Röntgenologische Beobachntungen ibber die Bewegungen der Wirbelsanie, Acta Radiol, Suppl. 13, 1931.

Bhalla, S.K, Simmons, E.H., Nomnal ranges of intervertebral joint motion of the cervical spine, Can. J. Surg., 12, $181-187,1969$.

Brown, R.H., Burstein, A.H., Nash, C.L., Shock, C.C., Spinal analysis using a three-dimensional radiographic technique, J. Biomechanics, 9, 355-365, 1976.

Buetti-Bäuml, C, Funktionelle Röntgendiagnostik der Halswirbelsäule. Georg Thiemè Verlag Stuttgart, 1954.

Deprenx, $R$, Mestdagh, $H_{3}$, Anarome fonctionelle de l'articulation sows-occipinale, Lille Med, 19, 122-125, 1974.

Sezze de, S., Djian, A., Abdelmoula, M., Etude radiologique de la dynamique cervicale dans la plan sagitlale. Rev. Rhum., 18 no. $3,111-116,1951$.

Dimnet, J, Pasquet, At, Krag, M.H., Panjabi, M.M., Cer vical spine motion in the sagithal plane, Kinematic and geometric parameters, $J$. Biomechanics, 15, no, 12, 959969, 1982 .

Gros, C., Mahovïtch, B., Frerebean, $P$., La chamidre médhocervicale. Enude radiographique dynamique de la flexion du rachis cenical, Montpellier Chir, 14, 349-356, 1968 . 


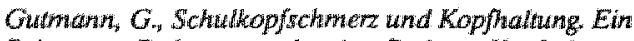
Beitrag zat Pathogenese des Anteflexionis-Kopfschmerzes und zur Mechanilk der Kopfgelenke, Z. Orthop., 105, $497-515,1968$

Lewil, Ku, Kronusowt, L, Messungen won Vor- und Ruckbeuge in den Kopfgelenkem, Fortschr. Rörtg, 99, 538 $543,1903$.

Mameren van, $H_{\text {.y }}$ Drukker, $J .$, Mobility in the cervical spine: Intra - and interindividual comparison of segmentai motion in the sagittal plane, Verh. Atat. Ges., 80, $771-$ 772,1986

Markuske, H., Untersuchungen zur Statik und Dynamik der kindlichen Fralswirbelsäule: Der Ausssagewert seitlicher Rontgenaufnahmen, Die Witbellaule in Forschung und Praxis, 50, 1971.

Penning $L$, Functioneel röntgenonderzoek bij degeneratieve en traumatische af fiw ijkingen der laag-cervicale be- wegingsisgmenten, Thesis, Univ, of Groningen, The Netherlands, 1960 .

Perning $L$, Functional radiologic investigation of degenerarive and traumatic diseases of tower cervical motor regments, Summary of Thesis, J. belge Radiol, 44, 55\%554,1961 .

Penting $L_{\text {. }}$ Functional pathology of the cervical spine, Excerpra Medica, Amsterdam, 1968.

Penning $L_{,}$Nomal movement in the cervical spine, Am. A. Roentgenol., 130, 317-326, 1978.

Virchow, $H_{\text {. }}$, Die sagittal flexarische Bewegung der menslichen Halswirbelsäule, Arch. Orhop. Unfall Chir., 20, $1-41_{4}, 1928$.

Weme, S., Studies in spontaneows allas dislocation, Acta Orthop., suppl. 23, 1957. 


\section{Test persons}

\subsection{Data on the persons tested}

The range of motion of the cervical spine in older people is smaller than in young adults (O'Driscoll and Tomenson, 1982). One may suppose that other characteristics of motion, too, will also be more clearly visible at an early age than in older people, e.g. over 65 . This is why we have opted for test persons of around 20 years old. So far we know of no differences in this respect between men and women. During selection of test persons we did not take their sex into consideration.

\subsection{Selection criteria}

Normal motion of the cervical spine is associated with absence of complaints about pain, of complaints about limited motion of the neck and back, both in daily functioning and in active and passive examination of motion. It is necessary to assure that such complaints do no exist in persons who are being taken as a reference for determining characteristics of normal motion.

This is why exclusion criteria for this re-

table 3.1

\begin{tabular}{|lllllllllll|}
\hline & $\mathrm{L}$ & $\mathrm{M}$ & $\mathrm{N}$ & $\mathrm{O}$ & $\mathrm{P}$ & $\mathrm{Q}$ & $\mathrm{R}$ & $\mathrm{S}$ & $\mathrm{T}$ & $\mathrm{U}$ \\
$\mathrm{age}$ & 19 & 19 & 22 & 20 & 21 & 21 & 21 & 20 & 20 & 21 \\
$\mathrm{~m} / \mathrm{f}$ & $\mathrm{V}$ & $\mathrm{V}$ & $\mathrm{M}$ & $\mathrm{V}$ & $\mathrm{V}$ & $\mathrm{V}$ & $\mathrm{V}$ & $\mathrm{M}$ & $\mathrm{M}$ & $\mathrm{M}$ \\
\hline
\end{tabular}

All persons tested were students at an Academy for Physiotherapy. Table 3.1. gives the age and $\operatorname{sex}(\mathrm{m} / \mathrm{f})$ of the 10 persons tested ( $L$ to $U$ ) during the period of examination.

Prior to X-ray examination of the motions of the cervical spine, each test person was examined in order to determine whether that person was free of complaints. This examination was carried out by two manual therapists with many years of experience in detecting neck complaints, Messrs. H.T.J.A. Wald and G.M.J.R. Verstegen. Examination of the test persons has taken place at three measuring moments (except for P and R, who were only examined twice). Prior to each subsequent measuring moment the person was asked whether a pattern of complaints had arisen during the intermediate period, because of which (one of) the exclusion criteria should be applied to this person. This was not the case in any of the persons included in this thesis. search were used. These are the presence now or in the past of:

- Complaints about motion of the cervical spine.

"limited range of motion,

* headache in specific positions and/or double vision,

" pain in the neck region, possibly radiating towards the shoulders (or between the shoulder blades) or towards the arms, at rest or during certain movements. This includes getting up with a stiff neck and tingling of the arms and/or hands.

- Local pain - with or without radiation - during active examination of motion of the cervical spine at:

*anteflexion-retroflexion,

" rotation,

- lateroflexion of the head.

- Local pain during passive examination of motion of the cervical spine at:

*anteflexion-retroflexion, 
"rotation,

- laterotlexion of the head.

- Tenderness on one of the cervical vertebrae.

Slight pain, indicated as an uncomfortable sensation, during powerful segmentary examination of motion is not considered deviating. Similar pain can be provoked in many persons that do not show complaints about dysfunctioning of the cervical spine.

- Complaints about pain or limited motion of the lumbar spine and sacroiliac region.

No additional X-ray examination aimed at detecting deviating shapes was carried out on the test persons. This research method does not discriminate between people with or without a normally functioning cervical spine (see chapter 1).

All 10 persons were found to be free of complaints (anamnestically and during physical diagnostic examination) that might indicate dysfunctioning of the cervical spine prior to the examination. During active examination of motion, no deviations were found, and pain during motion and/or in the final positions did not occur. In 6 of the 10 persons pain as an uncomfortable sensation proved to be provokable during passive or segmentary examination of motion.

These findings are listed below.

L

Tenderness in the final position during lateroflexion to the left is slightly painful.

Tenderness on the right transverse process of $\mathrm{C} 2$ and $\mathrm{C} 4$ during segmentary examination of motion.

\section{M}

Tenderness in the final positions during lateroflexion and rotation to both sides is slightly painful.
Tenderness on the right lateral mass $\mathrm{Cl}$ and transwerse process $\mathrm{C} 3$ and $\mathrm{C} 5$ during segmentary examination of motion.

N

Tenderness on the left lateral mass $\mathrm{Cl}$ and right transverse process $\mathrm{C2}$ during segmentary examination of motion.

\section{o}

Tenderness in the final positions during lateroflexion to the right is slightly painful.

$\mathbf{P}$

No complaints and pain provokable.

Q

Tenderness in final positions during lateroflexion and rotation to both sides is slightly painful.

Tenderness on the spinous process $\mathrm{C} 2$ to $\mathrm{C} 7$ during segmentary examination of motion.

\section{$\mathbf{R}$}

Tenderness on the left transverse process C5 during segmentary examination of motion.

$\mathbf{S}$

No pain provokable.

T

No pain provokable.

U

No pain provokable.

These findings show that we may assume "normal motion" of the cervical spine in the ten persons who took part in the research.

\section{Bibliography}

O'Driscoll, S.L., Tomenson, J, The cenical spine, Clin. Rheum. Dis., 8, 617-630, 1982. 


\section{Range of motion in the sagittal plane of the segments in the}

\section{cervical spine}

\subsection{Introduction}

In principle, all segments contribute to movements of the head and the cervical spine within the sagittal plane. The size of the maximum segmental contribution within the sagittal plane of a segment within the chain, expressed as rotation, is called segmental range of motion. Maximum rotation of the head with respect to $C 7$ is called range of motion of the head. Range of motion is usually divided into an anteflexion and retroflexion contribution from a "neutral" or "middle" position of the cervical spine (Diethelm, 1974).

Range of motion is determined on the basis of X-rays in laterolateral direction of these positions (Diethelm, 1974). The value of the segmental range of motion is the difference in rotating position within the sagittal plane between the vertebral projections of the two adjacent vertebrae on two $\mathrm{X}$-rays of the cervical spine in two extreme positions. For the range of motion of the head this is the difference in rotating position between the head and $\mathrm{C} 7$.

Determining the range of motion of the head and the cervical segments is one of the diagnostic and therapeutic aids in a patient suffering from complaints of the neck (Diethelm, 1974, Arlen, 1978, 1979).

In order to be able to draw conclusions from the range of motion determined in him/her as to a diagnosis or therapy in a certain patient, the following questions need to be answered.

- If the segmental range of motion has been determined in a person, which are then the boundaries that indicate for that person whether there is normal or abnormal range of motion? This requires insight in the interindividual variability of range of motion.
- If in a certain person a change in range of motion has been diagnosed after treatment, which are the boundaries that indicate that a change has actually taken place? This requires insight into the intraindividual variability of the range of motion.

In this thesis, interindividual dispersion is defined as the difference between the highest and lowest value within a group of persons free of complaints. Intraindividual dispersion is defined as the difference between the highest and lowest value of a range of motion of a certain segment or block in a certain person at different moments of measurement.

Table $4.1 \mathrm{a}$ and $4.1 \mathrm{~b}$ give mean values of the segmental range of motion (table 4.1 also gives - where available - the range of motion of the block (CO-C2)). They were classified per author. If indicated by the author, the dispersion is given between parentheses () on the next line.

Much research (Bakke, 1931; Albers, 1954; De Sèze et al. 1951; Penning, 1960; Zeitler and Markuske, 1962; Colachis and Strohm, 1965; Gros et al., 1968; Markuske, 1971, Arlen, 1978) uses a neutral or average position of the head for the determination of the anteflexion and retroflexion range of motion. Each author uses a different definition, which is usually not entirely reproducible (Lysell, 1969). This is why only the walues that relate to the entire path between a maximum anteflexion position and maximum retroflexion position of the head and cervical spine have been stated.

The mean values for the atlantooccipital and the atlantoaxial segment and the occipitoaxial block are given in a separate table, be- 
table 4.1a

\begin{tabular}{|c|c|c|c|c|c|c|c|c|}
\hline author & year & numb. & age & $C 2-C 3$ & $\mathrm{C} 3-\mathrm{C} 4$ & $C 4-C 5$ & $C 5-C 6$ & $c 6-c 7$ \\
\hline V1rchow, & 1928 & 1 & 7 & 16 & 20 & 20 & -- & -- \\
\hline Bakke, & 1931 & 15 & $13-61$ & $\begin{array}{l}12 \cdot 9 \\
(3-22)\end{array}$ & $\begin{array}{c}15 \cdot 8 \\
(8-23)\end{array}$ & $\begin{array}{c}17 \cdot 3 \\
(11-24\end{array}$ & $\begin{array}{c}20.2 \\
(12-29)\end{array}$ & $\begin{array}{l}18 \cdot 2 \\
(11-26)\end{array}$ \\
\hline De, seze, & 1951 & 9 & $15-55$ & 13.0 & 15.5 & 19.0 & 27.5 & 17.5 \\
\hline Buetti, & 1954 & 30 & $13-42$ & $\frac{11.1}{(5-18)}$ & $\begin{array}{l}16 \cdot 8 \\
(13-23)\end{array}$ & $\begin{array}{c}20.8 \\
(16-28\end{array}$ & $\begin{array}{c}22.5 \\
(18-28)\end{array}$ & $\begin{array}{c}17 \cdot 3 \\
(13-25)\end{array}$ \\
\hline Köttke, & 1959 & 78 & young & 11 . & 16 & 18. & 21 . & 18. \\
\hline Penning, & 1960 & 20 & $15-30$ & $\begin{array}{c}12.5 \\
(5-16)\end{array}$ & $\frac{18}{(13-26)}$ & $\begin{array}{l}20 . \\
(15-29\end{array}$ & $\begin{array}{c}21.5 \\
(16-29)\end{array}$ & $\begin{array}{c}15.5 \\
(6-25)\end{array}$ \\
\hline zeitler, & 1962 & 48 & $11-18$ & $\begin{array}{c}15.5 \\
(4-23)\end{array}$ & $\begin{array}{l}23 \cdot 1 \\
(13-38)\end{array}$ & $\begin{array}{l}26 . \\
(10-39\end{array}$ & $\begin{array}{l}25 \cdot 4 \\
(10-34)\end{array}$ & $\begin{array}{l}22 \\
(13-29)\end{array}$ \\
\hline Bhalla, & 1969 & 20 & $18-23$ & $\begin{array}{c}9 \\
(7-10)\end{array}$ & $\begin{array}{l}14 . \\
(13-17)\end{array}$ & $\begin{array}{l}22 \\
(19-24\end{array}$ & $\begin{array}{l}18 . \\
(18-24)\end{array}$ & $\frac{19}{(15-20)}$ \\
\hline Markuske, & 1971 & $\begin{array}{l}40 \\
40 \\
40\end{array}$ & $\begin{array}{c}3-6 \\
7-10 \\
11-14\end{array}$ & $\begin{array}{l}16.4 \\
17.9 \\
16.8\end{array}$ & $\begin{array}{l}21.3 \\
22.4 \\
22.1\end{array}$ & $\begin{array}{l}21.5 \\
22.6 \\
25.9\end{array}$ & $\begin{array}{l}22.1 \\
23.7 \\
26.0\end{array}$ & $\begin{array}{l}20.7 \\
22.0 \\
23.3\end{array}$ \\
\hline Mestdagh, & 1976 & 33 & adol. & 11 & 11.5 & 18 & 19.5 & 16 \\
\hline
\end{tabular}

table $4.1 \mathrm{~b}$

\begin{tabular}{|c|c|c|c|c|c|c|}
\hline author & year & numb. & age & $\mathrm{CO}-\mathrm{C} 2$ & $\mathrm{C} 0-\mathrm{Cl}$ & $\mathrm{C} 1-\mathrm{C} 2$ \\
\hline Virchow, & 1928 & 1 & $?$ & & 24 & 16. \\
\hline Bakke, & 1931 & 15 & $113-61$ & & & $\begin{array}{r}11.4 \\
5-18\end{array}$ \\
\hline Brocher, & 1955 & 7 & $11-18$ & & $\begin{array}{c}14.3 \\
(0-25)\end{array}$ & $\begin{array}{l}18 \\
(16-2)\end{array}$ \\
\hline Werne, & 1957 & 104 & $10-62$ & $\begin{array}{c}23.4 \\
(9-39.5)\end{array}$ & $\begin{array}{c}13.4 \\
(3.5-32.5)\end{array}$ & $\begin{array}{c}10 \\
(2-21.5)\end{array}$ \\
\hline Fielding, & 1957 & $?$ & $?$ & & 35 & 15 \\
\hline Kottke, & 1959 & 23 & $?$ & & $0-22$ & 11 \\
\hline Penning, & 1961 & 20 & adolesc & $20-40$ & & \\
\hline Lewit, & 1963 & 50 & $14-39$ & & 15 & 16 \\
\hline $\begin{array}{l}\text { Markuske, } \\
\text { Penning, }\end{array}$ & $\begin{array}{l}1971 \\
1968\end{array}$ & $\begin{array}{l}40 \\
40\end{array}$ & $\begin{array}{l}3-6 \\
7-10\end{array}$ & $\begin{array}{c}34.5 \\
35.0 \\
25-30 \\
\max .40\end{array}$ & $\begin{array}{l}14.6 \\
14.5 \\
\max .30\end{array}$ & $\begin{array}{c}19.9 \\
20.5 \\
\max .35\end{array}$ \\
\hline
\end{tabular}


cause many consider movements between (CO-C1) and (C1-C2) as so closely related that the mean value of the (CO-C2) block is given.

Tables 4.1a and 4.1b show that:

- The mean value of the range of motion per segment differs per research.

- Dispersion of a given mean value is large.

These differences and dispersion may be caused by:

1. The accuracy of determining the position of projections of the skull and vertebrae on an X-ray.

2. The choice of the way in which the head and cervical spine of the person to be examined are held in different positions.

Anteflexion position is defined in two ways (Gutmann, 1960; Diethelm, 1974). On the one hand, the head may be nodded as much as possible with respect to the neck. On the other hand, the head may be moved as far downwards as possible; this means that the chin is brought to the sternum as caudally as possible ("bending"). The range of motion within segments $(\mathrm{C} 0-\mathrm{C} 1)$ and $(\mathrm{C} 1-\mathrm{C} 2)$ respectively, is smaller in the "bending" than in the "nodding" position (Gutmann, 1960, 1968; Lewit and Krausovà, 1962; Arlen, 1977, 1979).

3 . Varying position of segments of the cervical spine in the same position of the head, in a person to be examined, at different moments of measurement (intraindividual variability) (Markuske, 1971).

4. Varying position of segments of the cervical spine in the same position of the head in different persons (interindividual variability). It is well known that within different groups of test persons - children, adolescents and adults - the degree of lordosis of the cervical spine may differ considerably (Albers, 1954; Penning, 1960; Gombert, 1957; Zeitler and Markuske, 1962; Gros et al., 1968, Markuske, 1971).

5. An actual difference in size of range of motion of segments between different persons (interindividual variability).

\section{Conclusions:}

- It is feasible to investigate the possibility to determine with our methods the range of motion of the cervical column and its segments with a smaller dispersion than hitherto found.

- There are hardly any data availlable that show how accurately values can be determined.

- There appear to be major differences between the results of the research done so far into the mean values of the range of motion of segments during anteflexion-retroflexion motion.

- It seems possible that the largest range of motion within segment ( $\mathrm{CO}-\mathrm{Cl})$ will not be found on comparison of a "bending" anteflexion of the entire cervical spine and a maximum retroflexion position, but in an intermediate position.

- It is not known whether range of motion of other segments during a motion actually performed, measured at an intermediate stage of motion of the cervical spine, will be larger. - The difference in size of the range of motion, determined at different moments of measurement, in which only the final position of the head is studied, is unknown. Even if determination took place on the basis of $\mathrm{X}$ ray cinematographic research (Fielding, 1957 , table $4.1 \mathrm{~b}$ ), the values relate to the final positions. In this position of the head, the segments of the cervical spine may take up different positions per moment of measurement.

- It is not known whether a value of the range of motion of the entire cervical spine or of a segment, determined on the basis of actually performed anteflexion of the cervical spine, differs from the one determined on the basis of retroflexion.

Data from literature have not made it clear to what extent the range of motion values mentioned can be used for diagnosis (interindividual variability) or evaluation of therapy (intraindividual variability).

Besides the segmental range of motion, range of motion of the entire cervical spine 
and the head may be aids for diagnosis and evaluation of therapy. Data on the range of motion of the entife cervical spine and the head, and their dispersion are not available. Because a neutral position cannot be defined, we have refrained from determining an anteflexion and retroflexion component. We have chosen to determine the maximum value of the range of motion of the complete chain and of the segments during the part between a maximum retroflexion position of the cervical spine and a maximum "bending" anteflexion position. This choilce was made because the data known so far on range of motion are measured on the basis of static images only of the extreme positions of the cervical spine. The aim of these measurements is to obtain data on the interindividual and intraindividual variability of the range of motion.

\subsection{Method}

The size of range of motion in this research was determined on the basis of actually performed anteflexion or retroflexion of the entire cervical spine and the head in 10 specified persons. It was not determined as the difference between the positions of a segment in maximum anteflexion or retroflexion position of the cervical spine, but as the largest rotational difference between two adjacent vertebrae on X-ray film of the actually performed anteflexion and retroflexion motion of the entire cervical spine and the head. The largest value is the difference between two positions somewhere between the final positions or between the position of the relevant segment in one final and an intermediate position of the cervical spine.

The range of motion (both total and segmental) can be read from diagrams in which

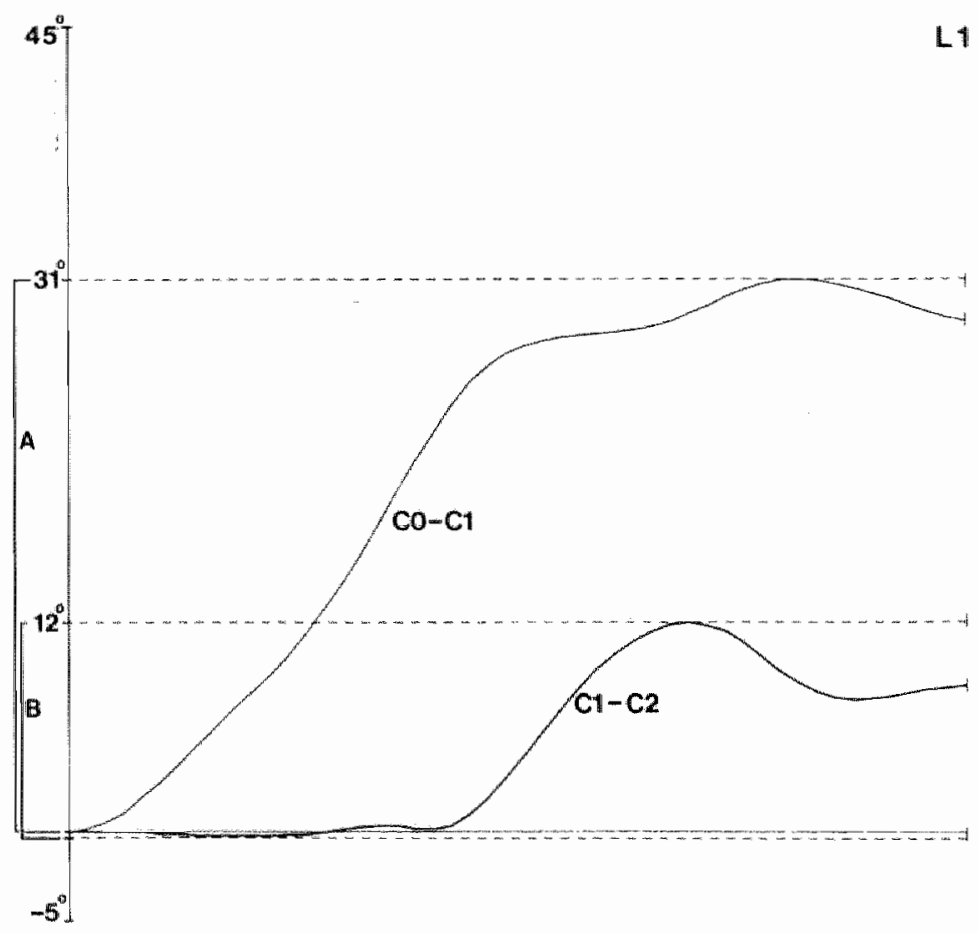

fig. 4.1 Absolute rotation of the segments $(\mathrm{CO}-\mathrm{C1})$ and $(\mathrm{C1}-\mathrm{C2})$ (test person $\mathrm{L}$ ), during anteflexion of the cervical spine at the first examination moment as a function of the 50 virtual pictures. The range of motion is maesured as the difference between the highest and lowest value of the graph. 
the images have been plotted on the $x$-axis ( 1 to 50 , and absolute rotation within a segment on the y-axis (see 2.9). This is the difference between the largest and smallest value of $y$ in the diagram (figure 4.1). In all tables mentioned below the numbers mentioned are degrees of rotation within the plane of the $\mathrm{X}$-ray.

The mean value of range of motion and dispersion was determined of the range of motion of the head in relation to the seventh cervical vertebra (interindividual variability).

The following was determined of the segmental range of motion of $(\mathrm{C} 0-\mathrm{C} 1)$ to $(\mathrm{C} 6-$ C7):

- The mean value of the range of motion of each segment for comparison to the values mentioned in literature.

- The dispersion (interindividual variability).

- The difference between the range of motion found in anteflexion or retroflexion respectively, within the same moment of measurement.

- The difference between the highest and lowest value of range of motion per segment at the three moments of measurement, both for values determined on the basis of anteflexion and retroflexion (intraindividual variability).

\section{Reproducibillity}

Film R3 served to make the diagrams for the five series (see 2.11) and the range of motion of each segment was determined in each of these diagrams. Table 4.2 shows the differences of the value of the range of motion determined of the graphs of five files of data of film R3 (P1 to P5). The difference between the highest and lowest value has been given for each segment in table 4.2. The maximum value is 2.6 degrees. For the sake of convenience, the maximal difference caused by the method used is considered to be 2.5 degrees.

\subsection{Results}

\subsubsection{Range of motion of the head in relation to $\mathrm{C} 7$}

Table 4.3 gives the mean values of the range of motion of the entire cervical spine and the head $(\mathrm{C} 0-\mathrm{C} 7)$ of the ten test persons examined ( $\mathrm{L}$ to $\mathrm{U}$ ) at the 3 moments of measurement. The upper number is an average of three values found during anteflexion of the table 4.2

\begin{tabular}{|cccccccc|}
\hline & $(\mathrm{C} 0-\mathrm{C} 1)$ & $(\mathrm{C} 1-\mathrm{C} 2)$ & $(\mathrm{C} 2-\mathrm{C} 3)$ & $(\mathrm{C} 3-\mathrm{C} 4)$ & $(\mathrm{C} 4-\mathrm{C} 5)$ & $(\mathrm{C} 5-\mathrm{C} 6)$ & $(\mathrm{C} 6-\mathrm{C} 7)$ \\
\hline \hline R3 & 2.0 & 2.6 & 0.8 & 1.4 & 2.6 & 2.0 & 2.5 \\
\hline
\end{tabular}

table 4.3

\begin{tabular}{|c|c|c|c|c|c|c|}
\hline L & $\begin{array}{l}130.2 \\
120.9\end{array}(124.6)$ & $\begin{array}{l}-133.7) \\
-131.6)\end{array}$ & $\mathbb{M}$ & $\begin{array}{l}118.5 \\
119.9\end{array}$ & $\begin{array}{l}(114.1 \\
(114.8\end{array}$ & $\begin{array}{l}-127.4) \\
-124.6)\end{array}$ \\
\hline $\mathbf{N}$ & $\begin{array}{l}104.1 \\
106.2\end{array}(100.1)$ & $\begin{array}{l}-108.5) \\
-107.8)\end{array}$ & 0 & $\begin{array}{l}129.0 \\
130.7\end{array}$ & $\left(\begin{array}{l}124.6 \\
128.8\end{array}\right.$ & $\begin{array}{l}-133.7) \\
-133.0)\end{array}$ \\
\hline $\mathbf{P}$ & $\begin{array}{l}120.7(119.0 \\
107.1)(100.1\end{array}$ & $\begin{array}{l}-122.5) \\
-114.1)\end{array}$ & $Q$ & $\begin{array}{l}118.8 \\
111.3\end{array}$ & $\begin{array}{l}(108.5 \\
(102.2\end{array}$ & $\begin{array}{l}-125.6) \\
-116.2)\end{array}$ \\
\hline $\mathbf{R}$ & $\begin{array}{l}117.6(117.6 \\
113.4\end{array}(111.3)$ & $\begin{array}{l}-117.6) \\
-115.5)\end{array}$ & $\mathbf{S}$ & $\begin{array}{l}95.9 \\
97.3\end{array}$ & $\left\{\begin{array}{l}93.8 \\
97.3\end{array}\right.$ & $\begin{array}{l}-97.31 \\
-\quad 97.31\end{array}$ \\
\hline $\mathrm{T}$ & 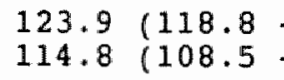 & $\begin{array}{l}-132.3) \\
-121.8)\end{array}$ & $\mathbf{U}$ & $\begin{array}{l}122.7 \\
121.3\end{array}$ & $\left(\begin{array}{l}114.8 \\
1113.4\end{array}\right.$ & $\begin{array}{l}-128.1) \\
-127.4)\end{array}$ \\
\hline
\end{tabular}


cervical spine. The lower number gives an average of three values of a retroflexion. The numbers between parentheses 0 are the lowest and highest values found in one of the three moments of measurement.

- The values found for anteflexion vary between 93.8 and 113.7 , i.e. a dispersion of 40 degrees. The values found for retroflexion motion vary between 97.3 and 113.0 , i.e. a dispersion of 35 degrees.

* In 1 person ( $\mathrm{P}$ ) the range of motion in retroflexion motion proved less than the minimum value for range of motion during anteflexion in both moments of measurement.

* The total range of motion of $\mathrm{CO}-\mathrm{C} 7$ of a given test person differs at the 3 moments of measurement, both for anteflexion and for retroflexion. The maximum differences found are:

$\begin{array}{ccll}0- & 5 & \text { degrees: } & \mathrm{R}, \mathrm{S} \\ 5- & 10 & \text { degrees: } & \mathrm{N}, \mathrm{O} \\ 10- & 15 & \text { degrees: } & \mathrm{M}, \mathrm{P}, \mathrm{Q}, \mathrm{T}, \mathrm{U} \\ 15 & & \text { degrees or more: } & \mathrm{L}\end{array}$

* In 6 persons (L, M, P, Q, R and T) the difference between the range of motion of the chain found during anteflexion and retroflexion at 1 of the 3 moments of measurement, was more than 5 degrees. For 3 persons (M, $Q$ and $T$ ) this even occurred in 2 moments of measurement and for 1 person $(Q)$ in all three moments of measurement.

\subsubsection{Segmental range of motion}

Tables $4.5 \mathrm{a}$ and $4.5 \mathrm{~b}$ give the mean values found during the different moments of measurement, for the segmental range of motion ( $\mathrm{CO}-\mathrm{C} 1)$ to $(\mathrm{C} 6-\mathrm{C} 7)$ of the persons $(\mathrm{L}$ to $\mathrm{U})$. The numbers in table $4.5 \mathrm{a}$ are based on shots of anteflexion, the numbers in table $4.5 \mathrm{~b}$ are based on shots of retroflexion.

* The differences between the mean values of the segmental anteflexional and retroflexional range of motion is less than the maximal difference caused by the method used. This is also true for the differences between

table 4.4

\begin{tabular}{||llll|rrrr||}
\hline moment: 0 & $0+2$ wks & $0+10$ wks & & 0 & $0+2$ wks & $0+10$ wks \\
\hline \hline L & $23.1 *$ & 2.1 & 2.8 & Q & $7.3 *$ & $7.0 *$ & $23.1 *$ \\
M & $10.5 *$ & 0.7 & $7.0 *$ & R & 2.1 & $6.3 *$ & \\
N & 1.4 & 3.5 & 4.2 & S & 0.7 & 0.0 & 2.5 \\
0 & 1.4 & 0.7 & 4.2 & T & 4.2 & $10.5 *$ & $12.6 *$ \\
P & $2.4 *$ & 4.9 & & U & 1.8 & 2.1 & 4.9 \\
\hline
\end{tabular}

Table 4.4 gives the differences between the range of motion of the entire chain ( $\mathrm{C} 0-\mathrm{C} 7)$ during anteflexion and retroflexion, at the 3 different moments of measurement of the persons examined ( $\mathrm{L}$ to $\mathrm{U})$.

Differences of more than 5 degrees (approximately 2 times the maximum difference which can be made in this arithmetic procedure from the moment of marking, see 4.3) are indicated with an asterisk (*). the dispersion of these values (except for the dispersion of $(\mathrm{C} 0-\mathrm{C} 1))$.

* In these 10 persons, the mean value of the range of motion of segments (C5-C6) and (C4-C5) is the largest.

* The mean value of the range of motion of segment $(\mathrm{C} 2-\mathrm{C} 3)$ is the smallest. The difference with the mean value of segments ( $\mathrm{CO}-\mathrm{C} 1)$ and (C1-C2) is less, however, than 5 degrees.

- The dispersion is largest for the mean value 


\begin{tabular}{|lccccccc|}
\hline & $(C 0-C 1)$ & $(C 1-C 2)$ & $(C 2-C 3)$ & $(C 3-C 4)$ & $(C 4-C 5)$ & $(C 5-C 6)$ & $(C 6-C 7)$ \\
\hline$L$ & 28.4 & 11.9 & 14.7 & 19.3 & 21.0 & 24.2 & 17.7 \\
$M$ & 19.0 & 10.2 & 15.0 & 17.3 & 21.6 & 22.5 & 16.2 \\
$N$ & 17.4 & 15.8 & 11.1 & 13.7 & 18.4 & 20.1 & 11.3 \\
$O$ & 24.3 & 24.3 & 13.7 & 16.8 & 23.9 & 23.2 & 15.5 \\
F & 4.1 & 16.1 & 14.9 & 21.6 & 23.1 & 25.4 & 21.7 \\
$Q$ & 18.6 & 10.5 & 13.6 & 19.6 & 20.8 & 23.1 & 18.4 \\
$R$ & 14.4 & 19.8 & 14.7 & 18.6 & 18.4 & 22.8 & 14.9 \\
S & 9.3 & 14.7 & 10.5 & 12.9 & 14.9 & 18.2 & 20.0 \\
$T$ & 13.5 & 16.8 & 13.5 & 18.3 & 18.3 & 24.0 & 20.1 \\
U & 18.2 & 20.6 & 14.1 & 18.1 & 20.8 & 22.3 & 15.3 \\
\hline Aver. & 16.7 & 16.1 & 13.6 & 17.6 & 20.1 & 22.6 & 17.1 \\
Disp. & $4.1-$ & $10.2-$ & $10.5-$ & $12.9-$ & $14.9-$ & $18.2-$ & $15.3-$ \\
& 28.4 & 24.3 & 15.0 & 21.6 & 23.9 & 25.4 & 21.7 \\
$=$ & 24.3 & 14.1 & 4.5 & 8.7 & 9.0 & 7.2 & 6.4 \\
\hline
\end{tabular}

table $4.5 b$

\begin{tabular}{|c|c|c|c|c|c|c|c|}
\hline & $(\mathrm{CO}-\mathrm{Cl})$ & $(\mathrm{C} 1-\mathrm{C} 2)$ & $(C 2-C 3)$ & $(\mathrm{C} 3-\mathrm{C} 4)$ & $(C 4-C 5)$ & $(c 5-c 6)$ & $(\mathrm{C} 6-\mathrm{C} 7)$ \\
\hline $\begin{array}{l}\mathrm{L} \\
\mathrm{M} \\
\mathrm{N} \\
\mathrm{O} \\
\mathrm{P} \\
\mathrm{Q} \\
\mathrm{R} \\
\mathrm{S} \\
\mathrm{T} \\
\mathrm{U}\end{array}$ & $\begin{array}{r}20.9 \\
12.8 \\
14.7 \\
26.4 \\
-9.0 \\
9.9 \\
5.3 \\
9.8 \\
15.3 \\
8.3\end{array}$ & $\begin{array}{r}15.7 \\
9.7 \\
14.0 \\
24.5 \\
13.3 \\
7.8 \\
19.6 \\
15.0 \\
17.9 \\
18.7\end{array}$ & $\begin{array}{l}14.4 \\
15.4 \\
10.3 \\
12.6 \\
14.7 \\
13.0 \\
14.0 \\
10.9 \\
12.1 \\
13.9\end{array}$ & $\begin{array}{l}17.4 \\
20.8 \\
14.1 \\
17.6 \\
21.6 \\
18.4 \\
21 \cdot 5 \\
12.7 \\
14.1 \\
18.1\end{array}$ & $\begin{array}{l}19.7 \\
23.1 \\
19.0 \\
24.1 \\
24.7 \\
21.6 \\
19.9 \\
15.1 \\
18.7 \\
21.1\end{array}$ & $\begin{array}{l}22.0 \\
25.9 \\
21.5 \\
21.5 \\
26.0 \\
25.0 \\
22.6 \\
18.3 \\
18.5 \\
25.0\end{array}$ & $\begin{array}{l}16.5 \\
16.4 \\
16.4 \\
16.1 \\
17.7 \\
19.5 \\
17.0 \\
18.7 \\
21.5 \\
18.1\end{array}$ \\
\hline $\begin{array}{l}\text { Av } \\
\text { Di } \\
=\end{array}$ & $\begin{array}{c}6.11 .3 \\
-9.0- \\
26.4 \\
35.4\end{array}$ & $\begin{array}{c}15.6 \\
7.8- \\
24.5 \\
16.7\end{array}$ & $\begin{array}{r}13.1 \\
10.3 \\
15.4 \\
5.1\end{array}$ & $\begin{array}{l}17.6 \\
12.7- \\
21.6 \\
8.9\end{array}$ & $\begin{array}{c}20.7 \\
15.1- \\
24.7 \\
9.6\end{array}$ & $\begin{array}{c}22.6 \\
18.3- \\
26.0 \\
7.7\end{array}$ & $\begin{array}{l}17.8 \\
16.4- \\
21.5 \\
5.1\end{array}$ \\
\hline
\end{tabular}

of the range of motion in segments $(\mathrm{CO}-\mathrm{Cl})$ and (C1-C2) and smallest for segment (C2C3).

Table 4.6 gives the highest and lowest values for the range of motion per segment of all persons together $(\mathbb{L}$ to $U$ ) found at the three different moments of measurement, both during anteflexion motion and retroflexion motion.

The range of motion difference at different moments of measurement for segments of the same level can be read from table 4.6. These differences are stated in table 4.7, along with the mean values of range of motion per segment (the mean of tables $4.5 \mathrm{a}$ and $4.5 b)$.

* A mean value for range of motion with a small dispersion cannot be determined for any of the segments, except maybe for segment (C2-C3); dispersion is large.

Table 4.8 gives the differences per person ( $\mathrm{L}$ 
to $\mathrm{U})$ between the range of motion during anteflexion and retroflexion per moment of measurement (the upper number is the difference at the ist moment of measurement, the lower number is the difference at the $3 \mathrm{rd}$ moment of measurement). Differences of more than 5 degrees between the values found during shots of anteflexion and during shots of retroflexion of the cervical spine have been marked with an asterisk (*).

Conclusion from table 4.8 :

* The values for range of motion of segments (C0-C1), (C5-C6) and ( $\mathrm{C} 6-\mathrm{C} 7)$ exceed a difference of twice as much as can be expected on the basis of maximal difference caused by the method used by 14,4 and 5 times respectively.
The differences marked with an asterisk (*) are more than twice as large as can be expected on the basis of the maximal difference caused by the method used.

* In segments (CO-C1) and (C6-C7) in particular, major differences in the size of the range of motion at different moments of measurement are to be expected for a given person. This applies both to the values determined on the basis of anteflexion and retroflexion. The method used does not show a difference for a given test person in segments $(\mathrm{C} 2-\mathrm{C} 3)$ and $(\mathrm{C3}-\mathrm{C} 4)$.

\subsection{Discussion}

The method used allows determination of

table 4.6

\begin{tabular}{|l|r|r|}
\hline & anteflexion & retroflexion \\
\cline { 2 - 3 }$(\mathrm{C} 0-C 1)$ & $3 .-30.8$ & $-10.4-30.0$ \\
$(\mathrm{C} 1-\mathrm{C} 2)$ & $8.4-27.0$ & $7.2-26.4$ \\
$(\mathrm{C} 2-\mathrm{C3})$ & $10.2-15.8$ & $9.0-16.0$ \\
$(\mathrm{C} 3-\mathrm{C4})$ & $12.3-22.1$ & $11.2-23.0$ \\
$(\mathrm{C4}-\mathrm{C5})$ & $14.0-25.2$ & $14.8-26.4$ \\
$(\mathrm{C} 5-\mathrm{C} 6)$ & $17.5-26.3$ & $17.0-26.8$ \\
$(\mathrm{C} 6-\mathrm{C})$ & $6.7-23.5$ & $9.4-22.8$ \\
\hline
\end{tabular}

table 4.7

\begin{tabular}{|c|c|c|c|c|c|}
\hline \multirow[b]{2}{*}{$\begin{array}{l}(\mathrm{C} 0-\mathrm{C} 1) \\
(\mathrm{C} 1-\mathrm{C} 2) \\
(\mathrm{C} 2-\mathrm{C} 3) \\
(\mathrm{C} 3-\mathrm{C} 4) \\
(\mathrm{C} 4-\mathrm{C} 5) \\
(\mathrm{C} 5-\mathrm{C} 6) \\
(\mathrm{C} 6-\mathrm{C} 7)\end{array}$} & \multicolumn{2}{|c|}{ difference } & aver. & range & of motion \\
\hline & $\begin{array}{l}\text { more than } \\
\text { approx. } \\
" \\
" \\
" \\
\text { " }\end{array}$ & $\begin{array}{rc}25 & \text { degrees } \\
20 & " \\
5 & " \\
10 & " \\
10 & " \\
10 & " \\
15 & "\end{array}$ & & $\begin{array}{l}14 \cdot 1 \\
15 \cdot 9 \\
13 \cdot 4 \\
17 \cdot 6 \\
20.4 \\
22.6 \\
17.4\end{array}$ & $\begin{array}{c}\text { degrees } \\
" \\
" \\
" \\
" \\
" \\
"\end{array}$ \\
\hline
\end{tabular}

Table 4.9 gives the difference per person ( $\mathrm{L}$ to $\mathrm{U}$ ) between the highest and lowest value of the range of motion. The upper number gives the differences between values determined on the basis of anteflexion, the lower number gives the difference between the values determined on the basis of retroflexion. the entire or segmental range of motion from the stage of positioning the $\mathrm{X}$-ray projections of the skull and cervical vertebrae with a maximal difference caused by the method used of 2.5 degrees. This matches the accuracy mentioned by Lewit and Krausová (1963). The differences of 5 degrees or more indicated in table 4.2 to 4.9 , are therefore dif- 


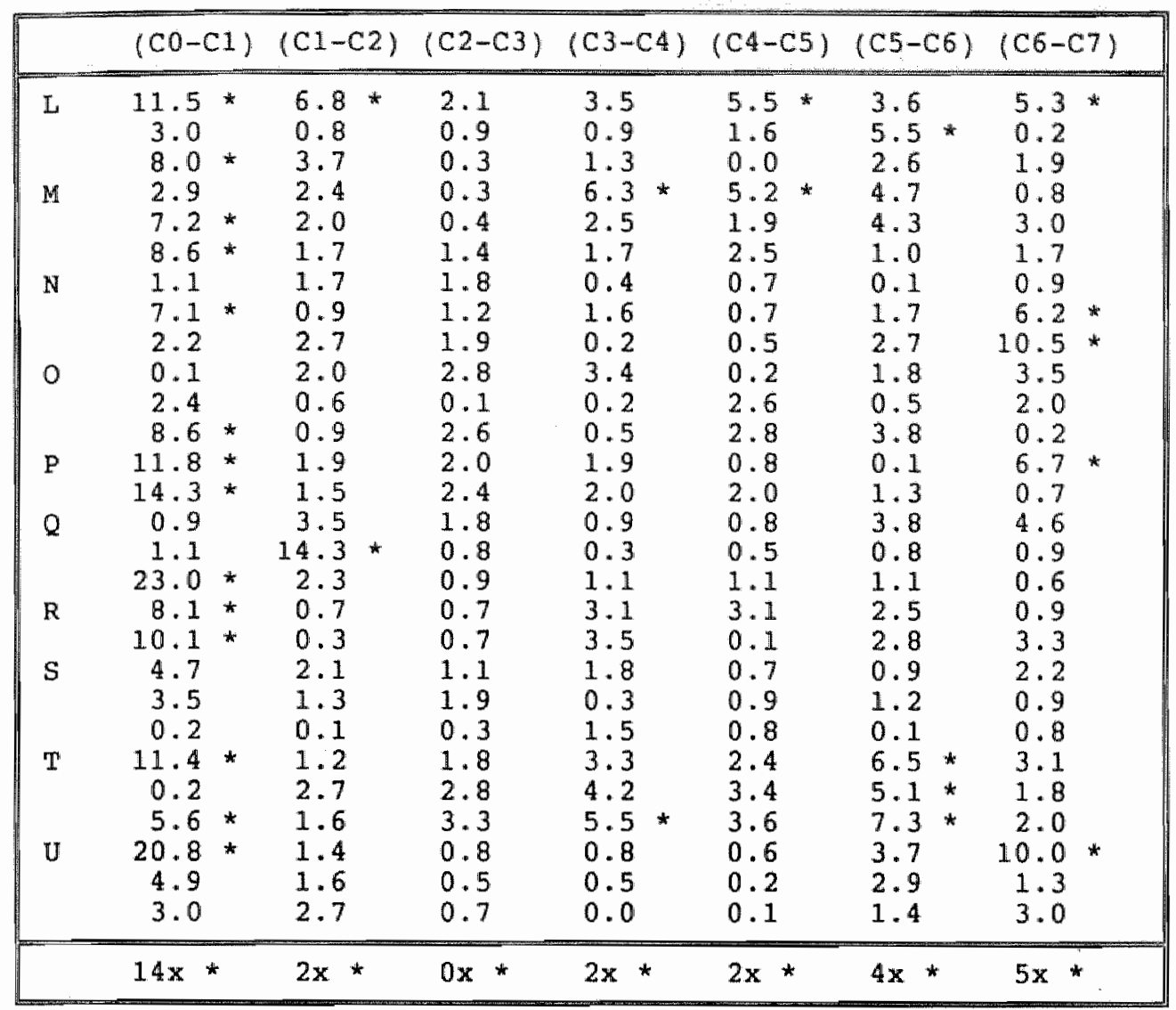

ferences in range of motion which are caused by a real different range of motion.

The mean values of the segmental range of motion and their dispersion match the ones found in literature (see table 4.1a and 4.1b compared to $4.5 \mathrm{a}$ and $4.5 \mathrm{~b}$ ). This suggests that the group of persons examined is comparable to the ones used by others to determine range of motion in persons free of complaints.

We found that the extreme positions in each of the segments do not necessarily coincide with the extreme positions of the head ("bending" anteflexion or retroflexion). In this thesis, range of motion is defined as the difference between the true extreme positions in each of the segments or in the entire cervical spine. Nevertheless we have to come to the following conclusions:

As to determining the range of motion of the head:

- It is superfluous to determine a mean value for the range of motion of the entire cervical spine and the head, since a difference of 35 40 degrees between the maximum and minimum has been found within this group.

- Despite the fact that during each moment of measurement we asked the test persons (after practice) to bend the head backwards as far as possible from the most caudal position on the sternum and vice versa, a difference of more than 10 degrees was found in more than half the persons examined on the different moments of measurement.

- These ten persons performed anteflexion and retroflexion motions of the cervical spine 28 times $(8 \times 3$ and $2 \times 2$ ) in succession. 10 times 


\begin{tabular}{|c|c|c|c|c|c|c|c|c|c|c|c|c|}
\hline & \multicolumn{2}{|c|}{$(\mathrm{CO}-\mathrm{C} 1)$} & \multicolumn{2}{|c|}{$(C 1-C 2)$} & $(\mathrm{C} 2-\mathrm{C} 3)$ & $(C 3-C 4)$ & \multicolumn{2}{|c|}{$(C 4-C 5)$} & \multicolumn{2}{|c|}{$(C 5-C 6)$} & \multicolumn{2}{|c|}{$(C 6-C 7)$} \\
\hline $\mathbb{L}$ & 4.5 & & 4.2 & & 0.0 & 0.0 & 2.1 & & 8.1 & $\star$ & 6.3 & $*$ \\
\hline & 10.2 & $\star$ & 1.8 & & 3.0 & 2.6 & 5.0 & & 7.6 & * & 11.4 & $*$ \\
\hline$M$ & 4.6 & & 2.8 & & 1.5 & 4.6 & 6.1 & $\star$ & 3.5 & & 6.7 & * \\
\hline & 6.4 & $\star$ & 1.6 & & 0.8 & 0.6 & 1.2 & & 2.2 & & 2.0 & \\
\hline $\mathbf{N}$ & 10.5 & 4 & 3.2 & & 1.7 & 1.8 & 1.4 & & 4.2 & & 12.4 & $\star$ \\
\hline & 13.6 & * & 5.0 & & 2.0 & 3.2 & 1.6 & & 1.4 & & 4.8 & \\
\hline 0 & 6.6 & $*$ & 7.4 & $*$ & 2.4 & 1.7 & $2 \cdot 4$ & & $2 \cdot 5$ & & 3.2 & \\
\hline & 6.4 & $\star$ & 4.8 & & $2 \cdot 4$ & 0.6 & 3.0 & & 1.8 & & 3.2 & \\
\hline $\mathbb{P}$ & 0.3 & & 2.8 & & 1.8 & 1.1 & 1.4 & & 1.8 & & 2.8 & \\
\hline & 2.8 & & 5.8 & $*$ & 2.6 & 2.8 & 3.4 & & 0.4 & & 9.4 & * \\
\hline$Q$ & 10.5 & $\star$ & 2.8 & & 2.1 & 0.4 & 1.7 & & 2.5 & & 7.7 & $*$ \\
\hline & 14.0 & * & 1.6 & & 1.4 & 1.2 & 1.4 & & 2.2 & & 2.2 & \\
\hline $\mathbb{R}$ & 1. 4 & & 1.8 & & 0.0 & 1.4 & 1.0 & & 2.1 & & 0.4 & \\
\hline & 3.4 & & 2.8 & & 0.0 & 1.0 & 2.2 & & 3.2 & & 2.8 & \\
\hline$S$ & 3.2 & & $2 \cdot 8$ & & 0.0 & 1.0 & 2.1 & & 1.4 & & 2.4 & \\
\hline & 5.4 & & 0.6 & & 2.8 & 2.6 & 0.6 & & 1.8 & & 1.6 & \\
\hline $\mathrm{T}$ & 12.6 & $*$ & 0.7 & & 3.5 & 2.5 & 0.4 & & 2.8 & & 7.7 & $\star$ \\
\hline & 8.2 & * & 3.6 & & 5.4 & 3.0 & 6.2 & * & 4.2 & & $2 \cdot 4$ & \\
\hline \multirow[t]{3}{*}{$\mathrm{U}$} & 6.3 & $\star$ & 1.7 & & 1.8 & 2.1 & 1.7 & & 1.7 & & 10.8 & * \\
\hline & 22.2 & * & 0.6 & & 1.4 & 2.2 & 2.2 & & 1.6 & & 2.2 & \\
\hline & $12 x$ & * & $2 x$ & * & $0 x *$ & $0 \mathrm{x} *$ & $2 x$ & * & $2 x$ & * & $8 x$ & * * \\
\hline
\end{tabular}

a difference in range of motion of 5 degrees or more (6 times even more than 10 degrees) was measured between anteflexion and retroflexion. This implies that in $1 / 3$ of the registrations a real difference in range of motion was determined.

As to determining segmental range of motion:

- No difference can be shown within this group of ten persons between the mean values of the segmental range of motion determined on the basis of shots of anteflexion and retroflexion of the cervical spine. With the exception of segment ( $\mathrm{CO}-\mathrm{C} 1)$, this also applies to the dispersion.

- The difference between the lowest and highest value of segmental motion is more than 10 degrees, except for segment (C0-C1). So the dispersion for the segmental range of motion is large too.

- Especially in the high and low cervical regions major differences were found between the values of the range of motion at different moments of measurement.

- The differences between the values of the segmental range of motion for a given person, determined on anteflexion and retroflexion of the cervical spine and the head performed immediately after each other, may differ considerably.

- Differences between the segmental range of motion determined on the basis of anteflexion and retroflexion of the cervical spine do not manifest themselves in the mean values and their dispersion, but do so in the values of a given person.

It is well known that the position in which the person is examined, i.e. in a lying (Jirout, 1972) or sitting position, (Jones, 1960) may cause a difference in the range of motion. Since our test persons were always examined in a sitting position, the influence of the position of the body on the measurement results can be ignored.

\section{Conclusion}

It appears that, if a person in a sitting position is asked insistently to bend the head forwards towards the trunk as far as possible 
(the chin as close to the sternum as possible) and subsequently as far backwards as possible, it is not certain that the largest possible anteflexion and retroflexion range of motion is performed in all segments. Especially in segments $(\mathrm{CO}-\mathrm{Cl}),(\mathrm{C} 5-\mathrm{C} 6)$ and (C6-C7), anteflexion and retroflexion motions may produce a different range of motion when performed immediately after each other. It is unclear whether this should be ascribed to time-dependent intraindividual variability or to direction of the motion (anteflexion compared to retroflexion) itself.

The range of motion of the entire cervical spine $(\mathrm{CO}-\mathrm{C} 7)$ and the range of motion of each of the segments within this chain do not produce useful motion parameters. These mean values cannot normally be used to determine in a given person with neck complaints whether a value for the range of motion constitutes the maximum for this patient or whether it deviates from the standard. The observation that no motion occurs can at best be of diagnostic value. Neither can determinination of the range of motion be used to evaluate a certain therapy. It is therefore necessary to look for other criteria which may serve to judge normal or abnormal functioning of the cervical spine.

\section{Bibliography}

Albers, $D$, Eine Studie wber die Funktion der Halswirbelsäule bei dorsaler und ventraler Flexion, Fortschr. Röntgenstr., 81,606- 615, 1954.

Arlen, A., Die "paradoxe Kippbewegung des Atlas" in der Funktionsdiagnostik der Halswirbelsäule, Man. Med., $15,16-22,1977$.

Arlen, A., Messverfahren zur Erfassung won Statik und Dynamik der Halswibtelsaule in der sagittalen Ebene, Man. Med., 16, 25-35, 1978.

Arlen, A., Biometrische Rönugen-Funktionsdiagnostik der Halswirbelsaule, Schriftenreihe Manuelle Medizin, S, Veriag für Medizin Dr. Ewald Fischer GmbH, Heidelberg, 1979.

Bakke, S.N., Röntgenologischen Beobachtungen aber die Bewegungen der Wistelsäulle. Acta Radiol, suppl. 13, 1931.
Bhalla, S.K, Simwmons, E.H., Nomal ranges of indener-

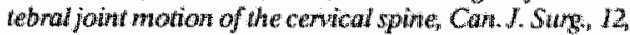
$181-187,1969$

Brocher J.E.W, Die Occipito-Cenical-Gegente. Eine di" agrastische pathogenetische Studie, Georg Thinene Verlag Stutgani, 1955.

Buetti-Bäuml, C., Furikionelle Röntgendiagnostik der Halswintelsäuk, Georg Thiem Verlag, Stutgrart, 1954.

Colachis, S.C. jr, Strohm, B.R., Radiographic studies of cervical spine motion in monnal subjects: Flexion and Ayperextemsion, Anch. Phys. Med. Rehabil. 46, 753-760, 1965.

Diethelm, L., Röntgendiagnostik der Wirthelsäule, In: Handbuch dermedizinischer Radiologie, Teil I, Springer Verlag, Berlin-Heidelbeng-NewYork, 79, 1974.

Fielding J.W., Cineroentgerlography of the nornal cervical spine, J. Bone and Jt. Surg., 39A, 1280-1288, 1957.

Gomben, H.J., Funktionsdiagnosid der Halswiblelsiulle mith der Bildwandler, Radiol. Awstr, 9, 21\%-226, 1957.

Gros, C., Mahovitch, B., Frerebeat, P., La chamidremediocervicale. Etude radiographique dynamique de la flexion du rachis cervicale, Monipellier Chir., 14, 349. 356,1968 .

Gumant, G., Die Wirbelblockierung und ihr röntgenologischer Nachweis, Die Wirbelsdule in Forschung und Praxis, Hippocrates, Stutgart, 15, 83-102, 1960.

Gutrmann, G., Schulkopfschmerz und Kophaltung. Ein Beitrag zur Pathogenese des Anteffexions-Kopfschmerzes und zur Mechanik der Kopfgelenke, Z. Orthop., 105, 497-515, 1968 .

Jirout, J., The influence of postural factors or the dynamics of the cerwical spine, Neuroradiol., 4, 239.244, 1972.

Jones, M.D., Cineradiographic studies of the nomul cerwical spine, Califor. Med, 93, no.5, 293.206, 1960 .

Kotuke, FJ., Mundale, M.O., Range of mobility of the cervical spine, Anch phys. Med. Rehabilo, 40, 379-382, 1959.

Lewit, K, Krausova, L., Beitrag zar Flexion der Halswirbelsaule, Fortschr. Röntgenstr, 97, 38-44, 1962.

Lewit, $K$, Krausowá, L. Messungen won Vorw und Rick beuge in den Kopfgelenken, Fortschr. Rontgenstr, 9o, $538-543,1963$.

Lysell, Ea, Motion in the cenvical spine, Acta Orthop. Scand., 123, suppl., 1969. 
Markuske, H. Untersuchumger zur Siatik und Dynamik. den kandichen Holowintelsidule: Der Aussagewert seltlicher Rontgenaufnahmen, Die Wintelsdule in Forschusig wnd Praxis, 50, 1971.

Mestdagh, $H_{\text {. }}$, Morphological aspects and biomechanical properties of the Vertebro-wial joint (C2-C3), Acta Morphol. Neerl-Scand, 14, 19-30, 1976.

Penting Ls, Funktionel rontgenonderzok bil degeneratiewe en trawmatische af wifkingen der ladag-cenicale be wiegingssegmenten, Thesis, University of Groningen, The Netherlands, 1060 .

Penming $L$, Allantowatial instability and functional $X$ ray examination, Med. Mundi, 7, no. 5, 113m126, 1961.
Penning L., Functional pathology of the cervical spine Excerpla Medica, Amsterdam, 1968.

Size de, Etude radiologique de la dynamique cenicale dants la plan sagitale, Rev. Rhum, 3, 111-116, 1951.

Virchow, $H_{\text {, }}$ Die sagittal flexorische Bewegung der menshchen Halswitbelsaule, Arch. Orthop. Unfall Chin, 26 , $1-41,1928$

Weme, $S_{\text {., }}$ Studies in spontaneous atlas dislocation, Acta Orthop. Scand., 23, suppl., 1957.

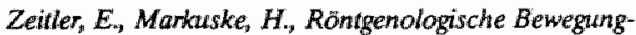
samalyse der Halswinbelsäule bei gesunden Kindern, Fonschr. Roentgenstr., 96,87-93, 1962. 


\section{Chapter 5}

\section{Position of the average instantaneous centre of rotation in segments (C0-C1) to (C6-C7)}

\subsection{Introduction}

Movement of the projection of the cranial vertebra in relation to the projection of the caudal vertebra within the sagittal plane, is based on the combination of motion within the region of the corpora and displacement between the facets. This displacement entails rotation and translation within the sagittal plane of the cranial vertebra, in relation to the caudal vertebra. In the preceding chapters we have defined range of motion within a segment only in relation to the rotary component (see chapter 4). A method for registering the displacement between two positions of the segment more completely is to indicate the position of the instantaneous centre of rotation next to rotation within the sagittal plane. In relation to this point of rotation any point in the projection of the cranial vertebra of a segment in a given position can be rotated towards the position of the corresponding point in the projection of the cranial vertebra in another position of the segment. A method of constructing such a centre of rotation has been described, among others, by Penning $(1960,1978)$. This point is only valid between the two positions of the segment chosen. If two different positions are used another centre will be found. The positions of all centres will only be identical if there is a pure hinge.

Positions of centres of rotation have been described for the cranial segments which are partly contradictory. White and Panjabi (1978) state that the instantaneous centre of rotation within segment $(\mathrm{C} 0-\mathrm{C} 1)$ is projected in the middle of the occipital condyle, immediately cranial of the top of the dens axis. Wackenheim and Lopez (1969) indicate the position of this centre immediately dorsally of the top of the dens axis in an area covering approximately the ventral part of the projection of the vertebral canal. Penning (1978) positions this centre cranial of the foramen magnum. The instantaneous centre of rotation within segment $(\mathrm{C} 1-\mathrm{C} 2)$ is indicated by Werne (in White and Panjabi, 1978) in an area covering the entire middle half of the projection in the dens axis. Penning (1978) gives this centre in the middle of the projection of the dens axis. White and Panjabi (1978) say that they knew of no specific research aimed at determining the correct position of the instantaneous centres of rotation for the caudal segments of the cervical spine. The position of these centres in segments (C2-C3) to (C6-C7) indicated by Penning (1960) show a large dispersion. Later research (Penning, 1964) states that these centres are in the caudal vertebral body of the segment; in the cranial segments they are more caudal than dorsal in comparison to the caudal segments. The centre of segment (C6C7) is in the centre of the cranial end-plate of $\mathrm{C7}$ or immediately beneath. Dimnet et al. (1982) state that the positions of the instantaneous centres of rotation are in a large area in the mid-cranial part of the caudal vertebral projection and the adjacent part of the projection of the intervertebral disc.

A number of conclusions seem appropriate, if we consider the literature:

- Thus far, the positions of the instantaneous centres of rotation could not be indicated unequivocally with the existing methods.

- To what extent the large dispersions found are due to the methods used is not clear. No data are available on the reproducibility of the methods used.

- It is not clear when a certain position of a given instantaneous centre of rotation has to 
be considered as normal or as an indication for deviating motion.

- So far, the instantaneous centre of rotation has only been determined on the basis of static shots of the cervical spine within the motion path of anteflexion/retroflexion (the extreme positions and maximally three intermediate positions) and not in a series of shots of actually performed anteflexion or retroflexion of the cervical spine.

- It has not been established whether the positions of the instantaneous centres of rotation, determined on the basis of registrations during anteflexion or retroflexion of the cervical spine, are identical.

- We do not know to what extent the positions of centres in a given individual are identical at different moments of measurement (intraindividual variability) and to what extent they differ in a group of persons free of complaints (interindividual variability).

In order to bring some clarity in the abovementioned problems, the positions of the "averaged" of the instantaneous centres of rotation have been determined in the ten persons free of complaints. As many images of the actually performed anteflexion and retroflexion of the cervical spine as possible have been used per film.

\subsection{Method}

In this research, the position of the "average" has been determined for the positions of the instantaneous centre of rotation for each segment $(\mathrm{C} 0-\mathrm{C} 1)$ to (C6-C7) between as many images of a series of shots. The "smoothing" ("running mean") effect on the first and last image of a series of shots, normalized to 50 images, differs from the effect on the other pictures. This has its effect on the values of the position parameters of the first and last four images (see chapter 2). Consequently, only images 5 to 45 have been included in the calculation of the position of the averaged instantaneous centres of rotation.

In this research, the position of the instantaneous centre of rotation between two positions of a segment has been calculated on the basis of the method used by Penning (1960). When this is applied to the average pentagons calculated (chapter 2), the following results emerge:

- Of the average pentagon of projection within the sagittal plane, two points (the cranioventral and the caudoventral vertex of the contour of the vertebral body) are indicated. This is done on each image ( 5 to 45 ) of the series of shots normalized to fifty.

- Of the positions of a segment, from which the instantaneous centre of rotation has to be determined, the average pentagons of the caudal vertebra of the segment are superimposed on each other in such a way that they overlap.

- The two corresponding points indicated on the average pentagon of the projection of the cranial vertebra in both positions are connected by a line. The perpendicular bisectors of these two lines are determined. The intersection of the two perpendicular bisectors is considered to be the position of the instantaneous centre of rotation within the segment between the two positions of the segment chosen during motion.

Marking of the points of the connecting lines will be possible within a certain range of precision. If the perpendicular bisectors are almost parallel, a small fault in indicating the points will lead to a major fault in the position of the intersection. Panjabi et al. (1982) indicate that this phenomenon is bound to occur if little rotation has taken place between the two positions of the segment. This is pre-eminently the case in two consecutive images of an X-ray film. Hence our choice to determine the position of the "average" of the instantaneous centres of rotation not on the basis of two consecutive images, but between two nonadjacent images. The number of images between the ones of which the position of an instantaneous centre of rotation is determined is called interval. The size of the interval is set. When an interval is used, it is still possible that little or no rotation takes place between the positions chosen within a segment. This is why we have determined that in order to include a given position of an 
instantaneous centre of rotation in the calculation of the position of the average, it is necessary that minimum rotation has taken place between two positions from which the position of an instantaneous centre of rotation is calculated. The size of this rotation is called minimum angle. The size of the minimum angle is set. Setting the interval and the minimum angle took place after the most favourable value for interval and minimum angle had been established. This value was used in all calculations.

Determining the position of the average on the basis of two nonconsecutive images (interval = I) may be done in two ways:

a. image 1 and image $1+(\mathrm{I})$, image $1+(\mathrm{I})$ and image $1+2(\mathbb{I I})$, etc.

b. image 1 and image $1+(\mathrm{I})$, image 2 and image $2+($ II), etc.

In a. it would be possible for a small value of (I) (e.g. 2) and a small minimum angle (e.g. 0.5 degrees) to determine a polode per segment of each film. This has not been done in this research, because it does not yield reproducible results. In the case of a small interval and a minimum angle of e.g. 5 degrees or more, the positions calculated will not be involved in the calculation of the position of the average either. For it often happens that rotation between two images is less than 5 degrees. In the case of a larger interval, e.g. (I) $=10$, use of a. entails that only 4 centres calculated are involved in the calculation of the position of the average. The other images are then left out. Use of $b$. would entail that in $(\mathrm{I})=10,31$ centres are involved in calculation of the average. Since we intend to use as many images as possible in the calculation of the position of the average, we have chosen the way of calculating mentioned under $b$.

The procedure described below was followed to determine the optimum values of interval and the minimum angle. Of the normalized series of shots (R3) the positions of the average of the instantaneous centres of rotation of segments ( $\mathrm{C} 0-\mathrm{C} 1)$ to $(\mathrm{C} 6-\mathrm{C} 7)$ were computed with an interval of $5,10,15$, 20,25 and 30 images. This was done with a minimum angle of 3, 5, 7 and 9 degrees. For a certain minimum angle, average positions have therefore been determined for six intervals. For each segment, this gives 24 determined positions of the average of the instantaneous centre of rotation within that seg. ment.

After the six averages per minimum angle were calculated, they were indicated on a drawing of the contours of bony structures of the cervical spine and the skull, which was adopted from an image in the middle of series (R3). With the aid of the $x-y$ digitizer the $x$-y coordinates of these six average instantaneous centres of rotation were fed into the computer. Subsequently the mean of these six positions and the distances between this mean and the six positions was computed. These distances can be seen in table 5.1. If --- is indicated this means that for that interval and that value of the minimum angle no position of the average of the instantaneous centre of rotation within a given segment was calculated. In this case rotation between all appropriate positions of the segment on the images chosen was less than the value of the minimum angle. Larger distances entail that the positions of the averages calculated in different intervals, are widely distributed. In table 5.1 all distances less than $1.5 \mathrm{~mm}$ are considered as the range of measurement error of the method used. This value may be considered the lowest minimum attainable. The values between 0 and 1.5 may have arisen from inaccurate positioning with the $x$-y digitizer.

Table 5.1 shows that:

1. Larger distances to the mean are found primarily in segments ( $\mathrm{C} 0-\mathrm{C} 1)$ and ( $\mathrm{C} 6-\mathrm{C} 7)$. For the remaining segments the distances in each combination are less than 1.8 .

2. With larger minimum angles, the distances of each position to the mean of the six positions are smaller. This phenomenon is most predominant in the positions of the average instantaneous centres of rotation of segments ( $\mathrm{C} 0-\mathrm{C} 1)$ and $(\mathrm{C} 6-\mathrm{C} 7)$ and to a lesser degree in the ones of segment (C2-C3).

3 . With a minimum angle of 5,7 and 9 de- 
grees, no positions are calculated during an interval of 5 images. This is also the case for a combination of minimum angle of $9 \mathrm{de}-$ grees and interval of 10 images.

For the reasons given above, we have chosen an interval of 20 images for calculating the position of the average instantaneous centre of rotation. This interval is large enough to avoid calculation problems and yet small enough to include all images ( 5 to 45$)$ in the calculation of the position of the instanta-

table $5 * 1$

\begin{tabular}{|c|c|c|c|c|c|c|c|c|c|c|c|c|}
\hline \multirow[t]{3}{*}{$m \backslash i$} & 5 & 10 & 15 & $20 \quad 2$ & 30 & & 5 & 10 & 15 & 20 & 25 & \\
\hline & \multicolumn{6}{|c|}{$(\mathrm{CO}-\mathrm{C} 1):$} & \multicolumn{6}{|c|}{$(\mathrm{c} 1-\mathrm{c} 2):$} \\
\hline & 4.9 & 9.2 & 6.1 & 9.8 & 4.7 & 8.6 & 1.0 & 0.5 & 1.2 & 0.3 & 0.7 & 0.6 \\
\hline 5 & -- & 3.2 & 2.0 & 4.5 & 5.0 & 11.2 & 0.8 & 2.4 & 1.1 & 0.5 & 0.7 & 0.9 \\
\hline 7 & --- & 1.6 & 1.5 & 2.6 & 4.3 & 7.3 & -- & 0.8 & 0.3 & 0.3 & 0.1 & 0.6 \\
\hline \multirow[t]{2}{*}{9} & --- & $-\cdots$ & 2.4 & 1.2 & 2.4 & 3.1 & --- & 1.4 & 0.3 & 0.5 & 0.4 & 0.7 \\
\hline & \multicolumn{6}{|c|}{$(\mathrm{C} 2-\mathrm{C} 3):$} & \multicolumn{6}{|c|}{$(\mathrm{C} 3-\mathrm{C} 4):$} \\
\hline 3 & 3.6 & 1.9 & 0.4 & 1.2 & 0.9 & 0.6 & 0.9 & 0.6 & 0.4 & 0.3 & 0.1 & 0.3 \\
\hline 5 & -- & 1.5 & 0.4 & 0.4 & 0.5 & 0.4 & -- & 1.2 & 0.4 & 0.3 & 0.5 & 0.3 \\
\hline 7 & --- & --- & 0.4 & 0.8 & 0.3 & 0.3 & --- & 1.7 & 0.2 & 0.6 & 0.6 & 0.3 \\
\hline \multirow[t]{2}{*}{9} & --- & -- & -- & 0.06 & 0.06 & 0.02 & -- & --- & 1.0 & 0.3 & 0.2 & 0.6 \\
\hline & \multicolumn{6}{|c|}{$(C 4-C 5):$} & \multicolumn{6}{|c|}{$(\mathrm{C} 5-\mathrm{C} 6):$} \\
\hline 3 & 0.6 & 0.3 & 0.1 & 0.5 & 0.3 & 0.3 & 1.3 & 1.3 & 1.2 & 0.5 & 0.4 & 0.1 \\
\hline 5 & --- & 0.9 & 0.4 & 0.3 & 0.4 & 0.5 & 1.6 & 1.8 & 0.4 & 0.8 & 0.6 & 0.2 \\
\hline 7 & -- & 0.5 & 0.3 & 0.2 & 0.2 & 0.4 & -- & 1.6 & 0.8 & 0.9 & 0.7 & 0.7 \\
\hline \multirow[t]{2}{*}{9} & --- & -- & 0.1 & 0.2 & 0.2 & 0.1 & -- & -- & 0.9 & 0.4 & 0.6 & 0.2 \\
\hline & \multicolumn{6}{|c|}{$(\mathrm{C} 6-\mathrm{C} 7):$} & & & & & & \\
\hline 3 & 5.3 & 0.9 & 2.7 & 3.1 & 2.0 & 1.1 & & & & & & \\
\hline 5 & 3.7 & 0.4 & 0.9 & 1.5 & 1.8 & 2.4 & & & & & & \\
\hline 7 & -- & 3.1 & 0.4 & 1.5 & 0.7 & 2.6 & & & & & & \\
\hline 9 & --- & --- & 0.8 & 1.7 & 0.2 & 1.5 & & & & & & \\
\hline
\end{tabular}


neous centre of rotation.

Table 5.1 shows that with a larger minimum angle the distances to a mean of the group of six positions is smaller than with a smaller minimum angle. The table does not make clear what is the smallest minimum angle at which positioning faults of the marker points do not influence calculation of the position of the instantaneous centre of rotation. This is why the positions were determined of the average instantaneous centres of rotation of film R3, of which the contours were marked at six different times (R3PAT, R3P1, R3P2, R3P3, R3P4 and R3P5). With an interval of 20 images, the mean of each of these six calculated positions of the average instantaneous centres of rotation, was computed with a minimum angle of 1,2 etc. to 10 degrees. The largest distance of one of these six positions to the mean of this group of six is indicated as a measure for dispersion in table 5.2. one position that deviates considerably from the others or whether all positions are grouped around an average. For this reason, the positions calculated of a number of minimum angles have also been given in relation to the actual contours. Figure 5.1 gives the positions of the average instantaneous centres of rotation of the six registered series of marker points for each segment of film R3 (R3PAT and R3P1 to R3P5). The mean of these six positions was calculated and indicated for each segment. This was done for a minimum angle of $1,3,7$ and 9 degrees (figure 5.1a, and 5.1b, 5.1c and 5.1d). These figures show that in each of these fout minimum angles, the points are grouped around the mean. The situation where only one point deviates considerably does not occur. It is possible that the groups in each segment, cal culated for the different minimum angles, are in a different position in relation to the con-

table 5.2

\begin{tabular}{|c|c|c|c|c|c|c|c|c|c|c|}
\hline segm. & dgr. 1 & 2 & $\begin{array}{c}\text { Inter } \\
3\end{array}$ & $\underset{4}{\mathrm{ral}} 20$ & $\frac{p i}{5}$ & $\frac{\text { ures }}{6}$ & 7 & 8 & 9 & 10 \\
\hline$(\mathrm{CO}-\mathrm{C} 1)$ & 13.49 & 7.66 & 6.65 & 6.45 & 6.36 & 6.27 & 5.11 & 4.36 & 4.57 & 4.29 \\
\hline$(\mathrm{Cl}-\mathrm{C} 2)$ & 2.44 & 2.67 & 2.20 & 1.87 & 1.44 & 1.37 & 1.54 & 1.43 & 1.45 & 1.51 \\
\hline$(\mathrm{C} 2-\mathrm{C} 3)$ & 1.45 & 1.32 & 0.94 & 1.23 & 0.87 & 1.49 & 2.51 & 1.59 & 1.31 & 0.89 \\
\hline$(\mathrm{C} 3-\mathrm{C} 4)$ & 1.42 & 1.50 & 1.23 & 1.03 & 1.44 & 1.41 & 1.31 & 0.92 & 0.99 & 1.20 \\
\hline$(\mathrm{C} 4-\mathrm{C} 5)$ & 0.83 & 0.79 & 0.83 & 1.02 & 0.89 & 1.20 & 0.82 & 1.09 & 0.47 & $1 * 02$ \\
\hline$(\mathrm{C} 5-\mathrm{C} 6)$ & 1.50 & 1.37 & 1.28 & 1.33 & 1.24 & 1. 36 & 1.29 & 1.24 & 0.83 & 2.09 \\
\hline$(C 6-C 7)$ & 3.25 & 3.35 & 2.47 & 3.06 & 2.70 & 3.19 & 2.02 & 3.43 & 2.81 & 3.46 \\
\hline
\end{tabular}

Table 5.2 shows that the largest distances to the mean of the six positions of the average instantaneous centres of rotation calculated, are found in segments ( $\mathrm{C0}-\mathrm{C} 1)$ and (C6-C7). These distances are smaller in case of a larger minimum angle. This applies to a lesser degree to the other segments. From a minimum angle of 5 degrees and more onwards the maximum distance does not get smaller.

Table 5.2 does not show whether it is only tour. This is why in figure 5.2 the positions of the four means (minimum angle $1,3,5$ and 9 degrees) of each segment are given in one contour drawing. The figure shows that the actual positions of the four means per segment do not differ a lot from a minimum angle of 3 degrees to 9 degrees either.

On the basis of the above-mentioned results, we have calculated the position of the aver- 

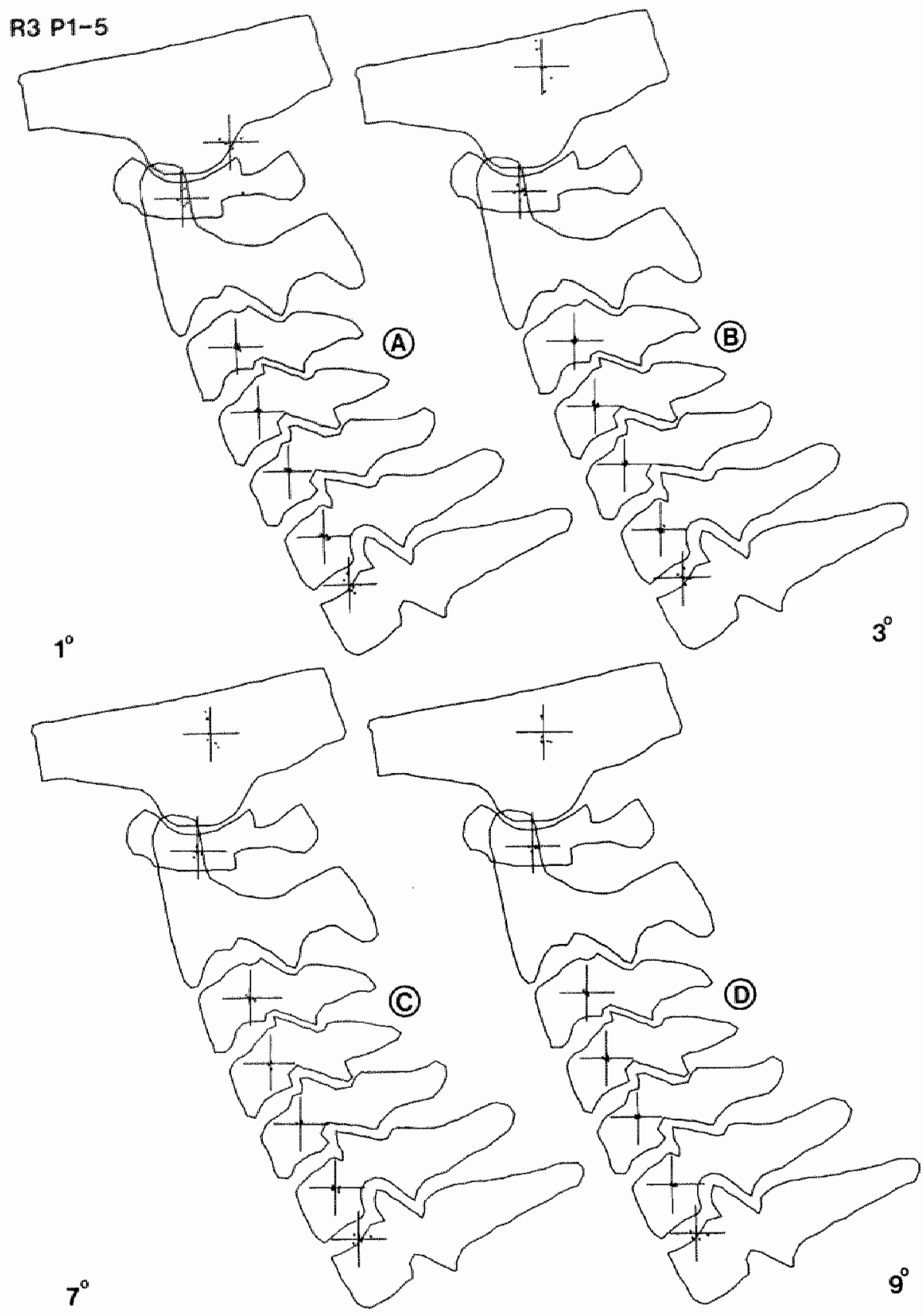

ng. 5.1 Position of the mean ( + ) of 6 average instantaneous centres of rotation (.) at a minimal angle of $1^{\circ}(\mathrm{A})$, $3^{\circ}(B), 7^{\circ}(C)$ and $9^{\circ}(D)$, determined in 6 files of data of film $R 3$ (PAT, 1, 2, 3, 4 and 5). 
R3 P1 - 5

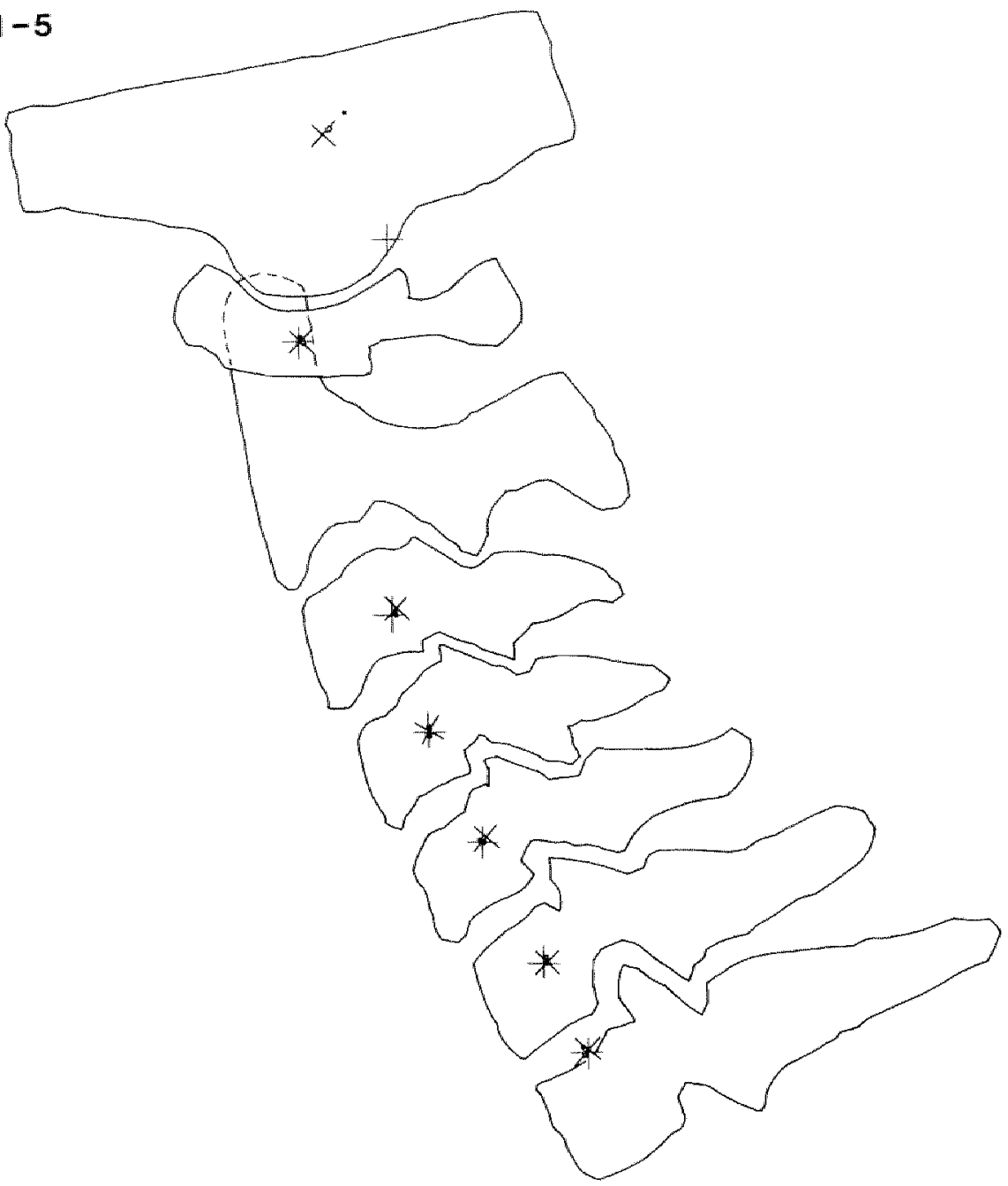

$+1^{\circ}=3^{\circ} \quad 07^{\circ} \quad \times 9^{\circ}$

fig. 5.2 The 4 positions of the mean in case of a minimal angle of $1^{\circ}, 3^{\circ}, 7^{\circ}$ and $9^{\circ}$ of each segment (same positions as in figure 5.1). Only the position of the instantaneous centre of rotation in the segment (CO-C1) at a minimal angle of $1^{\circ}$ differs strongly to the other calculated positions in this segment.

age instantaneous centres of rotation for positions on images with an interval of 20 and a minimum angle of 7 degrees, between images 5 to 45 of a normalized series of shots of anteflexion or retroflexion of the cervical spine.

\subsection{Reproducibility}

Table 5.2 gives the largest distances between each of the six positions of an awerage instantaneous centre of rotation, calculated with one of the six marker points registered at different times of one film (R3). In the cases where only one of the calculated positions is far removed from the others, table 5.3 will give the distance of each of the six (R3PAT, R3P1, R3P3, R3P4 and R3P5) series of (R3) registered to the mean of these six. They have 


\begin{tabular}{|l|cccccc|}
\hline segments & R3PAT & R3P1 & $\mathbb{R} 3$ 2 & R3P3 & R3P4 & R3P5 \\
\hline (C0-C1) & $5.1 *$ & 2.9 & 1.3 & 4.4 & 2.3 & 3.9 \\
$(\mathrm{C} 1-\mathrm{C} 2)$ & 0.9 & 1.3 & 1.2 & 1.0 & $1.5 *$ & 1.0 \\
$(\mathrm{C} 2-\mathrm{C} 3)$ & 2.1 & 0.2 & $2.5 *$ & 0.5 & 0.3 & 0.5 \\
$(\mathrm{C} 3-\mathrm{C} 4)$ & 0.7 & 0.1 & 0.7 & $1.3 *$ & 0.3 & 1.0 \\
$(\mathrm{C} 4-\mathrm{C} 5)$ & 0.8 & 0.4 & 0.6 & 0.6 & $0.8 *$ & 0.6 \\
$(\mathrm{C} 5-\mathrm{C} 6)$ & 1.3 & 0.6 & $1.3 *$ & 1.3 & 0.7 & 0.7 \\
$(\mathrm{C} 6-\mathrm{C} 7)$ & $2.0 *$ & 1.8 & 0.4 & 0.5 & 0.3 & 1.1 \\
\hline
\end{tabular}

been calculated with an interval of 20 images and a minimum angle of 7 degrees.

The values marked with an asterisk $\left(^{*}\right)$ are the values belonging to the column of $7 \mathrm{de}$ grees, included in table 5.2.

Table 5.3 shows that the clusters of points are all close to each other. The points in the clusters of the positions of the instantaneous centre of rotation of segment ( $\mathrm{CO}-\mathrm{C} 1)$, followed by those of (C2-C3) and (C6-C7), have the largest distance to the mean. We may conclude that the accuracy of determining a position of an average instantaneous centre of rotation using an interval of 20 images and at a minimum angle of 7 degrees, is different for each segment.

Table 5.3 gives distances representing the dispersions intrinsic to the method. If a distance of more than twice the maximum value is found for a position of an average instantaneous centre of rotation derived from an $\mathrm{X}$ ray film, this is not likely to be caused by the method of marking and calculating used. It is an indication for a way of rotation or translation in a segment within the sagittal plane during anteflexion or retroflexion of the cervical spine that differs from one during another moment of measurement. Table 5.4 gives the values of the distances concerned per segment. They amount to approximately twice the maximum distances for the relevant segment in table 5.3.

\subsection{Results}

In each person examined, the position was calculated of the average instantaneous centre of rotation per segment of anteflexion and retroflexion of the cervical spine. In eight persons this produced six positions, in two $(\mathbb{P}$ and R) four positions. Of these six and four positions a mean position was determined and the distances from each position to this mean were calculated. Figure 5.3 gives the positions of the average instantaneous centres of rotation of segments ( $\mathrm{C} 0-\mathrm{C} 1)$ to (C6C7) for persons $O$ and $S$, for the three ante-

table 5.4

\begin{tabular}{|l|c|}
\hline segment & distance \\
\hline$(C D-C 1)$ & 10 \\
$(C 1-C 2)$ & 3 \\
$(C 2-C 3)$ & 5 \\
$(C 3-C 4)$ & 3 \\
$(C 4-C 5)$ & 2 \\
$(C 5-C 6)$ & 3 \\
$(C 6-C 7)$ & 4 \\
\hline
\end{tabular}

flexion and the three retroflexion registrations, in relation to the contours of the projection of the skull and vertebrae as shown on 

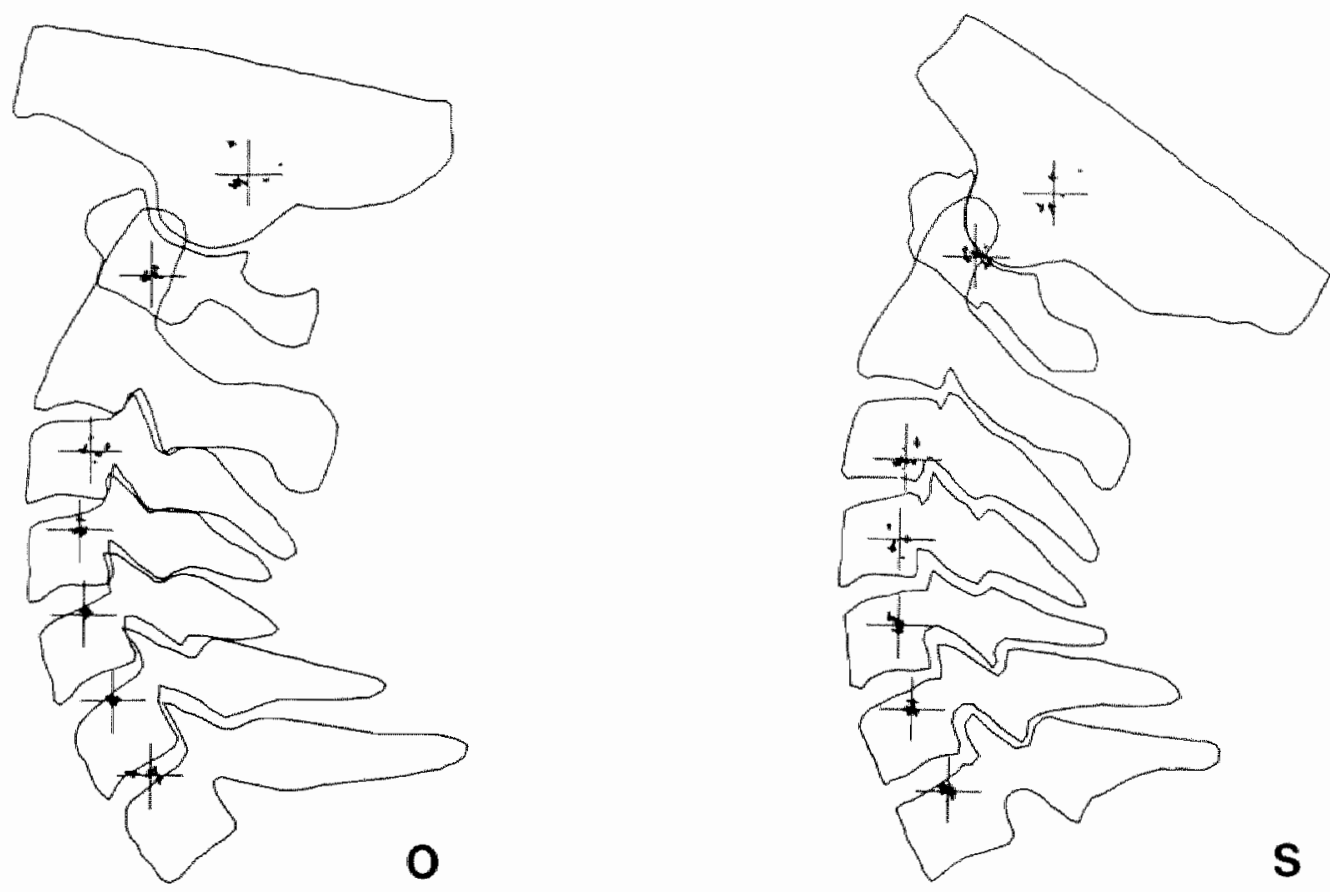

nig 53 The positions of all segmental average instantaneous centres of rotation and their mean of each recorded antellexion and retroflexion of the test persons $O$ and $S$.

an X-ray in the middle of a series of shots (O1 and $\mathrm{S} 1$ ). The mean of these positions was calculated. This mean is also shown in figure 5.3. The six positions of the centres and their mean are close together.

As to the position of the mean within the different segments the following can be observed:

\section{(CO-C1)}

In nine persons $(L, M, N, O, P, Q, R, S$ and $\mathrm{U})$ this is exactly above the middle (or positioned slightly darsally) of the projection of the occipital condyle. In one person (T) it is ventral within the projection of the occipital condyle. Note that little rotation within the sagittal plane takes place in the atlantooccipital joint in person (T). This means that the calculation of a position of an average instantaneous centre of rotation is inaccurate. Dis- persion of the six values is also extreme in this person.

\section{(C1-C2)}

In all persons the mean is in the middle or in the dorsal half of the projection of the dens axis. In craniocaudal direction it is also halfway in the projection of the dens axis.

\section{(C2-C3)}

In all persons the mean is in the dorsal half of the projection of the vertebral body. In three persons ( $\mathrm{L}, \mathrm{O}$ and $\mathrm{U}$ ) it is in the cranial half, in three other persons $(P, R$ and $S)$ in the caudal half and in four persons $(M, N, Q$ and $\mathrm{T}$ ) in the middle.

\section{(C3-C4)}

In all persons the mean is in the dorsal half of the projection of the vertebral body. In six persons $\left(L_{r}, N, O, P, R\right.$ and $\left.U\right)$ it is in the cra- 
nial half, in none of the persons examined in the caudal half and in four persons (M, Q, S and $T$ ) in the middle.

\section{(C4-C5)}

In all persons the mean is in the dorsal half of the projection of the vertebral body. In two persons ( $\mathrm{O}$ and $\mathrm{U}$ ) this position is in the cranial end-plate or just beneath. In none of the persons examined does it occur in the caudal part of the dorsal half; in five persons $(L, N$, $P, R, S$ ) it is in the cranial half, not including persons $\mathrm{O}$ and $\mathrm{U}$, and in three persons (M, Q and $T$ ) in the middle.

\section{(C5-C6)}

In all persons the position of the mean is in the dorsal half of the projection of the vertebral body. In five persons $(L, M, O, P$ and $U)$ it is in the cranial end-plate or just beneath; in the other five persons (N, Q, R, S and T) in the cranial part of the dorsal half.

\section{(C6-C7)}

In all persons the mean, seen in ventrodorsal direction is in the middle of the projection of the vertebral body. In two persons ( $M$ and $O$ ) it is in the projection of the intervertebral disc, in the remaining eight persons in the end-plate or just beneath.
We have determined that the positions of the average instantaneous centres of rotation within the different segments is found in:

* (CO-C1): Cranial to the projection of the occipital condyles,

* (C1-C2): In the craniocaudal direction halfway within the dorsal half of the dens axis, * (C2-C3): In the dorsal half of the vertebral body of $\mathrm{C} 3$,

- (C3-C4): In the dorsal half of the wertebral body of $\mathrm{C} 4$, but not in the caudal part.

* (C4-C5): In the dorsal half of the vertebral body of $\mathrm{C} 5$, varying from within the end-plate to the middle of the cranial part of the dorsal half.

* (C5-C6): In the dorsal half of the vertebral body of $\mathrm{C} 6$, varying from within the end-plate to the middle of the cranial part of the dorsal half. In most persons the position is found in the end-plate or immediately caudally to it.

* (C6-C7): Between the ventral and dorsal half of the vertebral body of $\mathrm{C} 7$ varying from within the intervertrebral disc to the endplate of $\mathrm{C} 7$ or just beneath.

In none of the persons examined, positions were found in the caudal part of the projection of the vertebral body of the caudal vertebra with the exception of segment (C2-C3). No positions occurred in the ventral part of

table 5.5

\begin{tabular}{|c|ccccccccccc|c||}
\hline \multicolumn{2}{|c|}{ segm-pers. $\mathrm{L}$} & $\mathrm{M}$ & $\mathrm{N}$ & $\mathrm{O}$ & $\mathrm{P}$ & $\mathrm{Q}$ & $\mathrm{R}$ & $\mathrm{S}$ & $\mathrm{T}$ & $\mathrm{U}$ & \\
\hline$(\mathrm{C} 0-\mathrm{C} 1)$ & 6.1 & 11.3 & 6.8 & 7.7 & 7.1 & 6.7 & 10.0 & 7.3 & 13.6 & 7.1 & $0 \mathrm{x}$ \\
$(\mathrm{C} 1-\mathrm{C} 2)$ & 2.8 & $6.0 *$ & $4.2 *$ & 2.0 & 2.0 & 11.4 & 2.2 & 2.9 & $5.1 *$ & 1.5 & $3 \mathrm{x}$ \\
$(\mathrm{C} 2-\mathrm{C} 3)$ & $5.1 *$ & $6.0 *$ & 3.5 & 3.0 & 2.4 & 3.5 & 1.5 & 4.1 & 5.0 & 4.5 & $2 \mathrm{x}$ \\
$(\mathrm{C} 3-\mathrm{C} 4)$ & 1.8 & 2.9 & 2.5 & 2.1 & 2.5 & $3.3 *$ & 2.3 & $4.4 *$ & $6.2 *$ & 1.8 & $3 \mathrm{x}$ \\
$(\mathrm{C} 4-\mathrm{C} 5)$ & 1.3 & $2.1 *$ & 1.8 & 1.5 & 1.3 & $2.3 *$ & 1.2 & 2.0 & $2.9 *$ & $2.4 *$ & $4 \mathrm{x}$ \\
$(\mathrm{C} 5-\mathrm{C} 6)$ & 1.9 & 2.7 & 2.7 & 0.7 & 1.4 & 2.6 & 1.3 & 1.6 & 2.1 & 2.1 & $0 \mathrm{x}$ \\
$(\mathrm{C} 6-\mathrm{C} 7)$ & 3.0 & 2.8 & $6.6 *$ & 3.5 & 3.2 & $4.3 *$ & 3.4 & 2.0 & 2.8 & 3.2 & $2 \mathrm{x}$ \\
\hline & $1 \mathrm{x}$ & $3 \mathrm{x}$ & $2 \mathrm{x}$ & $0 \mathrm{x}$ & $0 \mathrm{x}$ & $3 \mathrm{x}$ & $0 \mathrm{x}$ & $1 \mathrm{x}$ & $3 \mathrm{x}$ & $1 \mathrm{x}$ & \\
\hline
\end{tabular}


the vertebral body.

Table 5.5. gives for each person examined, and for each segment, the maximum distances of one of the six positions of the average instantaneous centre of rotation to the mean of these positions. The distances larger than the maximum mentioned in table 5.4 are marked with an asterisk (*). The number of occurrences of a distance marked has been indicated at the end of the line for each segment. This was also done at the bottom of each column for each person examined.

Two extreme positions were found (person $\mathrm{T},(\mathrm{C} 0-\mathrm{C} 1)$ and person $\mathrm{Q},(\mathrm{C} 1-\mathrm{C} 2)$; these have been underlined). In person $T$ all the positions of segment ( $\mathrm{CO}-\mathrm{C} 1)$ are far apart. This is because in segment $(\mathrm{CO}-\mathrm{C} 1)$ there was extremely little rotation in the sagittal plane; hence no reliable mean could be determined at an interval of 20 images and a minimum angle of 7 degrees. In person $Q$ one position of an anteflexion registration is far apart from the other positions. This position has also been ignored.

Table 5.5 shows that:

- The distances marked do not differ much from the maximum used. They are, however, more than twice as large as the distances caused by inaccuracy of the marking method. - In three persons ( $O, P$ and $R$ ) the positions are so close to each other that they have to be considered as identical under the method used. In three other persons ( $\mathrm{M}, \mathrm{Q}$ and $\mathrm{T})$ a dispersion was found in three segments that was larger than could be expected on the basis of the method used.

- In segment (C4-C5) four times a larger dispersion was found than could be expected on the basis of the method; this occurs three times in segments (C1-C2) and (C3-C4).

It is possible that for one person or one segment a distance larger than the value mentioned in table 5.4 occurs more than once. This cannot be seen from table 5.5. Consequently, a dispersion of more than one of the six values may have occurred in the cases where this has been mentioned.

\subsection{Discussion}

Research reports to date (Penning, 1960, 1964, 1978, 1988; Wackenheim and Loper, 1969; Werne (in White and Panjabi, 1978); Dimnet et al., 1982) have stated wide areas in which the instantaneous centre of rotation for anteflexion and retroflexion in relation to the projection of the contours of the segments may be found. In this research, the average position of the instantaneous centre of rotation proves to have a much smaller interindividual dispersion. One of the causes for the difference in dispersion between these two positions may be that the calculation of the instantaneous centre of rotation as described up to now, has made use of mar" ker points on only two $\mathrm{X}$-rays. Chapter 2 has shown that applying marker points per picture entails the possibility of inaccurate marking. In this research each contour is marked approximately 40 times (i.e. on each image of the X-ray film). Marking faults are averaged over the 40 marked positions, by means of averaging and iteration used (chapter 2.7). The positions of the contours in this research are therefore more reliable. In the method used by Dimnet et al. (1982) inaccuracy of marking points may be the reason for the large difference in positions of the four instantaneous centres of rotation between the five positions of a given segment in the path examined of anteflexion/retroflexion of the cervical spine.

The accuracy of indicating the instantaneous centre of rotation also depends on the degree of rotation within a given segment between the two positions used (Panjabi et al., 1982). Here too, the method described by Dimnet et al. is at a disadvantage, for between the five positions of the cervical spine used by him, rotation within a segment will be small compared to rotation within the segment be tween the extreme positions as used, e.g., by Penning. None of the research reports described in detail the reproducibility of indicating an instantaneous centre of rotation. The interindividual variation of the position of the instanteneous centre of rotation as des- 
cribed in literature covers a large area in the projection of the vertebral bodies. Our research produces a much smaller dispersion. This might be an indication that in the methods used until now there is an unfavourable relation between determining the actual position of an instantaneous centre of rotation and the accuracy of the method. This research includes data on the accuracy of determining the position of an instantaneous centre of rotation (table 5.3). One of the reasons for the high degree of accuracy of the method lies in the fact that so many positions (approximately 20) are used to calculate the average position of an instantaneous centre of rotation and in the fact that there is a large degree of rotation between two positions in which the instantaneous centre of rotation is calculated.

A disadvantage of the method used by us is the fact that no compilation, such as a polode, can be determined for the instantaneous centres of rotation, because the rotary centres between two consecutive images have not been determined. This means that this method does not allow an optimal insight into the degree of gliding and tilting of two vertebrae within a segment (see chapter 6) and their relation.

One of the questions in the introduction (5.1) concerned the difference between the positions of an instantaneous centre of rotation during anteflexion and during retroflexion of the cervical spine. It is impossible to distinguish two groups. This means that the method used in this research did not indicate a difference in the positions of the instantaneous centre of rotation during anteflexion and retroflexion. If there is a difference at all, it lies within the range of measurement error used to determine the instantaneous centre of rotation.

The six values of the positions of the instantaneous centres of rotation of segment ( $\mathrm{CO}$ C1) are far apart in all persons (figure 5.3). The same applies to the values of segment (C0-C1) as shown in figure 5.1. This phenomenon does not occur in the other seg- ments. This is because on the different pictures of an X-ray film, the projection of the skull within the sagittal plane shows more differentiation than that of the other bony structures. This probably stems from the fact that the skull, more so than the other vertebra, also moves within other planes (rotation around a vertical axis) during motion within the sagittal plane of the head and the cervical spine. As a result, the contour on the various pictures is caused by a different curvature of the skull. Since the skull can only be marked by using a template (reflecting the contour on one of the pictures), the best suitable overlap will have to be looked for on the remaining pictures of a film. This is less accurate than indicating the five individual marker points per vertebral contour. For this reason, the large dispersion is indicated as a methodological error. The seventh cervical vertebra has been marked with the use of a template as well. In this bony structure, the contour within the plane of the projection on the X-ray does not differ very much on the images, because the vertebra does not move in many other planes than the sagittal one. This is why marking of this vertebra with a template does not lead to the phenomena that occurred in the marking of the skull. If during one of the six motions performed, positions of average centres of rotation are found (see table 5.5) in which the dispersion within the group is larger than the one caused by inaccuracies of the method, this may be caused by a different way of motion in the segment in one moment of measurement (a different play of tilting and gliding combined with motion in the facets) compared to the other moments of measurement.

When we compare the positions of the average instantaneous centres of rotation in the different segments that were found to the positions of the instantaneous centres of rotation as described, we may observe the following:

- The position in segment $(\mathrm{CO}-\mathrm{C} 1)$ is completely different from the one described by Wackenheim and Lopez (1969). The position indicated by White and Panjabi (1978) also 
differs from the positions that we have calculated in ten persons. The position of the instantaneous centre of rotation corresponds most to the one used by Penning (1978). The position that we calculated seems more cranial and possibly more dorsal.

- The position in segment $(\mathrm{C} 1-\mathrm{C} 2)$ is within the area described by White and Panjabi (1978) for most of the persons examined. However, we have not found any positions in the ventral part of the projection of the dens axis. The area in which the instantaneous centre of rotation may be found is smaller in the persons examined by us. Penning (1978) indicates the instantaneous centre of rotation in the middle of the projection of the dens; we found this in a minority of the persons examined. In the majority the position is found in the dorsal half or immediately dorsal of the projection of the dens axis.

- The position in segment (C2-C3), contrary to what has been described by Penning (1964), can be both cranial and caudal in the dorsal part of the projection of the vertebral body. The tendency in the remaining segment matches the one described by Penning. We did not find a large area as described by Dimnet et al. (1982).

The fact that caudally in the vertebral spine a position of the segmental instantaneous centre of rotation is located more cranial than in the cranial segments, is - for that matter - a clue for the presence of a different relation between tilting and gliding in the region of the intervertebral disc in the cranial compared to the caudal part of the cervical spine. This may be related to a "steeper" position of the facets in the caudal segments than in the cranial segments. More gliding than tilting will take place in the cranial seg- ments; in the caudal segments this will be the other way around. This is further discussed in Chapter 6.

\section{Bibliography}

Dimuth, J., Pasquer, M.H., Krag M.H., Panjabi, M.M., Cervical spine motion in the sagittal plane: kintematic and geometric paranteters, J. Biomechanics, 15, no. 12 , 959-969, 1982.

Panjabi, M.M., Goel, V.K, Walter, S.D., Schick, S., Errors in the center and angle of motation of a joint: ant experimental study, J. Biom. Eng., 104, 232-237, 1982

Penning, L., Funktioneel röngenonderzoek bij degeneratieve en traumatische af wijkingen der laag-cenvicale be wegingssegmenten, Thesis, Univ of Groningen, The Netherlands, 1960.

Penning L., Nonpathologic and pathologic relationships between the lower cenvical vertebrae, Am. J. Rountgenol., $91,1036-1050,1964$.

Penting L., Normal movement in the cenical spine, Am. J. Roentgenol, 130, 317-326, 1978.

Pienning $L$, Differences in anatomy, motion development and aging of the tupper and lower cervical disk segments, Clin. Biomechanics, 3, 37-47, 1988.

Wackenheim, A., Lopez, F., Etude Radiographique des mouvements de $\mathrm{Cl}$ et de $\mathrm{C} 2$ lors de la flexion et de l'extension de la tête, Joumal belge de Radiologie, 52, 117 . $127,19.69$.

White, A.A., Panjabi, M.M., Clinical biomechanics of the cervical spine, J.P. Lippincalt Company, Philadetphia, Toronto, 1978 . 


\section{Chapter 6}

\section{Intrasegmental distortion of segments $(\mathrm{C} 2-\mathrm{C} 3)$ to $(\mathrm{C} 6-\mathrm{C} 7)$}

\subsection{Intraduction}

Motion within a segment of the cervical spine is partly determined by qualities of the intervertebral disc (e.g. shape, structure and consistency). Pathology within the intervertebral disc, such as (partial) laceration from the vertebral bodies or changes in the structure of the tissue of the disc and its surroundings, is considered a cause of deviating motion. This is why in diagnostics and evaluation of therapy, information is gathered about motion within the intervertebral disc. Distortion of the space between the projections within the sagittal plane of two consecutive vertebral bodies is a measure for such motion. This is referred to as intrasegmental distortion hereafter.

Motion of the cranial vertebral body in relation to the caudal vertebral body in this region has two components and their combination. These are:

1. Tilting.

2. Gliding.

3. Tilting and gliding.

\section{Titting.}

The width of the intervertebral fissure (the space visible on a laterolateral $X$-ray) within a segment on the ventral side diminishes during motion from the maximum retroflexion position of the cervical spine towards the maximum anteflexion position. This involves increased width of this fissure at the dorsal side. The opposite takes place in retroflexion of the cervical spine. Quantitative data are available on the difference in width at the ventral and dorsal side of the intervertebral fissure between a segment in anteflexion and retroflexion:

- Virchow (1928) has stated that the difference in width of this fissure at the wentral side ( 3 to $4 \mathrm{~mm}$ ) between the two positions mentioned in the segment is larger than the difference at the dorsal side $(1.5$ to $3 \mathrm{~mm})$. These differences are smallest in segment (C2-C3).

- Colachis and Strohm (1965) have determined the average sum of the differences in width for the fissures between the vertebral bodies of all segments in the cervical spine together, at the ventral side $(16.5 \mathrm{~mm})$ and the dorsal side $(9 \mathrm{~mm})$ respectively, between the maximum anteflexion position and the maximum retroflexion position of the cervical spine. The largest compression and decompression takes place in segment (C5-C6). - Fielding (1957) states that from the "neutral" position towards the maximum anteflexion position, the fissure between the projections of vertebral bodies changes from a rectangle into a trapezium. This never involves a regular narrowing of the space in ventrodorsal direction, provided the intervertebral disc is intact.

\section{Gliding.}

As to gliding the following data are available:

- Virchow (1928) observed that in an anteflexion position of the cervical spine the caudoventral vertex of the projection of a cranial vertebral body is ventral in relation to the cranioventral vertex of the projection of a caudal vertebral body. From this he concluded that during anteflexion a ventral giding of the cranial vertebra in relation to the caudal vertebra of a segment takes place at the intervertebral disc.

- Gombert (1957) mentioned that (a) cervical spines may be distinguished in which the cervical segments move evenly during anteflexion of the column, without development of a ladder-like arrangement of the vertebral bodies. In maximum anteflexion position, the cervical spine is evenly curved. Cervical spines may be distinguished (b) in which the 
segments contribute in a way resembling rooftiles to the motion. In these cervical spines there is more gliding in the intervertebral discs. In the maximum anteffexion position of the cervical spine the column is also evenly curved but there is a ladder-like arrangement of the vertebral bodies.

- Penning $(1960,1962,1964,1968,1978)$ described that this gliding motion leads to a ladder-like arrangement of the ventral sides of the vertebral bodies in maximum anteflexion position of the cervical spine. He classifies this phenomenon (anterolisthesis) as normal. In maximum retroflexion position there is a ladder-like arrangement of the dorsal sides of the vertebral bodies (retrolisthesis). According to Penning (1962), these phenomena only lead to complaints in those positions of the cervical spine, in which the vertebral spine has a dorsoventral cross section of less than $11 \mathrm{~mm}$. There are no values available for the anterolisthesis and retrolisthesis that could serve to make a distinction between what is normal and abnormal.

- Markuske (1971) stated that in children anterolisthesis or retrolisthesis can be more prominent in segments ( $\mathrm{C} 2-\mathrm{C} 3)$ and $(\mathrm{C} 3-\mathrm{C} 4)$ (values of more than $3 \mathrm{~mm}$ are found in $5.8 \%$ of the children examined). According to Penning (1964, 1978) and Markuske (1971), to name just a few, such findings can lead to the incorrect conclusion of (pseudo)luxation.

- Ross (1964) examined the occurrence of a ladder-like arrangement on the basis of $\mathrm{X}$ rays of 610 vertebral spines of persons without complaints. In $37 \%$ of these the phenomenon was determined in a maximum anteflexion position. In $80 \%$ of the cases it was found in a retroflexion position of the cervical spine. No correlation was found between occurrence of complaints and the presence of gliding in the intervertebral disc. - Gaizler (1971) - on the basis of a study by means of function pictures of 100 persons free of complaints (15-25 years old) - observed the ladder-like arrangement (which he called "Treppenphänomen") in $87 \%$ of the cases. It is assumed to be absent in the retroflexion position of the cervical spine. The phenomenon was also found in 50 children ( 2 days - 14 years old). Especially in the cranial part of the cervical spine it is more prominent. This "Treppenphänomen" occurs evenly in all segments. High prominence of anterolisthesis in a certain segment in the maximum anteflexion position of the cervical spine (and absence in the retroflexion position of the cervical spine) is considered an indication for pathology.

- Jones (1960) stated that gliding normally occurs more often in the midcervical segments than in the caudal cervical segments, while each gliding motion is considered as a sign of pathology by Aho et al. (1955).

- According to Hartman and Buonocore (1967), an increase of the gliding component indicates a pathologically changed intervertebral disc. It is not clear what should be considered an increase.

\section{Tilting and gliding.}

The combination of the two is described both as a sign of normal and abnormal functioning of the disc.

- Buonocore et al. (1966), as well as Hartman and Buonocore (1967), Penning (1960), Niemeyer and Penning (1963) and Brunton et al. (1982) considered the combination of simultaneous tilting and gliding in a segment as normal.

- Gaizler (1971) thought that tilting and gliding normally occur together too. If tilting was to occur by itself, this would result in the articular surfaces of the facets coming apart from each other in the anteflexion position of the segment.

- Jones (1961) concluded, in a cineradiographic study of 201 patients with complaints attributed to dysfunction of the cervical spine, that an early symptom of damage to the intervertebral disc consists of decreased widening or narrowing of the ventral and dorsal side of the disc fissure. A later symptom would be decreased gliding. Gliding would be more prominent at the end of the movement than tilting (Jones, 1960). This research states, however, that a clear distinction cannot be made between normal and abnormal widening and narrowing of the disc fissure.

- Brunton et al. (1982) mentioned a special 
type of movement which would indicate pathology in the segment. They call this the "single rock". This is a type of motion in which the gliding component is absent. The cranial vertebra tilts extremely over the caudal vertebra, causing a "pinch and gape" or "nutcracker movement".

In literature the motions tilting, gliding anterolisthesis, retrolisthesis and ladderlike arrangement are ambigiously defined. It appears that the terms are used synonymously. In this research gliding is defined as the displacement of the cranial vertebra parallel to the cranial endplate of the caudal vertebra. Tilting is the displacement perpendicular to gliding.

The above shows that it is not clear to what extent the data regarding the motion in the intervertebral disc allow a distinction to be made between normal and abnormal.

The following questions present themselves:

- Do the data about tilting and gliding, obtained with static $X$-rays, correspond to those calculated on the basis of $\mathrm{X}$-ray registration of actually performed motion?

- Which relation between tilting and gliding may be considered normal?

- Is this relation the same for each segmental level, or is the relation between gliding and tilting in the midcervical segments different from the relation in the caudal segments of the cervical spine?

- Can any segmental levels be indicated in the cervical spine in which tilting or gliding (ventral and dorsal) predominates?

- Does a larger gliding component in relation to a tilting component in segment (C2-C3) as is found in children - also occur in adults? - Is there a difference in the degree of anterolisthesis and retrolisthesis at the various segmental levels?

- Does gliding occur after tilting?

- Are there any differences in the distortion of the intervertebral disc during anteflexion or retroflexion of the cervical spine?

- Are there any differences which can be demonstrated in a given person at different moments of measurement (intraindividual variability)?

- Which are the differences between the persons themselves (interindividual variability)?

- Do types of movement, such as "single rock" or even narrowing of the disc fissure, which are known to be indications for pathology, occur in persons free of complaints?

In order to find an answer to the above questions, the degree of tilting and gliding in relation to rotation within the segment in the intervertebral disc was calculated in each segment and at each moment of measurement in the ten persons free of complaints. As a criterion for this movement within the intervertebral disc, this research used distortion of the quadrangle created by the marker points at the caudal side of the contour of the projection within the sagittal plane of the cranial vertebral body and the cranial marker points of the projection of the caudal vertebral body of a segment.

\subsection{Method}

Figure 6.1 gives the five marker points of a cranial vertebra (points 1a to 5a) and of a caudal vertebra (points $1 \mathrm{c}$ to $5 \mathrm{c}$ ). The five points $1 \mathrm{~b}$ to $5 \mathrm{~b}$ are the marker points of the cranial vertebra placed more in anteflexion in relation to the caudal vertebra. Points $2 a$ and $3 a$ and $2 b$ and $3 b$ of the cranial vertebra, and points $1 \mathrm{c}$ and $5 \mathrm{c}$ of the caudal vertebra mark the projection within the sagittal plane of the intervertebral disc in both positions of the segment. The difference between the quadrangle made up by points $2 a_{*} 3 a_{*}, 1 c$ and $5 c$ and the quadrangle made up by points $2 \mathrm{~b}, 3 \mathrm{~b}$, $1 \mathrm{c}$ and $5 \mathrm{c}$ represent distortion of the intervertebral disc. This distortion is expressed as the movement from point $2 \mathrm{a}$ (to $2 \mathrm{~b}$ ), represented by vector ( $\mathrm{vV}$ ) and from point $3 a($ to $3 b$ ) represented by vector (vD).

The number of images of the film of a motion was normalized to 50 (see chapter 2). Distortion ( $v V$ and $v D$ ) is calculated per film for each segment on each of the 49 images of an X-ray film following the first image, in relation to the position of these points on the first image. These vectors are resolwed into 


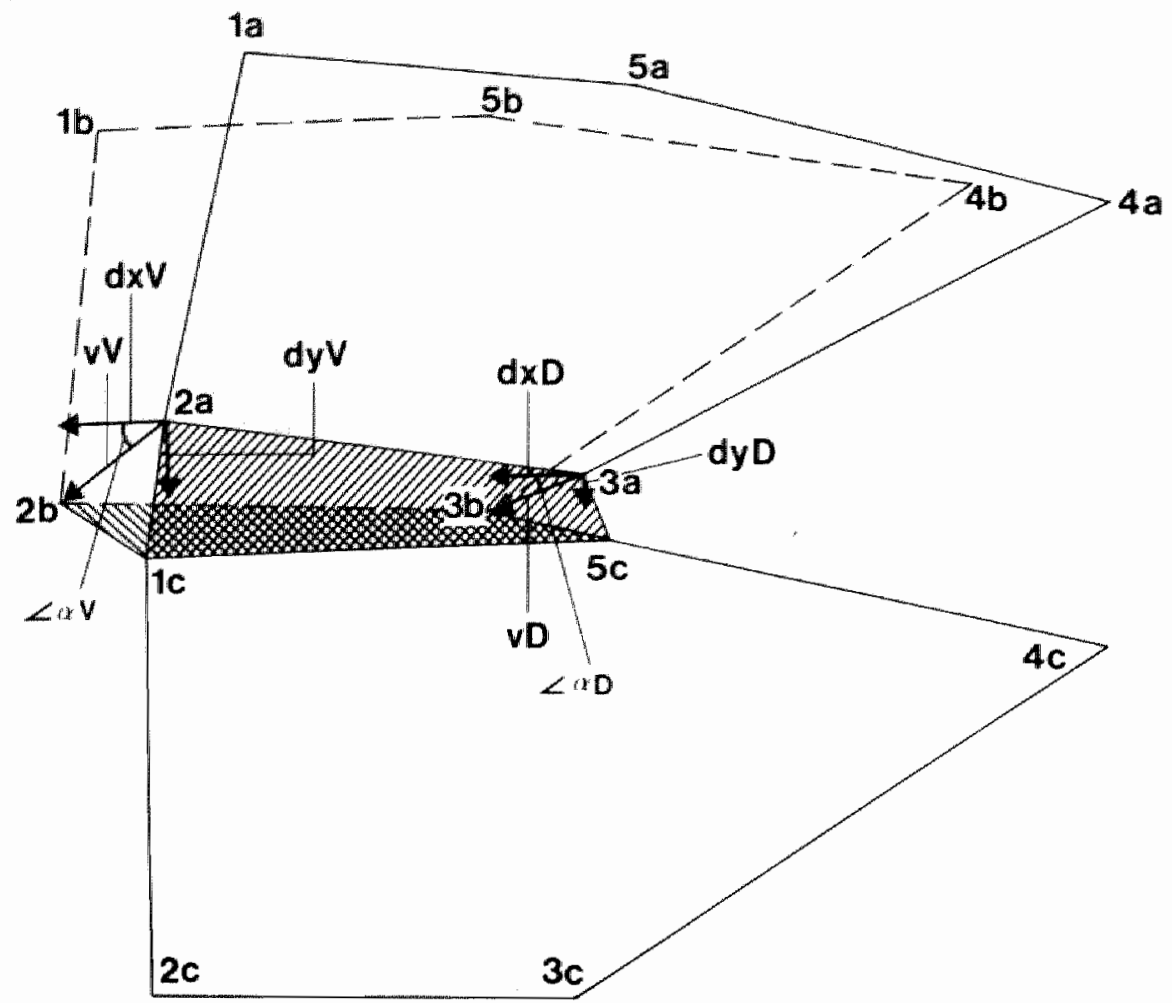

fig. 6.1 Distortion in the area of the intervertebral disc.

1a - Sa cranial vertebra before anteflexion.

$1 b$ - $5 b$ cranial vertebra after anteflexion.

Ic - $5 \mathrm{c}$ caudal vertebra.

two components, one (dx) in the direction of line $(1 c-5 c)$, the other (dy) perpendicular to it. Thus distortion consists of a gliding component within the segment, $(\mathrm{dxV})$ and $(\mathrm{dxD})$, and a tilting component (dyV) and (dyD).

The angle between ( $\mathrm{vV}$ ) and (dxV), and (vD) and (dxD), called alphaV and alphaD is a criterion for the relation between tilting and gliding of the cranial vertebra in relation to the caudal vertebra. If alphaV is more than 45 degrees - (dyV) is larger than $(\mathrm{dxV})$ - this is defined as more tilting than gliding; with smaller angles the reverse is the case.

In order to be able to read quantitative data on tilting and gliding in relation to the rotation within the segment, the movements of points $2 a$ (to $2 b$ ) and $3 a$ (to $3 b$ ), expressed as
$(\mathrm{dxV})$ and (dyV) for point 2a and (dxD) and (dyD) for point 3a, were calculated for each of the segments and at each moment of measurement in the ten persons examined. These four values have been plotted against absolute rotation (see chapter 2) in a segment on the ordinate in figure 6.2 . The values plotted in the five diagrams (C2-C3) to (C6C7) derive from the anteflexion registration (R3). During anteflexion point 3a moves towards the cranial direction, which is represented in the diagram by a curve (dyD) in positive $y$-direction. Point 2 a moves in caudal direction during anteflexion. The curve of (dyV) is therefore plotted in negative y-direction. During anteflexion both points move in a ventral direction. The curves of $(\mathrm{dxV})$ and $(d x D)$ have been plotted in negative $y$-di- 
rection. Movement in dorsal direction therefore produces a curve (dx) in a positive y-direction. Calculated on the basis of a retroflexion in the segment, the four curves have been plotted in negative $x$-direction; this was done in the opposite direction in an anteflexion film.

(dx) and (dy) of both points mentioned have been calculated for each image. If these $\mathbf{5 0}$ values are all plotted, the curve will show considerable noise. For this reason, onlly those values are plotted in the diagram, which have been calculated on the basis of images in which a certain minimum rotation took place between the image to be rendered and the previous image rendered. This minimum rotation, at which noise on the curves does not occur anymore, has been determined. In figure 6.2 , diagrams with a different minimum rotation threshold of $0,1,1.5$ and 2 degrees have been drawn of series R3P1. For example, in a threshold of 2.0 degrees the first value in a curve is the value calculated from image 2 , the next value is the value of the image at which the segment underwent 2.0 degrees rotation in relation to the previous position etc.

The maximum intrasegmental distortions (i.e. distortions between the extreme positions) are calculated with the values represented in the diagrams. Contrary to calculation of the position of the mean of the instantaneous centre of rotation the first and last images are included in this calculation of the maximum intrasegmental distortion. This is done because in this case the maximum distortion is calculated. In determining the position of an average instantaneous centre of rotation, a sufficient number of positions can be callculated from which this average can be determined. Only final values are used here. Figure 6.2 shows that in the diagram with a minimum rotation of 2 degrees, only those inaccuracies are absent from the curve that fall within the accuracy of the method, which are still present on the curves drawn with a lower threshold of minimum rotation. For this reason this threshold has been set at 2 degrees in the diagrams of all persons.

\subsection{Reproducibility}

The values of (dx) and (dy) of the segments on the film (R3), whose marking took place at five different moments (R3P1 to R3P5) hawe been calculated and rendered in diagrams of the same type as in figure 6.2. The final values of the curves in these diagrams, as well as the maximum value of segmental rotation (Rot along the abscissa) have been established and represented in table 6.1.

The units are neither metric values nor degrees but have been read from the diagrams. The conclusions as to distortion of the intervertebral discs are relative; for this reason we refrained from converting the values into metric values.

The largest difference in (Rot) is 4 units, read as the dispersion in (C4-C5). The major dispersion of a value for $(\mathrm{dx})$ or $(\mathrm{dy})$ is found amongst the values of segments (C4-C5), $(\mathrm{C} 5-\mathrm{C} 6)$ and $(\mathrm{C6}-\mathrm{C} 7)$ : 4 units as well.

\subsection{Results}

Figure 6.3 gives, as an example, the positions of points $2 \mathrm{~b}$ and $3 \mathrm{~b}$ of the cranial vertebra in relation to points $1 \mathrm{c}$ and $5 \mathrm{c}$ of the caudal vertebra of segments (C2-C3) to (C6-C7) of the anteflexion registrations of persons $\mathrm{L}, \mathrm{N}$ and $O$. This figure shows the qualitative distortion of the intervertebral disc during motion.

The following can be observed:

- Both at the dorsal side and at the ventral side of the disc, there is a combination of tilting and gliding.

- To what extent this takes place differs for the ventral and the dorsal side.

- The relation between tilting and gliding seems different at the ventral and dorsal side. - Tilting and gliding does not seem to occur to the same extent and to the same degree in the various segments.

Values (dxV), (dxD), (dyV) and (dyD) have been plotted against the absolute segmental rotation on each of the measuring moments with a threshold of minimum rotation of 2 de- 


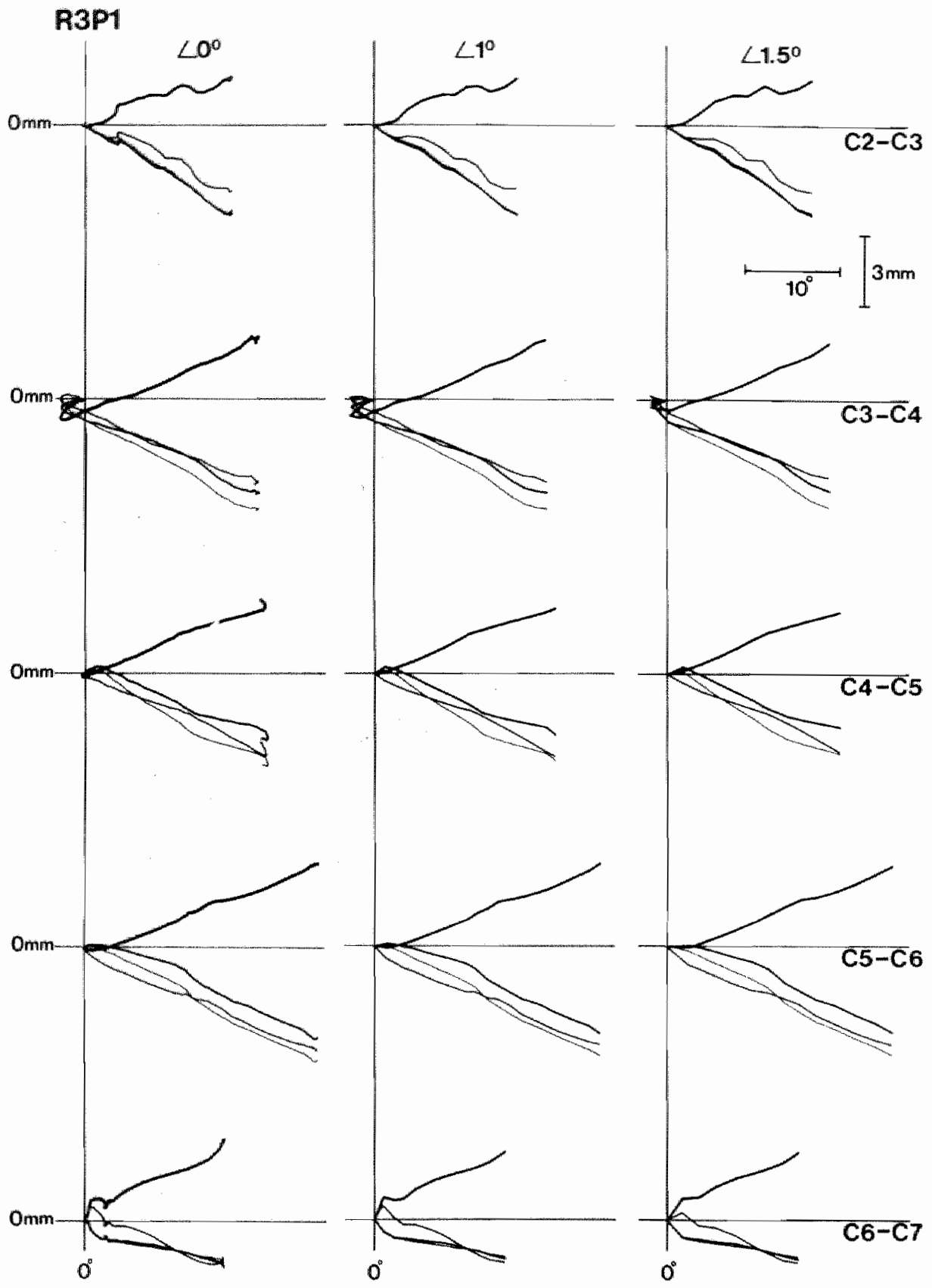

68 


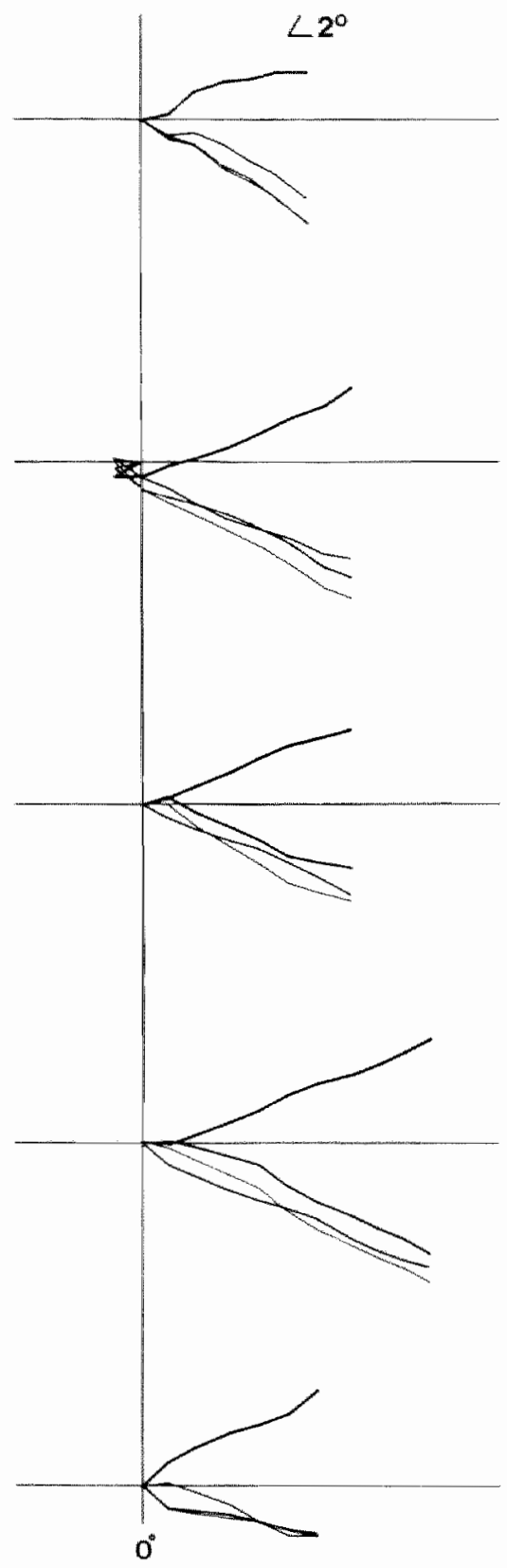

nig. 6.2 Increase of both components of gliding ( $\mathrm{dxV}$ and $\mathrm{dxD}$ ) and tilting (dyV and dyD) during motion in the segments ( $\left.\mathrm{C}_{2}-\mathrm{C} 3\right)$ to ( $\left.\mathrm{C} 6 \mathrm{C} 7\right)$ plotted against the absolute rotation in the segments calculated from the data of film R3. The 4 vertical columns represent data with a minimal rotation of $0^{\circ}, 1^{\circ}, 1.5^{\circ}$ and $2^{\circ}$.

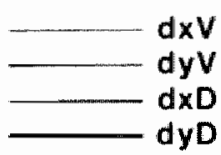


L1
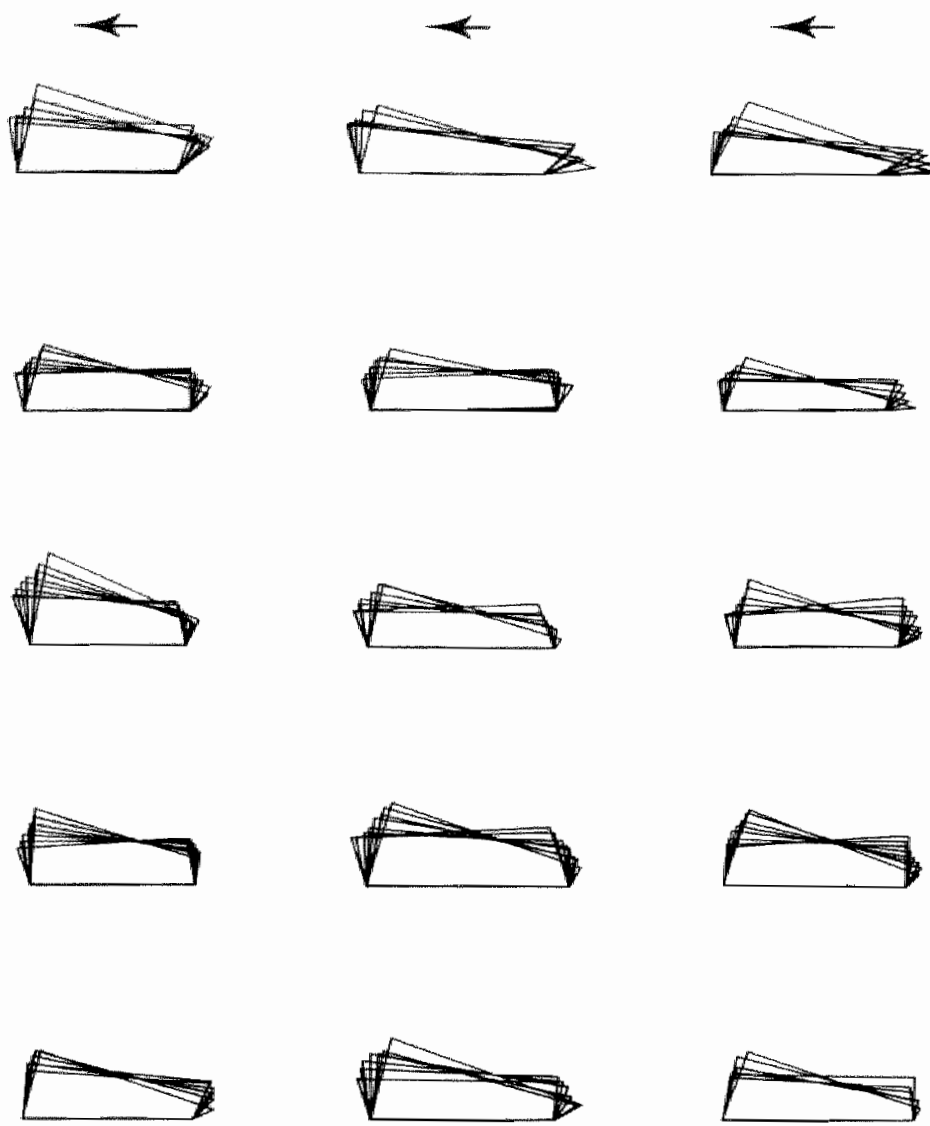

$\mathrm{C} 4-\mathrm{C} 5$

$\mathrm{C} 3-\mathrm{C} 4$

$\mathrm{C} 5-\mathrm{C} 6$

$\mathrm{C} 2-\mathrm{C} 3$

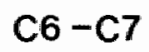

fig. 6.3 Distortion of the intervertebral discs in the segments (C2-C3) to (C6-C7). The shape of first, last and a number of intermediate quadrangles of the discs of each segment is presented of the recorded anteflexion $\mathrm{LJ}$, N1 and 01 .

grees for all persons examined (see figure 6.2). As an example, the diagrams $(\mathrm{C} 2-\mathrm{C} 3)$ to (C6-C7) of the three anteflexion (M1, M3 and M5) and the three retroflexion movements of the cervical spine (M2, M4 and M6) of person $M$ have been plotted in figure 6.4. These diagrams show, among other things, that:

- For each of the segments the relation between each of the four values and the rotation within the segment is almost linear.

- For each moment of measurement in all segments, it was found that movement of point 2 is in caudoventral direction during anteflexion. The reverse takes place during retroflexion of the cervical spine. Curve (dyD) of segment (C2-C3) of M1 and of (C6C7) of M1, M3, are below the abscissa, but considering the range of measurement error (table 6.1) this is not different from 0. - The relations between the angles of the curves of the four values with the abscissa are different in each segment. This means that the relation between tilting and gliding is different for the segments. E.g. in segment (CSC6) the angle between the abscissa and the 
table 6.1

\begin{tabular}{|c|c|c|c|c|c|c|c|}
\hline segment & & R3P1 & $\mathrm{R} 3 \mathrm{P} 2$ & R3P 3 & R3P4 & R3P 5 & range \\
\hline$(\mathrm{C} 2-\mathrm{C} 3)$ & $\begin{array}{l}\text { (dXV) } \\
(d Y V) \\
(d X D) \\
(d Y D) \\
(\mathbb{R O t})\end{array}$ & $\begin{array}{r}9 \\
12 \\
12 \\
5 \\
18\end{array}$ & $\begin{array}{r}12 \\
12 \\
13 \\
4 \\
20\end{array}$ & $\begin{array}{r}9 \\
11 \\
11 \\
4 \\
18\end{array}$ & $\begin{array}{r}10 \\
12 \\
12 \\
6 \\
20\end{array}$ & $\begin{array}{r}10 \\
10 \\
10 \\
6 \\
19\end{array}$ & $\begin{array}{r}9-12 \\
10-12 \\
10-13 \\
4-6 \\
18-20\end{array}$ \\
\hline$(C 3-C 4)$ & $\begin{array}{l}(\mathrm{dXV}) \\
(\mathrm{dYV}) \\
(\mathrm{dXD}) \\
(\mathrm{dYD}) \\
\text { (Rot) }\end{array}$ & $\begin{array}{r}14 \\
10 \\
12 \\
8 \\
23\end{array}$ & $\begin{array}{r}13 \\
9 \\
10 \\
10 \\
25\end{array}$ & $\begin{array}{l}13 \\
10 \\
10 \\
10 \\
24\end{array}$ & $\begin{array}{r}14 \\
9 \\
11 \\
9 \\
25\end{array}$ & $\begin{array}{r}14 \\
9 \\
11 \\
10 \\
24\end{array}$ & $\begin{array}{r}13-14 \\
9-10 \\
10-12 \\
8-10 \\
23-25\end{array}$ \\
\hline$(C 4-C 5)$ & $\begin{array}{l}(\mathrm{dXV}) \\
(\mathrm{dYV}) \\
(\mathrm{dXD}) \\
(\mathrm{dYD}) \\
(\mathrm{ROt})\end{array}$ & $\begin{array}{r}11 \\
10 \\
7 \\
9 \\
22\end{array}$ & $\begin{array}{r}14 \\
9 \\
10 \\
10 \\
24\end{array}$ & $\begin{array}{l}13 \\
10 \\
10 \\
10 \\
24\end{array}$ & $\begin{array}{r}12 \\
8 \\
10 \\
10 \\
22\end{array}$ & $\begin{array}{r}13 \\
12 \\
10 \\
9 \\
26\end{array}$ & $\begin{array}{r}11-14 \\
8-12 \\
7-10 \\
9-10 \\
22-26\end{array}$ \\
\hline$(c 5-c 6)$ & $\begin{array}{l}(\mathrm{dXV}) \\
(\mathrm{dYV}) \\
(\mathrm{dXD}) \\
(\mathrm{dYD}) \\
\text { (Rot) }\end{array}$ & $\begin{array}{l}15 \\
14 \\
12 \\
12 \\
31\end{array}$ & $\begin{array}{l}16 \\
13 \\
13 \\
10 \\
29\end{array}$ & $\begin{array}{l}16 \\
10 \\
12 \\
12 \\
29\end{array}$ & $\begin{array}{l}14 \\
12 \\
12 \\
10 \\
28\end{array}$ & $\begin{array}{l}15 \\
10 \\
12 \\
14 \\
28\end{array}$ & $\begin{array}{l}14-16 \\
10-14 \\
12-13 \\
10-14 \\
28-31\end{array}$ \\
\hline$(C 6-C 7)$ & $\begin{array}{l}\text { (dXV) } \\
\text { (dYV) } \\
\text { (dXD) } \\
\text { (dYD) } \\
\text { (Rot) }\end{array}$ & $\begin{array}{r}5 \\
5 \\
5 \\
11 \\
19\end{array}$ & $\begin{array}{r}5 \\
9 \\
5 \\
9 \\
19\end{array}$ & $\begin{array}{r}5 \\
8 \\
6 \\
10 \\
20\end{array}$ & $\begin{array}{r}6 \\
6 \\
6 \\
11 \\
21\end{array}$ & $\begin{array}{r}5 \\
9 \\
5 \\
7 \\
18\end{array}$ & $\begin{array}{r}5-6 \\
5-9 \\
5-6 \\
7-11 \\
18-21\end{array}$ \\
\hline
\end{tabular}

table 6.2

\begin{tabular}{|c|c|c|c|c|c|}
\hline & $(\mathrm{C} 2-\mathrm{C} 3)$ & $(C 3-C 4)$ & $(C 4-C 5)$ & $(C 5-C 6)$ & $(\mathrm{C} 6-\mathrm{C} 7)$ \\
\hline VV: & $\begin{array}{c}12.0-17.9 \\
(5.9)\end{array}$ & $\begin{array}{c}12.1-21.0 \\
(8.9)\end{array}$ & $\begin{array}{c}13.0-23.4 \\
(10.4)\end{array}$ & $\begin{array}{c}14.6-25.2 \\
(10.6)\end{array}$ & $\begin{array}{c}10.5-20.3 \\
(9.8)\end{array}$ \\
\hline$\vee D:$ & $\begin{array}{c}9.3-14.7 \\
(5.4)\end{array}$ & $\begin{array}{c}12.2-17.6 \\
(5.4)\end{array}$ & $\begin{array}{c}11 \cdot 3-17.9 \\
(6.6)\end{array}$ & $\begin{array}{c}13 \cdot 0-17 \cdot 3 \\
(4 \cdot 3)\end{array}$ & $\begin{array}{c}9.5-15 \cdot 8 \\
(6.3)\end{array}$ \\
\hline
\end{tabular}

curve of (dxV) in M1 to M6 is smaller than the angle between the abscissa and the curve of (dy V). This means that in this disc more tilting than gliding took place. In segment (C4-C5) this is the other way round in M1; in the remaining registrations of this segment, both angles are almost identical. When averaged over all registrations a little more glid- ing than tilting takes place in this segment. This has been expressed more clearly in figure 6.6 in the shape of the size of angle alphaV (determined as a mean maximum calculated on the basis of registrations in which maximum rotation in this segment took place) (for both these segments approximately 40 or 60 degrees). 
- The curves of $(d x V)$ and $(d x D)$ in segment (C6-C7) do not differ significantly from 0 in $\mathrm{M} 2$ and M6. This means that in this disc only tilting took place ("single rock"). This phenomenon also occurs in registrations of person 0 .

Since the relation between rotation in the segment and $(d x)$ and $(d y)$ is practically linear, the values at the end of the curves may be used as a measure for the maximum possible distortion at the ventral or dorsal side of an intervertebral disc. Maximum distortion of an intervertebral disc was calculated for each segment in all persons examined. To arrive at these, the values of a given segment on all films were used. Only where it was clear that on a certain film a segment had not gone through its maximum range of motion (see chapter 4), the values on this film were not used in the calculation. This means that calculation of the maximum values of (dx) and (dy) only involved those diagrams which show the highest value of the rotation marked out on the $x$-axis and those diagrams whose maximum rotation within the segment is not more than 4 units below the maximum. We assume that the method followed does not allow a distinction to be made between the maximum values in the diagrams used. These values are all considered to be the maximum ones. The mean of these maximum values is considered the maximum of a given $(d x)$ and (dy).

The mean was determined of the final values of (dx) and (dy) obtained from the diagrams selected as described above, for each segment of each person examined ( $L$ to $U$ ). The number of values involved in the calculation of the mean varied from 3 to 6 .

With these mean values of (dx) and (dy) the following was calculated:
- The size of the movement of each of points 2 and $3, v V$ or $v D$, between both extreme positions of the segment.

- Angles alpha $V$ and alphaD.

The lowest and highest maximum values of $w V$ or $v D$ found in the group of persons examined ( $\mathrm{L}$ to $\mathrm{U}$ ) have been given in table 6.2 .

Table 6.2 shows that there is considerable interindividual dispersion as to the size of the movement on the ventral side ( $\mathrm{VV}$ ) and on the dorsal side (vD) of the intervertebral disc in the group examined. This dispersion is larger on the ventral side than on the dorsal side of the disc. The large dispersion is present in (vV) in segments (C3-C4), (C4-C5), (C5-C6) and ( $\mathrm{C} 6-\mathrm{C} 7)$ in particular. The other dispersions are not much larger than the inaccuracy of measurement (4 units).

The maximum values ( $\mathrm{VV}$ ) or (vD) of segments $(\mathrm{C} 2-\mathrm{C} 3)$ to $(\mathrm{C} 6-\mathrm{C} 7)$ that were found have been plotted for each person in figure 6.5 .

This diagram shows that:

- In all persons the values of segment (C2C3) are smaller or identical to those of (C3C4).

- In eight persons (excluding persons $R$ and S) the values of $(\mathrm{vV})$ of $(\mathrm{C} 3-\mathrm{C} 4)$ are smaller or identical to those of (C4-C5). For seven persons (excluding persons $\mathrm{L}, \mathrm{R}$ and $\mathrm{U}$ ) this also applies to the values of (vD).

- In eight persons (excluding persons $\mathrm{N}$ and $\mathrm{O}$ ) the values of ( $\mathrm{VW}$ ) of (C4-C5) are smaller or identical to those of segment (C5-C6). This applies for eight persons (excluding persons $\mathrm{M}$ and $\mathrm{O}$ ) to the values of (vD).

- In all persons examined the values found in segment (C6-C7), both for (vV) and (vD), are smaller than those in segment (C5-C6) or identical to them.

7ig. 6.4 Distortion of the intervertebral discs during three anteflexion and three retroflexiom movements of the cervical spine of test person $\mathrm{M}\left(\mathrm{ML}, \mathrm{M} 3\right.$ and $\mathrm{MS}_{\text {, }}$ respectively $\mathrm{M2}$, M4 and M6).

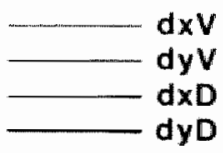




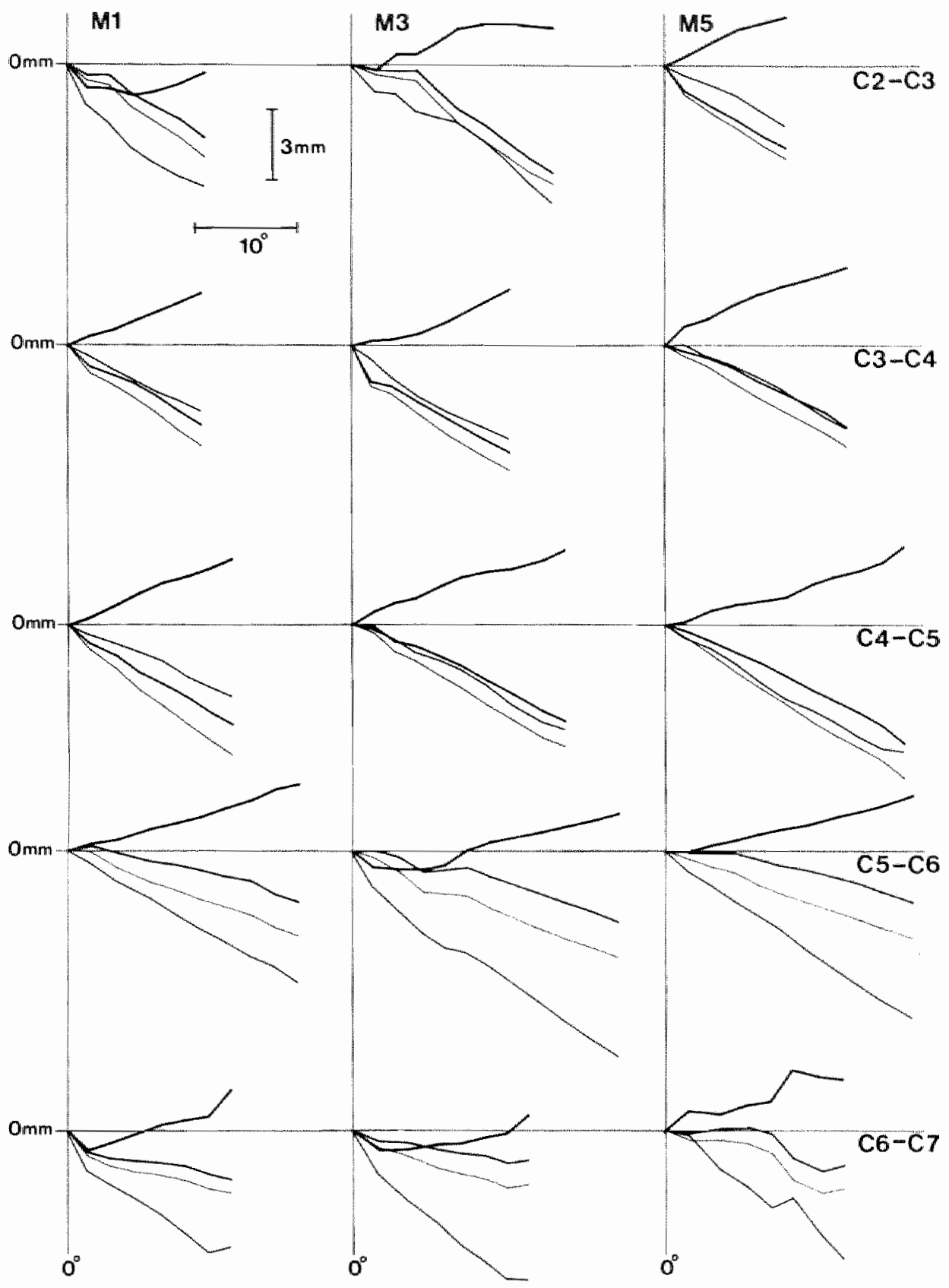




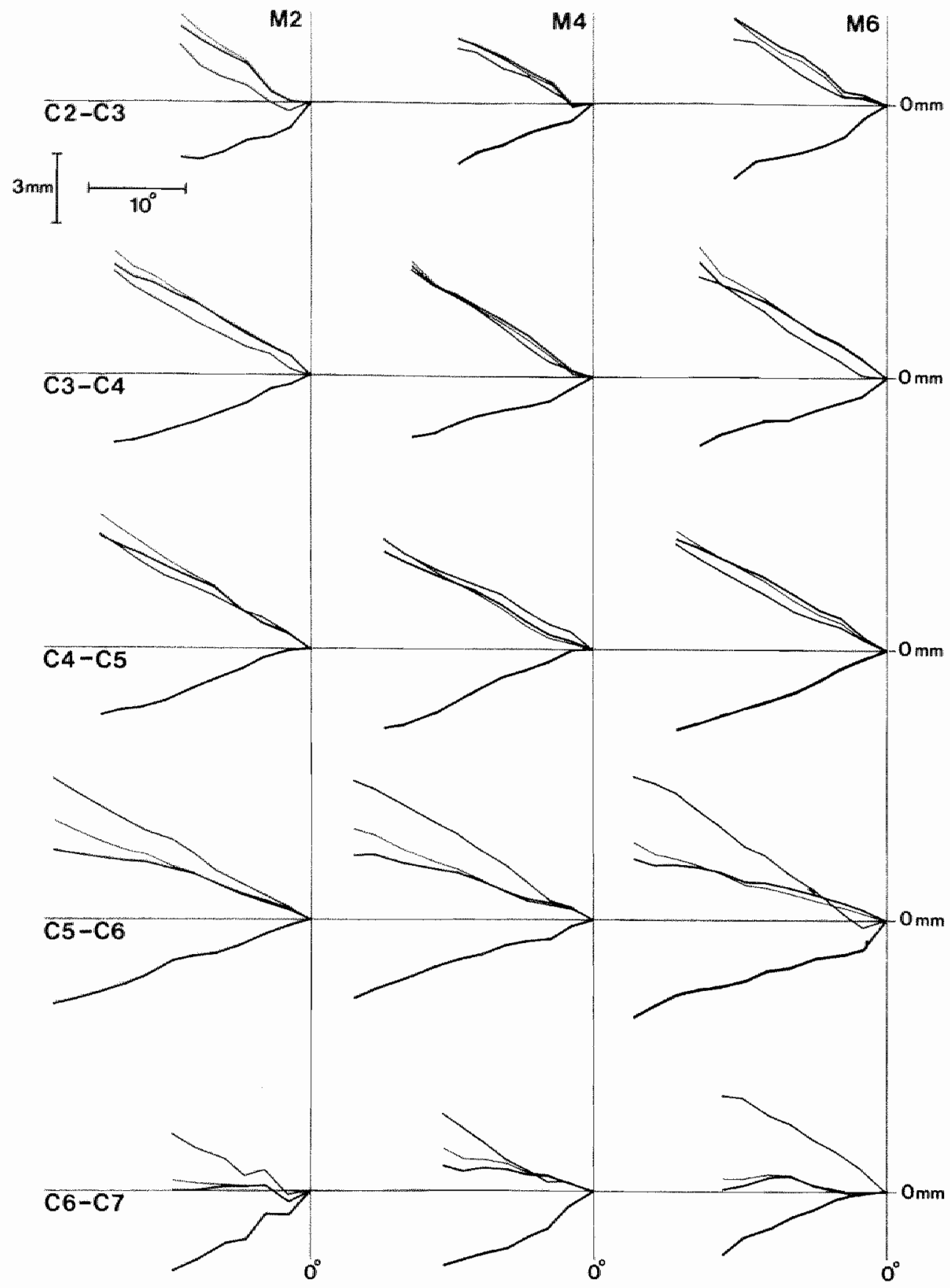


- Table 6.3 shows by means of an asterisk $\left({ }^{*}\right)$ in which person and in which segment the value of $(v V)$ is larger than the one of $(v D)$, and if this value is identical by means of an equal $\operatorname{sign}(=)$.

From table 6.3 we may conclude that especially in segments (C2-C3) and (C5-C6) larger ventral than dorsal movement in the disc may be expected. We have not found values for $(\mathrm{vV})$ that were lower than those for (vD).

- In four persons ( $L, N, O$ and $P$ ) there is a "broad top" in the curves of ( $\mathrm{vV}$ ) in segments (C4-C5) and (C5-C6), i.e. both are identical and maximum values; in persons $(\mathrm{M}, \mathrm{Q}, \mathrm{T}$ and $U$ ) the value of (vV) of segment (C5-C6) is highest as a single top. In two persons ( $R$ and S) the values of segments (C3-C4), (C4$\mathrm{C5}$ ) and (C5-C6) are more or less identical and larger than those of the other two seg. ments.

In one person (S) all values of the segments are practically identical.

Figure 6.5 does not show whether the maximum movements found entail tilting or gliding. For this reason the angle between the movement vectors $(\mathrm{vV})$ or $(\mathrm{vD})$ and the direction of $(\mathrm{dx})$, alphaV or alphaD, have been calculated. The angles alphaV and alphaD have been plotted per person in figure 6.6 for segments (C2-C3) to (C6-C7).

These diagrams show that:
- In all persons examined both angle alphaV and angle alphaD in segment $(\mathrm{C} 2-\mathrm{C} 3)$ are smaller than the ones in segments (C5-C6) and (C6-C7). In seven persons $(\mathrm{N}, \mathrm{O}, \mathrm{P}, \mathrm{Q}$, $R, S$ and $U$ ) these angles in segment ( $C 2-C 3)$ are smaller than the ones in segment $(\mathrm{C} 4$ $C 5)$; for four persons $(\mathrm{O}, \mathrm{P}, \mathrm{S}$ and $\mathrm{U})$ they are both smaller in segment $(\mathrm{C} 2-\mathrm{C} 3)$ than in segment (C3-C4).

- In all persons examined angle alphaV is more than 45 degrees in segments ( $\mathrm{C} 5$ - $\mathrm{C} 6)$ and (C6-C7).

- In all persons examined angle alphaV in segment (C2-C3) is less than 45 degrees.

- Angle alphaV may be larger than angle alphaD, but the opposite is equally possible.

\subsection{Discussion}

The method followed allows quantification of the intrasegmental distortion. It has been demonstrated that the relation between the motion at the ventral side and at the dorsal side in the segment and the rotation within the sagittal plane is linear (figure 6.4). Occasionally it may occur that in segment (C6-C7) no gliding takes place and a type of motion known as "single rock" takes place; this was not found in the other segments. This phenomenon was found in submaximum motion within the segment. Such a submaximum motion may normally occur within the maximum path from anteflexion towards retroflexion (or vice versa) of the entire cervical spine (chapter 4). A single occurrence of "single

table 6.3

\begin{tabular}{|c|c|c|c|c|c|c|c|c|c|c|c|}
\hline segm pers. & L & $\mathbf{M}$ & $\mathbf{N}$ & 0 & $\mathbf{P}$ & $Q$ & $\mathrm{R}$ & s & $\mathbf{T}$ & U & \\
\hline$(c 2-c 3)$ & * & * & * & * & * & * & * & * & * & $=$ & $9 x$ \\
\hline$(\mathrm{C} 3-\mathrm{C} 4)$ & $=$ & * & * & $=$ & * & * & * & * & * & $=$ & $7 x$ \\
\hline$(\mathrm{C} 4-\mathrm{C} 5)$ & * & * & * & * & * & * & * & $=$ & $=$ & * & $8 x$ \\
\hline$(\mathrm{C} 5-\mathrm{C} 6)$ & * & * & * & * & * & * & $=$ & * & * & * & $9 x$ \\
\hline \multirow[t]{2}{*}{$(C 6-C 7)$} & * & * & $=$ & * & * & $=$ & $=$ & $=$ & * & $\star$ & $6 x$ \\
\hline & $4 x$ & $5 x$ & $4 x$ & $3 x$ & $5 x$ & $4 x$ & $3 x$ & $3 x$ & $4 x$ & $3 x$ & \\
\hline
\end{tabular}


rock" need therefore not be linked to the presence of a pathology.

The method followed does not allow any statements to be made about the presence of anterolisthesis and retrolisthesis. The values calculated represent differences in the shape of the quadrangle, consisting of vertexes 2,3 , 1 and 5 in the extreme positions reached. This does not explain the shape of the intervertebral dises in those positions of the cervical spine.

There are two reasons for this:

- The contour of the vertebral body does not have to be identical on all images. An oblique position of a vertebra during registration may already produce other values for anterolisthesis or retrolisthesis.

- The relation between the vertexes of the quadrangle and the contours of both vertebral projections in the segment is not always exactly the same.

The method followed does not allow any statements to be made about the differences between distortion of the intervertebral discs during anteflexion and retroflexion of the cervical spine. Any possible differences fall within the range of measurement error of the method.

We may conclude from the diagrams in which the maximum movements at the ventral side or the dorsal side of an quadrangle have been indicated (figure 6.5 ) that:

- The largest maximum movements at the ventral side of the disc $(V)$ are found either only in segment (C5-C6), or in segment (C4$\mathrm{C5}$ ) and segment (C5-C6) together; the smaller movements in segments (C2-C3) and (C6-

$\mathrm{C7}$ ) and the maximum values of segment (C3-C4) are between those of the neighbouring segments.

- In most persons, movement is larger at the ventral side of the intervertebral disc than at the dorsal side. Where this is not so, it is in any case not smaller (table 6.3).

- The absolute values of the movements show strong interindividual differences (table 6.2), in which the dispersion at the ventral side is larger than at the dorsal side.

Given the fact that angle alpha $V$ is a measure for the relation between tilting and gliding, the following generally applies:

In segment $(\mathrm{C} 2-\mathrm{C} 3)$ the degree of gliding between the intervertebral bodies is larger than the degree of tilting. The reverse is true in segments (C5-C6) and (C6-C7). These findings confirm the conclusions reached by Penning (1988).

Between the consecutive segments no larger differences in angle alpha $V$ were found than:

Between (C2-C3) and (C3-C4): maximum approximately 10 degrees.

Between (C3-C4) and (C4-C5): maximum approximately 15 degrees.

Between (C4-C5) and (C5-C6): maximum approximately 20 degrees.

Between (C5-C6) and (C6-C7): maximum approximately 20 degrees.

If larger differences were found in angle alpha in a cervical spine this would confirm views about increased gliding over tilting (Markuske et al., 1971). This could be the case if within a segment a disc is not intact (Hohl and Brummett, 1968).

The maximum displacements show large dispersion. The chance that a displacement is found which is not within the dispersion mentioned seems very small. For this reason maximum displacement does not seem to be a good parameter for diagnostics. In a given cervical spine, however, the larger displacements are to be found in segments (C4-C5) or (C5-C6) and the smaller ones in (C2-C3) and (C6-C7).

Earlier questions may now be answered as follows. X-ray cinematographic research confirms the findings on the basis of function pictures obtained of the relation of the disc distortion at the ventral side in relation to the dorsal side. There is strong interindividual variability in the degree of displacement: this is most explicit at the ventral side of the disc. Tilting and gliding occur simultaneously and 

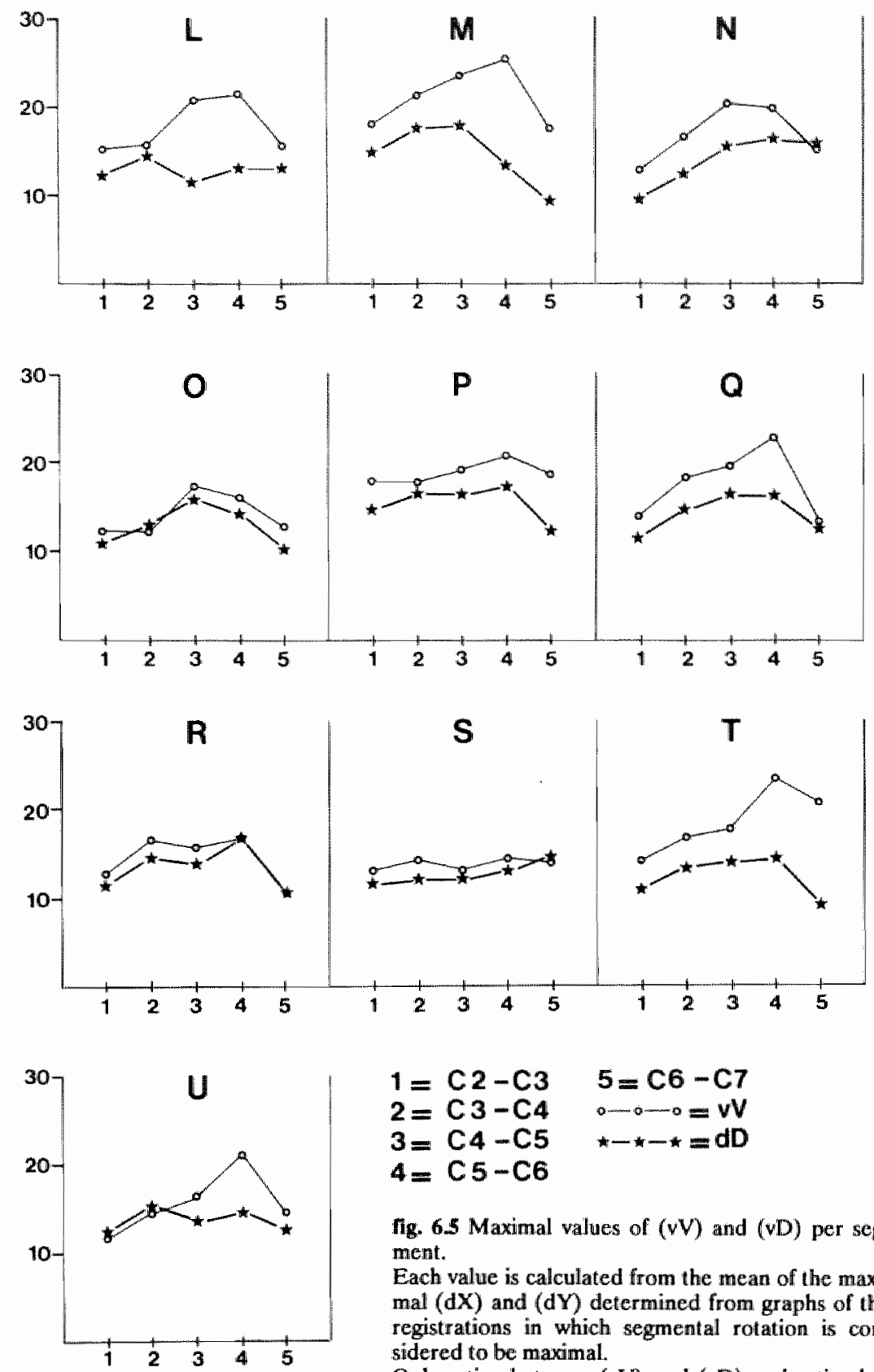

$$
\begin{array}{ll}
1=C 2-C 3 & 5=C 6-C 7 \\
2=C 3-C 4 & \cdots-D=V V \\
3=C 4-C 5 & \star-\star-\star=d D \\
4=C 5-C 6 &
\end{array}
$$

nig. 6.5 Maximal values of (vV) and (vD) per segment.

Each value is calculated from the mean of the maximal $(\mathrm{dX})$ and ( $\mathrm{dY}$ ) determined from graphs of the registrations in which segrnental rotation is considered to be maximal.

Only ratios between (vV) and (vD) and ratios between segments can be studied. 

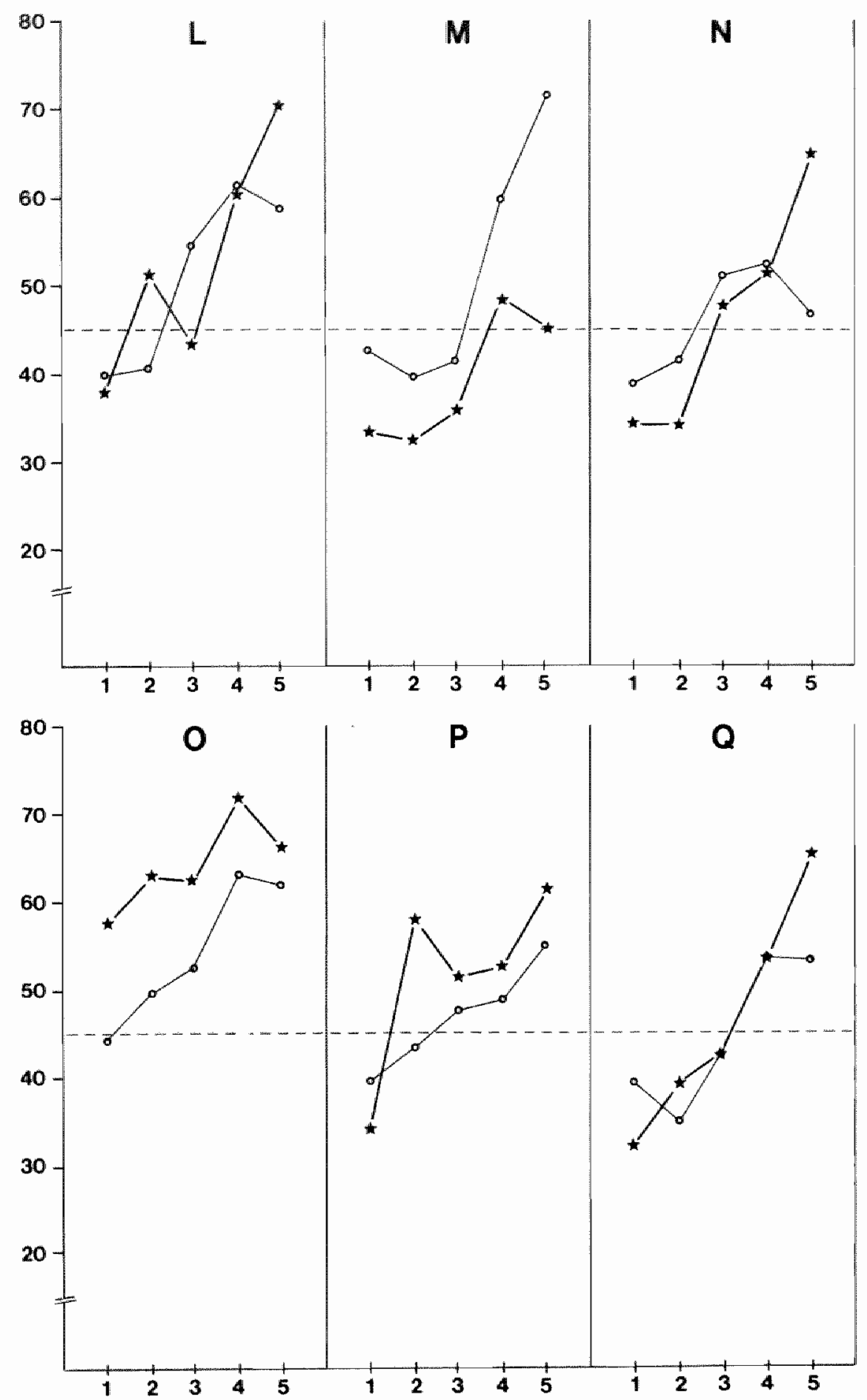

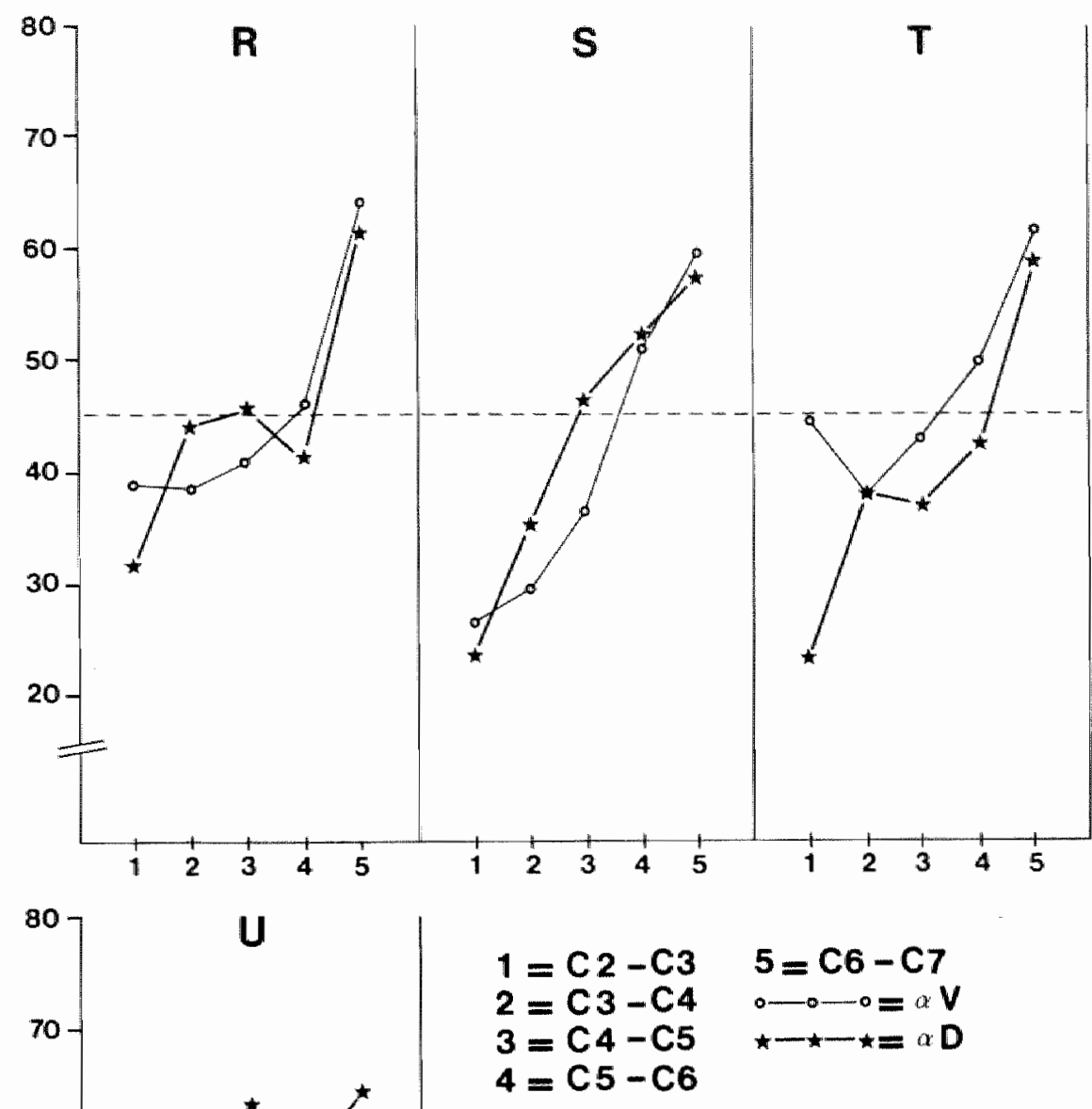

fig. 6.6 The ratios between tilting and gliding per segment. 
in the same relation during rotation within the segment. The relation between tilting and gliding depends on the segmental level. At the high-cervical level, gliding is more prominent, at the low-cervical level tilting is. "Single rock" need not be accompanied by pathological changes.

\section{Bibliography}

Aho, A, Vartianen, 0 , Salo, O., Segmentary anteroposterior mobilify of he cervical spine, Ann. Med. Intern. frenth. 44, 287-299, 1955.

Brinton, FJ, Wilkinson, J.An, Wise, KS.H., Simwnons, R.B. Cineradiography in cenicalspondylosis as a means of detemining the level for anteriofusion, Is Bone Jt. Sung. 64B, 390.404, 1982.

Buonocore, E., Harman, L.T., Netson, C.L., Cinteradilograms of centical spine in diagnosis of soft tissue injwites, JAMA, 198, 2\$-29, 1966.

Colachis, S.C. jr., Strohm, B.R., Radiographic situdies of cervical spine molion in nomal subjects: frexion and hyperextension, Arch. Phys. Med. Rehabil., 46, 753-760, 1965.

Fielding $J . W$. Cineradiography of the nomal cervical spine. New York State J. Med., S6, 2984-2986, 1956.

Fielding, J.W., Cineroentgenagraphy of the nomal cervical spine, J. Bone and Jt. Surg., 39A, 1280 1288, 1957.

Gaizler, G, Das Treppemphànomen an der Halswirbelsüule, Rófo, 114, 3, 317-322, 1971.

Gombent, H.J., Funktionsdiagnostik der Halswinbelsäule mit der Bildwandler, Radiol. Austr, 9, 217-226, 1957.

Hartman, $T$. Buonocom, $E_{\text {a, }}$ Soft tissue injury of cenim cal spine as demonstrated on cenvical cineradiogrophy. I. Bone It. Sugh, 49,4, 1021, 1967.

Hoh, M, Brummett, S. H, Cinefhorography in the diagmovis of diseasec or damaged cervical vertebral disc, $\int$. Bono It. Surg, $504,1060,1908$.
Jones, M.D, Cineradiographic sudies of the nomal cer Wical spine, Calif. Med, 93, 5, 293-296, 1960.

Lones, Cincradiographic studies of the degenerative dis. ease of the cenical spine, J. Cam. Ass. Rodwow, 12,52.55, 1961 .

Markaske, Untersuchungen aur Statik und Dymannik der kindlichen Halswitbelsalute: Der Aussagewen seithcher Röngenaufnahmen, Die Wibelsäule in Forschung und Praxis, 50, 1971.

Niemeyer, $T_{\text {, }}$ Penning $L$. Functional roengenographic examination in a case of cenvical spondylohisthesit, $J$. Bone Ji. Sang., 45A, 1671-1678,1963.

Penning L., Funktioneel röntgenonderzoek bij degener. atieve en trawmatische of wijkingen der lagg-cenvicale bewegingssegmenten, Thesis, Uniw. of Groningen, The Netherlands, 1960.

Penning, L., Some aspects of plain radiography of the cervical spine in chronic myelopathy. Neurol, 12, 513. 579,1062 .

Penning $L$, Nonpathologic and pathologic relationships between the lower cerwical wertebrae, Am. J. Roentgenol, $91,1036-1050,1964$.

Penning, L, Functional pathology of the cervical spine. part I, Excerpta medica foundation, Ansterdam-New York-London-Paris-Milan-Tokyo-Bwenas Aires, 1968

Penung, L., Normal movement in the cervical spine, Am. J. Roentgenol. 130,317-326, 1978.

Penming, L "Differences in anatomy, motion, development and aging of the upper and lower cenvical disk segments., Clin. Biomechanics, 3, 37-47, 1988.

Ross, E., Die Variantem des Verschiebusugshänonens an der Hals- und Lendenwiblsdule, Fortschr Röntgenstr., $100,242-2531964$.

Virchow, $H_{\text {, }}$ Die sagitial ferorische Bewegung der menslichen Haiswinbelsdule, Arch. Orthop. Unfall Chir., 26, $1-41,1928$. 


\section{Chapter 7}

\section{Sequences of motion in the sagittal plane in block $(\mathrm{CO}-\mathrm{C} 2)$}

\subsection{Introduction}

A striking feature in research of the anteflexion and retroflexion of the cervical spine during $X$-ray examination is the fact that the segments in block ( $\mathrm{CO}-\mathrm{C} 2)$ do not contribute constantly to motion of the cervical spine. Accelerations and decelerations may be abserved in these segments, which appear to occur in a certain order (van Mameren, 1986, 1988). It also appears that during anteflexion and retroflexion of the entire cervical spine and the head, the segments ( $\mathrm{CO}-\mathrm{C} 1)$ and $(\mathrm{Cl}$ C2) may move temporarily opposite to the direction of movement of the entire cervical spine and the head. Hitherto, this last phenomenon has only been described on the basis of function pictures, i.e. determined from two static positions. In a middle position, segment $(\mathrm{CO}-\mathrm{C} 1)$ is more in anteflexion than in the "bending" anteflexion position of the cervical spine (Lewit and Krausovà, 1963; Arlen, 1977, 1979). This could be explained by the fact that in segment ( $\mathrm{CO}-\mathrm{C} 1)$, starting from the middle position, anteflexion occurs first; this is followed by retroflexion (Gutmann, 1968). This phenomenon is called "inversion" or "paradox movement" within segment $(\mathrm{CO}-\mathrm{C} 1)$. The frequency of the inversion normally ranges from 60\% (Arlen, 1977) to $90 \%$ (Lewit and Krausovd, 1963). The former relates the absence of inversion to pathology; in patients with neck complaints inversion only occurs in $40 \%$.

We assume that segments ( $\mathrm{CO}-\mathrm{C} 1)$ and $(\mathrm{C} 1-$ $\mathrm{C2}$ ) contribute in a constant sequence to the motion of block $(\mathrm{CO}-\mathrm{C} 2)$ during anteflexion or retroflexion of the entire cervical spine, during which it is possible that one or both segments move temporarily opposite to the direction of movement of the entire cervical spine and the head.

When testing the above-mentioned hypothesis we posed the following questions:
1. Is the order in which both segments of ( $\mathrm{CO}$ $\mathrm{C} 2$ ) contribute to the motion of this block constant for a given individual in a group of persons free of complaints?

2 . If so, what is this order?

3 . Is the order the same for all persons free of complaints?

4. Does one/do both segment(s) in block $(\mathrm{C} 0-\mathrm{C} 2)$ and/or the entire block show inversion in a certain anteflexion or retroflexion path?

5. Is this inversion constant?

6. Can inversion be found by comparing a middle position and a position between the latter and the final position, when it cannot be found by comparing the middle and final position of the cervical spine?

In order to find an answer to the above questions, rotation within the sagittal plane of segments ( $\mathrm{C} 0-\mathrm{C} 1)$ and $(\mathrm{C} 1-\mathrm{C} 2)$ and of block (C0-C2) was determined during motion of the entire spine. These rotations have been rendered in the diagrams, from which the following can be read:

1. The sequences of the contribution of segments $(\mathrm{CO}-\mathrm{C} 1)$ and $(\mathrm{C} 1-\mathrm{C} 2)$ to motion within block ( $\mathrm{CO}-\mathrm{C} 2)$.

2. Inversion in segments $(\mathrm{CO}-\mathrm{Cl})$ and $(\mathrm{Cl}-$ $\mathrm{C} 2$ ) and in block ( $\mathrm{CO}-\mathrm{C} 2)$ as a whole. This inversion has been compared to inversion determined on the basis of two images from the X-ray film; one in maximum "bending" anteflexion and one in a middle position of the cervical spine and the head. 


\subsection{Method}

\subsubsection{Sequence and inversion on film}

The segmental contributions to motion have been rendered in diagrams in which the relative rotation of segment $(\mathrm{CO}-\mathrm{C} 1)$ and segment $(C 1-C 2)$ have been plotted against $a b-$ solute rotation of block ( $\mathrm{CO}-\mathrm{C} 2$ ) (figure 7.1a). This was done for each of the ten test persons for both motions at the three moments of measurement. The diagrams are numbered ( $L$ to $U$ ) 1, 3, 5 for anteflexion of the entire cervical spine and the head from a maximum retroflexion position of the spine (R) towards maximum "bending" anteflexion

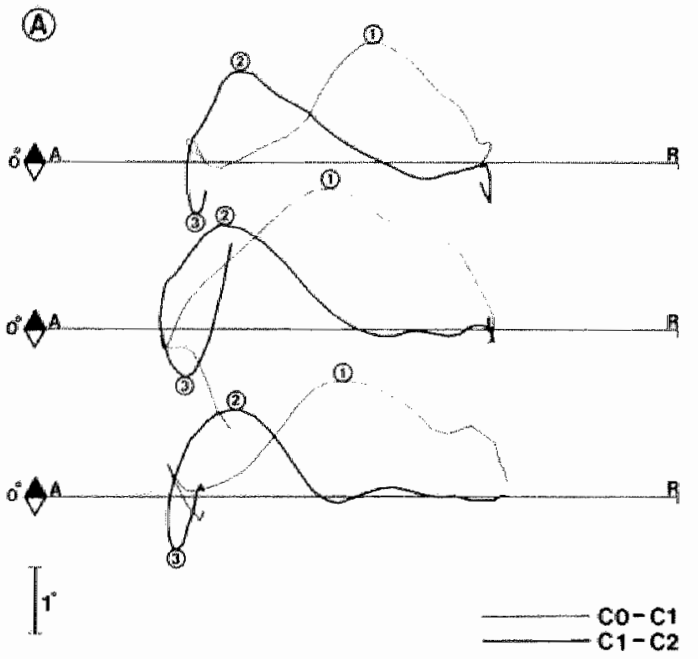

w1

(B)

(A)

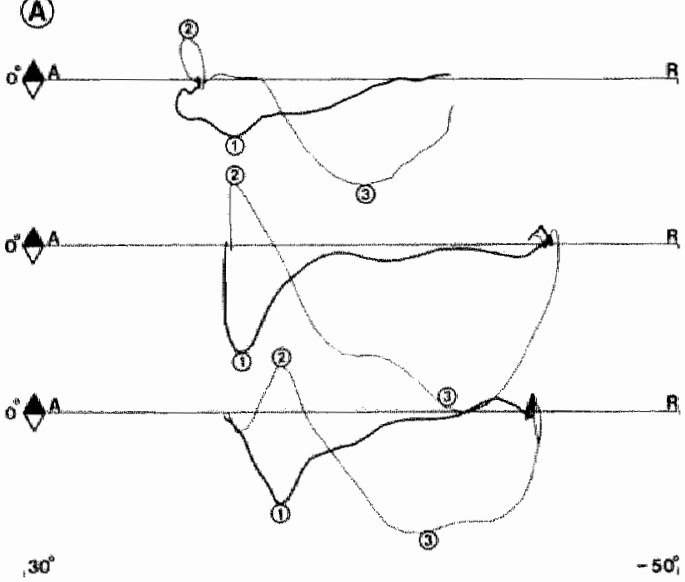

wk

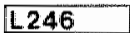

(B)

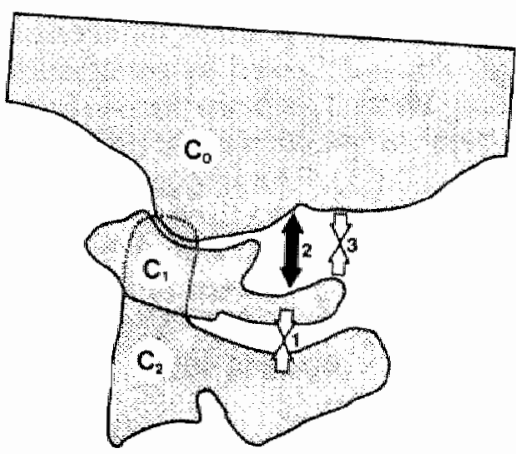

$-50^{\circ}$

\section{FLEXION EXTENSION}

ng. 7.1 Sequences of segmental contribuiions in test persons $\mathrm{L}, \mathrm{M}, \mathrm{O}$ and $\mathrm{S}$.

a Relative rotation in the segments $(\mathrm{CO}-\mathrm{C} 1)$ and $(\mathrm{C} 1-\mathrm{C} 2)$ plotted against absolute rotation in the block (CDC2). The sequence of the peaks is given by the numbers 1,2 and 3 .

b This sequence of segmental contribution of the segments $(\mathrm{CO}-\mathrm{Cl})$ and $(\mathrm{C1}-\mathrm{CZ})$ is indicated by numbered arrows.

0,2 and 10 wks represent measuring moments. 1,3 and 5 are anteflexion, 2,4 and 6 are retroflexion registrations. 
position (A), as well as for the opposite movement $2,4,6$. If the curve of a segment is situated above the abscissa, we speak of anteflexion in that segment, if the curve is situated below it, we speak of retroflexion. If in a diagram of an anteflexion (1,3 and 5) the curve of a segment is below the abscissa, then that segment shows retroflexion in that part of the path of motion in block ( $\mathrm{C} 0-\mathrm{C} 2)$, and consequently inversion. In a diagram of retroflex- ion we speak of inversion in a segment if the curve is above the abscissa, i.e. anteflexion in the segment concerned. A loop in both curves of the segmental relative rotation in an anteflexion registration of the cervical spine entails a retroflexion phase of block ( $\mathrm{CO}-\mathrm{C} 2)$. The presence of such a loop in a retroflexion registration therefore entails anteflexion in the block.
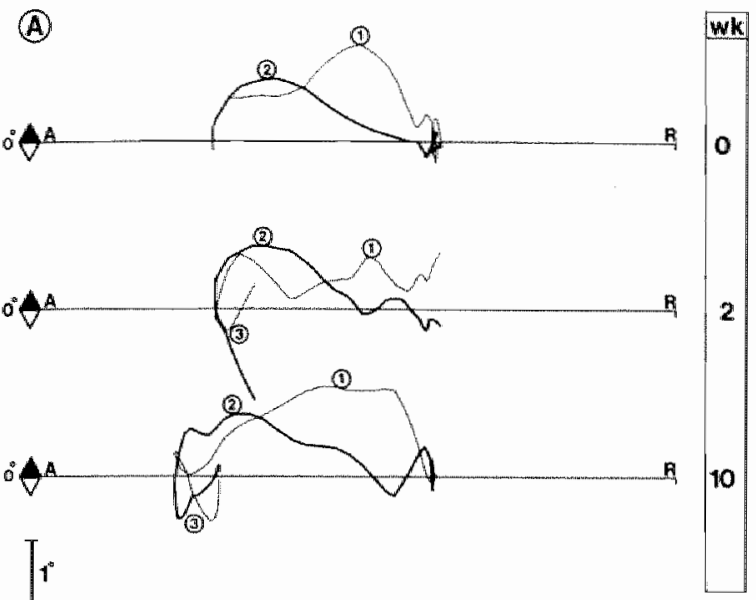

M135
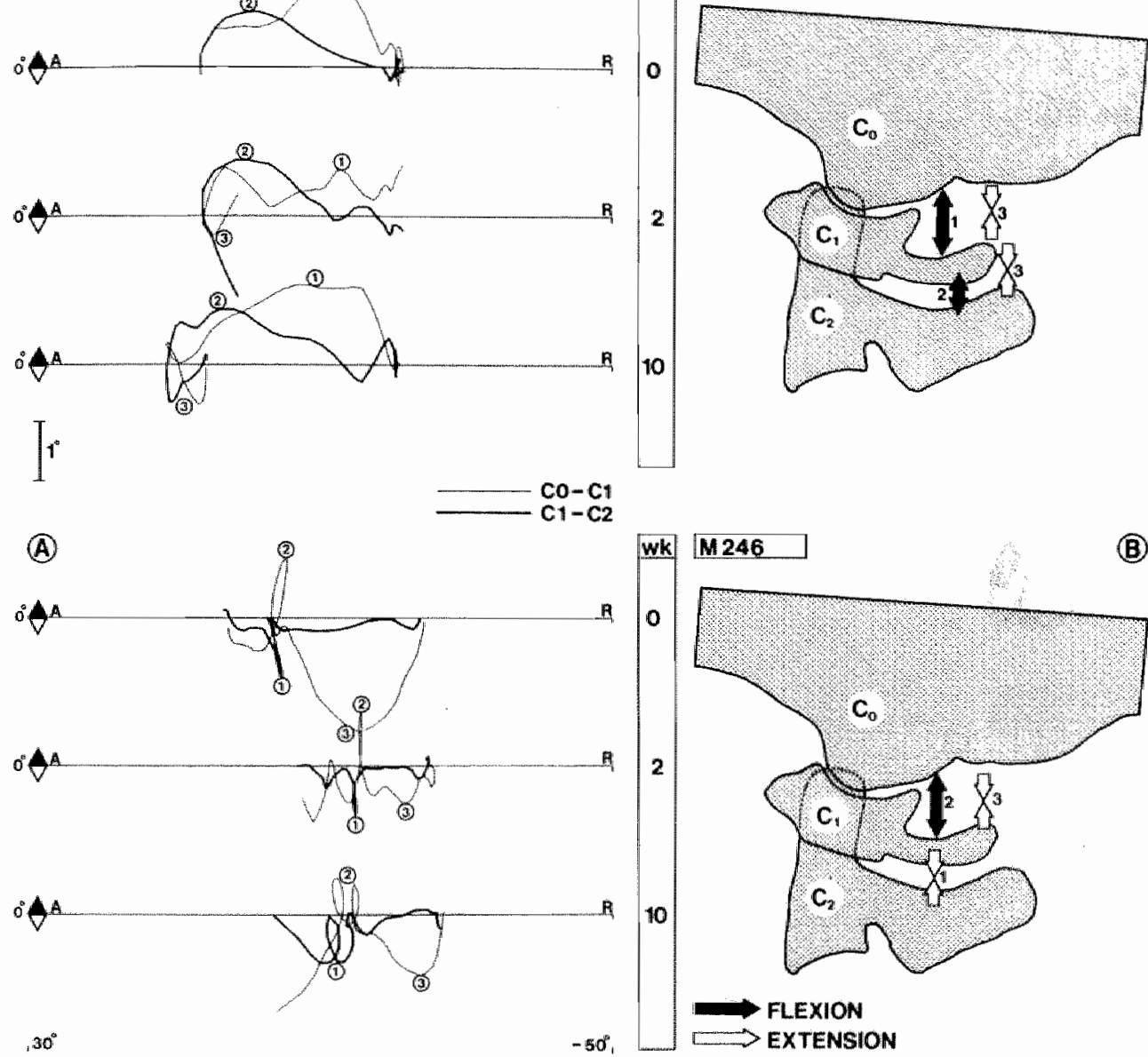
The order of motion in these diagrams has been indicated by means of numbers. The constant positions found at the three moments of measurement in the diagrams, where there is a maximum contribution of a segment per unit of rotation ( $\mathrm{CO}-\mathrm{C2})$, have been indicated on a diagram of block ( $\mathrm{CO}$ C2) (figure 7.1b) for each person examined; this was done by means of arrows with the same numbers as indicated in the diagrams
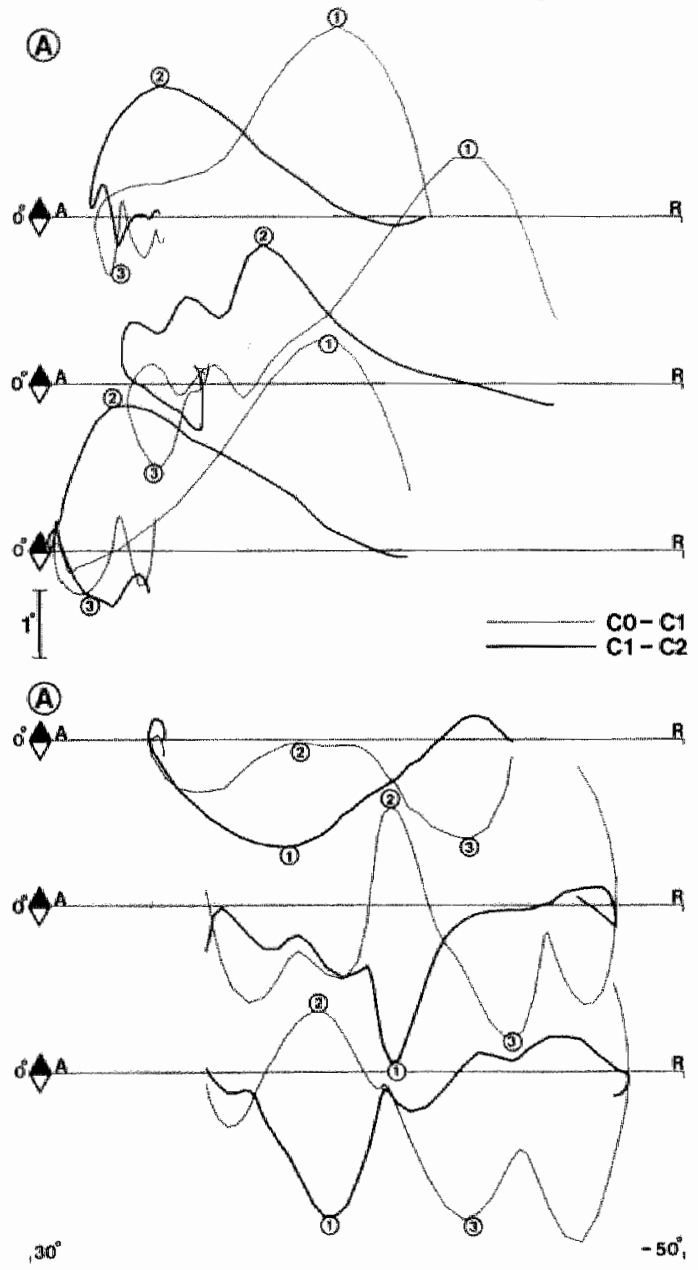

of figure 7.1a. The parameter "order of contribution of the segments" can be read from the order of the arrows (numbers 1,2 and 3) on the diagram of block ( $\mathrm{CO}-\mathrm{C} 2)$.

\subsubsection{Comparison of inversion on film to inversion on function pictures}

The occurrence of inversion during an actually performed motion, to be determined
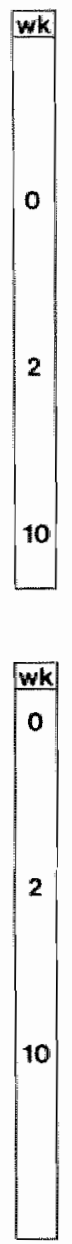

(B)

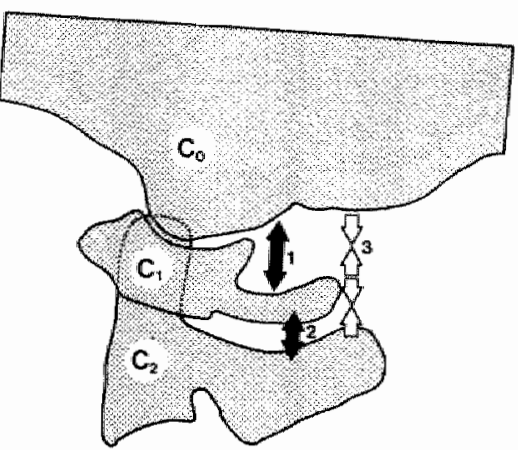

0246

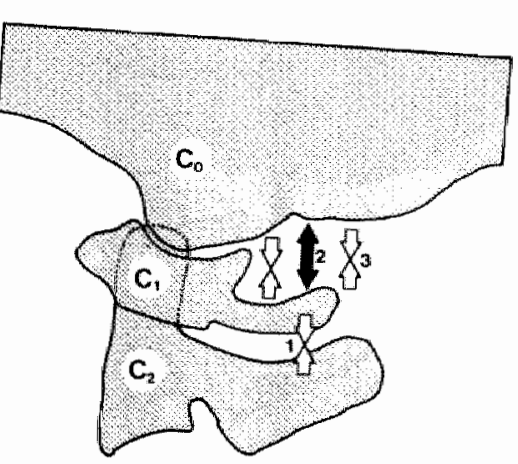

FLEXION EXTENSION 
on the basis of X-ray film, is compared to the results reached with the aid of only two function pictures. This is done by identifying two images in each film as the middle position (McGregor's line horizontally) and the "bending" anteflexion position of the cervical spine. The values of the absolute rotation of the skull, less the value on that image which is called middle position, have been plotted against the normalized images in diagrams (figure 7.2a and $7.2 \mathrm{~b}$ ). The values of the absolute rotation of segments $(\mathrm{CO}-\mathrm{Cl})$ and $(\mathrm{Cl}$ $\mathrm{C} 2)$ and of block ( $\mathrm{CO}-\mathrm{C} 2)$ have also been plotted in these diagrams. In these diagrams of $(\mathrm{C} 0-\mathrm{C} 1),(\mathrm{C} 1-\mathrm{C} 2)$ or $(\mathrm{CO}-\mathrm{C} 2)$ we have checked whether values occur in a certain
(A)
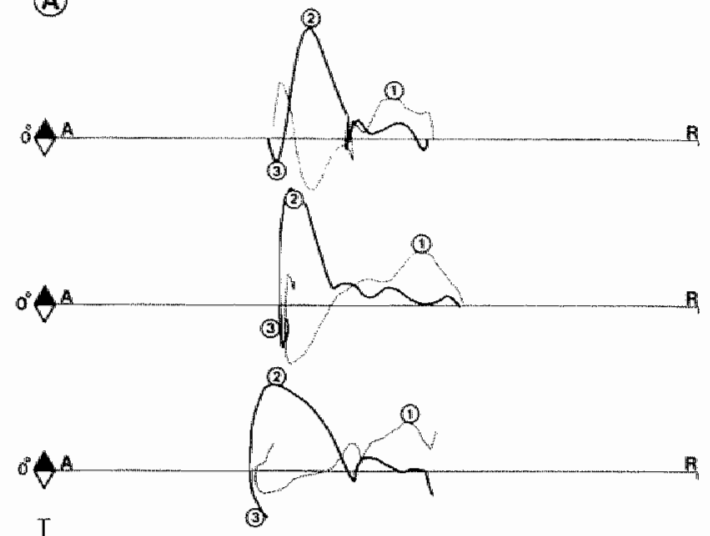

$1^{*}$

$\mathrm{CO}-\mathrm{Cl}$

$\mathrm{C}_{1}-\mathrm{C}_{2}$

(A)
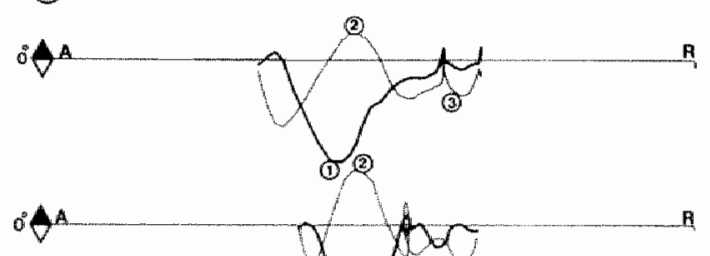

$300^{\circ}$

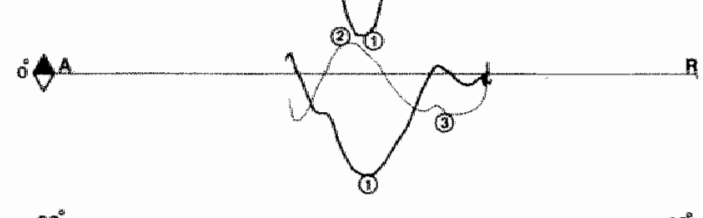

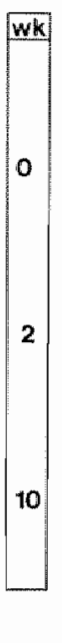

$S \| 35$

(B)

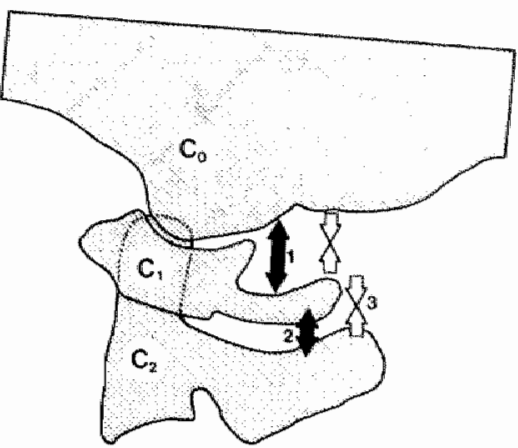

wk $\mathbf{5 2 4 6}$

(B)

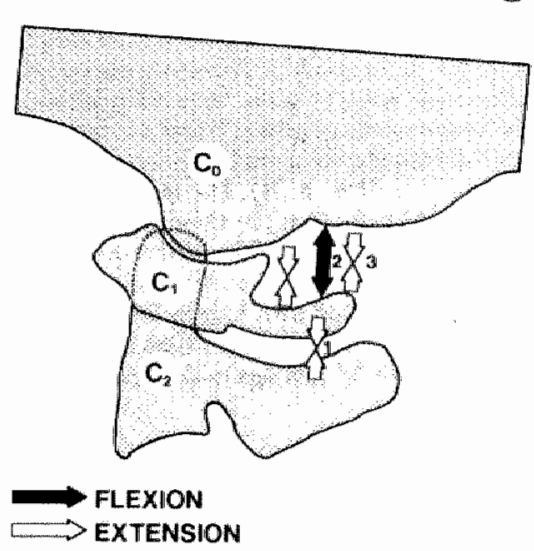



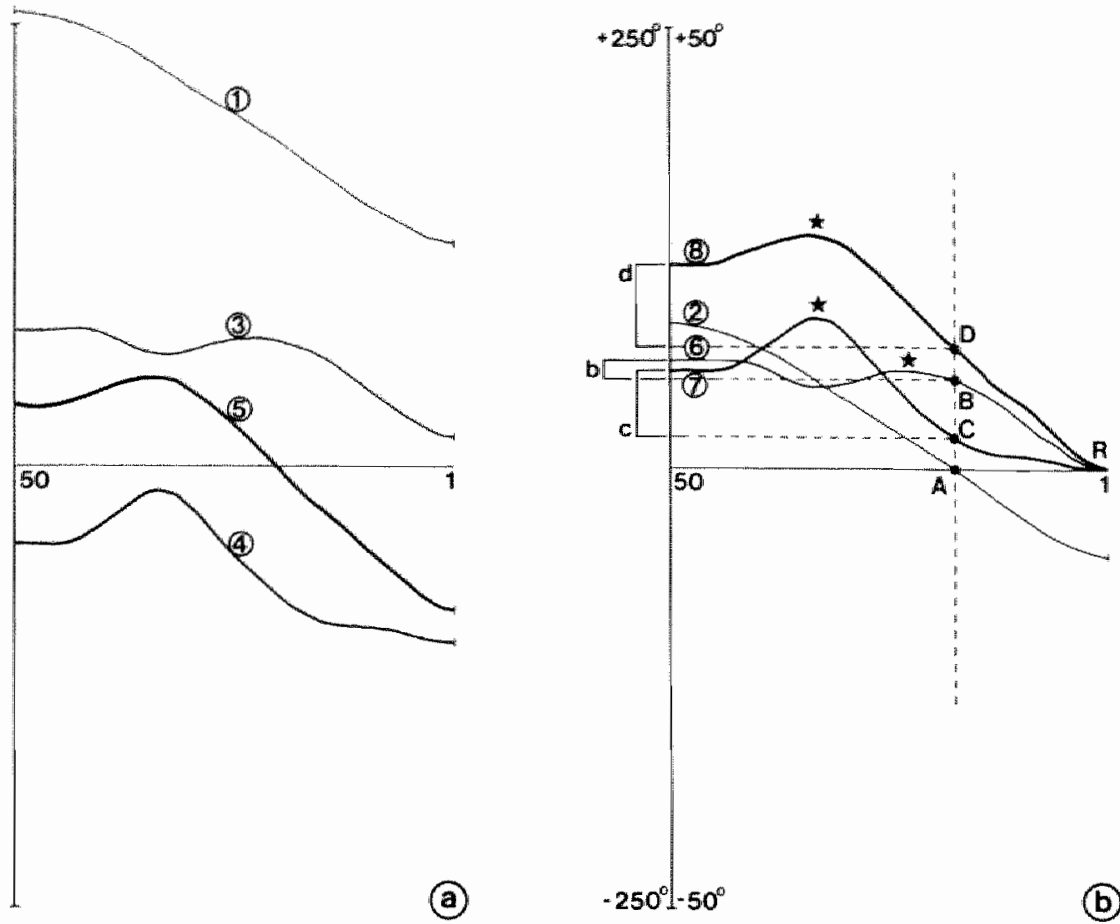

ng. 7.2 Comparison between "inversion" determined with the aid of "function pictures" and "inversiom" determined with the aid of film.

a Pictures of the X-ray film are plotted along the abscissa. In the $y$-direction the angle ROT of the skull (graph 1), relative rotation of the segments (CO-C1) (graph 3) and (C1-C2) (graph 4) and of the block (CO-C2) (graph 5) are plotted.

b The values of graph 1 are decreased with the value on that picture in which the line of McGregor is horizontal, resulting in graph 2 . Therefore the intersection between graph 2 and the abscissa gives the frame at which the cervical spine is in the "meutral" position.

The shape of the graphs, 6,7 and 8 is the same as respectively graphs 3,4 and 5 in figure a. Their values are decreased with the value on the picture in which the cervical spine is in maximal retroflexion. They are zero at maximal retroflexion (R). The intersection between the graphs 6,7 and 8 (B), (C) and (D) with a vertical line through (A) represent the values in $(\mathrm{CO}-\mathrm{C1}),(\mathrm{C1}-\mathrm{C2})$ and $(\mathrm{OO}-\mathrm{C2})$ of the cervical spine in the "'netutral" position. (b), (c) and (d) are the differences between the values of the graphs at the cervical spine in maximal "bending" anteflexion and "neutral" position.

The graphs marked with * show "inversion on film". This meams that in antellexion direction values are present which are more than $2^{\circ}$ lower than between this value and the walue found at "neutral" position.

Scaling $-50^{\circ}$ to $50^{\circ}$ bellongs to the graphs of $(\mathrm{CO}-\mathrm{Cl}),(\mathrm{C} 1-\mathrm{C} 2)$ and $(\mathrm{CO}-\mathrm{C} 2),-250^{\circ}$ to $+250^{\circ}$ to angle ROT of the skutl.

path of the range of motion that exceed the values plotted more towards the maximum anteflexion position. This is indicated in tables 7.2 and 7.3 . If this is the case, we speak of "inversion on film" (" in figure 7.2b).

\subsection{Reproducibility}

\subsubsection{Sequence and inversion on film}

The reproducibility of the sequences and inversion, determined in the diagrams of the segmental contributions to the block ( $\mathrm{CO}$ C2), has been determined by performing the 
procedure which gives diagram 7.1a five times with the five different files of film R3 (chapter 2.11) (figure 7.3).

The method of indicating the positions of the contours of the vertebrae and the skull, and the calculation of the rotations yield reproducible results as to the sequences of segmental contribution and inversion.
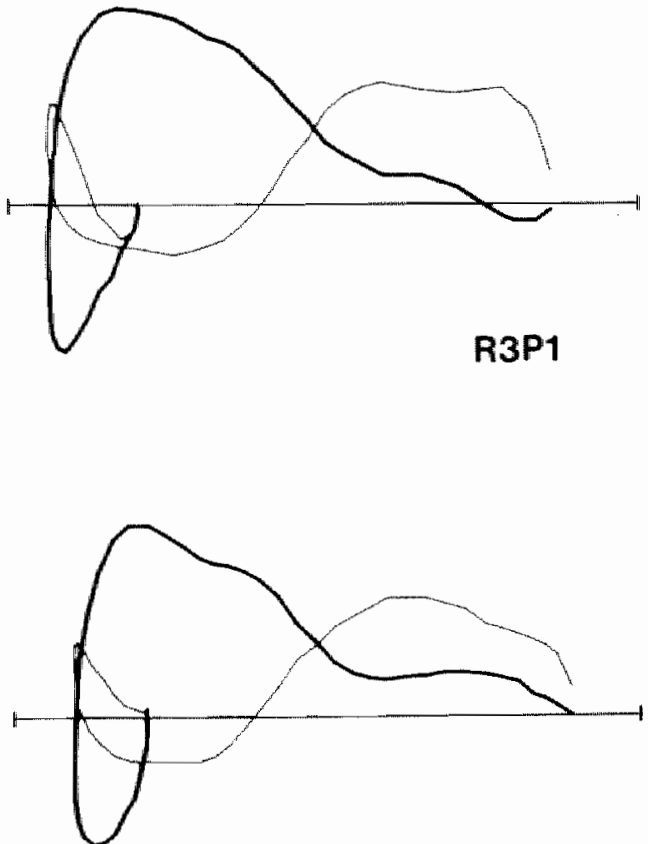

R3P3

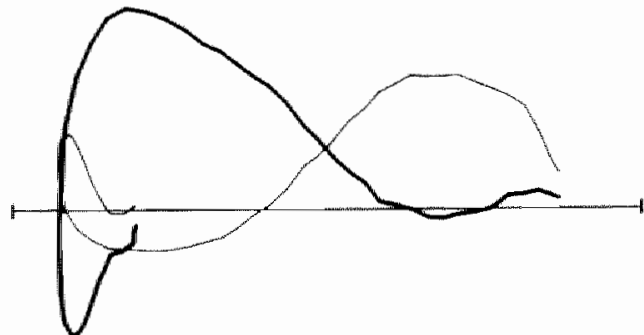

R3P5

\subsubsection{Comparison of inversion on film to inversion on function pictures}

The procedure described for figure $7.2 \mathrm{~b}$ has also been used in 5 diagrams (R3PI to R3P5) of film (R3) (see figure 7.4). The values of the differences between the rotary angle in the sagittal plane of segments $(\mathrm{CO}-\mathrm{Cl})$ (b) and

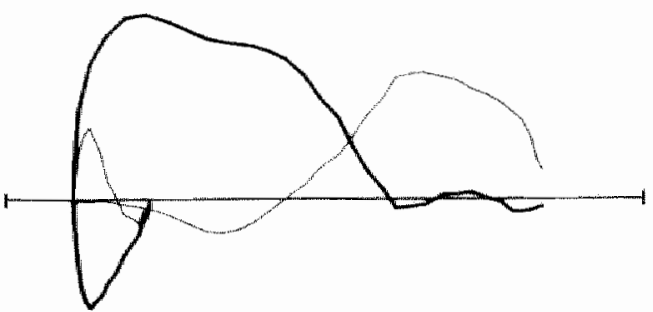

R3P2

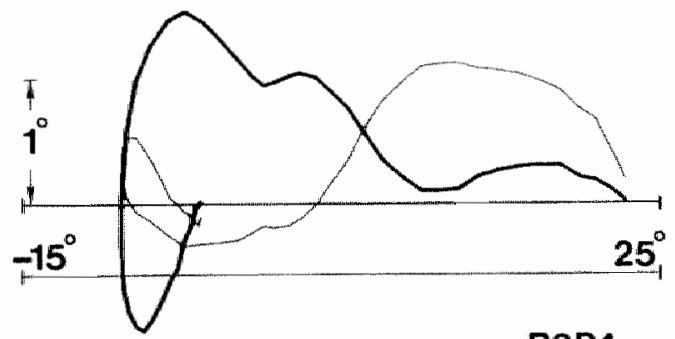

R3P4

7g. 7.3 Reproducibility of the determination of the sequence of segmental contribution and inversion. 5 graphs of film $\mathrm{R} 3$ are plotted. These graphs represent relative rotation of segments (CO-C1) and (C1-C2). Absolute rotation of block ( $\mathrm{CO}-\mathrm{C} 2)$ is plotted along the abscissa. 


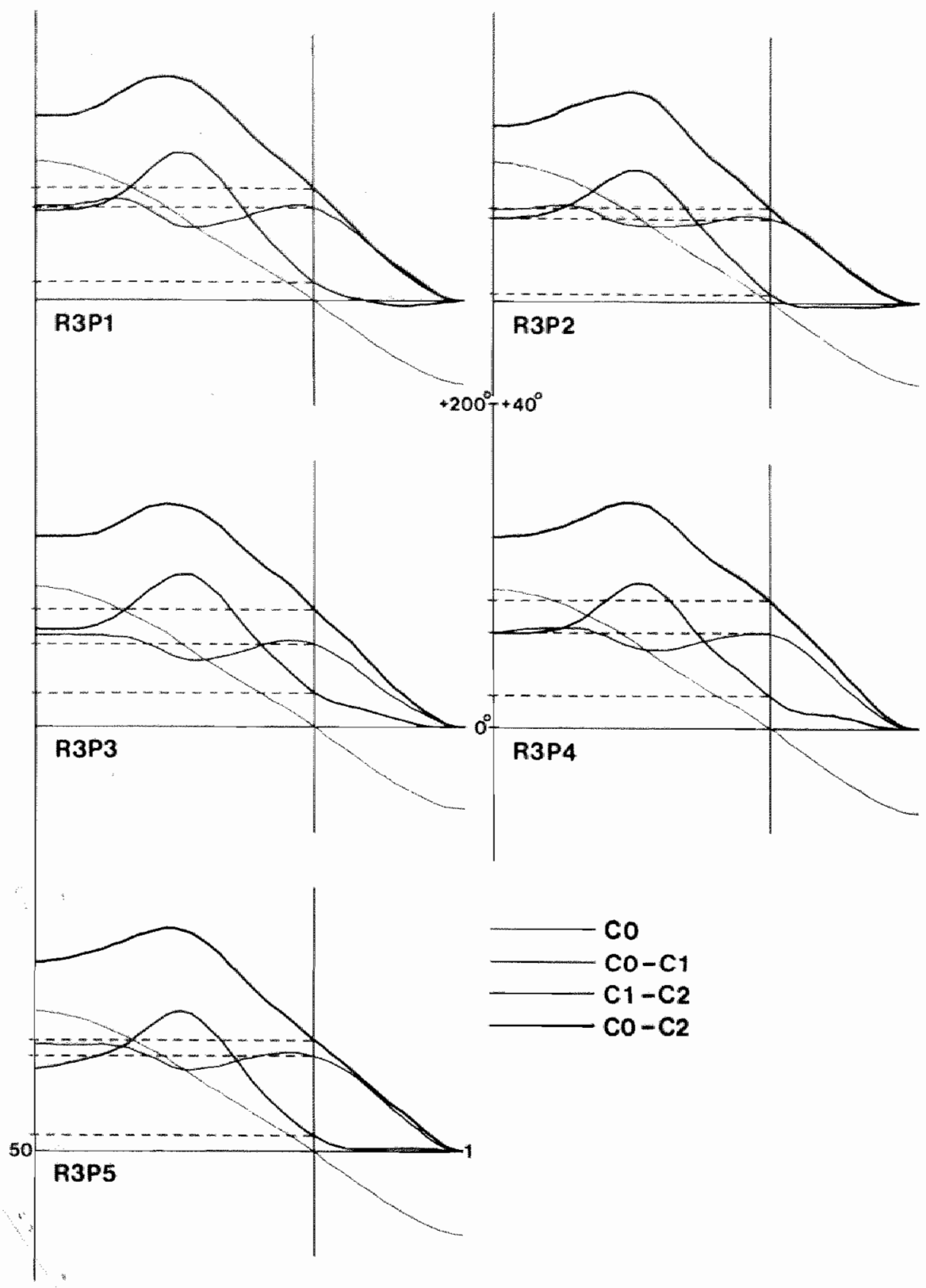

ng. 7. 4 Reproducibility of the comparison between "inversion on film" and "inversion on function pictures" in segments $(\mathrm{CO}-\mathrm{Cl})$ and $(\mathrm{C} 1-\mathrm{C2})$ and in block $(\mathrm{CO}-\mathrm{C2})$. 
table 7.1

\begin{tabular}{|c|c|c|c|}
\hline & $(\mathrm{CO}-\mathrm{C} 2)$ & $(\mathrm{CO}-\mathrm{C} 1)$ & $(\mathrm{C} 1-\mathrm{C} 2)$ \\
\hline R3P1 & 8.3 & 0.1 & 8.2 \\
\hline $\mathrm{R} 3 \mathrm{P} 2$ & 9.6 & 0.9 & 8.8 \\
\hline R3P3 & 8.3 & 0.9 & 7.5 \\
\hline R 3P4 & 7.5 & 0.1 & 7.2 \\
\hline R3P5 & 9.6 & 1.3 & 7.7 \\
\hline $\begin{array}{l}\text { Aver. } \\
\text { Disp.S }\end{array}$ & $\begin{array}{l}8.7 \\
9.6-7.5 \\
=2.1\end{array}$ & $\begin{array}{l}\quad 0.7 \\
1.3-0.1 \\
=1.2\end{array}$ & $\begin{aligned} & 7.9 \\
8.8-7.2 & \\
= & 1.6\end{aligned}$ \\
\hline
\end{tabular}

(C1-C2) (c) and block (CO-C2) (d) in anteflexion and middle position have been given in degrees in table 7.1. These values may be read from these five diagrams (R3P1 to R3P5). A value of more than 2 degrees is therefore outside the range of measurement error of the method.

\subsection{Results}

\subsubsection{Sequence and inversion on film}

In the ten persons mentioned, the following applies to the order of contribution of segments ( $\mathrm{C} 0-\mathrm{C} 1)$ and $(\mathrm{C} 1-\mathrm{C2})$ to motion of the block ( $\mathrm{C} 0-\mathrm{C} 2)$ during anteflexion of the cervical spine from maximum retroflexion position to a maximum "bending" anteflexion position (figure 7.1a and 7.1b):

1. The anteflexion in block (C0-C2) starts in all persons by an anteflexion contribution in segment $(\mathrm{CO}-\mathrm{C} 1)$. In one person $(\mathrm{P})$ anteflexion in segment $(\mathrm{CO}-\mathrm{Cl})$ in one measuring moment is accompanied by contribution in segment $(\mathrm{C} 1-\mathrm{C} 2)$.

2. This anteflexion contribution of $(\mathrm{CO}-\mathrm{Cl})$ is followed in all test persons by an anteflexion contribution in segment (C1-C2).

3 . In these ten persons retroflexion is seen in block $(\mathrm{CO}-\mathrm{C2})$ at the end of anteflexion of the entire spine and the head.

- In 2 persons ( $\mathrm{L}, \mathrm{R})$ this retroflexion is caused by a retroflexion in segment (C1-C2).
- In 1 person (S) this is caused by retrotlexion in segment $(\mathrm{CO}-\mathrm{Cl})$.

- In 1 person $(O)$ retroflexion in both segments occurs at the end of retroflexion in block (CO-C2).

- In 6 persons (M, N, P, Q, T, U) retroflexion also occurs in segments $(\mathrm{CO}-\mathrm{Cl})$ and $(\mathrm{Cl}$ C2). These can, however, only be registered clearly as the sum of both; retroflexion of each separate segment is within the range of measurement error of the method.

The following applies to the orders of motion in block ( $\mathrm{C} 0-\mathrm{C} 2)$ in a retroflexion of the cervical spine and the head from maximum "bending" anteflexion position to maximum retroflexion position:

\section{In all persons:}

- In the initial phase of retroflexion in block $(\mathrm{C} 0-\mathrm{C} 2)$ there is an almost simultaneous contribution of retroflexion in segment $(\mathrm{C} 1-\mathrm{C} 2)$ and anteflexion in segment ( $\mathrm{CO}-\mathrm{C} 1)$. In eight persons ( $\mathrm{L}, \mathrm{N}, \mathrm{O}, \mathrm{P}, \mathrm{Q}, \mathrm{R}, \mathrm{T}, \mathrm{U})$ the anteflexion contribution at the start of motion in segment $(\mathrm{CO}-\mathrm{C} 1)$ is accompanied by an anteflexion of the entire block $(\mathrm{CO}-\mathrm{C} 2)$ in one or more moments of measurement.

- In a next phase (in which retroflexion contribution in segment (C1-C2) decreases or has stopped) a retroflexion contribution occurs in segment ( $\mathrm{C} 0-\mathrm{C} 1)$.

2. In four persons $(M, N, O, S)$ the combination of the contributions mentioned is preceded by a small retroflexion contribution in segment $(\mathrm{CO}-\mathrm{Cl})$.

As to the order in which the segments contribute to motion in block ( $\mathrm{CO}-\mathrm{C} 2$ ), we may state in summary that:

The following applies to anteflexion in block (C0-C2):

- There is always first an anteflexion contribution in segment $(\mathrm{CO}-\mathrm{Cl})$ followed by an anteflexion contribution in segment (C1C2).

- In block (CO-C2), retroflexion occurs at the end of the anteflexion of the entire spine and the head. This retroflexion may occur in seg- 
ment $(\mathrm{CO}-\mathrm{C} 1)$, in segment $(\mathrm{C1}-\mathrm{C} 2)$ or in both.

The following applies to retroflexion in block ( $\mathrm{CO}-\mathrm{C} 2)$ :

- There is always first a retroflexion contribution in segment (C1-C2), which is accompanied by anteflexion in segment $(\mathrm{CO}$ C1), followed by the only or largest retroflexion contribution in segment (CO-C1).

-It is possible that a smaller retroflexion contribution in segment $(\mathrm{CO}-\mathrm{Cl})$ precedes this combination of motions.

\subsubsection{Comparison of inversion on film to inversion on function pictures}

Tables 7.2 and 7.3 show the inversion in segments (CO-C1) and (C1-C2) and the inversion in block (C0-C2). This inversion emerged from diagrams of the type in figure $7.2 \mathrm{~b}$. Only those differences have been indicated, which exceed 2 degrees (7.3.2).
Table 7.2. gives the inversion in segments ( $\mathrm{CO}-\mathrm{C} 1)$ and $(\mathrm{Cl}-\mathrm{C2})$ and in block $(\mathrm{CO}-\mathrm{C} 2)$ during anteflexion $(\mathrm{L} 1, \mathrm{~L} 3, \mathrm{~L} 5$ to $\mathrm{U} 1, \mathrm{U} 3$, U5):

Table 7.3 shows inversion in segments ( $\mathrm{CO}$ $\mathrm{C} 1)$ and $(\mathrm{C} 1-\mathrm{C} 2)$ and in block (CO-C2) during retroflexion (L2, L4, L6 to $U 2, U 4, U 66)$.

Table 7.2 and table 7.3 show that:

- The phenomenon of inversion occurs both in segments (CO-C1) and ( $\mathrm{Cl}-\mathrm{C2})$ and in the entire block (CO-C2) (cf. 7.4.1).

- Inversion on film in block ( $\mathrm{CO}-\mathrm{C} 2$ ) during anteflexion occurs in all films except one (S1). This inversion is caused by inversion in segment $(\mathrm{CO}-\mathrm{C} 1)$ or in segment (C1-C2), or in both (cf. 7.4.1).

- During retroflexion in the cervical spine, inversion on film of the entire block (CO-C2) occurs in only 12 of the $28 \mathrm{X}$-ray films.

- Inversion on film in segment (CO-C1) during retroflexion occurs in all films except one (O1).

table 7.2

\begin{tabular}{|c|c|c|c|c|c|c|c|c|c|c|}
\hline & L & $\mathrm{M}$ & $\mathrm{N}$ & 0 & $\mathbb{P}$ & $Q$ & $\mathrm{R}$ & $s$ & $\mathbf{T}$ & U \\
\hline 1 & & * & & $*+$ & $*+$ & * & -- & $*+$ & * & $*+$ \\
\hline 3 & * & * & & * + & $*+$ & & * & $*+$ & & $*+$ \\
\hline 5 & * & * & * & $*+$ & -- & * & -- & $*+$ & * & $*+$ \\
\hline 1 & $\$$ & & $\$$ & $\$$ & $\$$ & $\$$ & -- & $\$$ & & $\$$ \\
\hline 3 & $\$$ & $\$ x$ & $\$$ & $\$$ & $\$$ & $\$$ & $\$$ & $\$$ & $\$$ & $\$$ \\
\hline 5 & $\$ x$ & $\$$ & $\$$ & $\$ x$ & -- & $\$$ & - & $\$$ & $\$$ & $\$$ \\
\hline 1 & $\%$ & 8 & 8 & $8=$ & 8 & 8 & -- & & 8 & 8 \\
\hline 3 & $8=$ & $8=$ & 8 & $8=$ & 8 & 8 & 8 & 8 & 8 & 8 \\
\hline 5 & 8 & 8 & 8 & $8=$ & -- & * & -- & 8 & * & 8 \\
\hline $\begin{array}{l}* \\
+ \\
\$ \\
x \\
8 \\
= \\
--\end{array}$ & $\begin{array}{l}\text { inve } \\
\text { inve } \\
\text { inve } \\
\text { inve } \\
\text { inve } \\
\text { inve } \\
\text { val }\end{array}$ & $\begin{array}{l}\text { sion } \\
\text { sion } \\
\text { sion } \\
\text { sion } \\
\text { sion } \\
\text { sion } \\
\text { sinot }\end{array}$ & $\begin{array}{l}(\mathrm{CO}-\mathrm{C} 1) \\
(\mathrm{CO}-\mathrm{C} 1) \\
(\mathrm{C} 1-\mathrm{C} 2) \\
(\mathrm{C} 1-\mathrm{C} 2) \\
(\mathrm{CO}-\mathrm{C} 2) \\
(\mathrm{CO}-\mathrm{C} 2) \\
\text { availa }\end{array}$ & $\begin{array}{l}\text { on } \\
\text { on } \\
\text { on } \\
\text { on } \\
\text { on } \\
\text { on } \\
\text { ble }\end{array}$ & $\begin{array}{l}\operatorname{lm} \\
\operatorname{ncti} \\
\operatorname{lm} \\
\operatorname{acti} \\
\operatorname{lm} \\
\text { nctic }\end{array}$ & pic & es & & & \\
\hline
\end{tabular}


table 7.3

\begin{tabular}{|c|c|c|c|c|c|c|c|c|c|c|}
\hline & $\mathbb{L}$ & $\mathrm{M}$ & $\mathrm{N}$ & 0 & $\mathrm{P}$ & $Q$ & $\mathrm{R}$ & $\mathrm{s}$ & $\mathbb{T}$ & U \\
\hline 2 & $*+$ & $*+$ & * & & $*+$ & $*+$ & $*+$ & * & * & * + \\
\hline 4 & $\star+$ & * & $*+$ & * & * + & $*+$ & $*+$ & * & * & $*+$ \\
\hline 6 & * & * & * & $*+$ & -- & $*+$ & -- & * & * & * \\
\hline 2 & & & $\$$ & $\$$ & $\$$ & & $\$$ & & $\$$ & \\
\hline 4 & & & & & & & & & & $\$$ \\
\hline 6 & & & & & -- & $\$$ & -- & & & \\
\hline 2 & 8 & 8 & & & $8=$ & 8 & 8 & & & 8 \\
\hline 4 & & & 8 & & $8=$ & $8=$ & & & & \\
\hline 6 & & 8 & & & -- & 8 & -- & & & \\
\hline \multicolumn{11}{|c|}{ 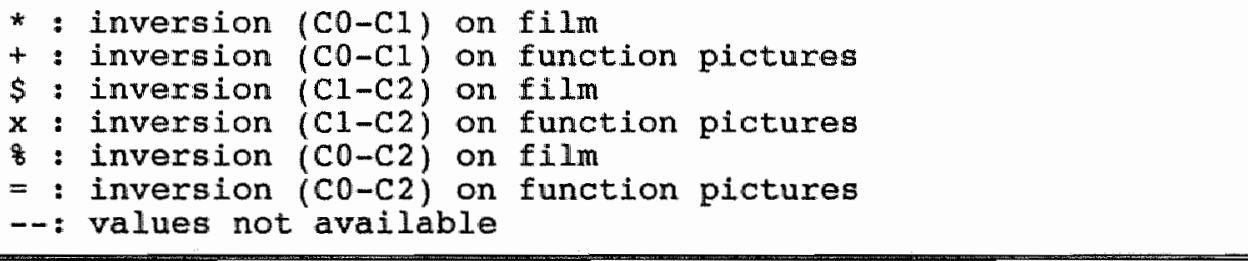 } \\
\hline
\end{tabular}

table 7.4

\begin{tabular}{|c|c|c|}
\hline inversion & $\begin{array}{c}\text { anteflexion } \\
(27 \text { films })\end{array}$ & $\begin{array}{l}\text { retroflexion } \\
(28 \text { films })\end{array}$ \\
\hline $\begin{array}{l}\text { 1. ( } \mathrm{CO}-\mathrm{C} 1) \text { on function pictures } \\
\text { 2. ( } \mathrm{C} 0-\mathrm{Cl} \text { ) on film } \\
\text { 3. difference between film and } \\
\text { function pictures }\end{array}$ & $\begin{array}{l}11 \\
22 \\
11\end{array}$ & $\begin{array}{l}14 \\
27 \\
13\end{array}$ \\
\hline $\begin{array}{l}\text { 4. ( } \mathrm{Cl}-\mathrm{C} 2) \text { on function pictures } \\
\text { 5. (CI-C2) on film } \\
\text { 6. difference between film and } \\
\text { function pictures }\end{array}$ & $\begin{array}{r}3 \\
25 \\
22\end{array}$ & $\begin{array}{r}-- \\
7 \\
7\end{array}$ \\
\hline $\begin{array}{l}\text { 7. ( } \mathrm{C} 0-\mathrm{C} 2) \text { on function pictures } \\
\text { 8. ( } \mathrm{C} 0-\mathrm{C} 2 \text { ) on film } \\
\text { 9. difference between film and } \\
\text { function pictures }\end{array}$ & $\begin{array}{r}5 \\
25 \\
20\end{array}$ & $\begin{array}{r}3 \\
12 \\
9\end{array}$ \\
\hline
\end{tabular}


- Inversion on film in segment ( $\mathrm{CO}-\mathrm{C} 1$ ) during anteflexion in the cervical spine was found 3 times less than inversion on film in segment ( $\mathrm{Cl}-\mathrm{C} 2)$.

- Inversion on film in segment (C1-C2) during a retroflexion was only found in 7 of the 28 cases.

Table 7.4 shows the number of times inversion during anteflexion or retroflexion of the cervical spine and the head was found on function pictures compared to the number of times it was found on filim.

Table 7.4 shows that:

- The largest differences found (20 times or morel between function pictures and film relate to the inversion in:

* segment (C1-C2) during anteflexion.

* block ( $\mathrm{C} 0-\mathrm{C} 2)$ during anteflexion.

- A difference concerning approximately half of the comparisons (between 10 times and 20 times) is inversion in:

* segment ( $\mathrm{C} 0-\mathrm{C} 1)$ during anteflexion and during retroflexion.

- A difference concerning approximately $1 / 4$ of the comparisons ( 7 times and 9 times) applies to inversion in:

* segment (C1-C2) during retroflexion.

* block $(\mathrm{CO}-\mathrm{C} 2)$ during retroflexion.

\subsection{Discussion}

In contrast to the range of motion (see chapter 4), the order for a given individual in whom segments (CO-C1) and (C1-C2) contribute in block ( $\mathrm{CO}-\mathrm{C} 2)$ during anteflexion or retroflexion of the entire cervical spine and the head, proved to be constant.

The order in which the segments contribute in the direction of motion in this block during anteflexion of the entire cervical spine and the head, is contrary to the one described during retroflexion. Thus far these orders have not been described.

Motion in block ( $\mathrm{CO}-\mathrm{C} 2)$ has a number of specific constant characteristics, which are different for motion in the block during anteflexion and retroflexion of the entire cervical spine and the head. During retroflexion of the cervical spine, anteflexion continually takes place in segment $(\mathrm{CO}-\mathrm{C} 1)$ in the path in which segment $(\mathrm{C} 1-\mathrm{C} 2)$ contributes its retroflexion. At the end of anteflexion of the cervical spine, retroflexion occurs in block ( $\mathrm{CO}$ C2). This is caused by retroflexion in segment (C0-C1), segment (C1-C2) or in both. This inversion of segments ( $\mathrm{C} 0-\mathrm{C} 1)$ and $(\mathrm{C} 1-\mathrm{C} 2)$ and of the entire block ( $\mathrm{CO}-\mathrm{C} 2)$ during the actually performed motions of the cervical spine has thus far not been described.

It is striking that inversion during anteflexion and retroflexion in the segments examined and in the block can be found much more frequently than inversion determined on the basis of function pictures. Inversion as it may be determined on the basis of function pictures is therefore a different phenomenon from the inversion found on images of actually performed motion. If inversion may be demonstrated on function pictures, this also applies to X-ray film, but the reverse is far from true. This results from the difference between the analysis result of only two images compared to that of a series of the entire movement. It is also possible that such inversion as may be determined on the basis of two static situations differs from the phenomenon which occurs in the dynamic situation.

We may conclude from the above that research by means of function pictures does not yield any information on the dynamics in block (CO-C2), such as orders of contribution of segments during anteflexion or retroflexion and the inversion occurring in this process. Such information may only be obtained by registration of the actually performed motion.

\section{Bibliography}

Arlen, A., Die "paradoxe Kippbewegung des Atlas" in der Funktionsdiagnostik der Halswirbelsaille, Man. Med, $15,16-22,1977$.

Arlen A., Biometrische Röntgen-funktions-diagnostik der Halswirbelsaule, In: Schriftenreihe manuelle 
Medizin, Band $5_{p}$ verlog für Medizin Dr. Ewald Fischer GmbH, Heidelberg, 1979.

Gutmann, G., Schulkopfschmerz und Kophalwung. Ein Beitrag zur Pashogenese des Anteflextons Kopfschmer zes und zur Mechanik der Kopfgelenke, Z. Orthop., I05, 497-515, 1968 .

Lewit, $\mathcal{K}$, Krausowd, Lu, Messungen won Vor-und Rückbeuge in den Kopfgelenken, Forisch. Röntg., 99, 538-543, 1963 .
Mamenen wan, $H$. Mobility in the cenical spine An in traind vidual companison of segmental motion in the sa-

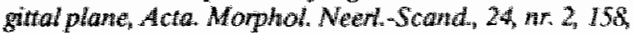
1986.

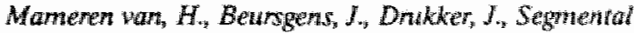
motion in the cenvical spine: A dynamic $X$-ray study of the mobility in the sagittal plane, Anm. Royal College Surg, 1988, In press. 


\section{A model of block (C0-C2)}

\subsection{Introduction}

Several authors have analyzed characteristics of cervical motion with the aid of model studies; in none of these, however, the segmental order and inversion in block (CO-C2) were expressed. Such models combine the shapes of the bony structures and the articular surfaces, as well as a number of ligamentous structures which are presumed to be of interest in checking motion.

These ligamentous structures are:

- An extensive system of collagenous connective tissue, between the ventral margin of the occipital foramen (extending towards the basilar part of the occipital bone) and the ventral part of the inside of the occipital condyles on the one hand, and the apex and laterodorsal side of the dens axis on the other hand. Here can be discerned - among other things - the apical dental ligament and the tectorial membrane (Williams and Warwick, 1980).

- The transverse ligament of the atlas. It brackets the dens at its basis. It is at a certain distance at the apex of the dens. As a result, the apex can move more freely than the basis in the sagittal plane in relation to this ligament and the anterior arch of the atlas (Werne, 1957). Putz and Pomaroli, 1972, Koebke and Brade, 1982 consider the special shape of the transverse ligament of the atlas a condition for anteflexion-retroflexion in segment (C1-C2) as well.

- The ligamentum nuchae. The funicular part may be recognized as a ligamentous structure, acting as point of attachment of both trapezius muscles and - in the caudal area as point of attachment of the rhomboid and splenius capitis muscles. This part attaches to the external occipital protuberance and the tips of the lower cervical spinous processes. Data on the lamellar part are of a conflicting nature: some mention a very thin membrane, others assume a mechanical function of this part in relation to cervical segments (Field- ing et al., 1976; White et al., 1975; Halliday et al., 1964, Jirout, 1974).

In models formulated by Werne (1957) and Penning (1978), the first two ligamentous structures and the shapes of the segments have been included. These ligamentous structures come under tension as the distance between the anterior margin of the occipital. foramen and apex and the dorsal side of the dens axis increases.

According to Werne (1957) this occurs during:

Retroflexion in segment (CO-C1):

- During this movement the articular surfaces of the atlas move over those of the occipital condyles towards a dorsal position. Anteflexion in segment (C1-C2):

- During this movement the anterior arch of the atlas glides towards a caudal position in relation to the anterior surface of the dens axis. This involves "cranial gaping" between the cranial part of the anterior surface of the dens axis and the anterior arch of the atlas (Werne, 1957). Such a movement would be in accordance with the position of the average instantaneous centre of rotation in segment ( $\mathrm{CO}-\mathrm{C} 1$ ) as described by us (chapter 5). During anteflexion in segment $(\mathrm{CO}-\mathrm{C} 1)$ or retroflexion in segment (C1-C2), the opposite occurs. Werne (1957) concludes that the ligamentous structures extended between the anterior margin of the occipital foramen and dens axis check retroflexion in segment (C0-C1) and anteflexion in segment (C1-C2). This means that if the tectorial membrane is stretched, further retroflexion in (CO-C1) is only possible in combination with retroflexion in (C1-C2). Another result is the fact that in the event of a stretched tectorial membrane, anteflexion in (C1-C2) has to involve anteflexion in ( $\mathrm{CO}-\mathrm{C} 1)$.

Penning assumes that this may also be the 
case in parts of the alar ligaments. In Penning's model, the position of the atlas depends on the position of the dens axis in relation to the occipital foramen; if the dens moves into a more ventral position in relation to the occipital foramen, the atlas will move into anteflexion position in relation to the occipitall bone.

Another model (Dul et al., 1982, 1984) consists of segment (CO-C1) as the cranial end of the cervical spine with the centre of rotation at the middle of the occipital condyle, and a force of dorsal neck muscles attached to the external occipital protuberance in equilibrium with the weight of the head. An important function is ascribed to the ligamentum nuchae, but the ligamentous structures extended between foramen magnum and dens axis are not included. In this model segment $(\mathrm{C} 1-\mathrm{C} 2)$ is not accounted for either. The optimum position of segment $(\mathrm{CO}-\mathrm{C} 1)$ in a maximum "bending" anteflexion position of the cervical spine is related to the use of minimum muscular force to maintain a position of the cervical spine.

The present model studies do not offer the opportunity to give statements as to the order in which the segments in this block may contribute to motion or to inversion phenomena such as occur during actually performed anteflexion and retroflexion. The models represent static situations of the cervical spine. They contain either the ligamentous structures around the segments in block ( $\mathrm{CO}$ C2) or the structures attached to the external occipitall protuberance.

In this chapter we shall attempt to formulate a (mechanical) model which can explain the orders and inversion phenomena found in chapter 7 . This model departs from a number of well-known anatomical data. The orders of motion are related to the efficiency principle of minimum muscular force already indicated by Dul (1982, 1984).

A number of presumptions as to the optimum order of contribution to motion within the sagittal plane of block ( $\mathrm{CO}-\mathrm{C} 2)$ during anteflexion and retroflexion of the entire cervical spine are derived from this model. These presumptions are tried against motions carried out by the persons examined. For this purpose the relative rotation of segments (C0-C1) and (C1-C2) is rendered graphically in such a way that any relation between the maximum of segmental contribution to motion of block ( $\mathrm{CO}-\mathrm{C} 2)$ and the position of this block in the gravitational field may be derived.

\subsection{Method}

\subsubsection{Construction of a model of block ( $\mathrm{CO}-\mathrm{C} 2)$}

Within block ( $\mathrm{C} 0-\mathrm{C} 2)$, the model uses the following anatomical data (figure 8.1). In a sagittal projection of the cervical spine two hinges ( 1 and 2 ), two bars (A and B) and two cables (I and II) are defined. Hinge (1) consists of the instantaneous centre of rotation in segment $(\mathrm{CO}-\mathrm{C} 1)$ in the middle of the occipital condyle, hinge (2) corresponds to the instantaneous centre of rotation in segment (C1-C2) at the dorsal side of the collum dentis. Bar (A) consists of the occipital bone; (B) lies between hinge points (1) and (2). The length of this bar is not constant, since the presumed existence of one centre of rotation during the entire motion in segment ( $\mathrm{C} 0-\mathrm{C} 1)$ and segment $(\mathrm{C} 1-\mathrm{C} 2)$ is a simplification. This phenomenon is neglected in this model. A cable (I) is attached to bar (A) in (4), the anterior margin of the occipital foramen. This cable embodies the tectorial membrane (and possibly the alar ligament and the apical dental ligament). The second attachment of cable (I) is at (3), the posterior of the dens axis. The length of cable (I) under tension is reached in maximum retroflexion of the head (Werne, 1957). A second cable (II), the funicular part of the ligamentum nuchae, is attached to (5) at the occipital bone. This cable (II) is attached to the spinous process of $\mathrm{C} 5$ at (6). No data are available on the relation between the length of the funicular part of the ligamentum nuchae and the position of 


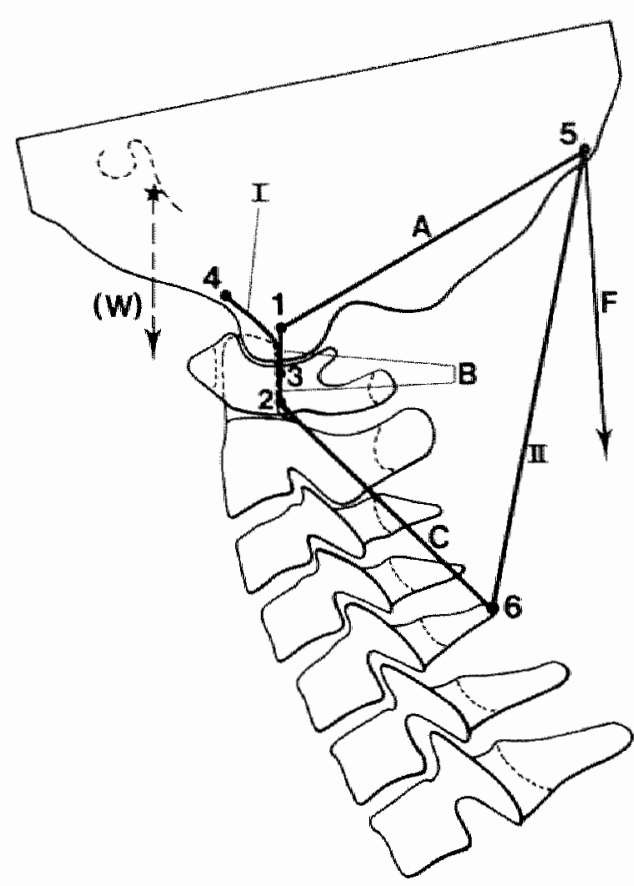

fig. 8.1 Diagram of the contours of the cervical spine in the "neutral" position. Indicated are:

pivoting points of segments (CO-C1) (1) and (C1C.2) (2); attachments of "cable I" (the tectorial membrane and parts of the alar ligaments, 3 respectively 4); attachment at the skull of the dorsal muscles and "cable III" (funicular part of the nuchal ligament, 5); attachment of "cable II" at CS (6). Next to these are indicated the centre of gravity of the head $(W)$ and two rods, occipital bone (A) and the distance between piwoting points (1) and (2) (B). The distance between (2) and (6) is named (C).

the cervical spine. During the last phase of a "bending" or "nodding" anteflexion this $\mathrm{i}$ gamentous structure is stretched, as may easily be demonstrated during in vivo examination. Anteflexion may nevertheless carry on for a while at that moment. The distance (C) between (2) and (6) is variable and very much dependent on the movements within the sagittal plane. Between a middle position and both extreme positions, there is a difference in length of approximately $15 \%$. This difference in length is allowed for when the supposed coherence of movement in the cervi- cal spine during motion within the sagittal plane is established.

The effect of two forces is applied to this system:

1. The mass of the head in the centre of gravity (rendered as a vector (W)) at the dorsocaudal side of the sella turcica, at the transition to the clivus (Le Veau et al., 1977).

2 . The dorsal neck muscles (trapezius, splenius capitis, semispinalis capitis muscles). They are considered to attach to the external 


\section{U1}
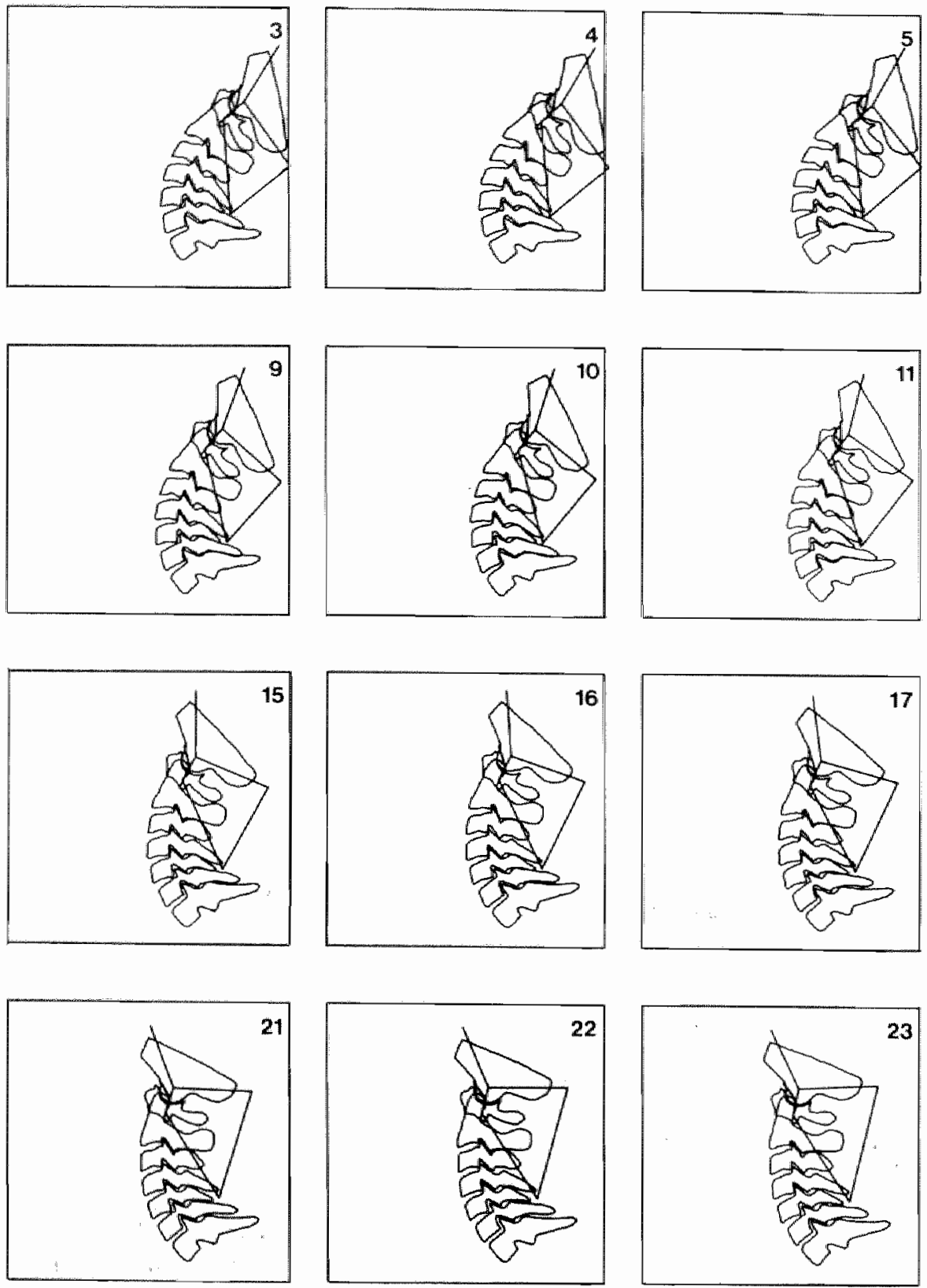

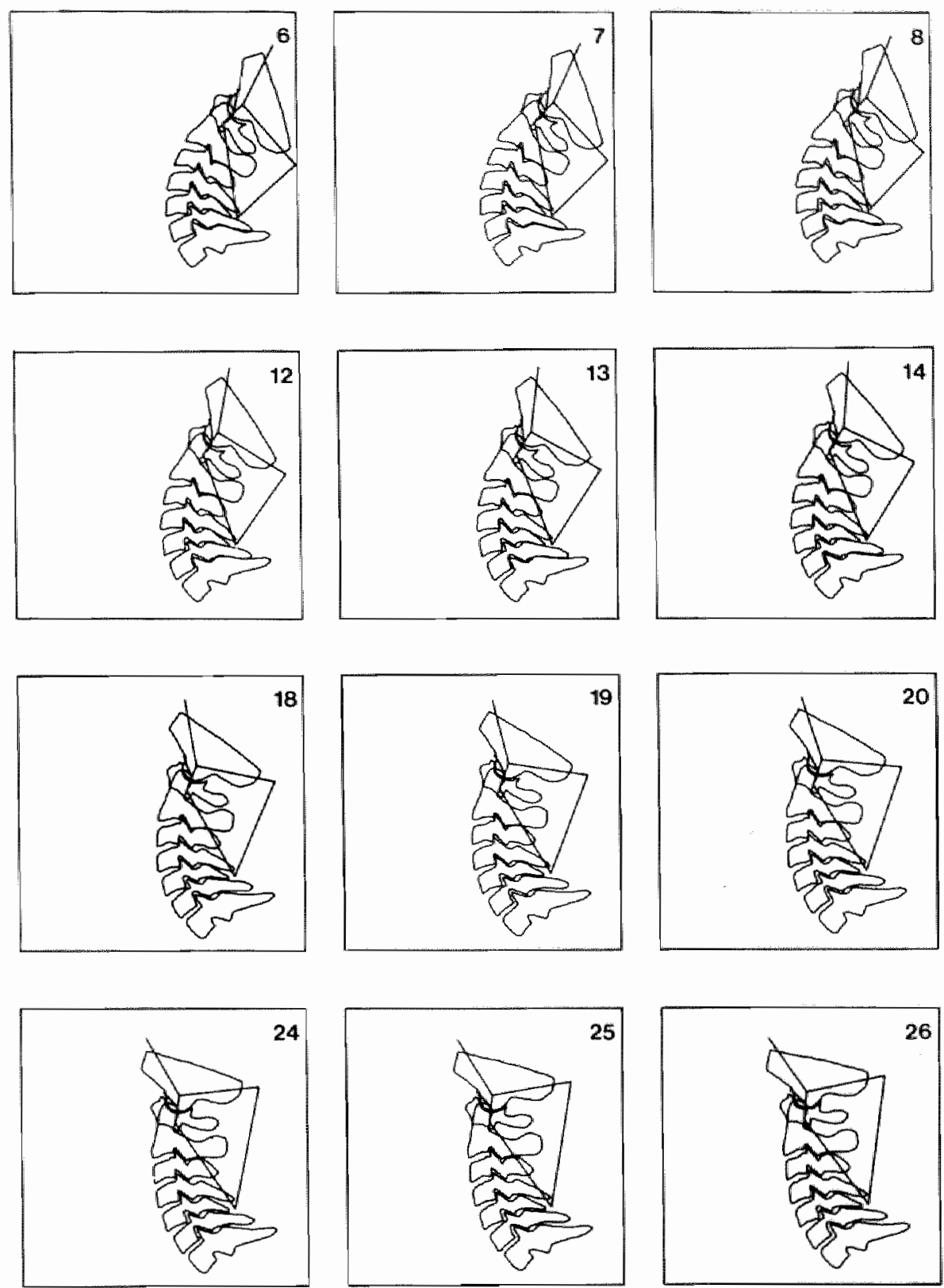

fig. 8.2 Components of the model related to the contours of the bony parts on pictures 3 to 50 of anteflexion of test person U1. Centre of gravity (W) and pivoting point (6) are indicated beyond the contour of $\mathrm{CO}$ because in this person a smaller part of the contour is drawn as compared to 

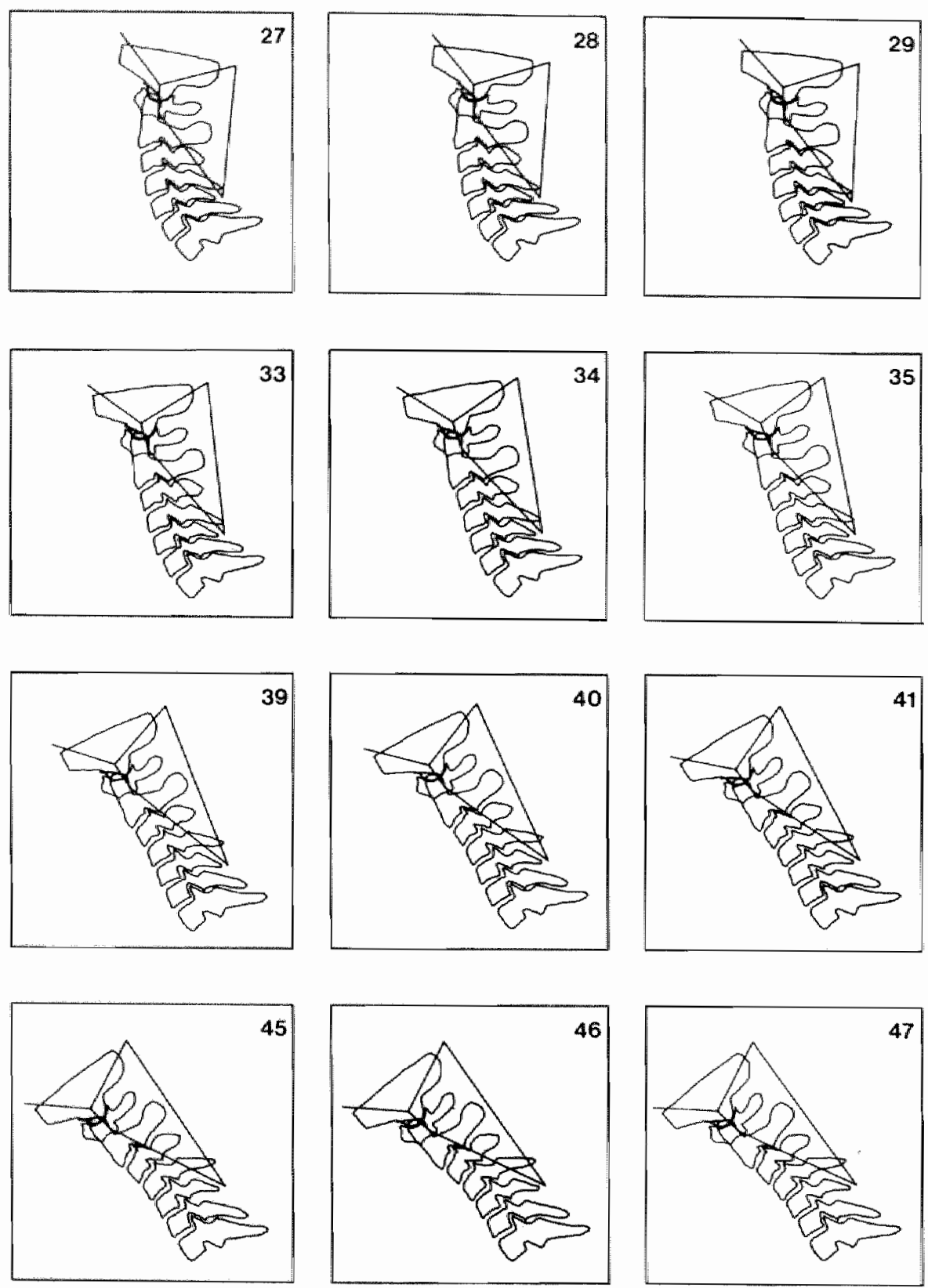

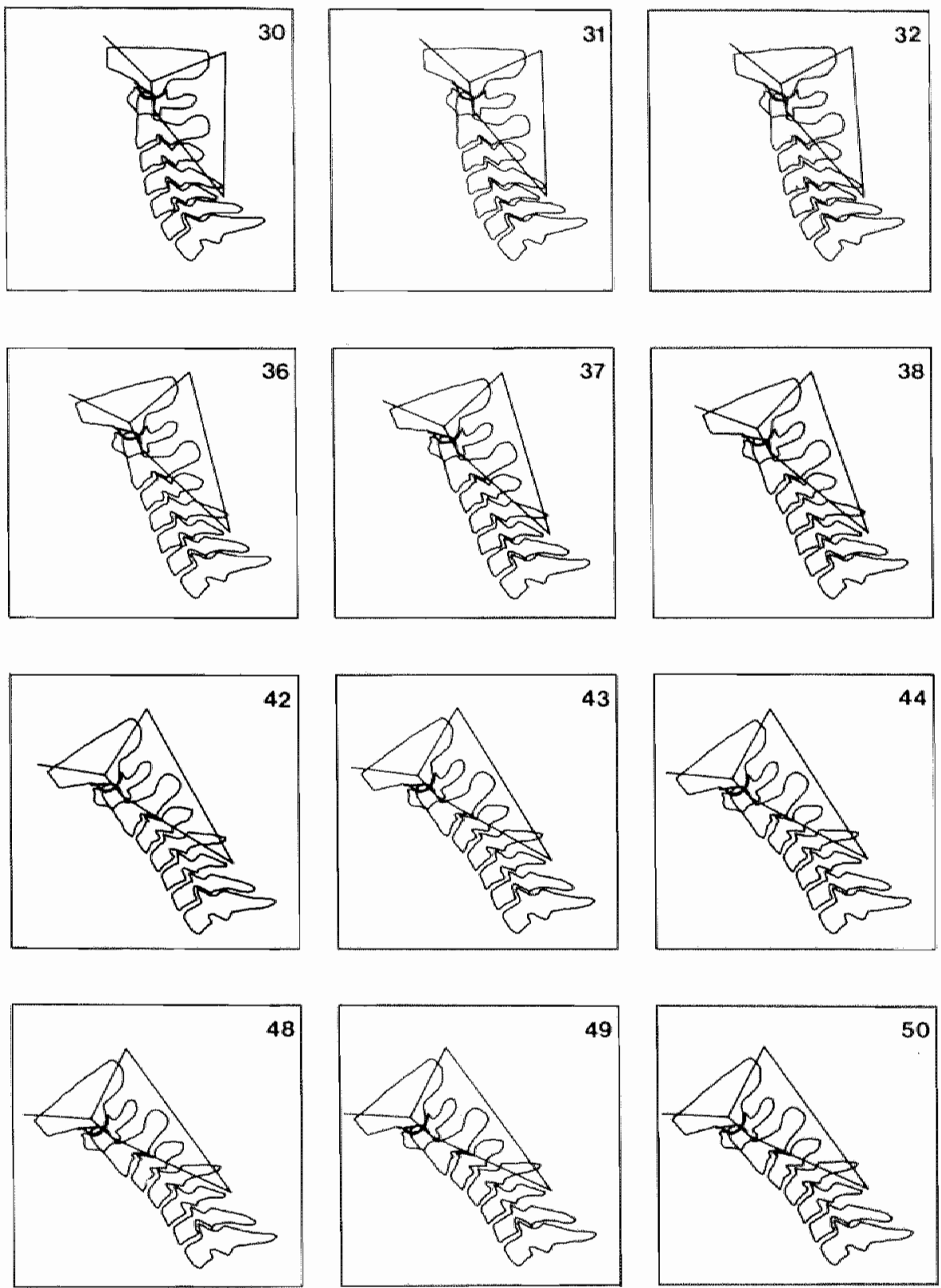
occipital protuberance. The direction of pulling is towards the top of the spinous process of C7.

For the system we assume that:

- Motion between the articular surfaces is frictionless (Williams and Warwick, 1980).

- We may consider the connections of the ligamentous structures and/or muscle tissue to the bones as hinges between the bone and soft tissue.

- Tension in other ligamentous structures than the ones described above, if present at all, is only in the final positions of the segments.

- We may neglect the mass of vertebrae $\mathrm{Cl}$ and $\mathrm{C} 2$ in relation to that of the head.

- The influence of the speed of motion may be neglected.

\subsubsection{Model in relation to the contours of the bony structures}

For each image on the anteflexion $\mathrm{X}$-ray film U1 (normalized to 50 images) the positions of the contours of the bony structures have been coupled to the positions of the average pentagons, triangle (skull) and quadrangle (atlas). The components of the model formulated in 8.2.1 were applied in relation to the contours on each image (figure 8.2). In this figure the change in distance (C) during anteflexion was determined between ( 3 ) and (4) along cable (1) and between (5) and (6). Figure 8.3 shows in one diagram:

a. The length of cable (II).

b. The distance (C).

The relative rotations of the following have also been plotted in this figure:

c. The skull compared to $\mathrm{C} 7,(\mathrm{CO}-\mathrm{C} 7)$.

d. Block ( $\mathrm{CO}$-C5).

e. Block (C2-C5).

f. Segment (C0-C1).

g Segment $(\mathrm{C} 1-\mathrm{C} 2)$.

h. Block ( $\mathrm{C} 0-\mathrm{C} 2)$.

The images may be recognized by the 50 points in the $\mathrm{x}$-direction.

Contours with the components of the model have also been drawn of the retroflexion $X$ ray film $L A$ (normalized to 50 images) (figure 8.4). Again, the same data as in U1 have been plotted in one diagram (figure 8.5). Images 1 and 2 of the anteflexion registration $\mathrm{U1}$ (figure 8.2) and images 49 and 50 of the retroflexion registration L4 (figure 8.4) have not been rendered.

\subsubsection{Model verification}

The relation has been studied between, on the one hand, the orders in which the segments contribute to motion of block ( $\mathrm{C} 0-\mathrm{C} 2)$ and, on the other hand, the position of the centre of gravity of the head, or the position of the hinges in the segments in relation to the force of gravity. We have rendered the relative rotations in block ( $\mathrm{C} 0-\mathrm{C} 2)$ in relation to the projection within the sagittal plane of the centre of gravity of the head and the hinges of segments ( $\mathrm{CO}-\mathrm{C} 1)$ and $(\mathrm{C} 1-\mathrm{C} 2)$. These data have been rendered in three diagrams in one vertical column (figure 8.6). Figure 8.6a shows the positions of the centre of gravity and both hinges during motions within the sagittal plane. The relative segmental rotation has been rendered in figure $8.6 \mathrm{~b}$. Figure $8.6 \mathrm{c}$ shows when the centre of gravity of the head is vertically above hinge (1), and when hinge (1) is vertically above hinge (2). In the three diagrams the values along the abscissae are the same. From this combination of three figures may be seen in which position in the gravitational field each of the two segments contributes most to motion (and in what direction), as well as the order in which this occurs.

\subsection{Results}

\subsubsection{Segmental order of motion in terms of the model}

\section{Anteflexion}

We know (chapter 7) that segment (CO-C1) and then segment (C1-C2) contribute to anteflexion in block ( $\mathrm{C} 0-\mathrm{C} 2)$. We also know that retroflexion occurs in block $(\mathrm{C} 0-\mathrm{C} 2)$ at the end of the anteflexion of the cervical 


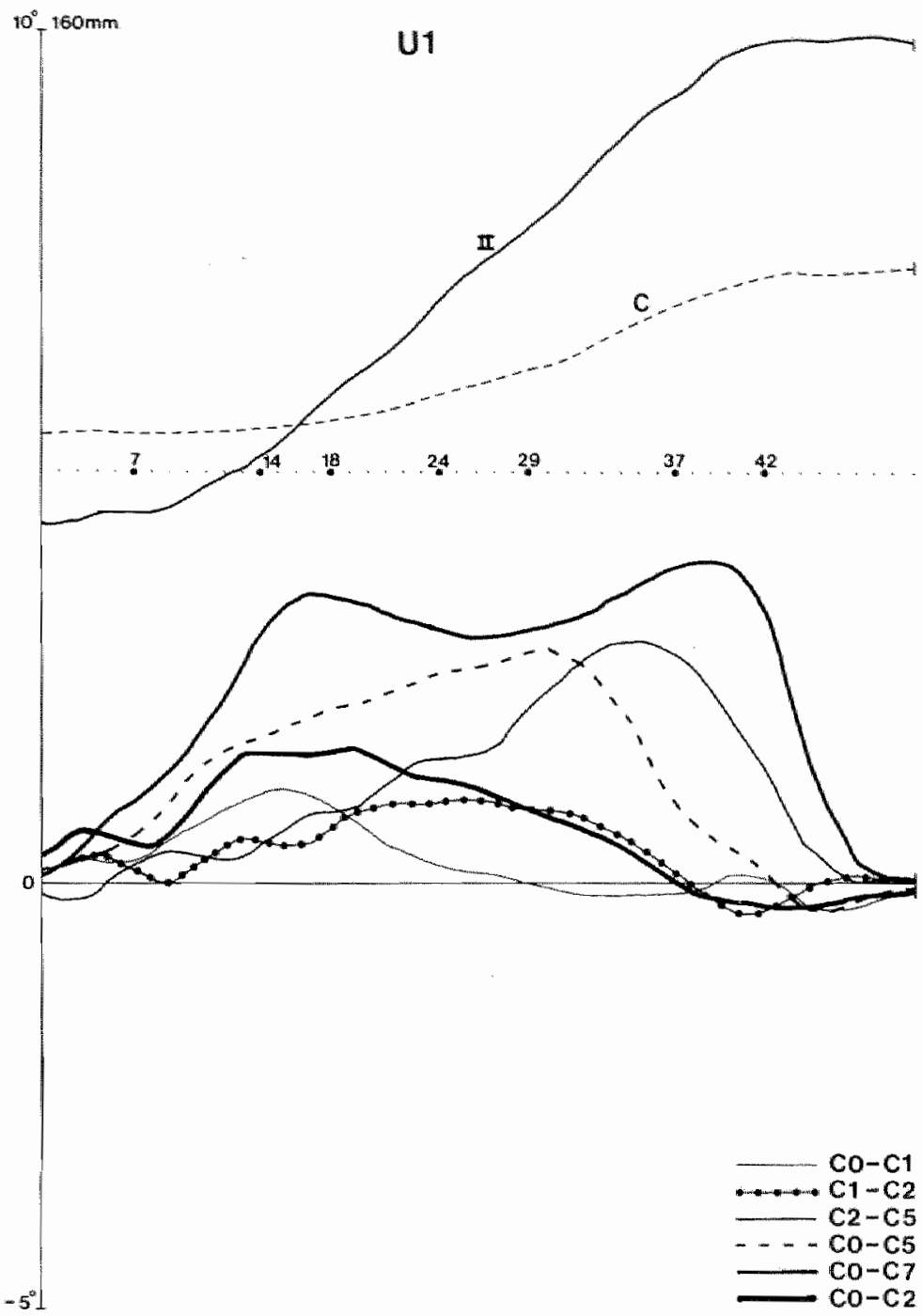

fig. 8.3 Relative rotations, distance between pivoting points (5) and (6), "cable II", and distance (C) plotted against normalized 50 frames (anteflexion $\mathrm{U} 1$ ).

spine. Now the following may be said about these contributions to motion: 1

- Up to image 7 , motion of the head in relation to $\mathrm{C} 7$ is almost entirely the result of motion in the caudal part of the cervical spine (compare curve $(\mathrm{CO}-\mathrm{C} 7)$ to $(\mathrm{CO}-\mathrm{C} 5)$ in figure
8.3).

- Between images 1 to 7 there is hardly any contribution of segment ( $\mathrm{CO}-\mathrm{C} 1)$. The largest contribution of segment (C0-C1) occurs around image 14. From image 24 onwards, anteflexion in segment ( $\mathrm{CO}-\mathrm{Cl})$ no longer occurs (figure 8.3). 


\section{L4}
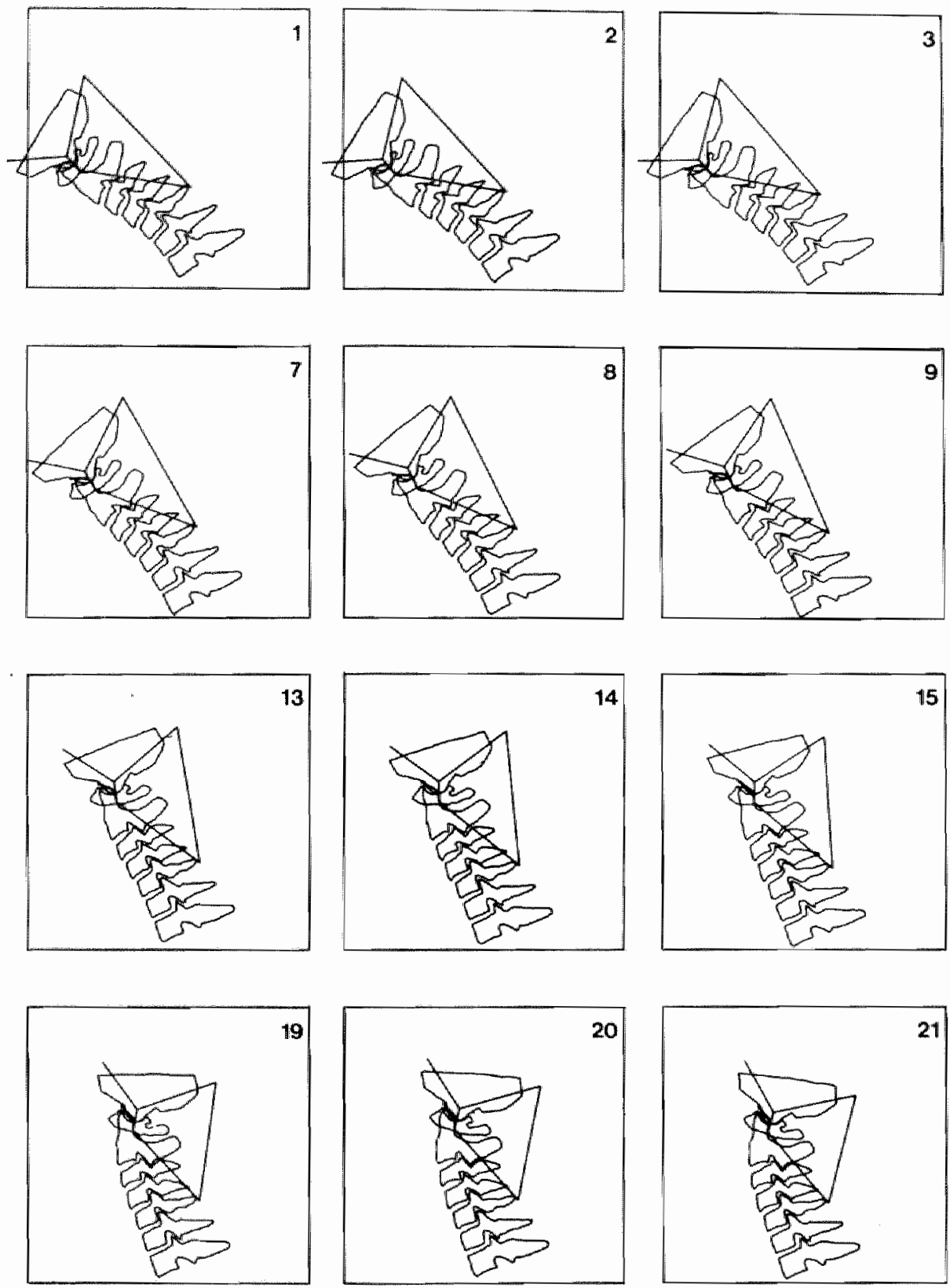

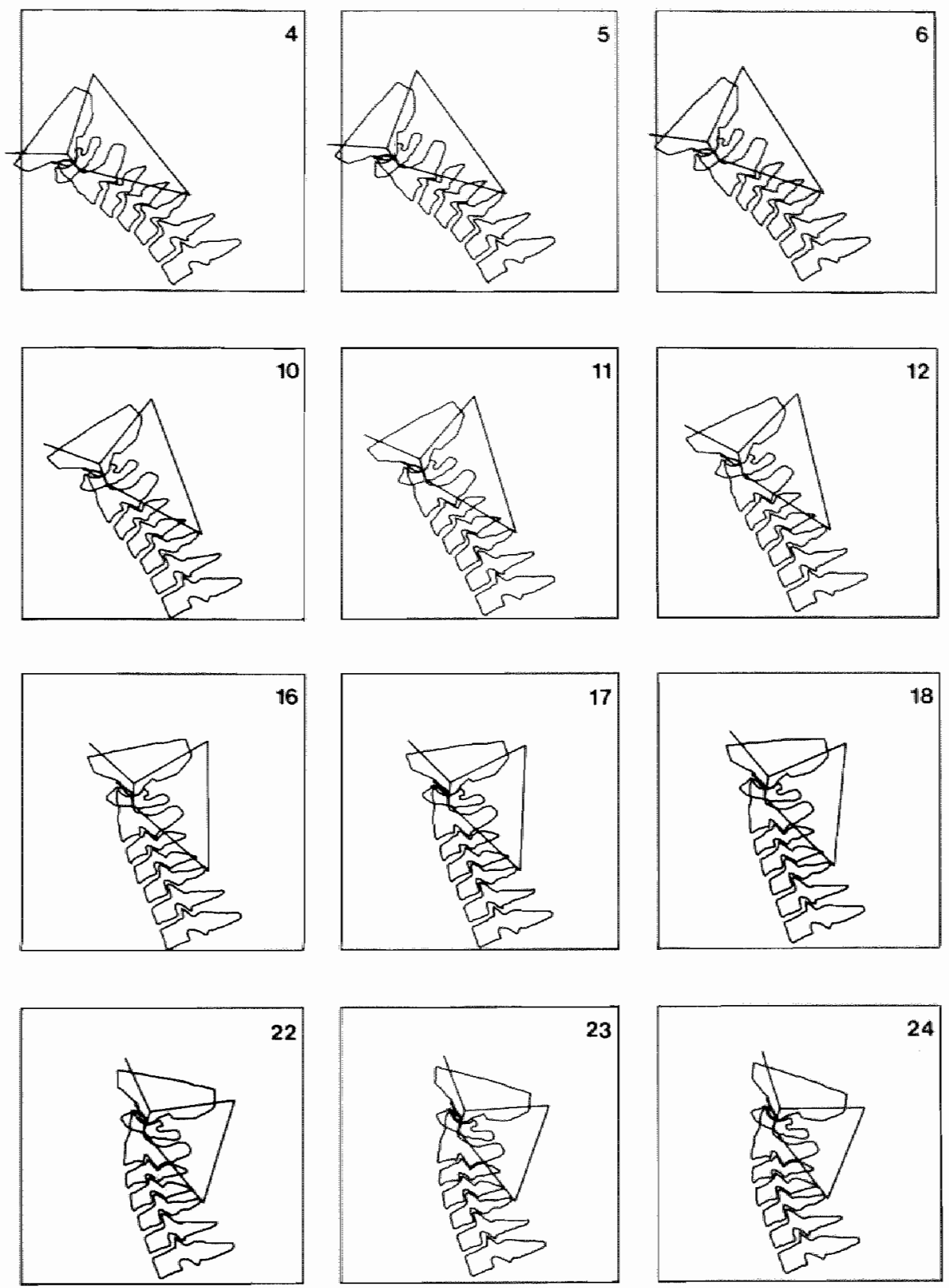

7ig. 8.4 Components of the model related to the contours of the bony parts on pictures 1 to 48 of retroflexion of test person L4. Centre of gravity (W) and pivoting point (6) are indicated beyond the contour of $O O$ because in this person a smaller part of the contour is drawn as compared to 

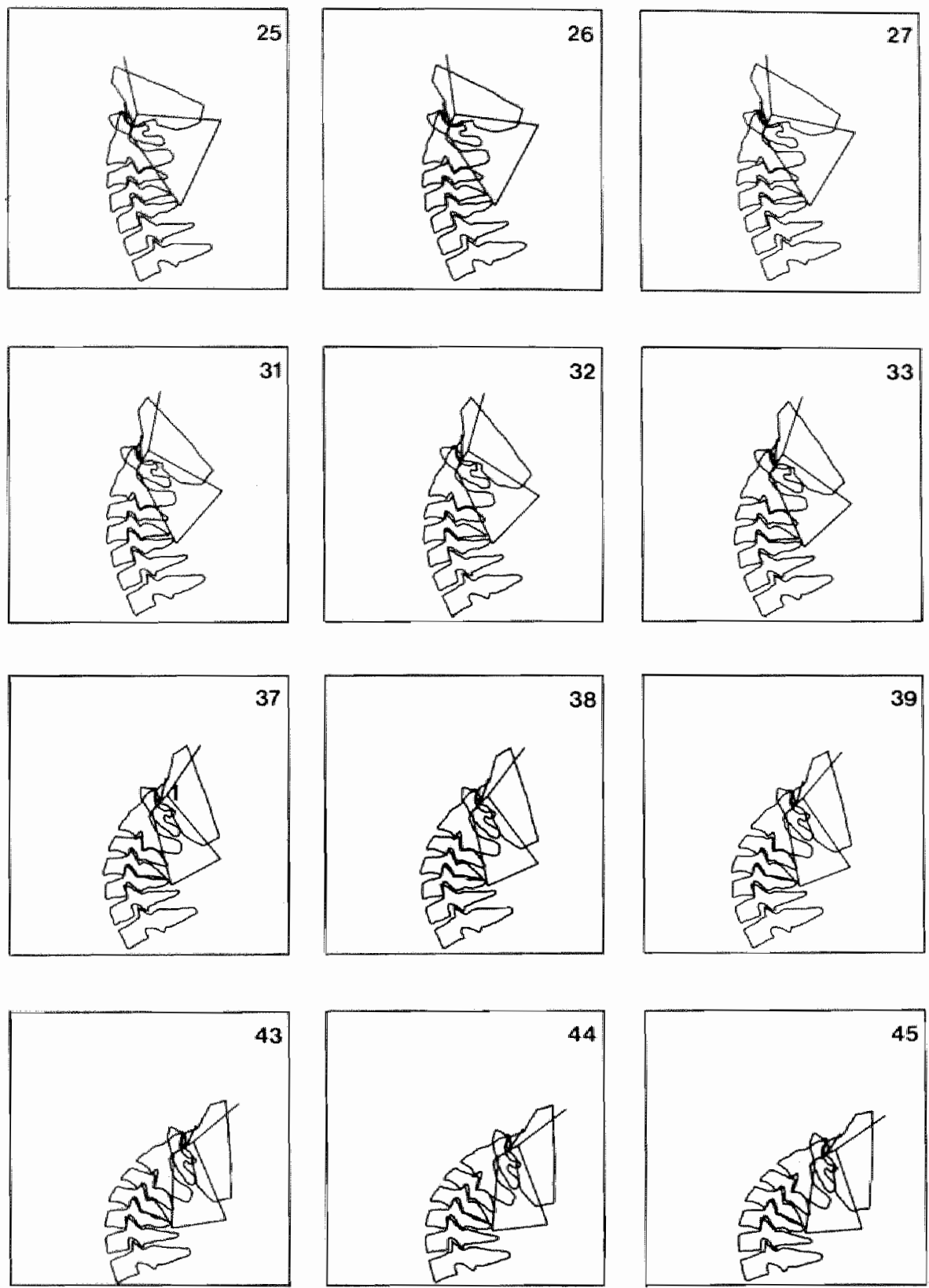

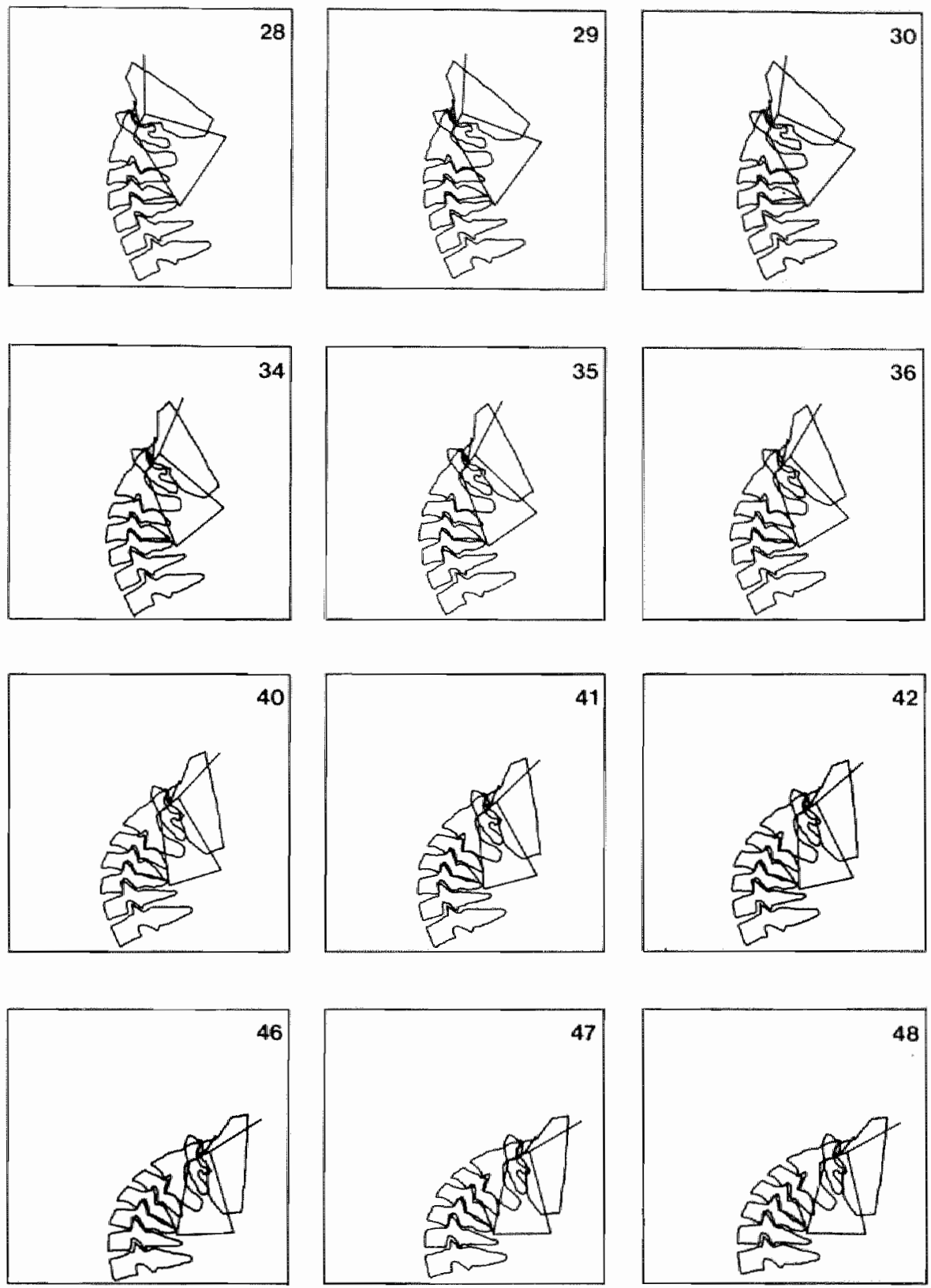


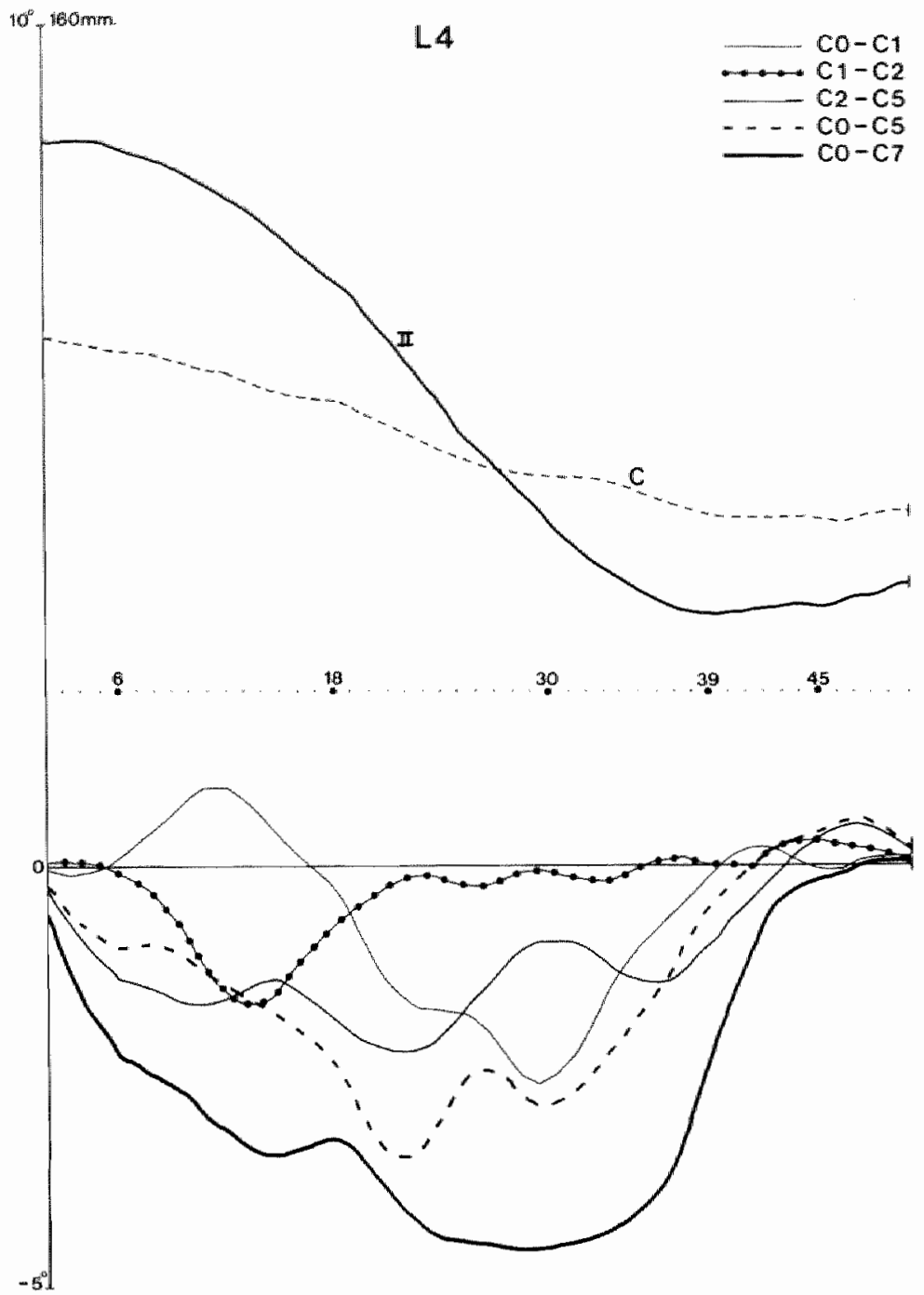

กg. 8.5 Relative rotations, distance between pivoting points (5) and (6), "cable II", and distance (C) plotted against normalized 50 frames (retroflexion $L A$ ).

- From image 15 , the centre of gravity of the skull is almost perpendicular to the hinge (1) or ventral of it. On the images prior to image 10 , this centre of gravity is clearly dorsal of the dorsal part of the vertebral body of $\mathrm{C} 7$ (figure 8.2).

* This means that only from approximately image 10 onwards anteflexion may take place in segment $(\mathrm{C} 0-\mathrm{Cl})$ checked by eccentric contraction of the dorsal muscles (attached to the external occipital protuberance).

* The criterion of minimum physical work is met if anteflexion in ( $\mathrm{C} 0-\mathrm{C} 2)$ occurs by means of eccentric contraction of the dorsal 
muscles. For this reason anteflexion of the cervical spine in the first part of anteflexion may be expected in the caudal part of the cervical spine rather than in the cranial part.

\section{2}

- In segment ( $\mathrm{C} 1-\mathrm{C} 2)$ little or no anteflexion occurs between images 1 and 14. The anteflexion contribution of segment $(\mathrm{C} 1-\mathrm{C} 2)$ occurs mainly between image 18 and image 37 (figure 8.3).

* It may be expected in the phase before image 14 that bar (B) tends to rotate backwards in relation to hinge (2) under the influence of the moment of the dorsal muscles and the mass of the head. Little or no anteflexion will therefore take place in segment (C1-C2).

- Between images 18 and 29 anteflexion occurs both in segment $(\mathrm{CO}-\mathrm{C} 1)$ and in segment (C1-C2) (figure 8.3).

* Because of this combination of contributions to motion, cable (I) may keep a constant length.

3

- As from image 37, the combination of retroflexion in segment $(\mathrm{CO}-\mathrm{C} 1)$ with anteflexion in segment (C1-C2) does not occur (figure 8.3).

- This combination might be expected at first. From image 37 onwards, but probably earlier, bar (B) tends to rotate forwards in relation to hinge (2). There are no muscles attached to the dorsal arch of the atlas which might prevent retroflexion in segment (COC1). It is therefore plausible to attribute this to cable (I).

4

- From image 37, the distance between ( 5 ) and (6), cable (II), reaches its maximum length (figure 8.3).

- From image 37 , there is no anteflexion in block ( $\mathrm{C} 0-\mathrm{C} 2)$ neither in segment $(\mathrm{CO}-\mathrm{C} 1)$ nor in segment (C1-C2) (figure 8.3).

- From image 37, cable (II) has reached the length at which it is stretched. Combined anteflexion in both segments in block (COC2), which would be possible in a constant length of cable (I), is prevented by cable (II). 5

- Between image 37 and 50, retroflexion oc- curs in block ( $\mathrm{CO}-\mathrm{C} 2)$, starting in segment (C1-C2), as a result of which retroflexion must occur in segment (C0-C1) (figure 8.3). - Between image 37 and image 42 , only little anteflexion occurs between the skull and $\mathrm{C} 5$. This anteflexion is not caused by block ( $\mathrm{CO}$ $\mathrm{C}$ ). It occurs in block (C2-C5). In this phase, distance (C) reaches its maximum length, while cable (II) is at maximum length too (figure 8.3).

- From image 42 to 50 , anteflexion in block (C2-C5) is exceeded by retroflexion in block (C0-C2) (figure 8.3).

- Because of the combination of anteflexion in block (C2-C5) and retroflexion in block $(\mathrm{C} 0-\mathrm{C} 2)$, cable (II) retains the same length. 6

- Between the skull and C7, anteflexion continues to occur in the phase following image 37 , but not between the skull and $\mathrm{C5}$. This anteflexion is mainly the result of anteflexion in the segments caudal of $\mathrm{C} 2$. Comparison between $(\mathrm{CO}-\mathrm{C} 7)$ and $(\mathrm{CO}-\mathrm{C5})$ shows that from image 42 anteflexion between the skull and $\mathrm{C7}$ is mainly effected in the caudal part of the cervical spine (figure 8.3).

* In that part of the path where both distance (C) and the distance between (5) and (6), cable (II), have their maximum length, effective anteflexion of the skull may only occur caudally of $\mathrm{C} 5$.

In the maximum "bending" anteflexion position, the muscles dorsal of the cervical spine are relaxed. In the bars-cable system tension is maintained in equilibrium with (W) in the ligamentous structures (such as cable (I) and (II)).

\section{Retroflexion}

We know (chapter 7) that during retroflexion of the cervical spine sometimes first there may be a small retroflexion contribution of segments (C0-C1) and (C1-C2). However, the main retroflexion contribution in segment (C1-C2) occurs in combination with an anteflexion contribution in segment (CO$\mathrm{C} 1$ ), followed by the strongest retroflexion contribution of segment $(\mathrm{CO}-\mathrm{C} 1)$. Of these 
contributions to motion the following may be said:

1

- Between image 1 and image 6, retroflexion of the skull in relation to $C 7$ occurs in the part of the cervical spine situated caudally of $\mathrm{C} 2$. - This is caused by concentric contraction of the dorsal muscles.

2

- Between image 1 and 6 , no motion occurs in segments ( $\mathrm{CO}-\mathrm{C} 1)$ and $(\mathrm{C} 1-\mathrm{C} 2)$ (figure 8.5).

- Between image 1 and 6 , the centre of gravity of the head is far ahead of hinges (1) and (2) (figure 8.4).

- The length of the distance between (5) and (6), cable (II), remains the same (figure 8.5). - From the first image, distance $C$ decreases. * In this path bar (B) tends to rotate forwards, which entails a combination of anteflexion in (C1-C2) and retroflexion in (COC1). This combination does not occur under the influence of cable (I).

* Cable (I) and cable (II) would allow the combination of retroflexion in segment (C1$\mathrm{C} 2)$ with retroflexion in segment $(\mathrm{CO}-\mathrm{C} 1)$. However, considering the position of the centre of gravity of the head, this would entail inefficient use of the force of the dorsal muscles.

* Since distance $(\mathrm{C})$ decreases, anteflexion in segment $(\mathrm{CO}-\mathrm{C} 1)$ and anteflexion in (C1-C2) might co-occur. That this does not in fact happen is because the dorsal muscles are con- tracted immediately from the start of the movement.

3

- Between image 6 and image 8 , retroflexion in segment ( $\mathrm{C1}-\mathrm{C2})$ combines with anteflexion in segment (CO-C1) (figure 8.5).

- In this path vector (W) will become more parallel to the longitudinal direction of block (C0-C2), while the direction of the muscular force remains almost unchanged (figure 8.4).

* As a consequence, the resultant of the force of the dorsal muscles and the mass of the head will be dorsal of hinge (2). Subsequently, bar (B) tends to rotate backwards. This comes down to the said combination of retroflexion in segment (C1-C2) and anteflexion in segment $\mathrm{C} 0-\mathrm{C} 1$ ). This combination of movement is not stopped by cable (I), whille the rectis capitis minores muscles (from the posterior arch of the atlas towards the skull) have too small a moment to prevent anteflexion in segment $(\mathrm{CO}-\mathrm{Cl})$.

4

- After this combination of contributions of motion, the retroflexion in segment $(\mathrm{C} 1-\mathrm{C} 2)$ is over and retroflexion contribution occurs in segment $(\mathrm{C} 0-\mathrm{C} 1)$ between image 19 and image 39 , with a maximum around image 30 (figure 8.5).

- Within that part of the motion of the cervical spine, in particular around image 30 , the centre of gravity of the head is vertical of hinge (1) and almost vertical to the dorsal part of the cervical body of $C 7$.

* In this path of the motion retroflexion in

ng. 8.6 Segmentall contributions of (CO-C1) and (C1-C2) related to the position of the cranial part of the cervical spine. Data is indicated of registrations L,1 to L6 and N1 to N6.

a Path in the sagittal plane of centre of gravity (W) and the pivoting points (1) and (2) connected to each other. 18 pasitions of these points are indicated (picture $1,4,7$, etc. and 50 )

b Relation between relatiwe rotation of segment ( $\mathrm{CO}-\mathrm{Cl}$ ) (ordinate) and $\mathrm{x}$-coordinate of pivoting point ( 1 ) ( $\mathrm{ab}$ scissa), respectively relation between relative rotation of segment $(\mathrm{C} 1-\mathrm{C} 2)$ (ordinate) and $\mathrm{x}$-coordinate of pivoting point (2) (abscissa).

c Difference between $x$-coordinate of the centre of gravity and $x$-coordinate of pivoting point (1) on one frame (ordinate) plotted against $x$-coordinate of pivoting point (1) (abscissa) respectively difference between $x$-coordinate of pivoting point (1) and $x$-coordinate of pivoting point (2) (ordinate) on the same picture plotted against $x$-coordinate of pivoting point (2). In case of a more ventral position of the former point with respect to the second point the graph is plotted in negative y-direction. The intersection of these graphs wilh the abscissa present the position in which centre of gravity and pivoting point (1), respectively pivoting point (1) and piwoting point (2) are vertical to each other.

The walues along the abscissa in $a, b$ and $c$ are equal. Vertical lines are drawn through the intersections with the abscissa in $c$ and are extended into the graphics $a$ and $b$. The first and last values of the graphs in $b$ and $c$ are connected to each other with an interrupted line extended to the graphic a. 

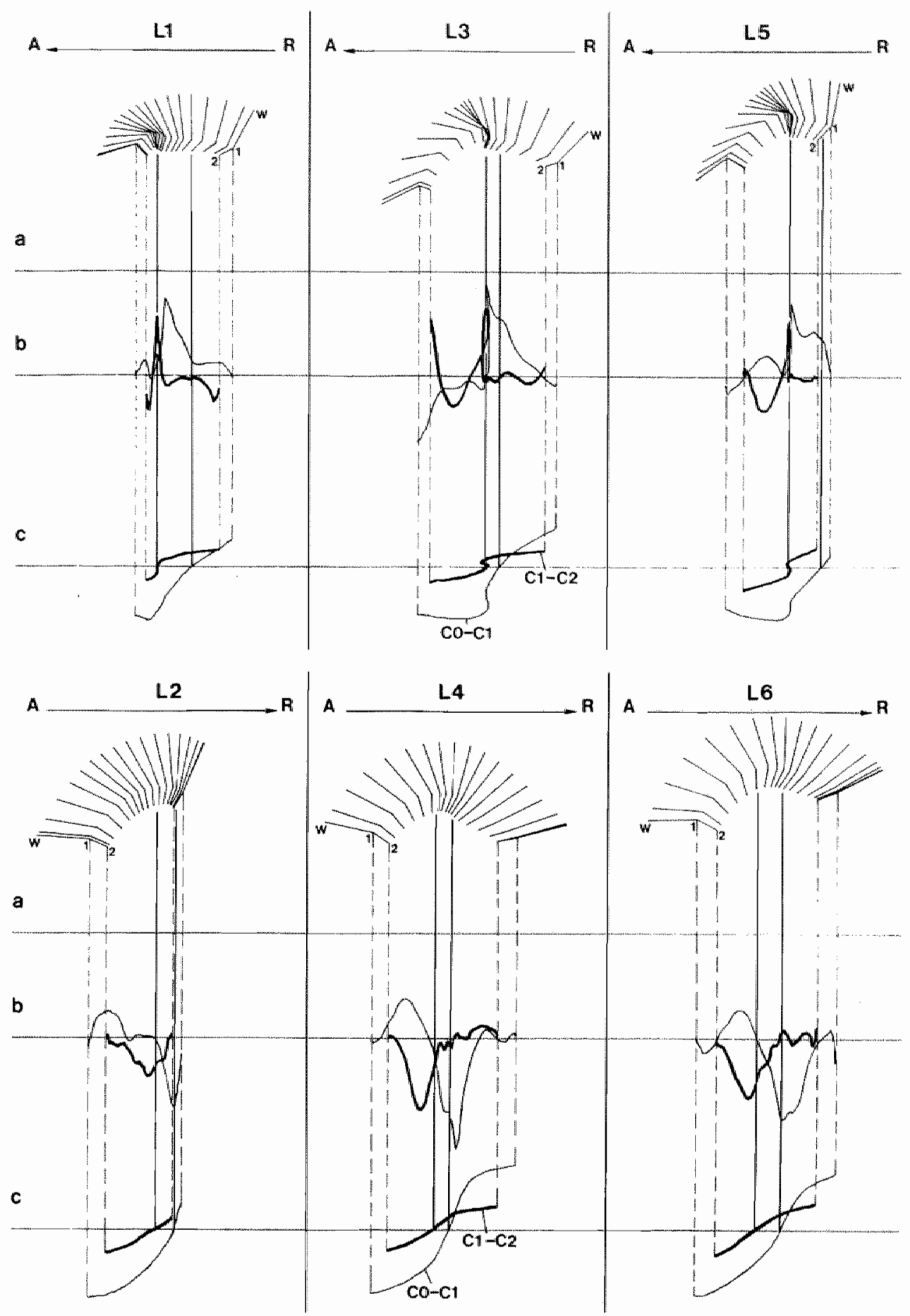

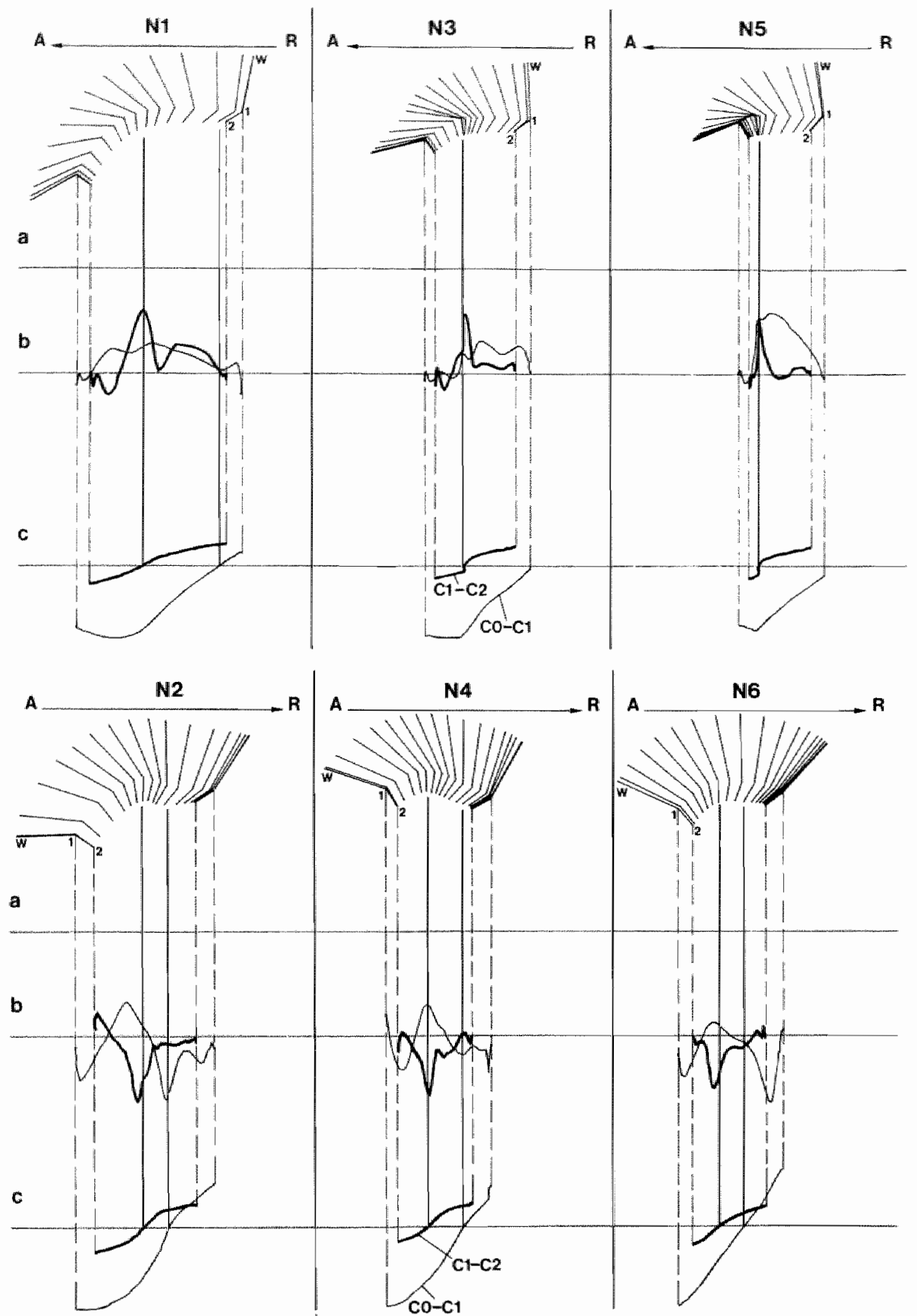
segment ( $\mathrm{C} 0-\mathrm{C} 1)$, not being held back by cable (I), involves efficient use of the dorsal muscles.

\section{5}

- From image 45 , no retroflexion occurs between the skull and C7. Between image 45 and image 50 , slight anteflexion occurs in the segments cranial of $\mathrm{C5}$ (figure 8.5).

* The test person cannot bend his head further backwards. An attempt is made to move the head towards a dorsal position, which is accompanied by slight anteflexion between the skull and C5, to be indicated as internal distortion of the cervical spine without retroflexion of the skull in relation to $\mathrm{C} 7$.

Summarizing the preceding allows the following general predictions to be made about segmental motion in block ( $\mathrm{CO}-\mathrm{C} 2)$.

As to anteflexion of the cervical spine:

1. Motion in block ( $\mathrm{C} 0-\mathrm{C} 2)$ starts in segment (C0-C1). The contribution to motion is largest after the centre of gravity of the head has been positioned ventral of the centre of rotation in segment $(\mathrm{CO}-\mathrm{C} 1)$.

2. When the motion in segment $(\mathrm{C} 0-\mathrm{C} 1)$ has provided its largest contribution, segment (C1-C2) will start to contribute to anteflexion in block $(\mathrm{C} 0-\mathrm{C} 2)$. The contribution to motion in segment (C1-C2) is largest around that position in the motion where the centre of rotation of segment $(\mathrm{CO}-\mathrm{Cl})$ is ventral of the centre of rotation of segment $(\mathrm{C} 1-\mathrm{C} 2)$.

3. During the phase of anteflexion contribution of segment (C1-C2), the contribution to the motion in segment ( $\mathrm{CO}-\mathrm{Cl})$ decreases; alternatively, retroflexion may occur in segment ( $\mathrm{C} 0-\mathrm{C} 1)$.

4. In the last phase, retroflexion occurs in block ( $\mathrm{CO}-\mathrm{C} 2)$, in segment ( $\mathrm{CO}-\mathrm{C1})$, segment $(\mathrm{C} 1-\mathrm{C} 2)$ or in both segments.

As to retroflexion of the cervical spine:

1. Anteflexion occurs in segment (CO-C1) in the phase in which segment (C1-C2) contributes most to retroflexion, or immediately after that. This combination of contributions to motion takes place immediately before or during that position of block ( $\mathrm{C} 0-\mathrm{C} 2)$ in which the centres of rotation of segment $(\mathrm{CO}$ C1) and $(\mathrm{Cl}-\mathrm{C2})$ are in vertical position to each other.

2. If at the beginning of motion in block ( $\mathrm{CO}$ $\mathrm{C} 2$ ), a retroflexion contribution in segment (C0-C1) occurs, this involves retroflexion in segment $(\mathrm{C} 1-\mathrm{C} 2)$ and it is smaller than the retroflexion contribution in segment $(\mathrm{CO}$ C1) which occurs after the retroflexion contribution of segment (C1-C2).

3. In the last phase of the motion, retroflexion contribution occurs in segment $(\mathrm{CO}-\mathrm{Cl}$ ). The retroflexion contribution in segment $(\mathrm{CO}-\mathrm{C} 1)$ is largest after the centre of gravity of the head has come to be dorsal of the centre of rotation of segment $(\mathrm{CO}-\mathrm{C} 1)$. In this phase the retroflexion contribution in segment $(\mathrm{C} 1-\mathrm{C} 2)$ is small.

\subsubsection{Model verification}

In the ten test persons, the following relation between the position of block ( $\mathrm{CO}-\mathrm{C} 2)$ in the gravitational field and the contributions to motion of segments (CO-C1) and (C1-C2) can be observed from the diagrams (figure 8.6). As an example, only the diagrams of registrations $\mathrm{L} 1$ to $\mathrm{L} 6$ and $\mathrm{N} 1$ to $\mathrm{N} 6$ have been included. The figures of the other registrations show similar phenomena.

\section{Anteflexion:}

In four persons ( $L, M, O$ and $P$ ), the centre of gravity of the head is dorsal of hinge (1) at all three moments of measurement at the beginning of motion. At one of the two moments of measurement, this is the case in five persons (N, Q, S, T and U). In one person (R) the centre of gravity of the head is ventral of the said hinge (1) during the entire motion. In all ten persons, anteflexion contribution in segment ( $\mathrm{C} 0-\mathrm{C} 1)$ occurs in the phase in which the centre of gravity of the head is ventral of hinge (1). The largest contribution to motion is reached in the phase prior to the one where the centres of rotation of both seg- 
ments are in a vertical position to each other. 2. In nine persons, anteflexion contribution in segment (C1-C2) occurs around the posithon where hinges (1) and (2) are in a vertical position to each other. The largest contribution to motion was seen either in this position or immediately after. In one person $(O)_{*}$ the largest contribution was found to occur prior to this position.

3. In 4 persons ( $O, P, R$ and $S$ ), it was found that in the phase in which the largest contribution to motion takes place in segment (C1-C2), retroflexion may be seen in segment (CO-C1) at all three moments of measurement. This retroflexion then accurs when the position has been reached at which hinge (1) and (2) are in a vertical position to each other.

4. In the last part of the movement, retroflexion occurs in segment (CO-C1), in segment (C1-C2) or in both.

\section{Retroflexion:}

1. In all ten persons, the largest contribution to motion in the retroflexion direction in segment (C1-C2) occurs prior to the point at which the centres of rotation of segments $(\mathrm{CO}-\mathrm{C} 1)$ and $(\mathrm{C} 1-\mathrm{C} 2)$ are in a vertical position to each other or at this point. In all ten persons, this involves anteflexion in segment (CO-C1). In this phase, the centre of gravity of the head is still ventral of both centres of rotation. Retroflexion in segment $(\mathrm{C1}-\mathrm{C} 2)$ is linked to antefllexion in segment $(\mathrm{CO}-\mathrm{C} 1)$ in this phase.

2. Contrary to anteflexion, one may recognize a phase during retroflexion, in all. ten persons and at each moment of measurement, at which the centre of gravity of the head is dorsal of the centre of rotation of segment ( $\mathrm{CO}-\mathrm{C} 1)$. In all ten persons, the largest retroflexion contribution in (CO-C1) occurs in this phase; the centres of rotation of segment $(\mathrm{CO}-\mathrm{C} 1)$ is dorsal of that of segment (C1-C2) and there is little or no retroflexion in segment (C1-C2). Segment $(\mathrm{Cl}-\mathrm{C} 2)$ is already in retroflexion.

\subsection{Discussion}

Previous models tended to relate only to the question in what position of the remaining part of the cervical spine in segments (CO$\mathrm{C} 1)$ and $(\mathrm{C} 1-\mathrm{C} 2)$ the maximum range of motion is reached (Penning, 1968, Depreux and Mestdagh, 1974). The models consist of the chain occipital bone, atlas, axis and tectorial membrane (Werne, 1957) and/or alar ligaments (Penning, 1978). The model of Dul et al. $(1982,1984)$, which was based on data by Gutmann (1968), Lewit and Krausovà (1963) and Arlen $(1977,1978)$ does not allow for the possibility that both (CO-C1) and (C1-C2) in isolation or in combination - may show retroflexion at the end of anteflexion on the entire cervical spine as described in chapter 7. The function of the funicular part of the ligamentum nuchae in this extreme position of the cervical spine is indicated. If this were to

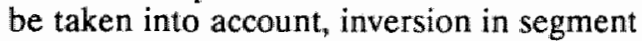
(C1-C2) would also involve efficient use of the muscles. We have formulated a model for the cranial part of the cervical spine in relation to the connections with the caudal part, which makes verifiable prognoses as to the order of segmental motion patterns and inversion phenomena. It contains all relevant hitherto recognized structures as to the shape of articular surfaces, and attachments and function of ligamentous connections between the bones in block ( $\mathrm{C} 0-\mathrm{C} 2)$ and data on the shape and function of lower segments. This new model is based on a presumed equilibrium of forces and moments (mass of the head as opposed to muscular force and tension in ligamentous structures) during slow motion in the sagittal plane of the head and the cervical spine between maximum retroflexion position of the chain and maximum "bending" anteflexion position.

In our model, only the fumicular part of the ligamentum nuchae has been included. Data from literature do not always make clear to what extent the lamellar part of the ligamentum nuchae may be of mechanical interest. Prior to deciding to include only the funicular part in the model, dissection of these ligamentous structures has been repeated as a 
check in five corpses (three preserved, two not preserved; Van Mameren, 1988). This study showed, among other things, that the attachment of the lamellar part to the posterior tubercle of the atlas and the spinous process of the axis, $\mathrm{C} 3$ and $\mathrm{C} 4$, consists of a very thin membrane. In this membrane few collagenous fibre bundles are visible in comparison to the other parts of this connective tissue complex. It may easily be pierced with a blunt object. The vertebrae mentioned can move freely in relation to their attachment to this complex of connective tissue. From C5, there is an intricate complex of connective tissue around the tops of the spinous processes of C5 to Th2 in the caudal direction. This is caused by the collagenous fibres from the trapezius muscles (transverse part), by the rhomboid muscles and the superior posterior serratus muscles and, further towards the transition between the spinous process and the vertebral arch, by collagenous fibres from the splenius capitis muscles. The funicular part is recognizable on a cross-section as a triangular structure from this complex in cranial direction and is attached to the external occipital protuberance. In the cranial part of the cervical spine, there is a medial cord which attaches more or less loosely from the trapezius muscles, at the external occipital protuberance. From the literature mentioned, our dissection results and the observations in vivo, the conclusion was drawn that in the model a ligamentous structure has to be taken into account between the external occipital protuberance and spinous process of C5.

A number of muscles, e.g. the lesser rectus capitis muscles, have not been included in the model. These may check anteflexion in segment ( $\mathrm{CO}-\mathrm{C} 1)$. The moment which they may develop was considered negligible. Other muscles at the ventral side of the cervical spine that might contribute to anteflexion of the cervical spine are the longus muscles and the anterior and middle scalene muscles. These have not been included either, since they only function in the part of the cervical spine caudal of block ( $\mathrm{CO}-\mathrm{C} 2)$.
The orders of motions found and the phases at which a segment contributes considerably to motion of the block in relation to the position of block $(\mathrm{CO}-\mathrm{C} 2)$ in the gravitational field, are in accordance with the predictions (8.3.1) drawn up. No contradictory motion phenomena were found. The combination of diagrams suffices to determine the phase at which a segment contributes considerably to motion in block ( $\mathrm{C} 0-\mathrm{C} 2)$ compared to the position of the centre of gravity of the head and the centres of rotation of both segments ( $\mathrm{CO}$ $\mathrm{C} 1)$ and (C1-C2). In the model, motion by minimum physical activity is presumed preferable. If this prerequisite is left out, at number of less efficient orders is possible. A small retroflexion contribution in $(\mathrm{CO}-\mathrm{Cl})$ during initial retroflexion of the entire cervical spine, preceding the combination of anteflexion in $(\mathrm{CO}-\mathrm{C} 1)$ and retroflexion in $(\mathrm{C} 1$ $\mathrm{C}$ ), is among the possibilities. Considering the constant (maximum) length of cable (I), this retroflexion contribution in $(\mathrm{CO}-\mathrm{C} 1)$ will then involve a retroflexion contribution in segment (C1-C2).

When the model described here is used, the initial question answered is not which is the difference in tension in ligamentous structures and muscle tissue between two different positions of segment (C0-C1) (Dul, 1982, 1984), but the question in what phase of the motion of the cervical spine a contribution may be expected to the motion by segment (CO-C1) and/or segment (C1-C2) with as little muscular force as possible (considering a constant - maximum - length of ligamentous structures). The orders and inversion movements in the segment appear predictable during both directions of movement.

During retroflexion, inversion in segment (CO-C1) occurs simultaneously with retroflexion in segment (C1-C2) in all persons. This zigzag movement cannot be prevented by any muscle or ligamentous structure. During anteflexion, inversion is present in only part of the persons. This zigzag movement may be prewented by cable (I). If cable (I) is not present, from the moment the result of (W) and the dorsal muscles are ventral of 
hinge (2), anteflexion will occur very rapidly in segment $(\mathrm{C1}-\mathrm{C2})$ together with retroflexion in segment ( $\mathrm{CO}-\mathrm{Cl})$.

We were unable to confirm Penning's presupposition (1968) that in the final phase of the "bending" anteflexion, deflexion of the head in relation to the thorax occurs. In this phase retroflexion in block (CO-C2) is smaller than the anteflexion in the remaining part of the cervical spine. The distance in caudal direction between head and sternum does not increase either. Further anteflexion in the part of the cervical spine between $\mathrm{C} 2$ and C5 involves "lengthening" of the dorsal side of the cervical spine. The length of the funicular part of the ligamentum nuchae should stay the same. This means that for that reason retroflexion must take place in block (C0-C2).

The proposed (kinematic) model therefore allows adequate explanation - better than with the analyses described so far - of phenomena such as retrograde motion of (numbers of) segments and the order of segmental contributions to motion of the block ( $\mathrm{CO}$ C2) related to the position of the cranial part of the cervical spine. Further research will have to be done as to what extent it may also serve as a basis for mathematical (or numerical) predictive modelling of (parts of) the cervical spine.

\section{Bibliography}

Arlen, A., Die "paradoxe Kippbewegung des Atlas" in der Funktionsidiagnostik der Halswirbelsäule, Man. Med., $15,16-22,1977$.

Arlen, A., Messverfahren zur Erfassung von Statik und Dynamik der Holswirbersäule in der sagittalen Ebene, Man. Med... 16, 25-35, 1978.

Deprewu, $R$, Mestdagh, $H$, Anatomie fonctionelle de l'articulation sons-occipitale, Lille Med. 19, 122-125, 1974

Dul, J., Snijders, C.J., Timmerman, P., Bewegungen und Krafte im oberen Kopfgelentik beim Vorbeugen der Hal- swintelsäule, Mam. Med, 20,51-58, 1982.

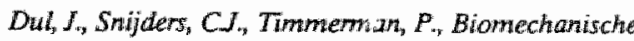
andiyse van de hoog-cenvicale wervelkolom, Ned. T. Man. ther. 39-45, 7984.

Fielding J.W, Burstein, A.H., Frankel, V.H., The nucheal ligament, Spine, 1, 3-14, 1976.

Gutmann, G., Schulkopfschmerz wnd Kopfhaltung. Ein Beitrag zur Pathogenese des Anteflexions-Kopfschmerzes und zur Mechanik der Kopfgetenke, Z. Onihop., 105, 497-515, 1968.

Halliday, D.R., Sullivan, C.R., Hollinshead, W.H. and Bahn, R.C. Tom cenvical ligaments: necropsy examination of normal cenical region, J. Trauma, 4, 219-232, 1964.

Jirout, $J$., The dymantic dependence of the lower cervical ventebrae on the atlanto-occipital joints, Neuroradiol., ?. 249-252, 1974 .

Koebke, J., Brade, $H_{\text {, }}$ Morphological and functional studies on the lateral joints of the first and second cervical wertebrae in man, Anat. Embryol, 164, 265-275, 1982.

Lewil, $K$, Krausowa, Ln, Messungen won Vor-und Rückbeuge in den Kopfgelenken, Fortsch. Röntg., 99, 538-543 1963.

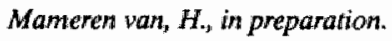

Penning, L., Functional pathology of the cervical spine, Excerpia Medica, Amsterdam, 1968.

Penning, L., Nomal movement in the cervical spine, Am. J. Roenigenol., 130, 317-326, 1978.

Putz, R., Pamaroli, A., Form und Funktion der Articulatio atlanto-axialis lateralis, Acta Anat., 83, 333-345, 1972.

Veau Le, B., Wilhoms and Lissmer: Biomechanics of human motion, W. B. Saunders Company, Philadelphia, London, Toronto, 2nd ed., 91, 1977.

Weme, S., Studies in spontaneous atlas dislocation, Acta Orhop. Scand., 23, suppl., 1957.

White, A.A., Johnson, R.M., Panjabi, M.M., Southwick, W. . Biomtechanical anatysis of clinical stability in the cenvical spine, Clin. Orthop. Rel. Res., vol. 109, 85-96, 1975.

Williams, P.L., Warwick, R., Groy's Anatomy, Churchill Livingstone, Edinbugh-London-New York, 36nd ed. 1980. 


\section{Sequences of motion in the other segments and blocks}

\subsection{Introduction}

So far little data is available on the orders in which the segments contribute to motion within the sagittal plane of the caudal cervical spine. In the numerous X-ray cinematographic researches on the normal motion of the cervical spine (Fielding, 1956, 1957; Gombert, 1957; Kottke and Lester 1958, Kottke and Mundale, 1959; Jones, 1960a; Fielding, 1964; Buonocore et al., 1966; Brunton et al., 1982) and on the abnormal motion (Gombert, 1957; Kottke and Lester, 1958; Jones, 1960b; Jones, 1961; Jones, 1962a, 1962b, Sollman, 1962; Bard and Jones, 1964; Buonocore et al., 1966; Jones and Bard, 1966; Hartman and Buonocore, 1967; Hohl and Brummet, 1968; Hartman et al., 1975; Brunton et al., 1982) little attention was paid to these sequences. Kottke and Mundale (1959) state that in the cranial part and in the caudal part of the cervical spine there is more "movability" in the sagittal plane than in the midcervical part, and a large interindividuall dispersion has to be taken into account. They stated that further research should be carried out into the motion patterns corresponding to certain complaints of the neck region.

Buonocore et al., (1966) note that during anteflexion of the cervical spine the segments move in a particular order: "The spinous processes during flexion separate in a smooth fan-like progression. Flexion motion begins in the upper cervical spine. The occiput separates smoothly from the posterior arch of the atlas, which then separates smoothly from the spine of the axis, and so on down the spine. The interspaces between the spinous processes become generally equal in complete flexion. Most important, the spinous processes separate in orderly progression. In extension the spines rhythmically approximate each other in reverse order to become fairly equidistant in full extension." During completion of the motion of the cervical spine within the sagittal plane the segments only contribute in the direction of the motion. A deviation to this feature is seen as a sign of pathology in the segment involved.

Thus only summary information is available on the orders in which the segments in the more caudal cervical spine move. Considering our findings with respect to the cranial part of the cervical spine it seemed opportune to devote a separate study to this feature.

Study of the order of contribution of segments to the motion of the cervical spine has a chance of success especially if this order is studied in smaller parts (blocks) of the cervical spine. One of the possibilities is that in a certain part of the cervical spine segments do not contribute in a certain order, but that they do in another part. In such a case, the presence of orders in that part in which orderly contribution does occur, will not be clearly visible if the contributions of both those segments that contribute orderly and the segments that do not, is registered in relation to the whole of these two parts. We therefore determined the order of segmental contributions in the cervical spine caudal of $\mathrm{C} 2$ in two overlapping blocks, block (C4-C7) and block (C2-C5) (figure 9.1a and 9.1b). The fact that these blocks overlap allows the orders of contribution of segment (C4-C5) to be related both to the contributions of segments cranial of this segment and the contributions of segments caudal of this segment.

Gombert (1957) describes that during motion within the sagittal plane certain parts of the cervical spine may be more rigid than other parts. In some types the largest "movability" may be seen in the region (C5-C7) and 


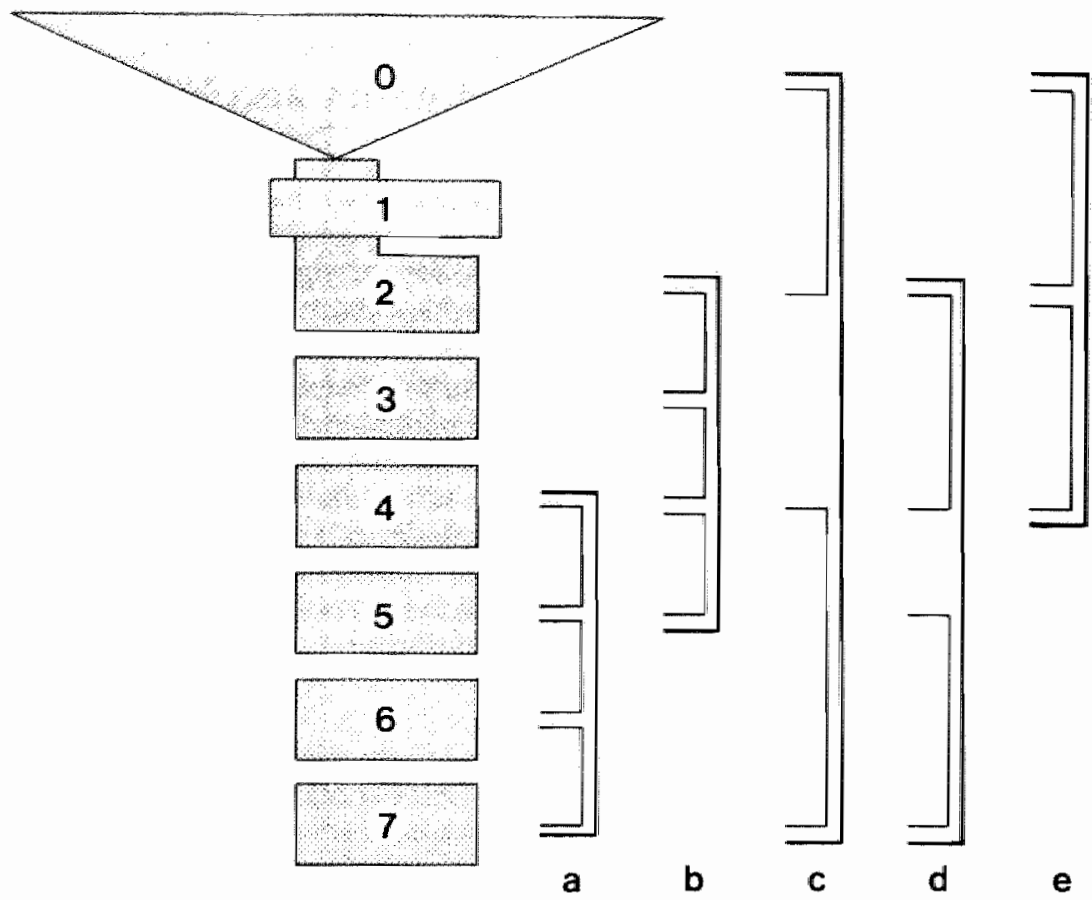

ng. 9.1 Diagram of the cervical spine divided in blocks and segments.

a Segments within block (C4-C7) (9.4.1).

b Segments within block (C2-C5) (9.4.2).

c Blocks ( $\mathrm{CO}-\mathrm{C2})$ and (C4-C7) in the whole spine (9.4.3).

d Blocks (C2-C4) and (C5-C7) in the whole spine (9.4.4)

e Blocks (CO-C2) and (C2-C4) in block (CO-C4) (9.4.5).

in other types this may be seen in the region (C3-C5). "Movability" may, however, also be equally distributed over the segments. The conclusion that in a cervical spine more rigid parts are next to regions with a larger "movability", prompts the assumption that blocks may move in relation to other blocks in the cervical spine. What the orders of these blocks are, is not known. We have described high-cervical, mid-cervical and low-cervical blocks. Apart from the already chosen segmental orders of contribution, this is the reason why we have also studied the orders of contribution of blocks within that part of the cervical spine in which they occur. Subsequently:

- A high-cervical block ( $\mathrm{C} 0-\mathrm{C} 2)$ and a lowcervical block (C4-C7) within $(\mathrm{C} 0-\mathrm{C} 7)$ (figure 9.1c).
- A mid-cervical block (C2-C4) and a lowcervical block (C5-C7) within (C2-C7) (figure 9.1d).

- A high-cervical block ( $\mathrm{CO}-\mathrm{C} 2)$ and a midcervical block (C2-C4) within (C0-C4) (figure 9.1e).

This choice also allows an answer to the question whether the contribution of a highcervical block occurs in a certain order in relation to a mid-cervical block or a low-cervical block, or in relation to both. This also applies to the aspects of order of a mid-cervical block in relation to a high- and low-cervical block. Of the orders described and assumed no data is available on intra- and interindividual variability (variability between different moments of measurement or between persons). There is also no information available 
on the extent in which a certain order found lies within the range of measurement error of the marking method used. We will try to find an answer to these questions.

Brunton et al. (1982) described a deviating segmental type of motion, called "double rock". This means that during anteflexion of the cervical spine from the retroflexion position towards the maximum anteflexion position, there is temporary retroflexion ("reversed movement"). During retroflexion of the cervical spine the opposite may be observed. A "double rock" may therefore only be found by means of cinematoradiography. It is also called "paradoxal motion". According to Hartman and Buonocore (1967) and Brunton et al. (1982) this type of motion does not occur in persons free of complaints. It occurs after whiplash injuries and would indicate degeneration in the intervertebral disc. We have already demonstrated that in segments (CO-C1) and (C1-C2) a phase of "reversed movement" ("inversion") occurs in persons free of complaints. For that reason the question was also posed whether this segmental type of motion caudal of $\mathrm{C} 2$ may also occur in persons free of complaints.

In order to answer the above questions the segmental or block contributions of each anteflexion of the cervical spine and of each retroflexion have been registered for each of the ten test persons, according to the method described in 7.2.1. From the diagrams obtained this way the sequences of the segmental contributions may be read.

\subsection{Method}

The segmental contributions in block (C4C7) are rendered in the same way as those in block ( $\mathrm{CO}-\mathrm{C} 2)$ (see 7.2.1). The orders of the segmental contributions in block (C2-C5), and the orders of the block contributions within a larger block or within the entire cervical spine have only been read from diagrams. Of the ten persons examined, the graphics of persons $L$ and $Q$ have been included in this thesis. The graphics of the other persons show similar findings.

\subsection{Reproducibility}

The diagrams as described in 7.3.2 and 7.3.1. of the above-mentioned film which was registered five times (R3) have also been made for the contributions discussed in this chapter (figures $9.2 c, 9.3 b, 9.4 b, 9.5 b$ and $9.6 b$ ). The method of indicating the positions of the contours and the calculation of rotations based on it therefore yield reproducible results.

\subsection{Results}

\subsubsection{Segments (C4-C5), (C5-C6) and (C6-C7) in block (C4-C7)}

During anteflexion of the cervical spine from a maximum retroflexion position towards maximum "bending" anteflexion, the following orders of segmental contributions to motion in block (C4-C7) have been found (figure 9.2a and 9.2b).

1. At each measuring moment, two maximums in the contributions of segments (C5C6) and (C6-C7) per unit of rotation may be distinguished during motion in block (C4C7) in all persons examined ( $L$ to $U$ ). These maximums are found in the first phase and in the last phase of motion in block (C4-C7).

2. In the first phase the order of these maximums is first segment (C6-C7), followed by segment (C5-C6). In 9 persons, the order of these maximums in the last phase is: segment (C5-C6) followed by a maximum of segment (C6-C7). In one person (M) this last order was the other way round at the first measuring moment.

3. In all persons examined the maximum of the contribution of segment (C4-C5) is between the first and the last phase. In four persons ( $L, M, N$ and $R$ ) two maximums may be distinguished in segment (C4-C5). These two maximums are found between the maximum of segment ( $\mathrm{C5}-\mathrm{C6}$ ) in the first and in the last phase. In the remaining six persons one maximum is present in segment (C4-C5) between the said maximums of segment (C5-C6). 
(A)
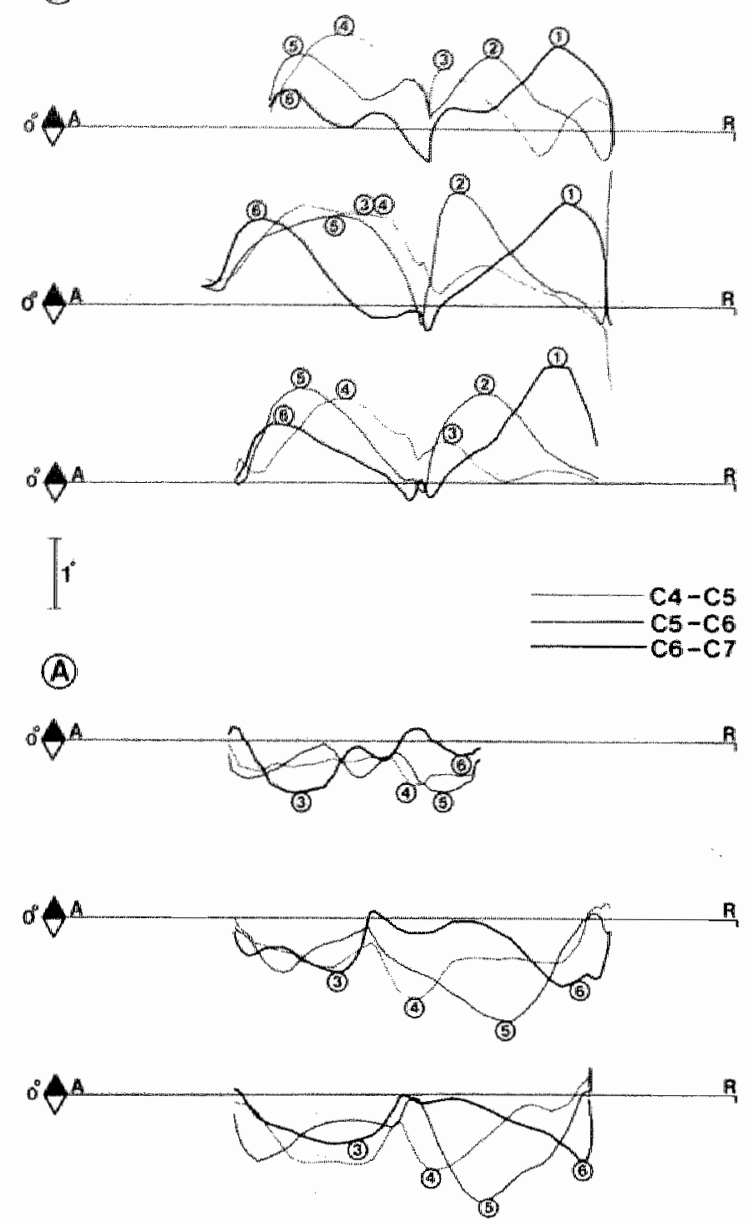

$160^{\circ}$

$-70^{\circ}$ wk 135

(B)
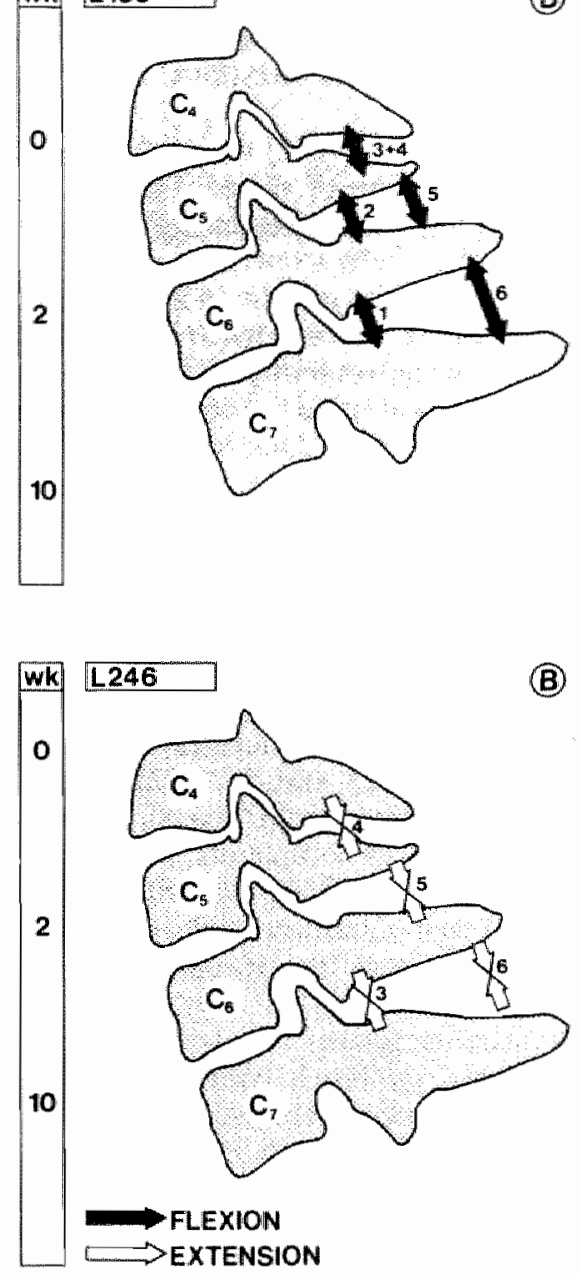

4. In seven persons ( $L, N, O, P, R, T$ and $U$ ) retroflexion occurs in segment $(C 6-C 7)$ between the first and the second maximum during anteflexion of block (C4-C7), and at each moment of measurement. This is also the case for one person $(\mathrm{M})$ at two measuring moments, and for two persons ( $Q$ and $S$ ) at one moment of measurement. In segment (C5-C6) this retroflexion may also be distinguished in two persons ( $\mathrm{L}$ and $\mathrm{N}$ ) at two mo- 
(A)
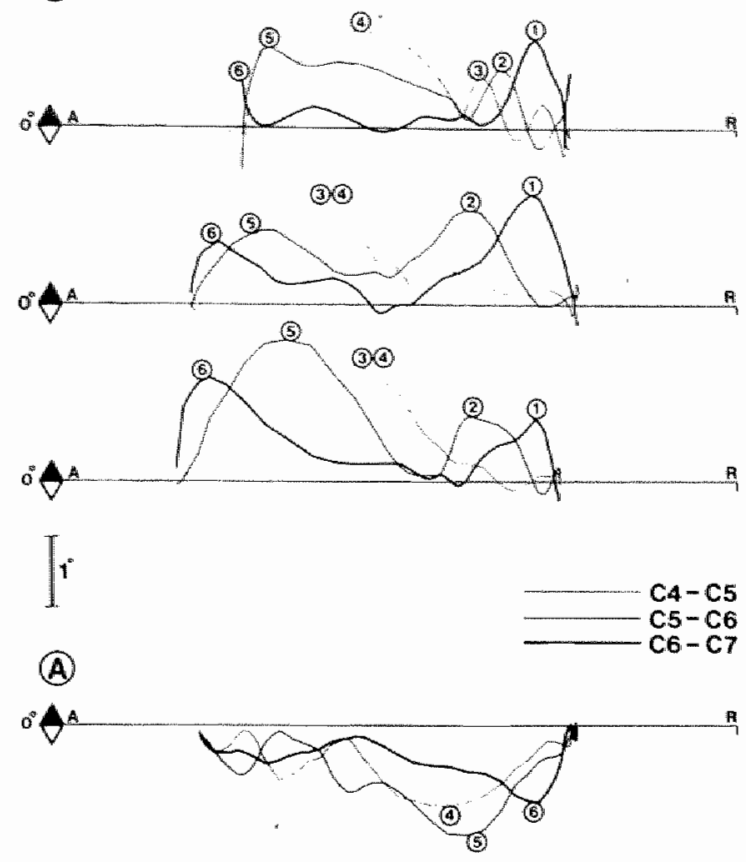

$$
0^{A}
$$

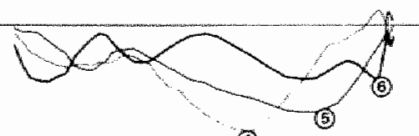

(4)

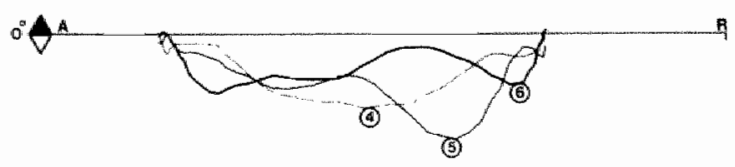

$150^{\circ}$

$-70^{\circ}$
WR 0135

(B)

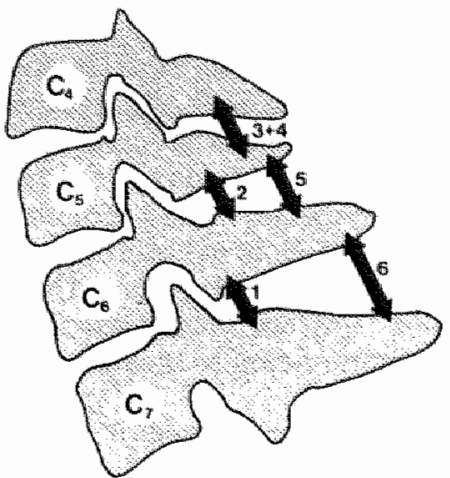

10

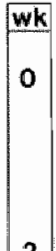

$\lcm{0246}$

(B)

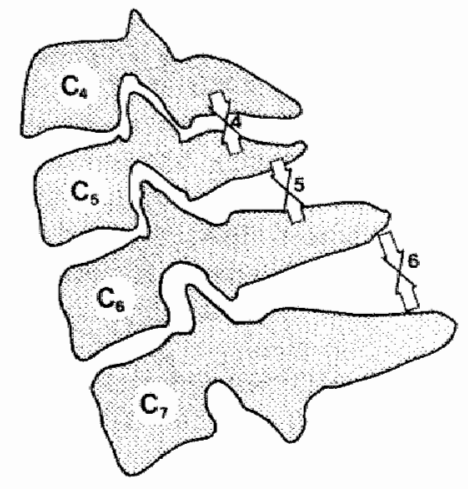

FLEXION

EXTENSION

ng. 9.2 Sequence of contributions of segments (C4-C5), (C5-C6) and (C6-C7) to motion in block (C4-C7). Test persons $L$ and $Q$, anteflexion registrations $(1,3,5)$ from $R$ to $A$, retroflexion registrations $(2,4,6)$ from $A$ to $R$. a Relative rotation in the segments plotted against absolute rotation in block (C4-C7). The sequence of peaks of the graphs shows the sequence of contribution. These peaks are numbered 1 to 6 .

b Nummered arrows, presenting this sequence, are indicated in relation to a diagram of the contours of block (C4-C7).

0,2 and 10 wks represent measuring moments, 1,3 and 5 are anteflexion, 2,4 and 6 are retroflexion registrations.

ments of measurement.

Summarizing, the following is found with respect to anteflexion in block (C4-C7):

1. In all persons examined a constant order of the segmental contributions in block (C4$\mathrm{C7}$ ) is demonstrated in the first phase of the motion within this block. In nine persons this also applies to the second phase.

2. In all persons examined motion in block 

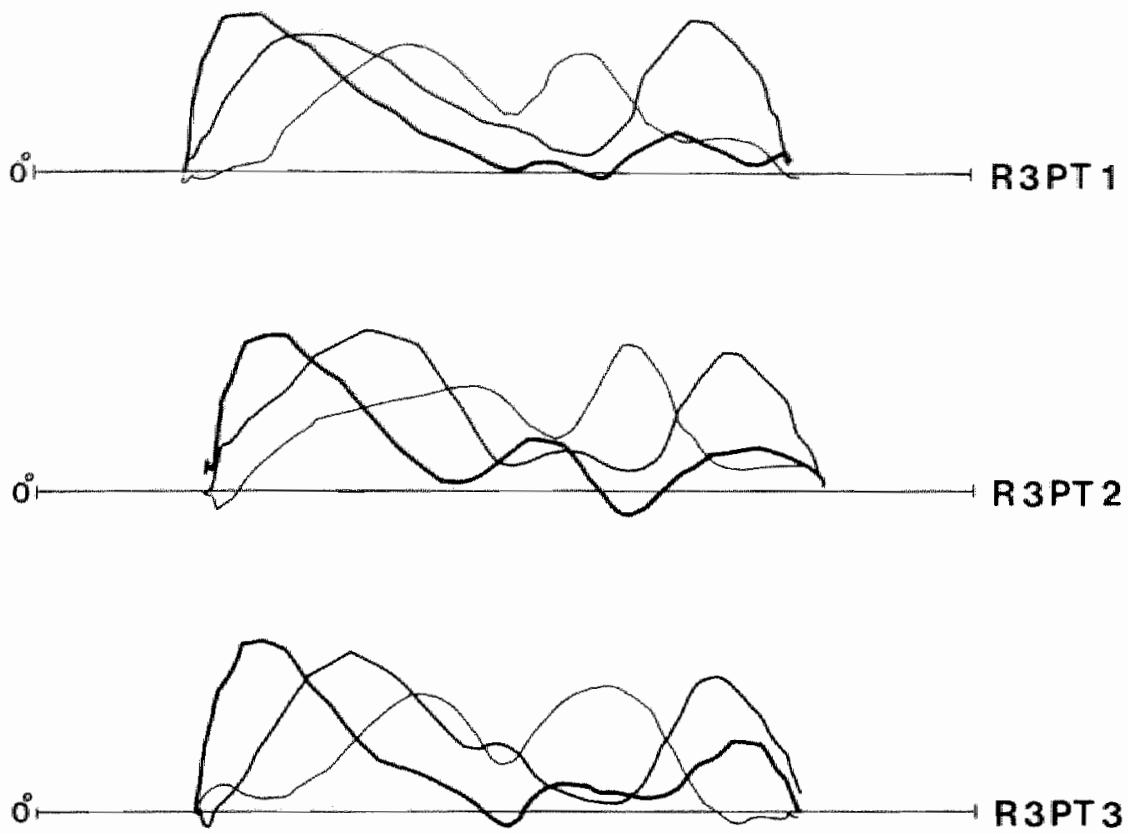

R 3 PT 3
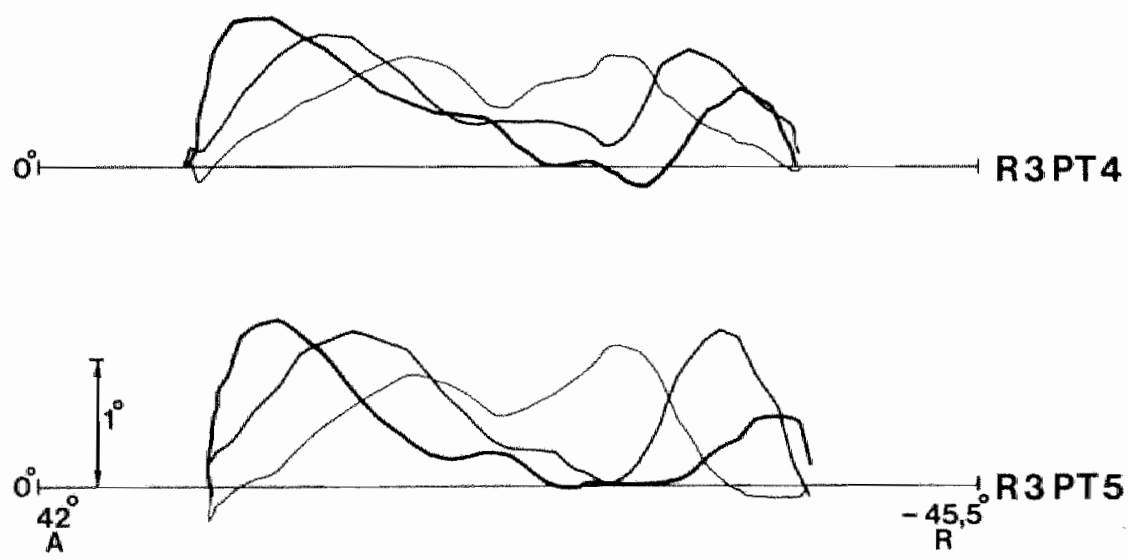

C4-C5

C5-C6 $\mathrm{C} 6-\mathrm{C} 7$

fig. $9.2 \mathrm{c}$. Reproducibility of sequence and inversion. 
(C4-C7) is started at each moment of measurement in segment (C6-C7), followed by contribution in segment ( $\mathrm{C} 5-\mathrm{C} 6)$ and in segment (C4-C5). In the second phase in nine persons this order of contribution is the other way round and motion in this block is concluded by a contribution of segment (C6-C7). 3. In four of the ten persons contribution at each moment of measurement in segment (C4-C5) is biphasic, both contributions occurring between the two contributions of the remaining segments in this block.

4. In seven of the persons examined a constant inversion phase in segment (C6-C7) may be distinguished. This inversion sometimes occurs in segment (C5-C6) too.

During retroflexion of the cervical spine from maximum "bending" anteflexion position towards maximum retroflexion position, the following orders of contribution to the movement have been found in block ( $\mathrm{C} 4-\mathrm{C} 7)$ (figure 9.2a and 9.2b):

1. In nine persons $(\mathrm{L}, \mathrm{M}, \mathrm{N}, \mathrm{O}, \mathrm{P}, \mathrm{Q}, \mathrm{S}, \mathrm{T}$ and $U)$ the orderly contribution to motion of block (C4-C7) distinguishable in the second phase of the movement at all three moments of measurement is as follows: first contribution of segment (C4-C5), followed by (C5$\mathrm{C} 6$ ) and then (C6-C7). In one person ( $R$ ) motion is concluded with a maximum of segment (C5-C6) instead of segment (C6-C7).

2 . In the first phase in seven persons $(\mathrm{M}, \mathrm{O}$, $\mathrm{Q}, \mathrm{R}, \mathrm{S}, \mathrm{T}$ and $\mathrm{U}$ ) no constant order in the maximum segmental contribution to motion may be found in block (C4-C7). In one person $(\mathrm{N})$ motion is started at three moments of measurement by segment ( $\mathrm{C} 6-\mathrm{C} 7)$, followed by a maximum in segment $(\mathrm{C} 5-\mathrm{C} 6)$ and then in segment (C4-C5). In one person the order of the maximums of the segmental contributions in the first phase was at three moments of measurement: first segment (C5C6), followed by that of segment (C6-C7) and then a maximum in segment (C4-C5). In the other persons there is a different order of the maximums at the different measuring moments, alternately first (C6-C7) followed by (C5-C6) and the other way round.

3. In none of the persons retroflexion in block
(C4-C7) is started in segment (C4-C5). All persons start either in segment ( $\mathrm{C} 6-\mathrm{C} 7)$ or in segment $(\mathrm{C} 5-\mathrm{C} 6)$.

4. In one person (U) the curve of segment (C6-C7) is between the first and the last phase of the movement at each moment of measurement above the abscissa. I.e. in segment ( $\mathrm{C} 6-\mathrm{C} 7)$ there is a short phase of anteflexion during retroflexion in block (C4-C7). For two persons ( $\mathrm{L}$ and $\mathrm{N}$ ) this occurs at two moments of measurement and for two others $(\mathrm{O}$ and $\mathrm{T})$ at one moment of measurement.

Summarizing, the following may be concluded as to retroflexion in block (C4-C7):

1. In all persons examined the order in which the segments contribute to the second phase of the motion of block (C4-C7) proved to be constant. In nine persons this order is from cranial towards caudal. In one person the maximum of (C5-C6) is last.

2. In only two persons a constant order (different ones for both) of the segmental contributions may be distinguished in the first phase of motion. For the remaining persons the order of the maximums of segmental contribution at the different moments of measurement is not the same, either segment (C5-C6) followed by segment ( $66-\mathrm{C} 7)$ or the other way round.

3. In none of the persons examined motion starts in segment (C4-C5). The maximum of the contribution of segment (C4-C5) never precedes that of one of the other two segments.

4. In six persons inversion occurs in segment $(\mathrm{C} 6-\mathrm{C} 7)$ between the first and the second phase of motion in block (C4-C7) at one or more moments of measurement.

\subsubsection{Segments (C2-C3), (C3-C4) and (C4-C5) in block (C2-C5)}

During anteflexion of the cervical spine from a maximum retroflexion position of the cervicall spine towards maximum "bending" anteflexion position the following orders of contribution of segments (C2-C3), (C3-C4) and (C4-C5) to motion of block (C2-C5) have been found (figure 9.3a): 


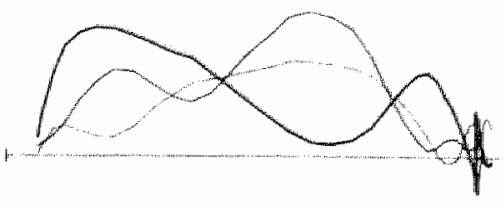

L1

$L 2$
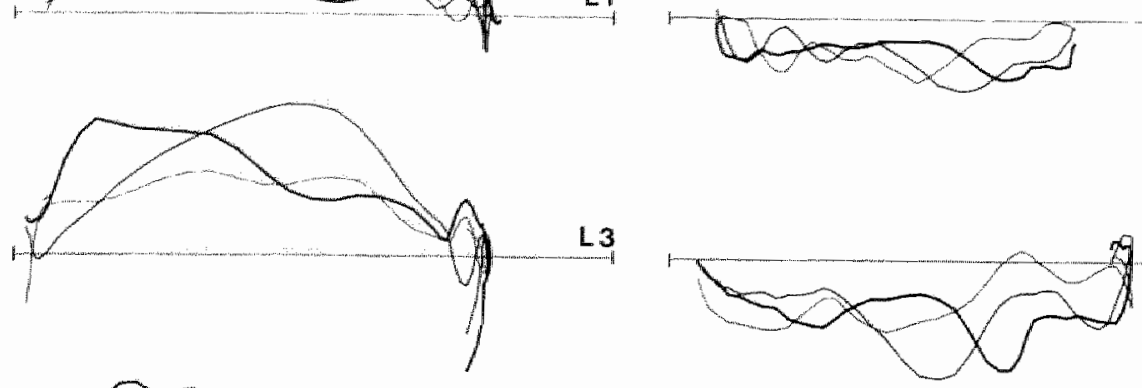

L4
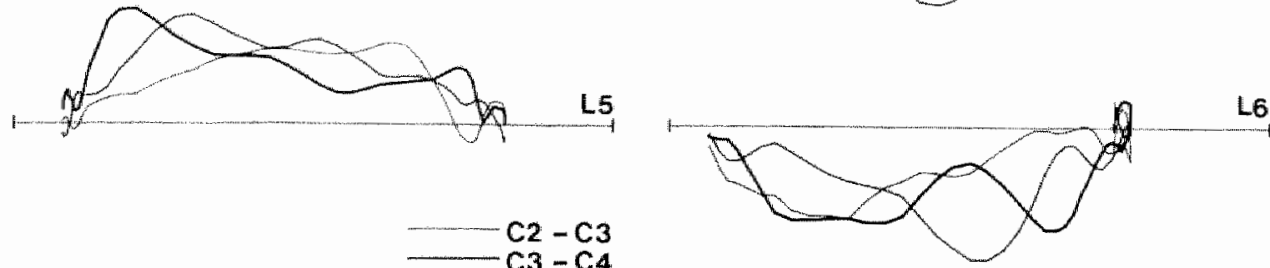

L6

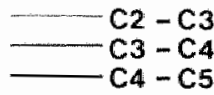

Q1

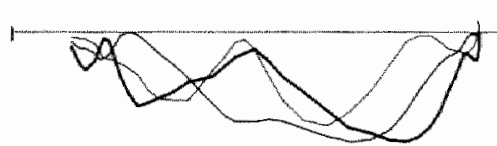

Q2
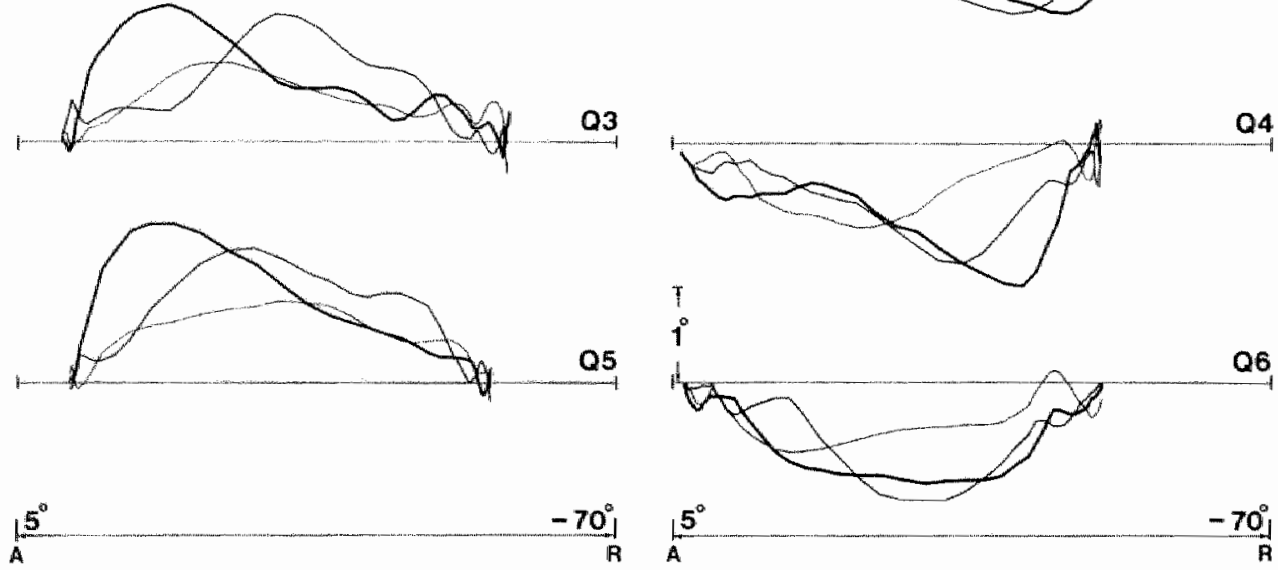

$5^{\circ}$

$-70^{\circ}$

fig. 9.3a Sequence of contributions of segments (C2-C3), (C3-C4) and (C4-CS) to motion in block (C2-C5). $T$ 'est persons $L$ and $Q$, anteflexion registrations $(1,3,5)$ from $R$ to $A$, retrollexion registrations $(2,4,6)$ from $A$ to $R$. 

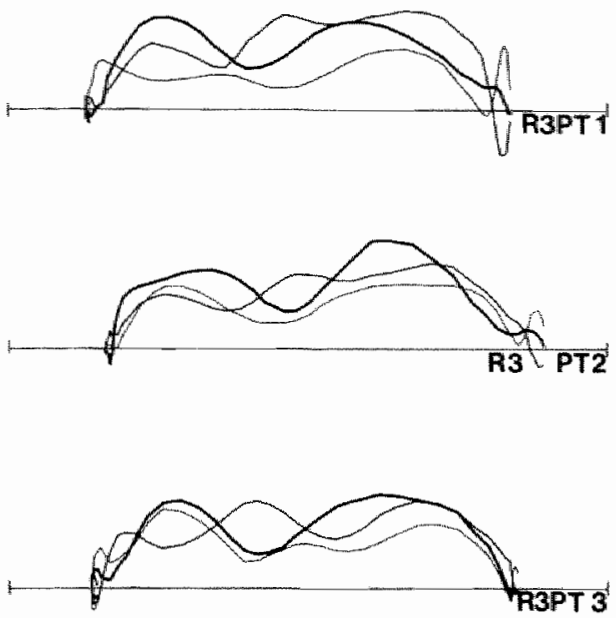

fig. 9.3b Reproducibility of sequence and inversion.

1. For segments (C2-C3) and (C3-C4) a sequence in the contributions present at each moment cannot be demonstrated for any of the persons examined.

2. In four persons ( $L, M, N$ and $R$ ) the contribution of segment (C4-C5) is biphasic at each moment of measurement (see also 9.4.1). In these persons at each moment of measurement the first maximum of segment (C4-C5) is found simultaneous to the maximums of segments (C2-C3) and (C3-C4) or in a previous part of the path of motion.

3 . The second maximum of segment (C4$C 5$ ), or the single, is in six persons ( $L, N, Q$, $R, T$ and $U$ ) at each moment of measurement after the maximums in segments $(\mathrm{C2}-\mathrm{C} 3)$ and (C3-C4). In two persons ( $M$ and $O$ ) this is the case at two moments of measurement. In two other persons ( $\mathrm{P}$ and $\mathrm{S}$ ) segment (C4-C5) is not the last segment to contribute to motion of block (C2-C5).

4. In four persons ( $L, Q, T$ and $U$ ) the contribution of segment (C4-C5) is larger at each moment of measurement in the second part of the path of motion than in the first part. In none of the persons examined the opposite occurs. In these six persons this differs per moment of measurement or there is no demonstrable difference.
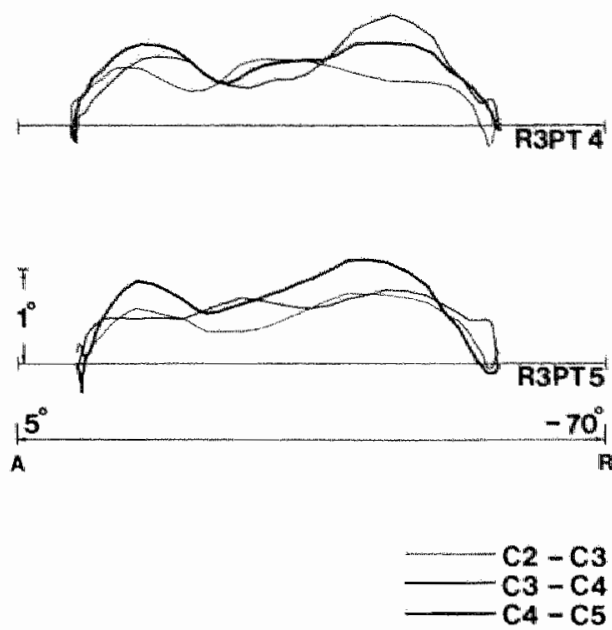

Summarizing, the following is concluded as to contributions of segments (C2-C3), (C3$\mathrm{C} 4)$ and (C4-C5) to anteflexion of block (C2C5):

1. As to their order, the contributions of segments (C2-C3) and (C3-C4) cannot be distinguished. The curves differ per moment of measurement.

2. If the contribution of segment (C4-C5) is biphasic, the first contribution may be prior or simultaneous to those of the other two segments. However, this was found in a minority of the persons examined as a constant phenomenon. Only in part of the persons examined the contribution of segment (C4-C5) is largest in the second part of the path of motion of block (C2-C5).

During retroflexion of the cervical spine from a maximum "bending" anteflexion position of the cervical spine towards a maximum retroflexion position, the following orders of segments (C2-C3), (C3-C4) and (C4-C5) to motion of block ( $\mathrm{C} 2-\mathrm{C} 5$ ) were found (figure 9.3a):

1. In all persons there is a mutually indistinguishable contribution of the three segments in the first phase of the path of motion; the method used does not allow an order in the 
contributions to be determined.

2. In six persons ( $L, M, N, \mathbb{P}, Q$ and $S$ ) a maximum of segment (C4-C5) occurs in the second phase of the path of motion which may be distinguished from the other segmental contributions; in the other persons $(\mathrm{O}, \mathrm{R}, \mathrm{T}$ and $U$ ) this is either varying in the first or second phase or only in the first phase. If the maximum of segment (C4-CS) occurs in the second phase, this is after the maximums of the other two segments.

Summarizing, the following is concluded as to the contributions of segments (C2-C3), (C3-C4) and (C4-C5) to retroflexion of block (C2-C5):

1. An order in the contributions of segments (C2-C3) and (C3-C4) cannot be demonstrated; the curves of these segments are almost the same.

2. In the first part of the path of motion of block (C2-C5) motion is caused by contributions of all three segments.

3. In the second part of the path of motion a large contribution occurs in segment (C4$\mathrm{C5}$ ) in almost half of the persons examined. 4. No order can be found in block (C2-C5) which applies to all persons examined.

\subsubsection{Blocks (C0-C2) and (C4-C7) in the cervical spine ( $\mathrm{CO}-\mathrm{C} 7)$}

During anteflexion of the cervical spine from a maximum retroflexion position towards a maximum "bending" anteflexion position, the following orders in which blocks (C0-C2) and (C4-C7) contribute to motion of (C0-C7) were found (figure 9.4a):

1. In eight persons ( $L, M, N, Q, R, S, T$ and $\mathrm{U})$ the contribution of block (C4-C7) to the movement in $(\mathrm{CO}-\mathrm{C} 7)$ is biphasic at each moment of measurement.

These two phases are at the beginning and at the end of the motion. In two persons $(O$ and $\mathrm{P}$ ) this phemomenon is present at two moments and one moment of measurement respectively.

2. In two persons (P and $S$ ) the contribution of $(\mathrm{CO}-\mathrm{C2})$ is biphasic at each moment of measurement. In both persons the contribu- tion per unit of rotation of (CO-C7) is small compared to that of the other persons examined. The first top in the curve is either before the contribution of $(\mathrm{C} 4-\mathrm{C} 7),(\mathrm{P})$, or in the same path (S).

3. In eight persons ( $L, M, N, Q, R, S, T$, and U) the path in which block $(\mathrm{CO}-\mathrm{C} 2)$ contributes maximally per unit of rotation of (CO-C7) is at each moment of measurement between the two paths in which block (C4C7) contributes. In two persons this is not so. In one person $(\mathrm{O})$ the path in which $(\mathrm{C} 0-\mathrm{C} 2)$ delivers its maximum contribution is before that of (C4-C7) at each moment of measurement, in the other person (P) the total contribution of $(\mathrm{CO}-\mathrm{C} 2)$ is so small that the method used does not allow the conclusive determination that the said contribution of $(\mathrm{CO}-\mathrm{C} 2)$ is between both paths of (C4-C7).

4. In nine persons $(L, M, N, O, P, Q, R, S, R$, $T$ and $U$ ) the curve of block ( $\mathrm{CO}-\mathrm{C} 2)$ is at the end of anteflexion of (CO-C7) below the abscissa at each moment of measurement, so in that path the contribution of block ( $\mathrm{C} 0-\mathrm{C} 2)$ is in retroflexion direction (inversion). In one person (S) this is not the case at one moment of measurement.

5. In none of the persons examined the curve of block (C4-C7) is below the abscissa during anteflexion of the cervical spine. Between $\mathrm{C} 4$ and $\mathrm{C} 7$ no inversion occurs during anteflexion.

Summarizing, the following is concluded with respect to the contributions of block $(\mathrm{CO}-\mathrm{C} 2)$ and $(\mathrm{C} 4-\mathrm{C} 7)$ to anteflexion of the entire cervical spine:

1. In nine persons the order in which blocks ( $\mathrm{C} 0-\mathrm{C} 2)$ and $(\mathrm{C} 4-\mathrm{C} 7)$ contribute to motion is constant during anteflexion between skull (CO) and the seventh vertebra; first contribution of block (C4-C7), followed by contribution of block ( $\mathrm{CO}-\mathrm{C} 2)$, after which another contribution of block (C4-C7) occurs.

2. In one person the largest contribution of block ( $\mathrm{CO}-\mathrm{C} 2)$ precedes both contributions of block (C4-C7).

3. At the end of anteflexion of the entire cervical spine inversion always occurs between the skull (CO) and the axis (C2) (see also 

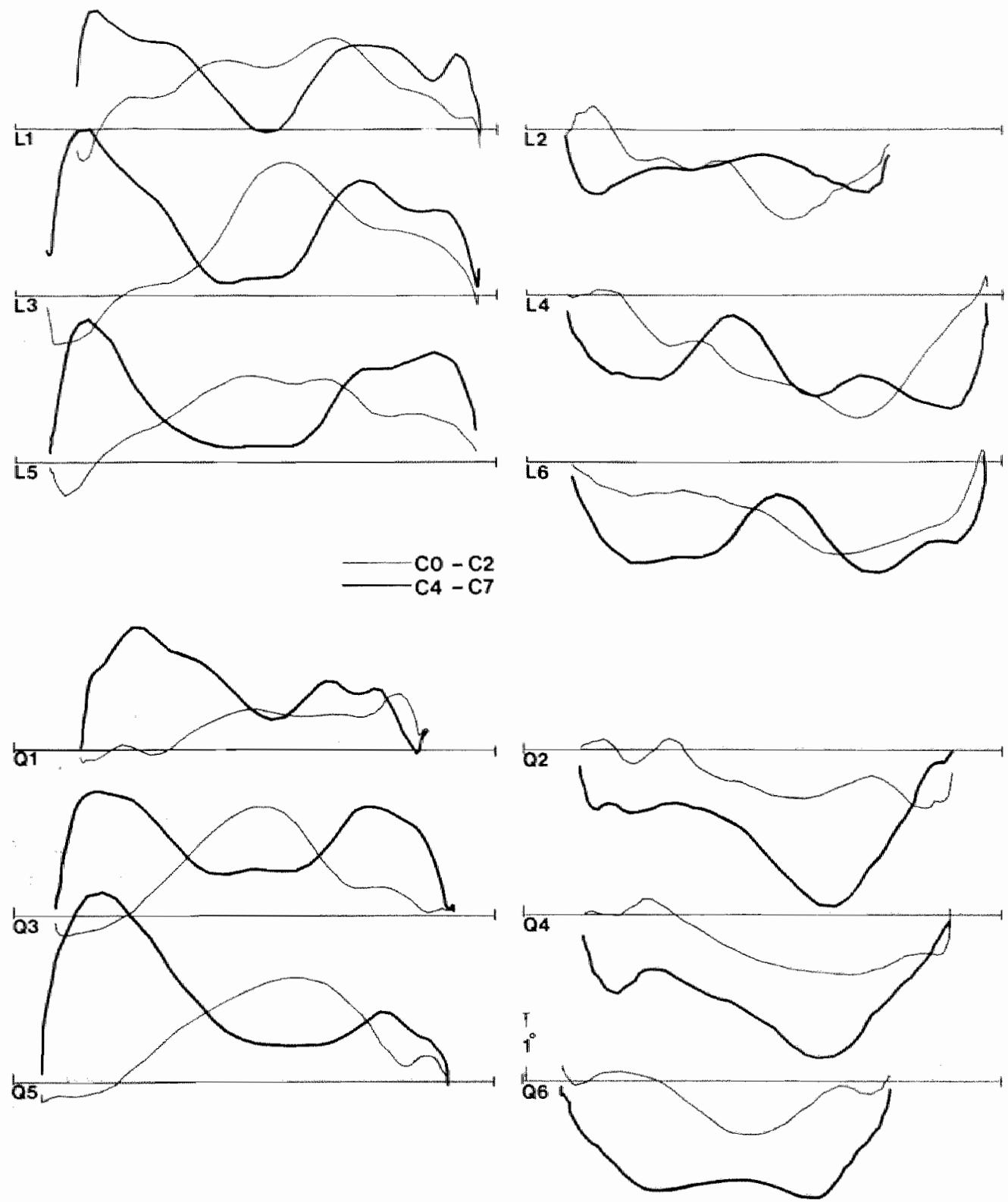

$130^{\circ}$

$-120^{\circ}, \quad 30^{\circ}$

$-120^{\circ}$

7ig. 9.4a Sequence of contributions of blocks (CO-C2) and (C4-C7) to motion of the whole column (CO-C7). Test persons $L$ and $Q$, anteflexion registrations $(1,3,5)$ from $R$ to $A$, retroflexion registrations $(2,4,6)$ from $A$ to $R$. 

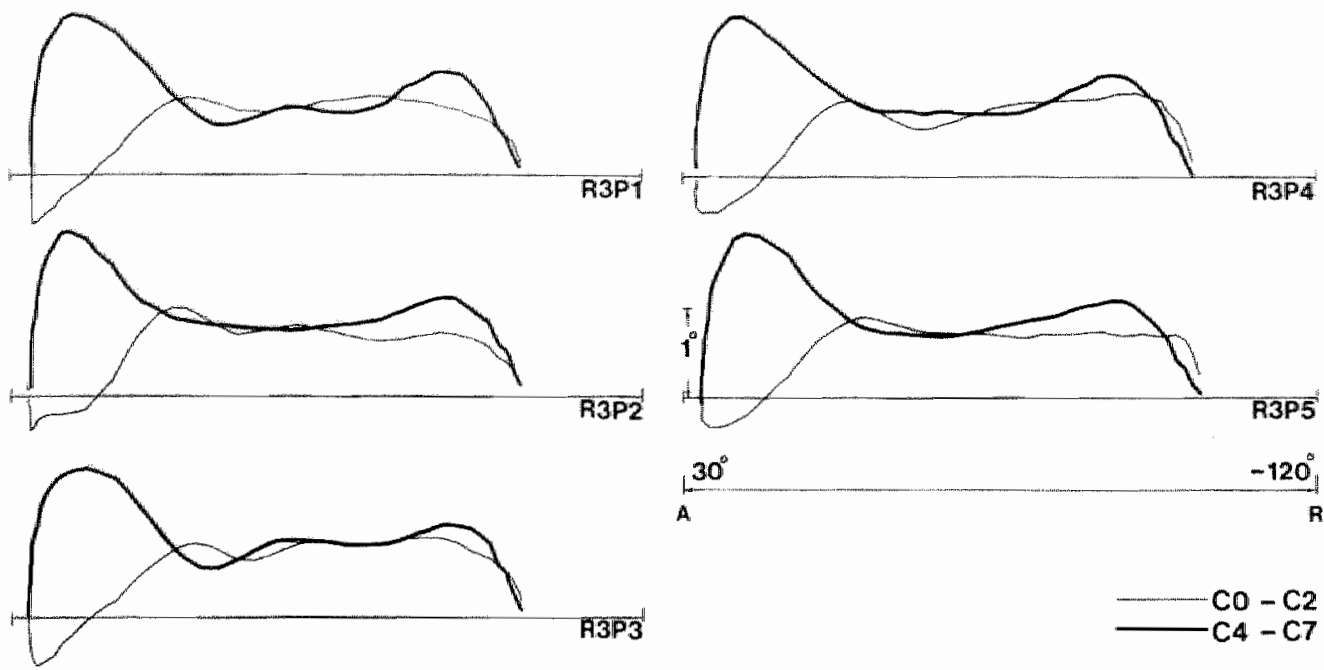

$30^{\circ}$

$-120^{\circ}$

A

Ig. 9.4b Reprodwcibility of sequence andi inversion.

chapter 7 and 8 ).

4. During anteflexion, inversion does not occur between the fourth vertebra and the seventh vertebra at any of the moments of measurement.

During retroflexion of the cervical spine from a maximum "bending" anteflexion position of the cervical spine towards a maximum retroflexion position, the following orders of contribution of blocks ( $\mathrm{C} 0-\mathrm{C} 2)$ and $(\mathrm{C} 4-\mathrm{C} 7)$ to motion of $(\mathrm{CO}-\mathrm{C} 7)$ were found (figure 9.4a):

1. In seven persons ( $L, M, N, R, S, T$ and $U$ ) the contribution of block (C4-C7) is biphasic at each measuring moment. In one person (O) this occurs at two, in two persons ( $P$ and Q) at one moment of measurement.

2. In five persons ( $M, N, O, S$ and $T)$ the contribution of block ( $\mathrm{CO}-\mathrm{C} 2)$ is biphasic at each moment of measurement. In one person (U) this occurs at two moments of measurement, in three persons $(P, Q, R)$ at one moment of measurement, and in one person at none of the moments of measurement.

3. In four persons $(\mathrm{M}, \mathrm{O}, \mathrm{Q}, \mathrm{R})$ the last contribution of segment $(\mathrm{CO}-\mathrm{C} 2)$ occurs after the

last contribution of segment (C4-C7) at each moment of measurement. In two persons ( $N$, S) this occurs at two measuring moments, in three persons $(\mathrm{P}, \mathrm{T}, \mathrm{U})$ at one measuring moment and in one person (L) at none of the measuring moments.

4. In none of the persons examined a situation occurs in which the contribution of block $(\mathrm{CO}-\mathrm{C} 2)$ is between the contributions of block (C4-C7) at each moment of measurement.

5. In one person inversion occurs in segment $(\mathrm{CO}-\mathrm{C2})$ in the initial path of the motion at each moment of measurement. This phenomenon is present in five persons $(\mathrm{L}, \mathrm{O}, \mathrm{P}$, $\mathrm{R}, \mathrm{U}$ ) at one of the moments of measurement. In two persons ( $M$ and $P$ ) inversion of block ( $\mathrm{CO}-\mathrm{C} 2)$ occurs in an intermediate phase of the movement.

6. In one person (T) inversion occurs in the intermediate phase of the movement at one moment of measurement.

Summarizing as to the contributions of blocks ( $\mathrm{C} 0-\mathrm{C} 2)$ and $(\mathrm{C} 4-\mathrm{C} 7)$ to retroflexion of the entire cervical spine the following was found: 

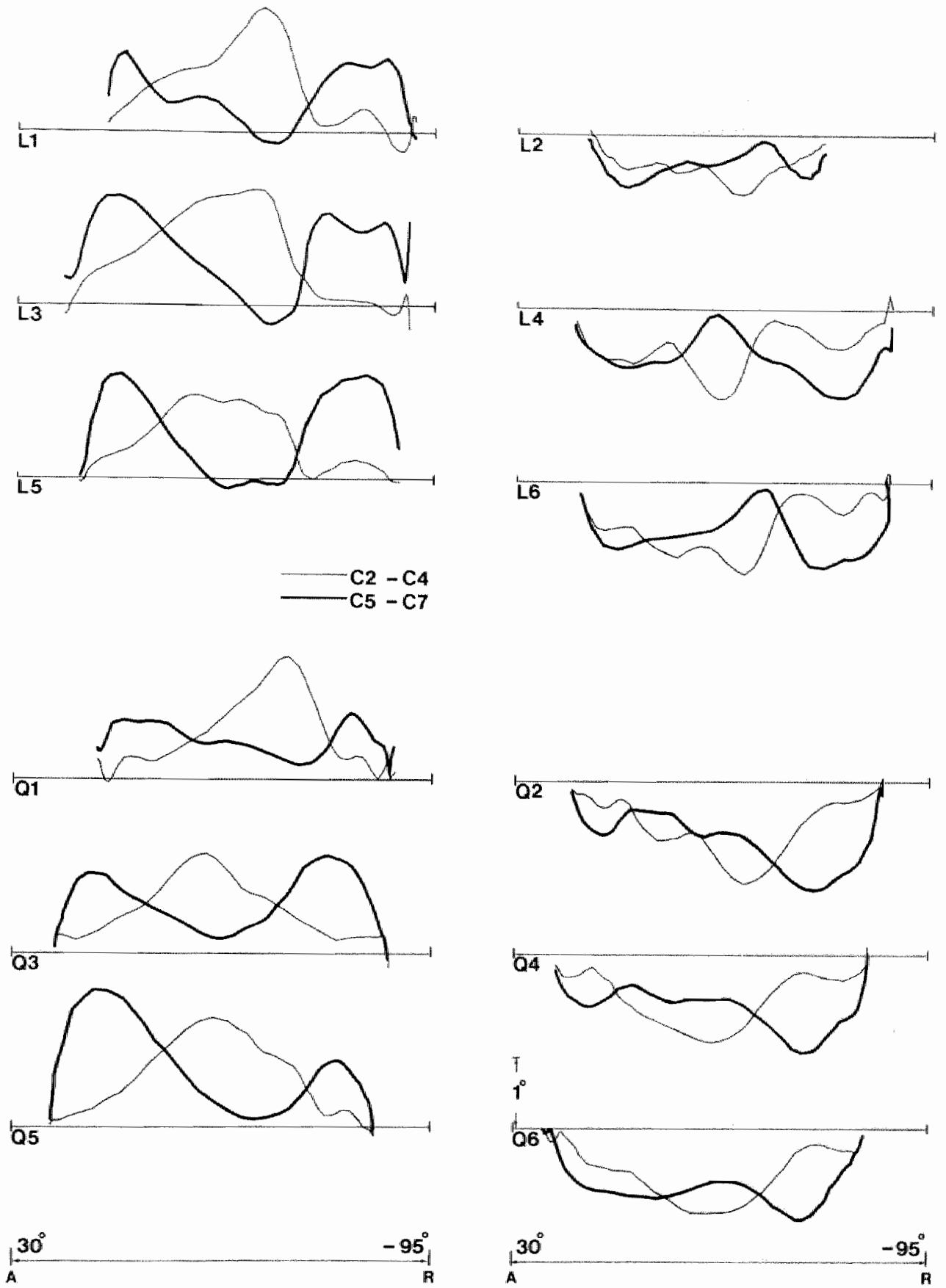

fig- 9.5a Sequence of contributions of blocks (C2-C4) and (C5-C7) to motion of block (C2-C7). Test persons $L$ and $Q$, anteflexion registrations $(1,3,5)$ from $R$ to $A$, retroflexion registrations $(2,4,6)$ from $A$ to $R$. 

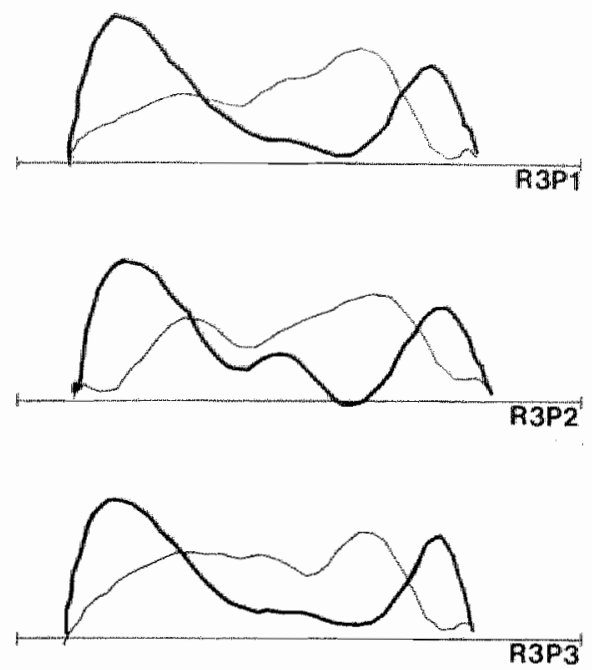

Mg. 9.5b Reproducibility of sequence and inversion.

1. In seven of the twelve persons contribution of blocks $(\mathrm{CO}-\mathrm{C2})$ and $(\mathrm{C} 4-\mathrm{C} 7)$ is biphasic at each moment of measurement.

2 . The point in the path of motion at which the contribution of block $(\mathrm{CO}-\mathrm{C} 2)$ is maximum is not at each moment of measurement at the same point in the path of $(\mathrm{CO}-\mathrm{C} 7)$ and is not always between the contributions of block (C4-C7).

3. Inversion of block $(\mathrm{C} 0-\mathrm{C} 2)$ is an inconstant phenomenon which occurs in a minority of the persons.

\subsubsection{Blocks (C2-C4) and (C5-C7) in block (C2-C7)}

During anteflexion of the cervical spine from a maximum retroflexion position towards a maximum "bending" anteflexion position, the following orders of blocks (C2-C4) and (C5-C7) to the motion of (C2-C7) have been found (figure 9.5a):

1. In all persons examined the contribution of block (C5-C7) is biphasic. The first contribution occurs at the beginning of the path of motion, the second at the end of it.

2. In five persons ( $L, O, P, R$ and $U$ ) the maximum of the contribution in the first part of the path of motion is larger at each moment of measurement than in the last part. In one
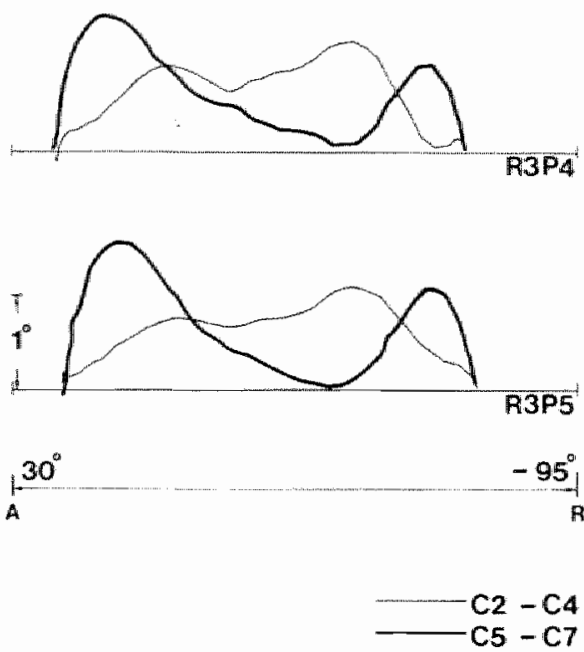

person ( $S$ ) the reverse occurs. In the remaining persons ( $M, N, Q$ and $T$ ) this differs at the different moments of measurement.

3 . In none of the persons examined the contribution of block (C2-C4) is biphasic. In nine persons ( $L, N, O, P, Q, R, S, T$ and $U$ ) the maximum of the contribution in this block is at each moment of measurement between the tops of the contributions of block (C5-C7). In one person (M) this occurred at two of the three moments of measurement.

4. During anteflexion of the cervical spine inversion may occur in block (C5-C7) in the path between both anteflexion contributions. In one person $(L)$ this is the case at each moment of measurement, in two persons ( $\mathrm{N}$ and $\mathrm{T}$ ) at two moments of measurement and in two persons ( $M$ and $U$ ) at one moment of measurement. In block (C2-C4) inversion occurs in one person $(\mathrm{T})$ at the end of the path of motion at one moment of measurement.

Summarizing, the following was found as to the contributions of blocks (C2-C4) and (C5C7) to anteflexion of block (C2-C7):

1. The order in which both blocks contribute to motion is: first contribution of block (C5C7), followed by the contribution of block (C2-C4), after which the movement is con- 
cluded by a contribution of block (C5-C7).

2. In which of the two contributions of block (C5-C7) relative rotation is largest may differ.

3. In block (C5-C7) inversion was found at nine of the twenty-eight moments of measurement. At one moment of measurement this was in block (C2-C4).

During retroflexion of the cervical spine from a maximum "bending" anteflexion position of the cervical spine towards a maximum retroflexion position the following orders of blocks (C2-C4) and (C5-C7) to motion of (C2-C7) were found (figure 9.5a):

1. In all persons examined the contribution of block (C5-C7) is biphasic. The first contribution occurs at the beginning of the path of motion, the second contribution at the end of it.

2. In three persons $(\mathrm{N}, \mathrm{R}$ and $\mathrm{T})$ the maximum of the contribution of block (C5-C7) is larger in the first part of the path of motion than the one in the last part, at each moment of measurement. In three persons ( $M, Q$ and S) the opposite occurs. In the remaining persons $(\mathrm{L}, \mathrm{O}, \mathrm{P}$ and $\mathrm{U})$ this differs at the different moments of measurement.

3. The contribution of block (C2-C4) is biphasic at some moments of measurement (S4, T6). In six persons ( $L, M, N, Q, R$ and $U$ ) the maximum of the contribution of this block is between the tops of the contributions of block (C5-C7) at each moment of measurement. In two persons ( $\mathrm{S}$ and $\mathrm{T}$ ) this occurs at two moments of measurement, in one person $(\mathrm{O})$ at one of the three moments of measurement, in one person $(P)$ at none of the moments of measurement.

4. During retroflexion of the cervical spine inversion of block (C5-C7) occurs in only one person $(\mathrm{T})$ at one moment of measurement between the two retroflexion contributions. 5 . In one person $(\mathrm{O})$ inversion of block ( $\mathrm{C} 2$ C4) occurs at the end of the path of motion at each of the three moments of measurement.

Summarizing, the following was found as to the contributions of block (C2-C4) and (C5-
C7) to retroflexion of block $(\mathrm{C} 2-\mathrm{C} 7)$ :

1. In six of the ten persons the orders in which the two blocks contribute to the motion is: first a contribution of block (C5-C7), followed by the contribution of block (C2-C4), after which the movement is concluded by a contribution of block (C5-C7).

2. It may differ in which of the two contributions of block ( $\mathrm{C} 5-\mathrm{C} 7)$ the relative rotation is largest.

3. In block (C5-C7) inversion was found at only one moment of measurement and in block (C2-C4) inversion was found in one person at all three moments of measurement.

\subsubsection{Blocks $(\mathrm{C} 0-\mathrm{C} 2)$ and $(\mathrm{C} 2-\mathrm{C} 4)$ in block (C0-C4)}

During anteflexion of the cervical spine from a maximum retroflexion position towards a maximum "bending" anteflexion position of the cervical spine the following orders of blocks ( $\mathrm{C} 0-\mathrm{C} 2)$ and $(\mathrm{C} 2-\mathrm{C} 4)$ to motion of (C0-C4) were found (figure 9.6a):

1. In seven persons ( $L, M, O, Q, R, S$ and $U$ ) the order of the maximums of the contributions is as follows at each moment of measurement: first the maximum of block (CO-C2), followed by that of block ( $\mathrm{C2}-\mathrm{C} 4)$. In one person $(\mathrm{N})$ this occurs at two moments of measurement. In one person the order is reversed at one moment of measurement.

2. In nine persons ( $L, M, N, O, P, Q, R, T$ and $\mathrm{U})$ inversion occurs in block ( $\mathrm{CO}-\mathrm{C} 2)$ at the end of the path of motion at each moment of measurement. In one person (S) this occurs at two of the three moments of measurement. In block (C2-C4) this inversion occurs in one person $(\mathrm{T})$ at one moment of measurement at the end of the path of motion.

Summarizing, the following was found as to the contributions of blocks ( $\mathrm{C} 0-\mathrm{C} 2)$ and $(\mathrm{C} 2-$ C4) to anteflexion of block ( $\mathrm{C}(1-\mathrm{C} 4)$ :

1. In more than half the persons examined does the order of contributions consist of first the contribution of block ( $\mathrm{CO}-\mathrm{C} 2)$, followed by the contribution of block (C2-C4) at each moment of measurement.

2. In block ( $\mathrm{CO}-\mathrm{C} 2)$ inversion occurs at the 

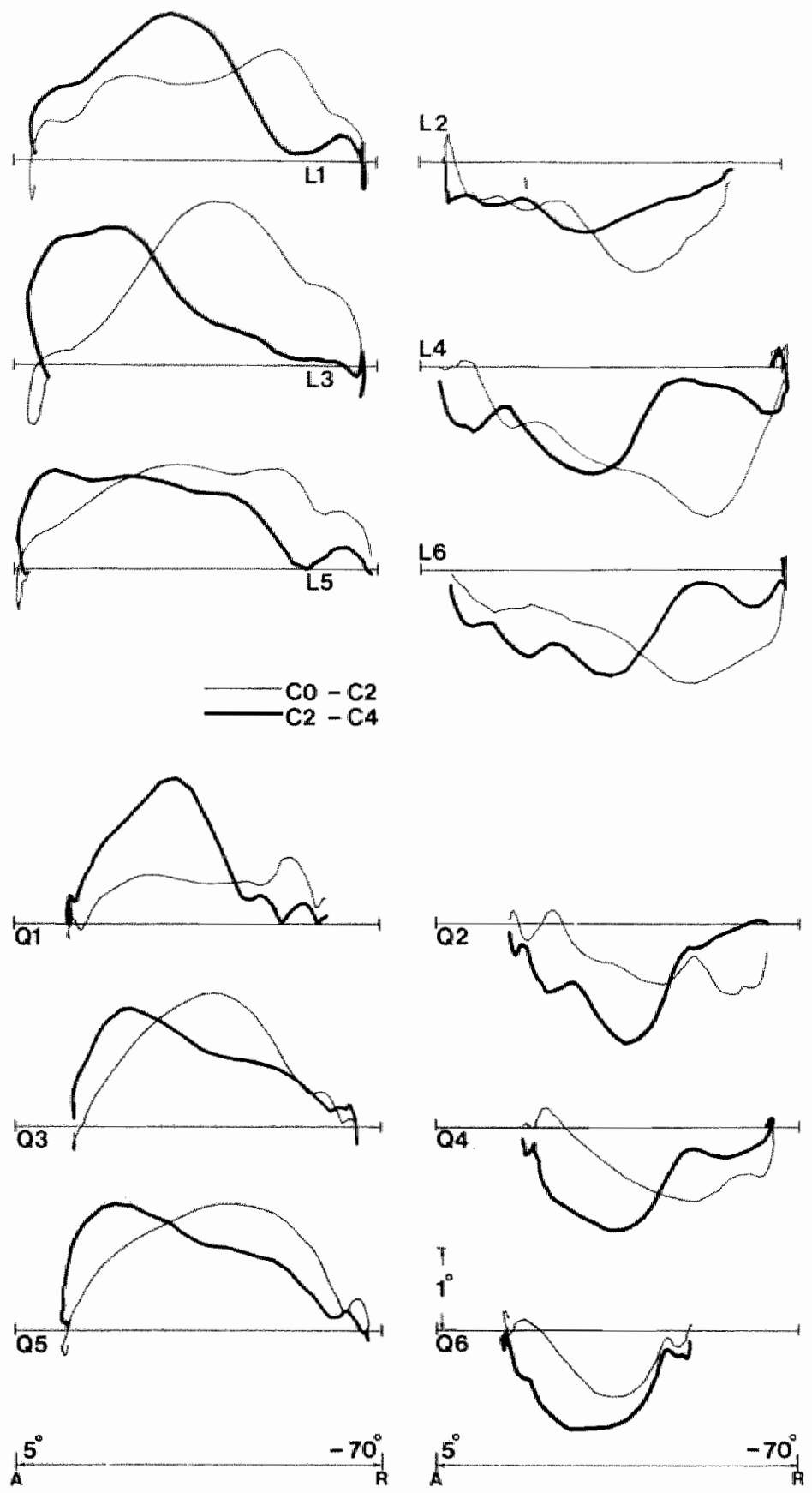

fg. 9.6a Sequence of contributions of blocks (CO-C2) and (C2-C4) to motion of block (CO-C4). Test persons $\mathrm{L}$ and $Q$, anteflexion registrations $(1,3,5)$ from $R$ to $A$, retroflexion registrations $(2,4,6)$ from $A$ to $R$. 

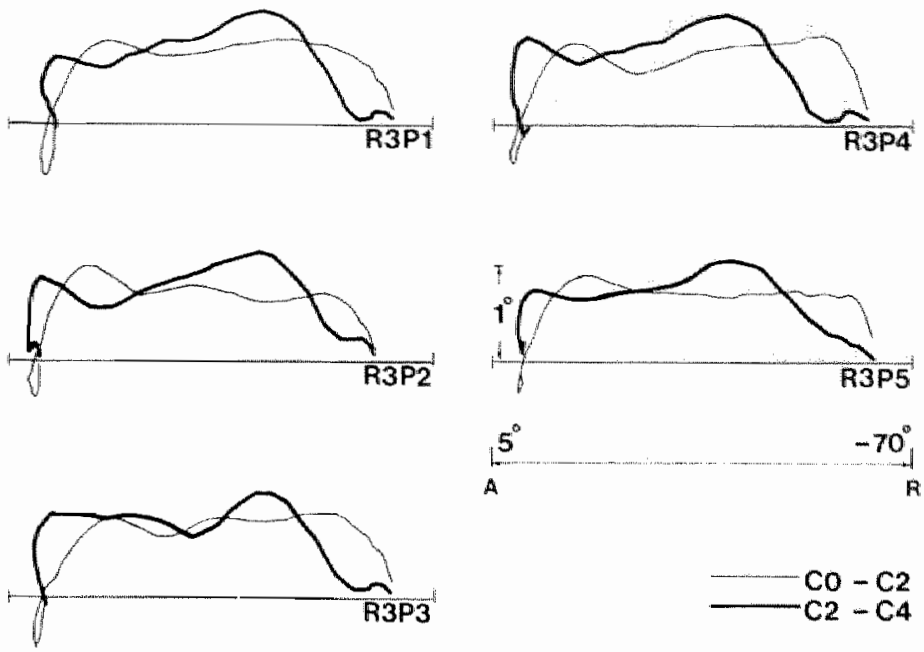

nig. 9.6b Reproducibility of sequence and inversion.

end of the path of motion in twenty-seven of the twenty-eight anteflexion registrations (see chapter 4,7 and 8). Inversion in block (C2-C4) occurs only incidentally.

During retroflexion of the cervical spine from a maximum "bending" anteflexion position of the cervical spine towards maximum retroflexion position the following orders of blocks (CO-C2) and ( $\mathrm{C} 2-\mathrm{C} 4)$ to motion of (C0-C4) have been found (figure 9.6a):

1. In seven persons ( $L, N, P, Q, R, T$ and $U$ ) the order of the maximums of the contributions is at each moment of measurement:

first the maximum of block (C2-C4), followed by that of block ( $\mathrm{C} 0-\mathrm{C} 2)$. This occurs in two persons ( $O$ and $Q$ ) at two of the three moments of measurement. In the remaining persons the method used does not allow a definite order to be indicated, or the order is reversed $(\mathrm{S})$.

2. The curve of block ( $\mathrm{CO}-\mathrm{C} 2)$ may be found in a part of the path of motion above the abscissa (inversion). This is so in two persons ( $M$ and $Q$ ) at each of the three moments of measurement; in one person $(\mathrm{P})$, who was registered at two moments of measurement, also at both moments of measurement and in four persons $(\mathrm{O}, \mathrm{R}, \mathrm{S}$ and $\mathrm{U})$ at one moment of measurement. In block (C2-C4) inversion is observed in one person (O) at each moment of measurement (see also 9.4.4).

Summarizing, the following was found as to the contributions of blocks $(\mathrm{C})-\mathrm{C} 2)$ and $(\mathrm{C} 2$ $\mathrm{C4}$ ) to retroflexion of block ( $\mathrm{CO}-\mathrm{C} 4)$ :

1. In more than half the persons examined does the order of contribution at each moment of measurement consist of: first the contribution of block (C2-C4) followed by the contribution of block ( $\mathrm{C} 0-\mathrm{C} 2)$.

2. In twelve of the twenty-eight retroflexion registrations inversion occurs in part of the path of motion. In two persons this inversion is present at each of the three moments of measurement (see chapter 4, 7 and 8 ). Inversion in block (C2-C4) occurs only incidentally.

\subsection{Discussion}

The method of indicating the positions of the contours of the vertebrae and the skull, and the calculation of the rotations, produce such reproducible results with respect to the orders of segmental contributions, that one may presume that the orders distinguishable are not within the range of measurement error of the method. 
The intraindividual and interindividual var:ability is not entirely the same during both directions of movement. Comparison of the aspects of sequences examined show:

As to the orders of segmental contributions within block (C4-C7):

1. During anteflexion of the cervical spine the order is more constant and equal for the persons examined than during retroflexion.

2. During both motions two phases of a larger contribution of block (C4-C7) may be distinguished, which are characterized by a maximum of segments (C5-C6) and (C6-C7).

3. During both motions inversion may occur in segment (C6-C7) between the two contributions in the direction of motion of the entire cervical spine. This occurs in a number of them both during anteflexion and during retroflexion of the cervical spine, in some only during anteflexion. In some persons this phenomenon was not found at each moment of measurement. Incidentally inversion also occurs in the segment (C5-C6).

As to the orders of segmental contributions within block (C2-C5):

1. The method used does not allow an order to be indicated between the contributions of segments (C2-C3) and (C3-C4).

2. During anteflexion biphasic contributions to motion in segment (C4-C5) occur more often than during retroflexion. In segments (C2-C3) and (C3-C4) we see that the rotation contribution is constant during the entire path of motion of block (C2-C5) or we may distinguish one distinct top.

3. In all persons examined the order of the contributions of the segments within block (C2-C5) is different during both anteflexion and retroflexion. A constant order cannot be distinguished.

As to the orders of the contributions of blocks ( $\mathrm{C} 0-\mathrm{C} 2)$ and (C4-C7) within the entire cervical spine:

1. During anteflexion a contribution of block (C4-C7) usually occurs in the first part of the motion, followed by the contribution of block (C0-C2). In the last part of the path of mo- tion of anteflexion of ( $\mathrm{CO}-\mathrm{C} 7)$ another contribution occurs in block (C4-C7). The order in which a contribution of (C4-C7) is followed by a contribution of $(\mathrm{CO}-\mathrm{C} 2)$ and subsequently by contribution of (C4-C7) is less often observed during retroflexion of the cervical spine. During retroflexion of the cervical spine the contribution of segment ( $\mathrm{CO}$ $\mathrm{C} 2$ ) shows a less constant relation to the contributions of block ( $\mathrm{C} 4-\mathrm{C} 7)$ than during anteflexion.

2. In the last part of the path of motion of anteflexion, inversion occurs in block (COC2) (see also chapter 4,7 and 8). This inversion occurs only incidentally during retroflexion and is then found halfway through the path of motion.

As to the orders of the contributions of blocks (C2-C4) and (C5-C7) within block (C2-C7):

1. In all persons the contribution of block (C5-C7) is biphasic during both motions. In which of the two contributions the relative rotation is largest, differs.

2. In all persons examined the order in which the contributions of blocks (C2-C4) and (C5C7) occur is the same during anteflexion of the cervical spine. This is not so during retroflexion.

3. During anteflexion of the cervical spine inversion in block (C5-C7) occurs in $30 \%$ of the moments of measurement. In only one person it is a constant phenomenon. In retroflexion it only occurs in one of the twenty-eight moments of measurement.

4. Inversion in block (C2-C4) may be expected incidentally during anteflexion.

As to the orders of the contributions of blocks ( $\mathrm{C} 0-\mathrm{C} 2)$ and $(\mathrm{C} 2-\mathrm{C} 4)$ within block (C0-C4):

1. The orders of the contributions of these blocks show a large degree of intra- and interindividual variability during both motions.

2. During anteflexion of the cervical spine, orders of contributions of both blocks which are present at each of the three moments of measurement are found more often than during the retroflexion. 
3. At the end of the path of motion of block ( $\mathrm{CO}-\mathrm{C} 4)$ inversion in block $(\mathrm{CO}-\mathrm{C} 2)$ during anteflexion occurs in all persons examined. Inversion also occurs during retroflexion of the cervical spine, but in a minority of the persons examined. In a number of persons the phenomenon is present at some times and absent at others.

Generally the following is concluded as to the orders in which the contributions occur between the extreme positions of the cervical spine during anteflexion and retroflexion:

\section{Anteflexion:}

- The anteflexion is started by a contribution of block (C4-C7) in nine of the ten persons examined. Within this block contribution always starts in segment (C6-C7). After this first contribution to block (C4-C7) there follows a contribution of segment (C5-C6), and then a contribution of segment (C4-C5).

- After this first contribution of block (C4C7) has largely taken place and the centre of gravity of the head is approximately vertically above the vertebral body of $C 7$ (see chapter 8) the largest contribution of block ( $\mathrm{C} 0-\mathrm{C} 2)$ occurs.

- After this contribution of block ( $\mathrm{C} 0-\mathrm{C} 2)$ another contribution of block (C4-C7) follows. In this second contribution of the block (C4C7) the order of the segments is not from caudal towards cranial, but from cranial towards caudal. In only one person the contribution of block $(\mathrm{CO}-\mathrm{C} 2)$ precedes for the greater part the two contributions of block (C4-C7). - The orders of the contributions of the midcervical part of the cervical spine (C2-C4) in relation to the low-cervical part (C5-C7) within the block $(\mathrm{C} 2-\mathrm{C} 7)$ proved to be constant. The contribution of block (C2-C4) is always between the contributions of block (C5-C7). The order of the segments (C5-C6) and $(\mathrm{C} 6-\mathrm{C} 7)$ is the same as found in block (C4-C7). The order of the segments (C2-C3) and $(\mathrm{C} 3-\mathrm{C} 4)$ is not the same for the different moments of measurement or cannot be distinguished with the measuring method used. - Within block (C2-C5) we cannot demonstrate a constant and for all persons identical order in which the segments contribute to the path of motion. The contributions ustally occur at the same time or in different orders. They are, however, preceded by the contributions of the low-cervical segments (the order of which is constant). With the cranial adjacent block ( $\mathrm{CO}-\mathrm{C} 2)$ no constant order relation which is identical for all persons was found either. In more than $50 \%$ of the cases, the maximum of the contribution of block $(\mathrm{CO}-\mathrm{C} 2)$ was found before that of block ( $\mathrm{C} 2$ C4) at each moment of measurement.

-In none of the persons examined the motion is started or concluded by a contribution of the mid-cervical segments.

- In block (CO-C2), in all persons examined, the motion is concluded by inversion between skull and axis (see chapter 7). During the course of motion inversion may also occur in block (C5-C7). This is then the case between the two anteflexion contributions of block (C4-C7). Apart from that, inversion occurs in the mid-cervical part of the spine, but less frequently than in block (C5-C7). In that case it usually occurs in the final phase of the motion.

\section{Retroflexion:}

- At the beginning of the motion there is always a contribution of the block ( $\mathrm{C} 4-\mathrm{C} 7)$, while the maximum of the contribution of block ( $\mathrm{C} 0-\mathrm{C} 2)$ follows.

- The motion is concluded by a contribution in the low-cervical part preceded by or simultaneous with a contribution in block ( $\mathrm{CO}$ C2). The contribution of block (C4-C7) to the motion of the entire cervical spine, is not always biphasic. Within block $(\mathrm{C} 4-\mathrm{C} 7)$ the order of the segmental contributions in the last part of the path of motion is constant insofar that the path is concluded by a contribution in block (C5-C7), usually in segment (C6-C7).

- The orders of the segmental contributions in the mid-cervical part of the spine are not more constant than during the anteflexion of the cervical spine.

- In none of the persons examined the motion is started or concluded by a contribution of the mid-cervical segments. 
- Inversion in the low-cervical part of the spine occurs less often during retroflexion than during anteflexion.

The questions as to the aspects of order of the segmental contributions within a block and contributions of blocks within a larger block or within the entire cervical spine and their intra-and interindividual variability may now be answered. Buonocore et al. (1966) state that the order of contribution is normally from cranial towards caudal. This does not correspond to our findings.

The orders of the mid-cervical segments in block (C2-C5) are those most subject to both intra- and interindividual variability. Both in the cranial part of the cervical spine (see chapter 7) and in the caudal part the segmental contributions come in a certain order and they have a constant position in the path of motion of the entire cervical spine. The interindividual variability is larger during retroflexion of the cervical spine than during anteflexion. The "double rock" described by Brunton et al. (1966) and Hartman and Buonocore (1967) as a sign of pathology was also found in the persons free of complaints examined by us. This phenomenon may not be considered in these persons as a sign of pathology.

On the basis of a model of block ( $\mathrm{C} 0-\mathrm{C} 2)$ in relation to the other parts of the cervical spine in the gravitational field, we made plausible in chapter 8 , that the segmental order in the cranial part of the cervical spine is determined by - among other things - the position of this block in the gravitational field. Information from diagrams that render the relation between the order and the position in relation to gravitation appeared to correspond to this plausibility. If such a model were to be designed for the remaining part of the cervical spine, the position of the cervical spine in relation to gravitation would also be an important datum, as is the fact that a number of ligamentous connections around the mid-cervical part, in which larger freedom of orders exists, are absent (see chapter 8).

However, there is no model as yet which can predict the constant phenomena described in this chapter.

\section{Bíbliography}

Bard, G., Jones, N.D., Cineradiographic recording of traction of the cervical spine, Arch. Phys. Med. Rehab., $45,403-406,1964$.

Brunton, FJ., Wilkinson, J.A., Wise, KS.H., Simmons, R.B., Cineradiography in cenvical spondwosis as a means of deternining the level for anteriofusion, $J$. Bone $J t$ Surerg., 64B, 399-404, 1982.

Buonocore, E., Hartman, J.T, Nelson, C.L., Cineradiograms of cenvical spine in diagnosis of soft tissue injuries, JAMA, 198, 25-29, 1966.

Fielding, J.W., Cineradiography of the nomal cenical spine., New York State J. Med., 56, 2984-2986, 1956.

Fielding J.W., Cineroentgenography of the nomal centcal spine., J. Bone and Jt. Surg., 39A, 1280-1288, 1957.

Fielding $J . W$, Nomal and selected abnomal motion of the cervical spine from the second cerwical vertebra to the seventh cervical vertebra based on cineroentgenography, J. Bone and Jt. Surg, 46A, 1779-1781, 1964.

Gombert, H.J. Funktionsdiagnostik der Halswirbelsäule mit der Bildwandler, Radiol. Austr., 9, 217-226, 1957.

Hartman, $T$, Bltonocore, $E$., Soft tissue injury of cenical spine as demonstrated on cenvical cineradiography, J. Bone It. Surg, 49A, 1021, 1967.

Harmax, J.T., Palumbo, F., Hill, B.J., Cineradiography of the braced normal cervical spinte. A comparitive study of five commonty used cervical orthoses., Clin. Orthop. and Ret. Res., 109, 97-102, 1975 .

Hohl, M., Bnummett, S.W., Cinefluorography in the diagnosis of the diseased or damaged cenvical vertebral disc., J. Bone and Jt. Sung., 50A, 1060, 1968.

Jones, M.D. Cineradiographic studies of the nommal cervical spine, Calif. Med. J., 93, 293-296, 1960a.

Jones, M.D., Cineradiograpic studies of collar-immobilized cervical spine., J. Neurosurg, 17, 633-637, 19606 .

Jones, M.D., Cineradiographic studies of the degenerative disease of the cervical spine. J. Can. Ass. Radiol, $12,52-55,1967$.

Jones, M.D., Cinteradiographic studies of patients with cervical spine fusions., Am. J. Roentgenol, 87, 1054 1057, 1962a. 
Jones, M.D., Cenvical spine cineradiography after inaffic accidents., Arch. Surg, 85, 974-981, 19626.

Jones, M.D., Bard, $G_{.,}$Cineradiography of the unstable cervical spine., Am. J. Phys. Med., 45, 291-295, 1966.

Kotke, FJ., Lester, R.G. Use of cinefinorography for evaluation of nomol and abnomal ntotion in the neck.
Anch. Phys. Med. Rehabil, 39, 228-231, 1958

Korke, FI. Mundale, M.O., Range of mobility of the term wical spine, Anch. Phys. Med Rehabil, $40,379-3821959$.

Sollman, A., Klinilk und Röntgenkinematographie der basilaren Impression, Die Winbelsadule in Forschumg and Praxis, 25, 83-88, 1962. 


\section{Summary and conclusions}

For many people the spine is a source of complaints. Beside low back pain, the painful cervical spine ("neck") is frequently the reason for reduced quality of life. Such disorders often lead to limited motion of the spine. Conversely, many attempts are made to use the degree of limited motion to objectify of the source of the complaints. Quantitative data on motion can play a role as a diagnostic criterion and as a touchstone for therapeutic effect.

This thesis focused on the cervical spine. Examination of motion of the cervical spine may comprise classic physical diagnosis of the locomotor system on the basis of a limited number of X-ray "function pictures" and through $X$-ray cinematography. Like the other techniques mentioned, $X$-ray cinematography was so far mainly used to obtain a qualitative impression of motion within the sagittal plane of the (bony) structures of the cervical spine and the head. Problems that make quantitative examination of motion difficult are on the one hand insufficient sharpness of the images on fillm (or video) to mark the contours accurately, and on the other hand the fact that there is such a large number of contours to be marked, that positioning of the contours is very time-consuming, which also increases the chance of incorrect marking. This adds to the chance of obtaining faults when calculating motion parameters.

We used a $105 \mathrm{~mm}$. spot film camera (4 frames per second), conceived as $\mathrm{X}$-ray cinematography, to registrate actual motion. The $\mathrm{X}$-ray cinematographic and marking techniques used in this research allow the positions of the contours per image to be marked accurately enough.

Per image 40 positions are registered. Assuming that an X-ray film has an average of 40 images, this means that 1600 positions have to be registered per film. 58 films were made of ten persons examined by us. 92800 points have therefore been marked and fed into the computer. The method of calculating the positions developed by us, automatically corrects faults that are made during marking. Only a technique like the one we used allows registration of the positions of bony structures and calculation of motion parameters.

For the use of a registration and calculation technique in patient examination it is necessary to obtain reliable data within a reasonably short time. Our technique provides values of the motion parameters desired within approximately one hour. The technique served to determine a number of parameters of motion within the sagittal plane of the cervical spine and the head in ten persons free of complaints. Intraindividual and interindividual variability have been registered, in order to be able to examine which parameters could be suitable for objectifying the motion within the sagittal plane of the column. The following motion parameters of the actually performed motion have been determined: total and segmental range of motion, position of the segmental instantaneous centre of rotation, intrasegmental distortion, and order and direction of motion. The definition of such terms may depend on the method used to determine their parameters. This is why in this research a definition was given for each parameter. This definition differed sometimes from the ones formulated hitherto.

Parameters determinable witly static X -ray as well as $\mathrm{X}$-ray cinematography are:

\section{Range of motion}

Range of motion is usually defined as the difference in rotating position between two bony structures on X-rays of the extreme positions within the sagittal plane of the cervicall spine and the head. We did not always find the maximum difference in rotating position between two bony structures on the X-rays of 
the two extreme positions of the cervical spine (comparable to function pictures). This is why range of motion is defined here as the difference between the position on the image in which the two bony structures are in maximum retroflexion and the one on which they are in maximum anteflexion. These may therefore be positions on images between the extreme positions of the cervical spine. The values for range of motion determined this way show, as in literature, a large dispersion. It is therefore impossible to derive from this parameter "normal values" which can be used in practice. No data were known as to intraindividual variability of range of motion. The values in this research were determined at three moments of measurement. In the cranial and caudal part in particular, large intraindividual variability appears to exist as to segmental range of motion. For a given patient/test person no normal values or reference values for judging the course of a process or therapeutic effect, can be gathered.

\section{Position of the segmental instantaneous centre of rotation}

Thus far, this has been determined on the basis of a limited number of static positions of the cervical spine of the path of motion within the sagittal plane. For the position of this centre a large interindividual variability per segmental level is given. If the positions are determined on the basis of pictures of smaller paths within the entire path of motion, a compilation of centres in a large area arises: a polode cannot be constructed. This is caused by an unfavourable relation between the accuracy of marking contours on $\mathrm{X}$-rays and the way in which the construction of such a centre takes place. This parameter was thus far not suitable for registering changes in segmental motion objectively.

The positions of the centres of rotation in this research have been determined on the basis of actual motion performed. Calculated between consecutive images, this also produces a compilation of centres which are far apart. That is why, also with our method of positioning, it is not possible to construct a polode reproducible within acceptable limits. For this reason we determined per segment of each X-ray film the average of the positions of the instantaneous centres of rotation per segment, using as many non-consecutive images as possible. This average position can be reproduced easily. Within these ten test persons, a much smaller interindividual dispersion exists per segment than has been described up to now for the instantaneous centre of rotation determined on the basis of two extreme positions of the cervical spine. In addition, there is hardly any intraindividual dispersion. Further research is required to find out whether the position of the average instantaneous centre of rotation can be used as a standard for comparing positions found in a meaningful way.

\section{Intrasegmental distortion}

Another parameter used to register changes in motions, i.e. distortion of the intervertebral disc, has up to now only been determined quantitatively on the basis of function pictures. $X$-ray cinematography has shown that in segments in which the intervertebral disc is assumed abnormal, deviating motion takes place. These types of motions occur, however, also in the group of persons examined by us. The presence of such distortion of the intervertebral disc does therefore not necessarily indicate pathology within the disc.

We did determine in the persons examined by us that more gliding than tilting takes place in the cranial discs and that reverse occurs in the caudal segments. We also determined that normally the relation between tilting and gliding at the ventral side of the intervertebral disc does not differ much from the one in the adjacent segments. The major movements at the ventral side are found in segments (C4-C5) and (C5-C6). Considering the range of measurement error of the method used, no statements can be made about intraindividual variability. The absolute displacements, especially at the ventral side of the intervertebral discs show large interindividual dispersion.

Parameters only determinable with $\mathrm{X}$-ray 
cinematography are:

\section{Sequences of contribution}

Hardly any qualitative and no quantitative data were known on this subject.

A large number of phenomena of these sequences are identical for all persons examined. Both anteflexion and retroflexion between the maximum retroflexion position and "bending" anteflexion position of the cervical spine commence and end in the caudal part of the cervical spine. Motion never starts or ends in the mid-cervical part. Our research also shows that the sequence of segmental contributions in the cranial and caudal part of the cervical spine is constant. In addition, the sequence between contributions of the cranial part and the caudal part to motion of the entire cervical spine is constant. This also applies to the contribution of the mid-cervical part of the spine in relation to the caudal part. No constant sequence was found for contribution of segments within block (C2$\mathrm{C5}$ ) nor for the sequence between block ( $\mathrm{CO}$ $\mathrm{C} 2)$ and block (C2-C4) within block ( $\mathrm{CO}-\mathrm{C} 4)$. A model analysis explains the constant sequence of the contributions within the cranial part of the cervical spine.

\section{Inversion}

At the end of the "bending" anteflexion of the cervical spine, retroflexion always takes place in block ( $\mathrm{CO}-\mathrm{C} 2)$. During retroflexion of the cervical spine, anteflexion within segment $(\mathrm{C} 0-\mathrm{C} 1)$ always takes place during retroflexion contribution in segment (C1$\mathrm{C} 2$ ). These motions in reversed direction are called inversion. This is a different phenomenon than the inversion within segment $(\mathrm{CO}$ C1) which has been observed in the function pictures of part of the persons free of complaints. The inversion examined by us is a retrograde movement. Although the inversion determined by comparing two function pictures is based on this motion, it is defined statically. Inversion also occurs more often within the path between an "intermediate position" of the cervical spine and maximum "bending" anteflexion, than only as the difference between the neutral and the final position. Inversion as it takes place during an actually performed motion within segments (C0-C1) and/or (C1-C2) can thus be overlooked on function pictures. Apart from that, inversion within the cranial part of the cervical spine during retroflexion is based on a different phenomenon than inversion during anteflexion of the cervical spine. This can be explained from a model of the cervical spine. Inversion can be considered as a normal phenomenon within the caudal part of the cervical spine as well. In that case it takes place in segment (C6-C7) and, although less often, in segment (C5-C6). If inversion occurs in the caudal part of the cervical spine, this takes place in the path between both contributions of this part in the direction of the movement.

\section{Continuation of this research}

1. Further modelling of motion of the cervical spine:

The model discussed, on the basis of which the orders of motion and the inversion possibility high in the cervical spine have been predicted, will have to be perfected. We expect that it is possible to derive the sequence mentioned for other regions as well. Sufficient information on the use of muscular tissue during the motions examined is one of the data that should be the basis of such modelling. This may be derived from electromyographic research. Furthermore, macroscopic anatomical research in the neck of the actual relations between muscular tissue, collagenous connective tissue around the bony structures and the bony structures themselves, should provide a more firm basis for such modelling than is possible with the data known up to now. We recommend the development of numerical models - besides mechanical ones for the different elements of the cervical spine. A numerical model can then generate stronger hypotheses on aspects of motion of the cervical spine. These are subject to verification with the aid of the above-mentioned experimental techniques.

2. Objective verification of diagnosis of 
physical-diagnostic segmental examination of motion within the cervical spine and assesment of therapy.

The technique discussed in this thesis allows parameters to be determined objectively and independent of the examiner/therapist. This may be done on the basis of "normal values" of the above-mentioned motion parameters in persons free of complaints and the information obtained on intraindividual and interindividual variability. It can be examined whether in patients with complaints about pain or limited motion of the cervical spine or complaints like "a feeling that motion is different" other values for the motion parameters mentioned occur.

The following is the background for the expectation that in patients with complaints of the neck other values will be found:

- Changes in soft tissue are accompanied by a change in transmission of tension and in distortion.

- Changes in the shape of the joint and/or the surface of the joint cartilage cause changed direction of movement or increased friction in the joints. These changes in shape are accompanied by complaints about pain.

- Pain in the region of a joint is accompanied by different use of that joint region within the cervical spine.

In addition, research can be done on whether these values are again identical to those in persons free of complaints, after treatment which has led to diminution of complaints.

Given the fact that range of motion within the cranial and caudal parts of the cervical spine produces inapt parameters, the following questions may constitute a basis for further examination in groups of patients with a certain pattern of complaints:

- Can determining the maximum displacement and the relation between tilting and gliding within an intervertebral disc compared to the values in the adjacent segments give a clue about the presence of an abnormal disc?

* It may be expected that the ratio gliding : tilting is changed in case of of discus pathology or altered position of the zygapophyseal joints.

- Is determining the position of the mean of the instantaneous centre of rotation an appropriate parameter?

- The prediction is that the instanteneous center of rotation is to be found in other areas of the projection of the vertebral body when the interwertebral disc is lacerated or the facet joints are abnormal.

- Is the sequence of contribution of the segments within blocks and of blocks to the entire cervical spine during anteflexion and retroflexion motion a valuable parameter in diagnostics and/or evaluation of therapy in patients with complaints of the neck.

* In case of pathology (articular surfaces or soft tissues) pain may be provoked during motion. This could lead to other sequences of segmental or block contributions to the motion of the cervical spine. Another consequence could be alterations in inversion behaviour. Inversion may be decreased or may occur in other parts of the path of motion or in other segments than normally observed.

One of the developments in modern medicine is the increasing prominence of obtaining quantitative data. These are a basis for objective diagnosis and provide the opportunity for quantification of the course of a process, and the influence of therapeutic measures on it. In addition, this type of "clinimetrics" is a condition for controlling the prognosis, especially as to prediction of the final level to be expected, or the remaining impairment or disability in patients. For a long time, chemical diagnosis has been expected to provide objective standards for comparing individual values in a meaningful way. Thus far, physical diagnosis, especially of the locomotor system, has been able to fulfil such expectations to a much lesser extent. A first requirement is the development of calibrated measuring equipment for obtaining valid data on relevant qualities. We hope that the method described here for defining a number of functional qualities dependent on the morphology of the cervical spine, contributes to the above-mentioned development. 


\section{Samenvatting en conclusies}

De wervelkolom is voor vele mensen een bron van klachten. Naast lage-rugpijn is de pijnlijke halswervelkolom ("nek") zeer frequent oorzaak van een verminderde "quality of life". Dergelijke stoornissen leiden zeer frequent tot bewegingsbeperking in de wervelkolom. Omgekeerd wordt vaak gepoogd de mate van bewegingsbeperking als objectivering van de grond van de klachten te gebruiken. Kwantitatieve gegevens over de beweging kunnen een rol spelen als diagnostisch criterium en als toetssteen van therapeutisch effect.

In dit proefschrift is de aandacht gericht op de halswervelkolom. Het bewegingsonderzoek daarvan wordt o.a. ondernomen als klassieke fysische diagnostiek van het bewegingsapparaat, aan een beperkt aantal röntgenfoto's ("functie-foto's") en door middel van röntgencinematografie.

Evenals de andere genoemde technieken werd röntgencinematografie tot dusverrre in hoofdzaak gebruikt om een kwalitatieve indruk te verkrijgen van het bewegen in het sagittale vlak van de (benige) structuren van de halswervelkolom en het hoofd. Tot de problemen, die kwantitatief onderzoek van het bewegen niet goed mogelijk maakt behoren, enerzijds onvoldoende scherpte van de beelden op film (of video) om de contouren nauwkeurig genoeg te markeren, anderzijds is de hoeveelheid te markeren contouren zo groot, dat de positie bepaling van de contouren zeer tijdrovend is, waardoor tevens de kans op onjuist markeren groot is. Hierdoor is de kans op fouten bij de berekening van bewegingsparameters groot.

In ons onderzoek gebruikten we een 105 $\mathrm{mm}$. spot film camera (4 beelden per seconde), eveneens röntgencinematografie genoemd, om de werkelijk uitgevoerde beweging vast te leggen.

Met de röntgencinematografische en markeringstechniek die in dit onderzoek is gebruikt, is het wel mogelijk de posities van de contouren per filmbeeld voldoende nauw- keurig te bepalen.

Per filmbeeld worden 40 punten ingenomen. Wanneer er van wordt uitgegaan dat een röntgenfilm gemiddeld 40 beelden bevat, houdt dit in dat per film 1600 punten moeten worden ingenomen. Van tien door ons onderzochte personen zijn 58 fiims vervaardigd. In dit onderzoek zijn dus 92800 punten gemarkeerd en in de computer ingevoerd. In de door ons ontwikkelde positie berekeningsmethode worden fouten bij het markeren automatisch gecorrigeerd. Alleen met een techniek, zoals door ons gebruikt is, is het vastleggen van de posities van de benige structuren en berekenen van bewegingsparameters mogelijk.

Voor gebruik van een registratie- en berekeningstechniek bij patientenonderzoek is het noodzakelijk dat men in een redelijk korte tijd over betrouwbare gegevens beschikt. Met onze techniek heeft men inderdaad binnen ongeveer éen uur de beschikking over de waarden van de gewenste bewegingsparameters.

Met de techniek is een aantal parameters van de beweging in het sagittale vlak van de halswervelkolom en het hoofd van tien klachtenvrije personen bepaald. De intra- en interindividuele variabiliteit is vastgelegd, om te onderzoeken welke parameters geschikt zouden kunnen zijn om de beweging in het sagittale vlak van de kolom te objectiveren.

Als bewegingsparameters van de werkelijk uitgevoerde beweging zijn bepaald: totale en segmentale bewegingsomvang, de positie van de segmentale rotatieas, de intrasegmentale vervorming en de bewegingsvolgorde en richting. De definitie van dergelijke begrippen kan afhangen van de methode die gebruikt is om ze te parametriseren. Daarom wordt van elke parameter in dit onderzoek een definitie gegeven, deze wijkt soms af van de tot dusver geformuleerde bepalingen.

Parameters welke met statische röntgenfoto's en met röntgencinematografie te bepalen zijn: 


\section{De bewegingsomvang}

De bewegingsomvang wordt doorgaans gedefinieerd als het verschil in rotatiestand tussen twee benige structuren op röntgenfoto's wan de extreme posities in het sagittale wlak van de halswervelkolom en het hoofd. Het maximale verschil in rotatiestand tussen twee benige structuren wordt door ons niet altijd gevonden op de röntgenbeelden van de twee extreme standen van de halswervelkolom (vergelijkbaar met functiefoto's). Daarom wordt hier bewegingsomvang gedefinieerd als het verschil tussen de stand op het filmbeeld waarop de twee benige structuren het meest in retroflexie staan en die stand waarop ze het meest in anteflexie staan. Dit kunnen dus standen op filmbeelden tussen de extreme posities van de halswervelkolom zijn. De aldus bepaalde waarden voor de bewegingsomvang tonen, evenals die uit de literatuur, een grote spreiding. Het is derhalve onmogelijk om aan deze parameter in de praktijk bruikbare "normaalwaarden" te ontlenen.

M.b.t. de intraindividuele variabiliteit van de bewegingsomvang waren geen gegevens bekend. In dit onderzoek zijn de waarden bepaald op drie meetmomenten. Er blijkt met name in het craniale en het caudale deel een grote intraindividuele variabiliteit te bestaan m.b.t. de segmentale bewegingsomvang. Ook voor een gegeven patient/proefpersoon zijn dus geen normaalwaarden, respectievelijk uitgangswaarden ter beoordeling van het beloop van een proces of een therapeutisch effect, te destilleren.

\section{De positie van de segmentale rotatieas}

Deze wordt tot nu toe bepaald aan een beperkt aantal statische posities van de halswervelkolom van het bewegingstraject in het sagittale vlak. Voor de positie van deze as wordt een grote interindividuele variabiliteit per segmentaal niveau opgegeven. Er ontstaat een verzameling van assen die in een groot gebied liggen wanneer deze aan foto's van kleinere trajecten binnen het gehele be- wegingstraject wordt bepaald; een polode is niet te construeren. Dit wordt veroorzaakt door een ongunstige verhouding tussen de nauwkeurigheid waarmee de contouren op röntgenfoto's tot nu toe kunnen worden gemarkeerd en de wijze waarop constructie van een dergelijke as plaatsvindt. Deze parameter is tot nu toe dan ook ongeschikt om veranderingen in het bewegen objectief vast te leggen.

In ons onderzoek zijn de posities van de assen van beweging bepaald van de werkelijk uitgevoerde beweging. Tussen aansluitende beelden uitgerekend, levert dit ook een verzameling ver uit elkaar liggende assen op. Daarom is het ook met onze methode van innemen niet mogelijk een, binnen aanvaardbare grenzen reproduceerbare, polode te construeren. Om deze reden is door ons per segment van elke röntgenfilm het gemiddelde bepaald van de posities van assen van rotatie per segment gebruikmakend van zoveel mogelijk niet aansluitende filmbeelden. Deze "gemiddelde" positie is wel goed reproduceerbaar. Voor deze "gemiddelde" positie geldt ook dat bij deze tien proefpersonen, per segment, een veel kleinere interindividuele spreiding bestaat dan tot nu toe beschreven is voor de as van rotatie bepaald aan twee extreme posities van de halswervelkolom. Bovendien is er nauwelijks enige intraindividuele spreiding. Nader onderzoek is vereist om na te gaan of de ligging van de gemiddelde as van rotatie toegepast kan worden als norm waarmee gevonden posities zinvol kunnen worden vergeleken.

\section{Intrasegmentale vervorming}

Een andere parameter die gebruikt kan worden om veranderingen in het bewegen te registreren, de vervorming van de discus intervertebralis, is tot nu toe alleen kwantitatief bepaald aan functiefoto's. Röntgencinematografisch is waargenomen dat in segmenten, waarvan wordt verondersteld dat de discus intervertebralis niet normaal is, afwijkend wordt bewogen. In de door ons onderzochte groep personen komen deze vormen van bewegen echter ook voor. De aanwezigheid 
van een dergelijke vervorming van de discus intervertebralis hoeft dus niet op pathologie in de discus te wijzen. In de door ons onderzochte personen is wel vastgesteld dat in de craniale disci meer gegleden wordt dan gekanteld en dat dit in de caudale segmenten andersom is. Tevens is vastgesteld dat normaliter de verhouding tussen kantelen en glijden aan de ventrale zijde van de discus intervertebralis niet veel van die in de aansluitende segmenten verschilt. De grootste verplaatsingen aan de ventrale zijde worden gevonden in de segmenten (C4-C5) en (C5$\mathrm{C6}$ ). Gezien de foutenmarge van de gebruikte methode zijn geen uitspraken te doen over de intraindividuele variabiliteit. De absolute verplaatsingen, vooral aan de ventrale zijde van de disci intervertebrales tonen een grote interindividuele spreiding.

Parameters welke alleen met röntgencinematografie te bepalen zijn:

\section{De volgorde van bijdragen}

Hierover zijn tot nu toe nauwelijks kwalitatieve en geen kwantitatieve gegevens bekend. Een groot aantal fenomenen van deze volgorden zijn voor alle onderzochte personen gelijk.

Zowel een anteflexie als een retroflexie tussen de maximale retroflexiepositie en "bending" anteflexiepositie van de halswervelkolom wordt gestart en afgesloten in het caudale deel van de halswervel kolom. De beweging wordt nimmer gestart of afgesloten in thet mid-cervicale deel.

In ons onderzoek is tevens gebleken dat de volgorde van segmentale bijdragen in het craniale en het caudale deel van de halswervelkolom constant is. Tevens is de volgorde tussen de bijdragen van het craniale deel en het caudale deel aan de beweging van de gehele halswervelkolom constant. Dit geldt ook voor de bijdrage van het mid-cervicale deel van de kolom t.o.v. het caudale deel. Er is geen constante volgorde gevonden waarin de segmenten bijdragen in het blok (C2-C5) evenals voor de volgorde tussen het blok ( $\mathrm{CO}$ $\mathrm{C} 2$ ) en het blok (C2-C4). Uit een modelana- lyse is de constante volgorde van de bijdragen in het craniale deel wan de halswervelkolom verklaarbaar.

\section{Inversie}

Aan het einde van de "bending" anteflexie van de halswervelkolom vindt altijd in het blok (CO-C2) retroflexie plaats. Tijdens een retroflexie van de halswervelkolom vindt tijdens de retroflexiebijdrage in het segment (C1-C2) altijd anteflexie in het segment (COC1) plaats. Deze bewegingen worden door ons inversie genoemd. Dit is een ander fenomeen dan de inversie in het segment $(\mathrm{CO}-\mathrm{Cl})$ die bij een deel van de klachtenwrije personen op functiefoto's is waargenomen. De door ons bestudeerde inversie is een retrograde beweging; de inversie die wordt bepaald door de vergelijking van twee functiefoto's berust weliswaar op deze beweging, maar is statisch gedefinieerd. De beweging treedt ook in het traject tussen een "middenstand" van de halswervelkolom en een maximale "bending" anteflexie veel vaker op dan hij aan de eindstanden nog gevonden kan worden.

Op functiefoto's kan inversie, zoals deze tijdens een werkelijk uitgevoerde beweging plaatsvindt, in het segment (CO-C1) en/of in het segment (C1-C2) gemist worden.

Overigens berust inversie in het craniale deel van de halswervelkolom tijdens retroflexie op een ander fenomeen dan inversie tijdens anteflexie van de halswervelkolom. Uit een mode wan de halswervelkolom is dit verklaarbaar.

Ook in het caudale deel van de halswervelkolom kan inversie als een normaal verschijnsel worden beschouwd. Het vindt dan plaats in het segment (C6-C7) en, alhoewel minder vaak, in het segment ( $\mathrm{C5}-\mathrm{C} 6$ ). Indien in het caudale deel van de halswervelkolom inversie optreedt vindt dit plaats in het traject tussen de beide bijdragen van dit deel in de richting van de beweging. 


\section{Voortzetting van het onderzoek}

1. Verdere modelvorming van het bewegen van de halswervelkolom:

Het besproken model waarvan volgorden van bewegen en de mogelijkheid tot inversie hoog in de halswervelkolom zijn afgeleid, zal moeten worden vervolmaakt. Het is onze verwachting dat het ook mogelijk is om voor de andere regionen genoemde volgorden te voorspellen. Tot de gegevens die aan dergelijke modelvorming ten grondslag zullen moeten liggen behoort voldoende informatie over het gebruik van spierweefsel tijdens de onderzochte bewegingen. Dit kan mogelijk worden ontleend aan electromyografische onderzoek. Daarnaast zal macroscopisch anatomisch onderzoek in de nek van de werkelijke verhoudingen tussen spierweefsel, collageen bindweefsel rond de benige structuren en die benige structuren zelf, een steviger basis voor dergelijke modelvorming moeten geven dan met de tot nu toe bekende gegevens mogelijk is.

Het verdient aanbeveling om, naast een mechanisch model, numerieke modellen voor verscheidene elementen van de halswervelkolom te ontwikkelen. Een numeriek model kan dan scherpere hypothesen genereren over aspecten van de beweeglijkheid van de halswervelkolom. Deze zijn onderhevig aan verificatie met behulp van de bovengenoemde experimentele technieken.

2. Objectieve verificatie van diagnostiek van fysisch-diagnostisch segmentaal bewegingsonderzoek in de halswervelkolom en therapie-evaluatie.

De techniek die in dit proefschrift wordt besproken, levert de mogelijkheid een aantal parameters objectief, onafhankelijk van de onderzoeker/behandelaar, te bepalen. Dit kan plaatsvinden aan de hand van de "normaalwaarden" van de hiervoor genoemde bewegingsparameters bij klachtenvrije personen en de verkregen informatie over intraen interindividuele variabiliteit. Onderzocht kan worden of bij patienten met pijnklachten of klachten van bewegingsbeperking van de halswervelkolom c.q. klachten in de zin van "een gevoel dat anders bewogen wordt" andere waarden voor de genoemde bewegingsparameters voorkomen.

Achtergrond voor de verwachting dat bij patiënten met nekklachten andere waarden zullen worden gevonden zijn:

- Veranderingen in weke delen gaan gepaard met een verandering in spanningsdoorleiding c.q. vervorming.

- Veranderingen in de gewrichtsvlakworm en/of het gewrichtskraakbeenopperwlak veroorzaken wijziging van bewegingsrichting c.q. toename van wrijving in de gewrichten. Deze vormveranderingen gaan met pijnklachten gepaard.

- Pijn in de regio van een gewricht gaat gepaard met een ander gebruik van die gewrichtsregio in de keten halswervelkolom.

Tevens kan onderzocht worden of na een behandeling die tot vermindering van de klachten leidde, deze waarden dan weer gelijk zijn aan die bij de klachtenvrije personen.

Gegeven dat de bewegingsomvang in de craniale en caudale delen van de halswervelkolom ongeschikte parameters oplevert, kunnen de volgende vragen een basis zijn voor verder onderzoek in groepen patienten met een bepaald klachtenpatroon:

- Kan het bepalen van de maximale verplaatsing en de verhouding tussen kantelen en glijden in een discus intervertebralis t.o.v. van de waarden in de aansluitende segmenten aanwijzingen geven over de aanwezigheid van een niet-normale discus ?

* Verondersteld kan worden dat de ratio glijden : kantelen verandert bij discus-pathologie of bij veranderde stand van de facetgewrichten.

- Is het bepalen van de positie van de gemiddelde as van rotatie wel een geschikte parameter?

* De verwachting is dat de gemiddelde as van rotatie in andere gebieden van de projectie van het wervellichaam terechtkomt bij een discus-lesie of bij abnormale facet-gewrichten.

- Is de volgorde van bijdragen wan de segmenten binnen blokken en van blokken aan de gehele halswervelkolom tijdens een ante- 
flexie en een retroflexie beweging een waardevolle parameter bij diagnostiek en/of therapie-evaluatie van patienten met klachten van de nek?

* In geval van pathologie (gewrichtsvlakken of weke delen) kan pijn ontstaan tijdens het bewegen. Dit kan tot andere blok- of segmentale bewegingsvolgorden of inversie-gedrag leiden. Inversie kan afwezig of verminderd zijn of in andere bewegings-trajecten of andere segmenten optreden.

Een der ontwikkelingen in de moderne geneeskunde is dat het verkrijgen van kwantitatieve gegevens meer en meer op de voorgrond komt. Deze vormen een basis voor een geobjectiveerde diagnostiek en leveren de mogelijkheid het beloop van een proces, en de invloed van therapeutische maatregelen daarop, te kwantificeren. Bovendien is deze "clinimetrie" een voorwaarde om de prognos- tiek met name ook in de voorspelling van het te verwachten eindniveau, respectievelijk de resterende stoornis of beperking, bij patiênten te beheersen. Van de chemische diagnostiek wordt reeds lang verwacht dat die objectieve standaarden levert waarmee individuele waarden op zinvolle wijze kunnen worden wergeleken. De fysische diagnostiek, met name van het bewegingsapparaat, is tot dusver in veel geringere mate in staat aan de rgelijke verwachtingen te voldoen. Een eerste vereiste is de ontwikkeling van geijkt meetgerei, waarmee valide gegevens over relevante eigenschappen kunnen worden verkregen. Het is onze hoop dat de hier beschreven methode om een aantal functionele eigenschappen in afhankelijkheid van de morfologie van de halswervelkolom te beschrijven, een bijdrage aan bovenbedoelde ontwikkeling zal blijken. 


\section{Nawoord}

Zo, nu is dit dus afgerond.

Dat het tot deze afronding is kunnen komen is aan een groot aantal mensen te danken. Waarschijnlijk heb ik de invloed van een aantal van hen tot nu toe niet bewust beleefd. Al zou ik ze er voor willen bedanken, ik kan dat dus niet. Degenen van wiens steun ik me op dit moment wel bewust ben, wil ik hierbij danken.

Mijn interesse in het bewegingsapparaat, m.n. in de bewegingsfunctie van de wervelkolom, is angewakkerd door J.C. Jansen. Beste Mark, hiervoor mijn dank; datgene waarmee jij mij op het Reumacentrum in Amsterdam in contact hebt gebracht, heeft tot nu toe voor $\mathrm{mij}$ een belangrijke plaats ingenomen in het dagelijks leven.

Tot degenen die het voor mij mogelijk hebben gemaakt de noodzakelijke röntgenfilms te verkrijgen behoren, naast de "test persons" zelf, zij die hen als klachtenvrij konden aanmerken, H.T.J.A. Wald en G.M.J.R. Verstegen, beste Harry en Gart, hiervoor mijn dank; en zij die de opnamen hebben gemaakt, dr. H. Sanchez en $H$. Nelissen, beste Henk en Hetty, ik denk graag terug aan al de tijd die jullie, tussen de drukke dagelijkse werkzaamheden op de röntgenafdeling, voor dit onderzoek hebben vrij gemaakt.

Medewerkers en (toen) studenten van de vakgroep rond Prof. dr. ir. J.D. Janssen zijn mij, vooral in het begin, zeer behulpzaam geweest bij het ontwikkelen van de bewerkingstechniek, met name dr. ir. L.J.M.G.D. Dortmans in zijn stage bij de vakgroep Anatomie en Embryologie van de R.L., beste Ardi en achterban ik denk graag terug aan de wijze waarop jullie mij vanuit jullie vak begeleid hebben. Gerrit Peters dank ik voor zijn commentaar.

De instrumentele dienst van de R.L., in het bijzonder de heer C. Kouw, dank ik voor de snelle en accurate wijze waarop de noodzakelijke apparatuur is gemaakt, beste Casper uit de vele "ontwerpschetsen" heb je altijd goed werkende en mooie dingen ge- maakt.

De medewerkers van de vakgroep Anatomie en Embryologie van de R.L. (en deels ook hun gezinsleden), hebben een groot deel van de "ups en downs" van mij, ook veroorzaakt door dit stuk onderzoek, meegekregen. In het bijzonder Jaap en Els van der Wall, Hans en Edith Rensema, Jacques en Anita Beursgens, dank ik voor de wijze waarop zij mij ter zijde hebben gestaan. Bart Reuten dank ik voor de technische ondersteuning.

Op het tot stand komen van dit proefschrift is de invloed van M.M.L. Koekkelkoren niet weg te denken. Lieve Monique, ik ben niet altijd even makkelijk voor je. Ik dank je voor de momenten van warmte en gezelligheid en voor de opvang van Kees Jan en Eveline. Ik hoop dat wij, nu dit klaar is, meer tijd hebben voor de andere "dingen in het leven".

Zonder de inzet en vakkennis van Jacques Beursgens was dit resultaat niet bereikt. Beste Jacques, elke keer als ik weer eens iets nieuws verzon, met "vage randvoorwaarden", nam je de moeite en was je in staat dit tot scherp geformuleerde, in een computerprogramma op te nemen, rekenbewerkingen om te vormen. Onze (luidruchtige) discussies op dagen dat we het niet eens waren, en de momenten dat de oplossing gevonden was, waren denk ik voor de hele vakgroep zichtbaar en hoorbaar. Wat een berg programmatuur heb je gemaakt, hiervoor mijn dank.

Hans Rensema was ook altijd bereid de vele noodzakelijke tekeningen te maken. Beste Hans, bedankt voor je altijd aanwezige bereidheid om, als je dacht dat het af was, toch weer met nieuwe energie, andere, nog betere tekeningen, te maken. Door jouw kennis en inzet en die van Jacques is de vormgeving van dit proefschrift tot standgekomen. Beste Jacques en Hans, aan ons "teamwork" bewaar ik dierbare herinneringen. Met name de wijze waarop jullie de laatste veranderingen, aanvullingen en verbeteringen vanuit de beoordelingscommissie, hebben aangebracht is hiervan een goed voorbeeld.

Francy van Lieshout bedank ik voor haar 
bereidheid om de vertaling in een korte tijd tot stand te brengen.

Mijn promotor Prof. dr. J. Drukker dank ik voor het vertrouwen dat hij in mij had, ook op momenten dat ik het zelf niet meer zag zitten. Beste Jan, ik dank je voor de enorme vrijheid die ik van jou gekregen heb om dit onderzoek op deze wijze te kunnen uitvoeren. Vooral m.b.t. apparatuur gold voor Jacques en voor mij de uitspraak "Houdt het dan nooit op ? ? $^{\text {H }}$ Ook voor het aangeven van de "definitieve strepen", op momenten dat ik toch weer "nog iets nieuws" wilde doen, ben ik je zeer erkentelijk. Ik ben je zeer dankbaar voor je vergaande bereidheid tot aanpassen aan mijn "werk"wijze. De carnavalsweek 1988 is hiervan een goed voorbeeld. Je vraag
"Wat bedoel je nu eigenlijk?" is het eerste begin van menige alinea van dit proefschrift geweest. Ik dank je voor de leiding en begeleiding die je gegeven hebt, niet alleen binnen dit stuk onderzoek, maar ook bij het tot stand komen van de overige, hierin niet genoemde publicaties, vanaf 1978 in Santpoort tot nu in Klimmen. Ik heb het niet alleen als werk gevoeld maar ook als leuk.

Ik dank de leden van de beoordelingscommissie voor hun moeite om het manuscript kritisch te bestuderen. O.a. uit gesprekken met hen zijn al weer vele nieuwe ideeën voortgekomen.

Het begint dus weer opnieuw.... 


\section{Curriculum vitae}

1959 - 1965 HBS-B, Marnix van St. Aldegonde lyceum te Haarlem

1965 - 1971 Universiteit van Amsterdam, faculteit der geneeskunde

1971 -1978 Wetenschappelijk medewerker aan het laboratorium van Anatomie/Embryologie, Universiteit van Amsterdam

1975 Artsexamen, Universiteit van Amsterdam

1978 - Universitair docent aan de vakgroep Anatomie/Embryologie, Rijksuniversiteit Limburg 


\section{Errata:}

pg. 21, col. $1, \ln .42$

in stead of: "... within the image in the middle of the picture ...."

read: "....within an image in the middle of the X-ray film...."

pg. 23, col. $2, \ln .24$

in stead of: "Each picture consists..."

read: "Each X-ray film consists...."

pg. 28 , col. $2, \ln .1$

in stead of: "...contours of a film and of each picture,...."

read: "....contours of each picture of a film,...."

pg. 28 , col. 2 , ln. 11

in stead of: "....and of each...."

read: "...of each...."

pg. 46 , col. $1, \ln .18$

in stead of: "...(CO-C1)..."

read: "....(C2-C3)...."

pg. 49 , col. 2 , ln. 21

in stead of: "....caudal than...."

read: "....caudal and more...."

pg. 95 , col. $2, \ln .27$

in stead of: "....(C0-C1)..."

read: "....(C1-C2)...."

pg. 99 , fig. $8.2, \ln .3$

in stead of: "....compared to"

read: "....compared to fig. 8.1."

pg. 102 , col. $1, \ln .30$ and 31

in stead of: "....was determined between (3) and (4) along cable (I) and between (5) and (6)." read: "....was determined, as well as the distances between ( 3 ) and (4) along cable (I) and between (5) and (6) along cable (II)."

pg. 105 , fig $8.4, \ln .3$

in stead of: "....compared to"

read: "....compared to fig. 8.1."

pg. 118 , fig. $9.1, \ln .5$

in stead of: "....in the whole spine...."

read: "....in block (C2-C7)...."

pg. 133, col. 2 , ln. 12

in stead of: "....inversion occurs...."

read: "....inversion in $(\mathrm{CO}-\mathrm{C} 2)$ occurs...." 